Sciences technologies

\title{
Insectes ravageurs des graines \\ de légumineuses
}

Biologie des Bruchinae et lutte raisonnée en Afrique

J. Huignard, I. A. Glitho, J.-P. Monge,

C. Regnault-Roger, coord. 



\section{Insectes ravageurs}

des graines

de légumineuses

Biologie des Bruchinae et lutte raisonnée en Afrique

J. Huignard, I. A. Glitho, J.-P. Monge,

C. Regnault-Roger, coordinateurs 


\section{Collection Update Sciences \& Technologies}

Companion Modelling

Michel Étienne coordinateur

2011, 384 p., e-book

Analyses économiques du paysage

Walid Oueslati, coordinateur

2011, 248 p.

Géographie des interfaces

Une nouvelle vision des territoires

Corinne Lampin-Maillet, Sandra Pérez, Jean-Paul Ferrier, Paul Allard, coordinateurs 2010, 168 p.

Coopérations, territoires et entreprises agroalimentaires

Colette Fourcade, José Muchnik, Roland Treillon

2010, 136 p.

La modélisation d'accompagnement

Une démarche participative en appui au développement durable

Michel Étienne, coordinateur

2010, $384 \mathrm{p}$

\section{Éditions Quæ}

RD 10, 78026 Versailles Cedex, France

(c) Éditions Quæ, 2011

ISBN : 978-2-7592-1656-7

ISSN : 1773-7923

Le code de la propriété intellectuelle interdit la photocopie à usage collectif sans autorisation des ayants droit. Le non-respect de cette disposition met en danger l'édition, notamment scientifique, et est sanctionné pénalement. Toute reproduction même partielle du présent ouvrage est interdite sans autorisation du Centre français d'exploitation du droit de copie (CFC), 20 rue des Grands-Augustins, Paris 6e. 


\section{Sommaire}

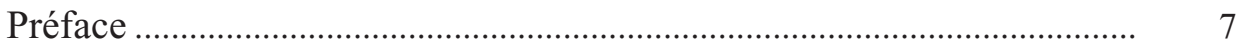

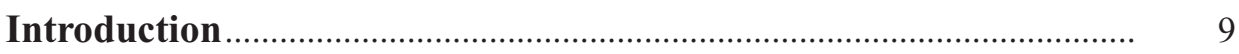

Chapitre 1. La protection des cultures en Afrique.................................... 13

Nazaire N'Kouka

Quelques rappels historiques.................................................................. 13

La situation actuelle de la protection des cultures en Afrique.................... 14

Vers une nouvelle vision de la protection des plantes en Afrique ............. $\quad 15$

Chapitre 2. Les légumineuses alimentaires en Afrique ............................ 17

Jacques Huignard, Isabelle Adolé Glitho

Leur importance agronomique et alimentaire ........................................... 17

Les principales légumineuses consommées en Afrique............................. 19

Chapitre 3. Évolution de la spécificité des relations

entre les bruches et leurs plantes-hôtes

et de leur aptitude à devenir des ravageurs........................................... 25

Gaël J. Kergoat

Apport de la phylogénie dans la compréhension

des associations entre les bruches et leurs plantes-hôtes............................. 27

Facteurs pouvant expliquer le statut de ravageurs

des denrées stockées de certaines espèces

Chapitre 4. L'infestation des cultures puis des stocks de graines

par les Coléoptères Bruchinae.

Jacques Huignard, Isabelle Adolé Glitho, Mbacke Sembene

Les Bruchinae du genre Bruchus

Les Bruchinae inféodés au niébé Vigna unguiculata. 
Les Bruchinae inféodés au haricot (Phaseolus vulgaris) .......................... 57

La bruche de l'arachide : Careydon serratus ............................................ 60

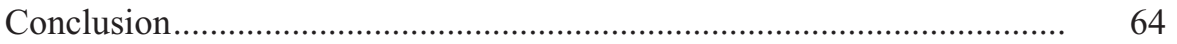

Chapitre 5. Biologie des hyménoptères parasitoïdes

des larves et des nymphes de Bruchinae ............................................... 65

Jean-Paul Monge, Jacques Huignard

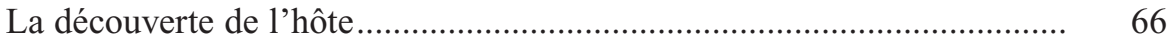

La phase d'exploration de la graine puis de l'hôte...................................... 66

Le comportement en situation de compétition............................................ 67

La régulation du taux sexuel ................................................................. $\quad 70$

La ponte et le développement des larves .................................................... 71

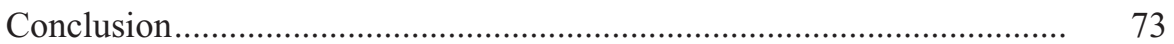

Chapitre 6. Les stratégies de lutte chimique

en pré- et post-récolte en Afrique ………………………………….... $\quad 75$

Francis Fleurat-Lessard

Pratique raisonnée de protection des cultures

et des stocks de graines par des pesticides chimiques.............................. $\quad 76$

Les inconvénients des pesticides et les risques encourus

par les utilisateurs................................................................................ 84

Préconisations dans le cadre d'une protection phytosanitaire durable ...... 87

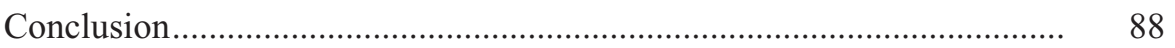

Chapitre 7. Biocontrôle des Bruchinae par les substances végétales :

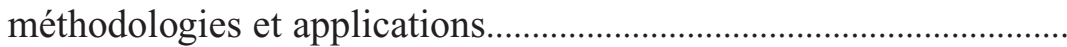

Catherine Regnault-Roger

Approche méthodologique pour la prospection de molécules végétales

à potentiel phytosanitaire

Contrôle de la bruche du haricot Acanthoscelides obtectus (Say)

par les plantes aromatiques méditerranéennes pour la protection

des graines de légumineuses ................................................................... 94

Perspectives et prospective pour l'utilisation des molécules

allélochimiques et des extraits végétaux dans la lutte phytosanitaire........ 96

Conclusion

Chapitre 8. Contrôle des Bruchinae par sélection variétale et génie génétique

Jacques Huignard, Catherine Regnault-Roger

La résistance acquise par sélection variétale ……………………............ 102

Les lignées résistantes obtenues par transgenèse...................................... 106

La sélection assistée par marqueurs (SAM) de lignées résistantes .......... 108

Conclusion ...................................................................................... 108 
Chapitre 9. Méthodes de biocontrôle par lutte biologique impliquant des macro-organismes

Jacques Huignard, Isabelle Adolé Glitho, Mbacke Sembene

La lutte biologique dans les systèmes de stockage de niébé

à l'aide des hyménoptères parasitoïdes.....

La lutte biologique contre Acanthoscelides obtectus

dans les stocks de graines de haricot......

La lutte biologique contre la bruche de l'arachide

Comment développer la lutte biologique dans les stocks de niébé au niveau paysan?

Conclusion. Comment assurer la protection des graines

de légumineuses dans le cadre d'une agriculture durable?

Isabelle Adolé Glitho

Références bibliographiques

Liste des auteurs 



\section{Préface}

La sécurité alimentaire est l'une des réponses majeures attendues de la communauté scientifique par les populations des pays africains. L'accroissement de la production agricole s'avère urgent pour faire face à la croissance démographique. Il s'agit donc de mieux gérer à la fois les facteurs édaphiques, climatiques et biotiques qui influencent la pression parasitaire sur les cultures et les récoltes.

En effet, l'agriculture qui fournit l'essentiel de l'alimentation humaine est soumise aux contraintes de l'environnement qui peuvent avoir des répercussions importantes sur la qualité et la quantité des produits attendus. Les agriculteurs ont pu utiliser la flore sauvage et sélectionner des plantes permettant d'assurer les besoins alimentaires des populations humaines. Ces efforts de sélection qui ont tout d'abord été réalisés de façon empirique, puis de façon scientifique au fur et à mesure de la progression des connaissances, représentent une prouesse technologique remarquable.

Même lorsque l'agriculteur améliore les performances agronomiques de la plante cultivée dans un environnement édaphique et climatique contrôlé, il doit toujours composer avec d'autres agents biologiques comme les insectes. La plante représente pour les insectes soit un élément de la chaîne alimentaire soit un hôte obligatoire. Les dommages phénotypiques causés par ces insectes et les pertes qu'ils provoquent, tant au champ qu'en stockage, ne peuvent qu'exposer le producteur à l'insécurité et à la précarité. Il lui faut accroître les rendements tout en limitant les pertes dues aux ennemis des plantes et notamment aux insectes.

La lutte chimique est la méthode de protection la plus utilisée pour sauvegarder les cultures et les stocks, mais elle est malheureusement onéreuse et peut avoir des conséquences néfastes sur la santé des producteurs et des consommateurs, et sur l'environnement.

La croissance démographique et l'économie de marché poussent la société à accroître les surfaces cultivées et à diversifier les stratégies de production et de protection, afin d'en limiter les coûts tout en produisant des aliments de qualité.

La mise en œuvre des différentes méthodes de lutte préconisées dans cet ouvrage devrait permettre aux agriculteurs africains de limiter l'utilisation de produits phytosanitaires de synthèse et de favoriser le développement d'autres méthodes alternatives, 
fondées sur la diversité de la flore et de la faune africaines, pour assurer la protection des graines. On peut cependant se poser des questions sur l'efficacité et la fiabilité à long terme de ces méthodes, en rapport avec la taille et le volume de l'échantillon de graines à traiter.

Dans les pays tropicaux où l'utilisation des engrais azotés en agriculture n'est pas économiquement évidente, les légumineuses alimentaires arbustives ou herbacées, qui fixent l'azote atmosphérique, constituent une solution dans les itinéraires techniques de production agricole. Elle permettra aux populations rurales d'exploiter les produits et sous-produits de cette grande famille botanique comme fertilisants du sol, tout en profitant de leur haute valeur nutritive, notamment en raison de leur richesse en protéines.

La protection des graines de légumineuses pour une agriculture durable en Afrique par des méthodes de lutte biologique n'a donc pas préoccupé les auteurs de cet ouvrage pour une simple distraction intellectuelle. Au contraire, le large spectre d'alternatives de lutte phytosanitaire, alliant quantité et qualité, présenté dans l'ouvrage est une contribution scientifique pour une protection responsable des cultures et des stocks.

Cette vision des scientifiques est en adéquation avec celle des décideurs politiques de la Commission de l'Union africaine dont le département de l'économie rurale et de l'agriculture en a fait une des priorités, inscrites dans son programme détaillé du développement de l'agriculture en Afrique (PDDAA/Nepad).

La publication de cet ouvrage vient donc en synergie pour le renforcement des capacités et la promotion du paysan africain avec la volonté du Conseil phytosanitaire interafricain de la Commission de l'Union africaine (UA/CPI), résolu à finaliser la stratégie africaine commune de la protection des végétaux basée sur deux approches : lutte systémique et lutte intégrée.

En tout état de cause, l'UA/CPI est convaincue que ce livre sera utile pour les agriculteurs et les agronomes qui disposeront de données scientifiques récentes, permettant de progresser dans le domaine de la protection des végétaux et notamment des denrées stockées en Afrique et dans le monde.

Les auteurs de l'ouvrage ont voulu expressément l'ouvrir sur une orientation présentant d'une manière pédagogique le bien-fondé d'une méthode alternative de protection des plantes, fortement inspirée des évolutions du monde (changements climatiques, diversité biologique, protection de l'environnement, etc.), avant de le clore sur un exposé des moyens efficaces pour assurer la protection des graines de légumineuses dans le cadre d'une agriculture durable.

Les études écophysiologiques et phylogénétiques de la famille des Coléoptères Bruchinae présentées dans ce volume ne manqueront certainement pas d'attirer l'attention des personnes intéressées par les problèmes entomologiques, eu égard à leur impact sur la qualité et la quantité des récoltes.

Que toute la communauté scientifique africaine et du monde (chercheurs, enseignants et étudiants), que tous les praticiens et utilisateurs des bienfaits de la science trouvent ici des outils appropriés pour les avancées et la réussite de leurs entreprises dans ce vaste champ de la protection des végétaux et surtout des denrées entreposées, champ dans lequel il y a encore fort à faire.

Dr Jean Gérard Mezui M'ella

Directeur du Conseil phytosanitaire interafricain de la Commission de l'Union africaine, Yaoundé (Cameroun) 


\section{Introduction}

Les pays tropicaux se caractérisent par une flore riche et variée qui est exploitée par de nombreuses espèces d'insectes phytophages. La plupart des espèces qui ont été identifiées se développent aux dépens des plantes sauvages, mais leur biologie est très souvent mal connue. Les études entomologiques ont surtout porté sur les insectes s'attaquant à des plantes cultivées dans les champs ou à des graines stockées après la récolte. Ces attaques sont dues soit à des espèces indigènes qui ont été capables de changer de plantes-hôtes et de s'adapter à de nouvelles conditions environnementales imposées par l'homme dans les cultures ou dans les systèmes de stockage, soit à des espèces qui ont été introduites en Afrique avec des plantes importées provenant d'autres continents. Lorsqu'ils s'attaquent aux plantes cultivées, les insectes peuvent provoquer des pertes élevées qui ont souvent des conséquences économiques et alimentaires importantes. Ceci est particulièrement vrai lorsque les insectes se développent aux dépens des graines dans les systèmes de stockage, car toute une récolte peut être détruite en quelques mois. Il faut donc limiter ces pertes si l'on veut nourrir sa famille et vendre sa production.

Confrontés à cette réalité, les agriculteurs africains ont eu recours à différentes méthodes de lutte afin de tenter de conserver leurs récoltes. Les méthodes traditionnelles, peu coûteuses, sont encore fréquemment utilisées pour contrôler l'accroissement des populations d'insectes ravageurs dans les petits systèmes de stockage villageois. Ainsi, les agriculteurs introduisent des plantes aromatiques dans les greniers en terre ou en paille tressée où sont stockées des graines de céréales ou de légumineuses. Ces plantes sont supposées libérer des composés volatils ayant des propriétés insecticides ou répulsives qui peuvent limiter le développement des populations d'insectes et préserver les récoltes. De nombreuses espèces végétales, connues dans la pharmacopée africaine traditionnelle, sont utilisées, mais leur efficacité est souvent limitée. Les chercheurs et agronomes africains se sont particulièrement intéressés à cette méthode de lutte ; ils ont étudié l'activité insecticide de ces plantes en laboratoire, puis sur le terrain, et ont ensuite analysé la nature chimique des substances actives ainsi que leur mode d'action. Un certain nombre de substances actives ont été identifiées chimiquement et plusieurs biopesticides d'origine végétale sont maintenant utilisés ou sont en voie de développement. Il reste cependant beaucoup à faire, compte tenu de la richesse de la flore africaine, 
et de nombreux biopesticides d'origine végétale sont encore à découvrir. D'autres méthodes simples sont également employées par les petits agriculteurs. Ils introduisent dans les greniers de la cendre ou du sable fin qui sont mélangés avec les graines. Ces matières inertes limitent les déplacements des insectes et les empêchent de se reproduire sur les graines. La conservation des graines dans des récipients hermétiques est également une méthode de protection fréquemment utilisée. Elle provoque la mort des insectes adultes ou des larves par anoxie. Ces méthodes de conservation traditionnelles, employées dans les greniers villageois, sont difficilement extrapolables dans des stocks plus importants. Or, l'augmentation des surfaces emblavées et la culture de variétés de plantes hautement productives entraînent un accroissement de la quantité de graines stockées. Le développement d'autres méthodes de conservation des récoltes s'avère donc nécessaire. La lutte chimique à l'aide d'insecticides de synthèse devient alors la méthode de protection la plus efficace, mais elle a un coût et elle doit être utilisée à bon escient. Les méthodes de traitement des systèmes de stockage, notamment par fumigation, nécessitent un certain savoir-faire et doivent être pratiquées par du personnel qualifié. Le mauvais usage de ces produits phytosanitaires ou l'utilisation de produits non homologués peut avoir de graves conséquences sanitaires et environnementales. De nouvelles méthodes de contrôle, fondées sur une meilleure connaissance de la biologie des insectes phytophages et de leurs ennemis naturels sont maintenant proposées. Elles s'appuient sur la lutte biologique à l'aide d'hyménoptères entomophages ou sur la sélection variétale permettant de disposer de plantes produisant des graines résistantes vis-à-vis des insectes. Des ennemis naturels des insectes ravageurs des denrées stockées ont ainsi pu être identifiés et leur biologie commence à être connue ; certaines espèces sont des agents de lutte biologique et permettent une bonne conservation des graines. Il y a certainement en Afrique beaucoup d'ennemis naturels (insectes, micro-organismes) susceptibles d'être utilisés dans la lutte contre les insectes ravageurs des cultures ou des stocks de graines. Ce potentiel est encore largement inexploité en raison du faible nombre d'études systématiques. Le développement de recherches sur ce thème permet de proposer des méthodes de lutte biologique facilement utilisables et n'ayant aucun impact sur l'environnement si elles sont bien maîtrisées. Les centres de recherche internationaux ont sélectionné chez un certain nombre d'espèces végétales des lignées résistantes vis-à-vis des ravageurs et notamment des insectes. La compréhension des mécanismes de résistance et de leurs conséquences sur la qualité gustative et nutritionnelle des graines représente une orientation de recherche qui est particulièrement développée en Amérique du Sud et en Asie. Elle doit être également abordée en Afrique afin de mettre à la disposition des agriculteurs des plantes beaucoup moins sensibles aux attaques d'insectes. C'est tout un ensemble de méthodes de protection des récoltes de céréales ou de légumineuses qui doit être proposé aux producteurs afin de leur assurer un revenu suffisant, tout en permettant le développement d'une agriculture respectueuse de l'environnement.

Ce livre examine un exemple concret, celui de la protection des graines de légumineuses stockées en Afrique. L'analyse de cet exemple permettra de proposer différentes méthodes de contrôle des ravageurs s'inscrivant dans le cadre du développement durable. Les légumineuses sont cultivées sur tout le continent africain ; elles produisent des graines riches en protéines, en vitamines B, en fer, en zinc et en calcium. En zone sahélienne, les jeunes enfants sont essentiellement nourris de farines de céréales pauvres en protéines. Les graines de légumineuses apportent un complément protéique nécessaire à leur 
croissance. Le niébé (Vigna unguiculata Walp.), l'arachide (Arachis hypogaea L.) et le haricot (Phaseolus vulgaris L.) sont cultivés en Afrique subsaharienne. Les cultures de fèves (Vicia faba L.), de pois (Pisum sativum L.) ou de lentilles (Lens esculenta Moench) sont très développées au Maghreb, au Moyen-Orient et en Afrique de l'Est. Leurs graines entrent dans la composition de nombreuses préparations culinaires. Cependant, les graines de légumineuses sont très attaquées par des insectes, les Coléoptères Bruchinae, qui provoquent des pertes importantes dans les systèmes de stockage dans toutes les régions du monde où ces plantes sont cultivées. Leurs larves se développent à l'intérieur des graines en consommant les réserves contenues dans les cotylédons et provoquent des pertes quantitatives et qualitatives importantes. Elles réduisent la qualité nutritionnelle des graines en diminuant leur teneur protéique et en favorisant la pénétration de champignons producteurs d'aflatoxines. La libération d'acide urique à l'intérieur des graines affecte leur qualité gustative. L'importance des pertes dues aux larves de Bruchinae limite le développement de ces cultures de légumineuses qui présentent pourtant, comme nous venons de le souligner, un grand intérêt alimentaire. Le contrôle de ces populations d'insectes est complexe et pose de nombreux problèmes même dans les grands centres de stockage où la lutte chimique est largement pratiquée.

Nous examinerons dans ce livre la biologie de ce groupe d'insectes qui présentent tous un certain nombre de caractéristiques morphologiques et physiologiques communes, mais ont des capacités d'adaptation différentes. Certaines espèces de Bruchinae n'exploitent qu'une seule plante-hôte et ne se reproduisent que dans les cultures avant la récolte des graines. Elles doivent survivre pendant une grande partie de l'année dans la nature lorsque les gousses de légumineuses permettant la reproduction et le développement ne sont pas disponibles. En revanche, d'autres espèces de Bruchinae peuvent se reproduire et se développer sur différentes plantes-hôtes de la famille des légumineuses, aussi bien dans les cultures que dans les systèmes de stockage. Elles sont capables de s'adapter à des environnements très différents et sont devenues d'importants ravageurs des denrées stockées. C'est à partir de la connaissance de ces données biologiques et évolutives qu'il est possible de proposer un certain nombre de méthodes de contrôle qui se complètent dans le cadre d'une stratégie de lutte intégrée. 



\title{
Chapitre 1 \\ La protection des cultures en Afrique
}

\author{
NAZAIRE N'KOUKA
}

\section{Quelques rappels historiques}

Les premiers écrits concernant la recherche agronomique en Afrique datent du XIX ${ }^{\mathrm{e}}$ siècle. Ils ont été rédigés par des agronomes français qui ont créé des jardins leur permettant d'étudier des plantes pouvant être consommées par les colons pour améliorer leur vie quotidienne ou être exportées vers l'Europe. Les autorités coloniales françaises souhaitent, dès la fin du XIX ${ }^{\mathrm{e}}$ siècle, développer l'agriculture et notamment les cultures de rente. Ainsi commence à s'instituer une recherche agronomique qui a pour but, comme l'indique l'agronome Jean Dybowski en 1892, de « rechercher par voie d'expérimentation quelles sont les espèces végétales qui peuvent donner des produits industriels ou vivriers ; obtenir par sélection ou hybridation des variétés plus résistantes et des rendements plus élevés ; propager les espèces utiles et en distribuer les semences aux colons ». Les jardins d'essai permettent d'introduire en Afrique des plantes provenant d'autres continents, de suivre leur développement et d'évaluer leur intérêt agronomique. Des essais de protection des cultures contre les ravageurs des plantes cultivées sont également réalisés dans ces jardins. Le développement de la recherche agronomique se poursuit au $\mathrm{XX}^{\mathrm{e}}$ siècle avec la création de stations étudiant chacune un type de plantes. C'est au Sénégal, dans la station de Bambey, que sont étudiées les légumineuses comme l'arachide et le niébé. L'Office de la recherche scientifique et technique d'outre-mer (Orstom) est créé en 1943. Il va assurer la gouvernance des différentes stations en Afrique et coordonner les programmes de recherche. L'Orstom développe surtout des programmes de recherche fondamentale consacrés aux cultures de subsistance, les cultures de rente étant confiées à des instituts spécialisés. Au cours du Xxe siècle, l'Institut national pour l'étude agronomique, créé en 1933 au Congo belge, et les centres de recherche des pays africains du Commonwealth développent également des programmes de recherche importants sur 
les cultures vivrières et les légumineuses, abordant les aspects agronomiques, pathologiques et technologiques.

Après l'indépendance des pays africains, des équipes de recherche ont développé de nouvelles thématiques orientées vers l'autosuffisance alimentaire et la bonne gestion des récoltes par le producteur. Les cultures de rente, qui présentent une grande importance pour les économies des pays, mobilisent également les chercheurs africains.

\section{La situation actuelle de la protection des cultures en Afrique}

Le développement des cultures vivrières et des cultures de rente s'accompagne d'une prolifération des ravageurs qui trouvent en zone tropicale des conditions favorables à leur développement et causent des pertes importantes, quel que soit le type de culture. La mise en place de programmes de protection des plantes en champ et dans les stocks devient un objectif prioritaire. Ceci explique l'intérêt accordé à ce domaine par les universités et centres de recherche agronomique tant en Afrique que dans le monde. Il convient de protéger les légumineuses dans les champs, puis dans les stocks, car leurs graines riches en protéines entrent dans les régimes alimentaires de nombreux Africains. Leur introduction dans les rotations de cultures contribue à améliorer l'alimentation azotée des autres cultures assolées, en particulier les céréales, et limite l'apport d'engrais azotés.

\section{Impact de la composante phytosanitaire}

Il est admis que 30 à $40 \%$ des pertes de production sont causées par les bioagresseurs : adventices, ravageurs, parasites et agents pathogènes. Pour assurer la production et la conservation des stocks de graines, la protection phytosanitaire est encore de nos jours largement dominée par le recours aux pesticides de synthèse. Ces produits sont très accessibles malgré leur coût. Leur commercialisation représente un enjeu économique fort pour les entreprises agroalimentaires du secteur et notamment pour celles des pays émergents (Chine, Inde) très présents en Afrique. Certains industriels profitent des grandes invasions d'acridiens et d'oiseaux granivores pour écouler en Afrique, en dépit des règles d'éthique, des pesticides qui ne sont plus homologués dans les pays développés. Ces produits peuvent s'avérer dangereux pour la santé des populations locales, polluer l'environnement et favoriser l'apparition de résistances chez les bioagresseurs.

Il est nécessaire de mettre en place des stratégies alternatives, facilement utilisables par les producteurs agricoles africains, permettant ainsi l'appropriation d'une véritable lutte intégrée. Ce changement d'approche n'est pas si nouveau en soi, mais se trouve largement partagé de nos jours. Les institutions internationales des Nations unies (FAO, OMS, etc.) doivent peser davantage sur les décisions dans l'attribution des marchés d'achat des produits phytosanitaires, car les demandes des pays ne sont pas toujours bien évaluées.

\section{Environnement institutionnel et réglementaire}

La protection des végétaux est restée pendant plusieurs années en Afrique francophone et lusophone une préoccupation des ministères de l'Agriculture et des stations d'expérimentation. Mais l'importance des pertes dues aux bioagresseurs nécessite 
maintenant une approche de recherche pluridisciplinaire associant les centres de recherche agronomique, les universités, les sociétés de développement publiques ou privées et les populations rurales. Cette nouvelle vision explique l'élargissement actuel de l'environnement institutionnel permettant, sur le continent africain, la mise en place d'une réglementation et d'une législation phytosanitaires conformes aux normes internationales. Il devrait donc être possible de réduire les dégâts causés par les insectes pour assurer une meilleure sécurité alimentaire.

Les gouvernements africains et les organisations internationales ont mis en place des comités régionaux des pesticides chargés de contrôler l'usage et la commercialisation des produits phytosanitaires, d'éliminer les molécules qui ne sont plus homologuées, de supprimer les stocks obsolètes et de mettre en place une meilleure réglementation. Ces comités régionaux doivent assurer un suivi de la protection phytosanitaire, car la pression des industriels et l'obligation d'accroître les rendements agricoles constituent deux contraintes importantes. Un meilleur contrôle des productions africaines valorisera les cultures vivrières traditionnelles de niébé, de pois ou de haricot, en permettant la commercialisation de produits de qualité sur le marché intérieur ou à l'exportation.

Il est important de coordonner les politiques de protection des cultures au niveau régional, afin de contrôler les introductions d'ennemis des plantes cultivées provenant d'autres zones et d'éviter qu'ils s'établissent, car ils peuvent provoquer rapidement des pertes importantes et ruiner les agriculteurs. La coopération et la solidarité intergouvernementales sur une base régionale s'avèrent donc une nécessité inéluctable de la prévention phytosanitaire.

Une région doit pouvoir compter sur la valeur des garanties phytosanitaires, c'està-dire sur des certificats et des bonnes pratiques, qui lui sont fournies lors de l'importation d'un végétal. La définition de ces bonnes pratiques en Afrique doit être, comme pour les autres continents, un objectif important. La coopération et la solidarité sont donc aussi un impératif international, à l'échelle mondiale, en matière de protection sanitaire des plantes.

Ces impératifs sont exprimés et sanctionnés par la Convention internationale pour la protection des végétaux établie à Rome en 1951, sous l'égide de la FAO. Les dispositions de cette convention mettent sous gérance, avec veille phytosanitaire, les différents continents. L'Afrique est placée sous la responsabilité du Conseil phytosanitaire interafricain qui fonctionne comme un observatoire des questions phytosanitaires pour cette partie du monde.

\section{Vers une nouvelle vision de la protection des plantes en Afrique}

Le recours à la lutte chimique a été longtemps considéré comme le moyen de défense le plus efficace contre les bioagresseurs des plantes. Cette domination sans partage de ce type de lutte a permis de limiter les pertes, mais peut avoir, comme nous l'avons vu précédemment, des retombées négatives sur l'environnement et la santé des agriculteurs et des consommateurs. Le concept de protection intégrée qui met en avant la gestion des populations de bioagresseurs en associant diverses approches (techniques culturales, résistance du végétal, antagonistes biologiques, etc.) peut permettre de maintenir leurs 
niveaux en dessous des seuils de nuisibilité. Le développement des recherches sur les biopesticides et la lutte biologique représente des voies prometteuses. Ces études réalisées dans de nombreuses universités africaines permettent de contrôler certains ravageurs en évitant ou en limitant l'emploi des pesticides de synthèse (voir chapitre 7).

La protection des cultures dans les pays africains pose de nombreux problèmes qui ne sont que très partiellement résolus. La manipulation des substances toxiques contenues dans les pesticides par des petits paysans, mal informés quant aux risques et peu éduqués sur les impacts environnementaux, peut avoir de graves conséquences. Cependant si l'on veut lutter contre la précarité alimentaire mondiale et augmenter la productivité des agriculteurs du Sud, le recours aux intrants semble encore incontournable, même si des innovations peuvent en réduire l'importance. La nécessité d'employer des pesticides, les conditions de leur emploi et les conséquences de leur application doivent être étudiées avec plus de profondeur et la prise de décision ne semble pas évidente dans les systèmes de production où interviennent de nombreux acteurs. La formation des paysans à la lutte raisonnée doit absolument être développée en Afrique, notamment pour la protection de plantes vivrières comme les légumineuses. 


\section{Chapitre 2}

\section{Les légumineuses alimentaires en Afrique}

Jacques Huignard, Isabelle Adolé Glitho

Les graines de légumineuses jouent un rôle important dans l'alimentation de nombreuses populations d'Afrique, d'Amérique du Sud et d'Asie. On estime que plus de 150 espèces de légumineuses sont cultivées à travers le monde, mais la plupart le sont par de petits agriculteurs et sont en voie de régression. Seules quelques espèces entrent dans l'alimentation des populations africaines ou sont devenues des cultures de rente destinées soit à l'exportation, soit à la production d'huile.

\section{Leur importance agronomique et alimentaire}

\section{Les légumineuses produisent des graines riches en protéines sans apport d'engrais azotés}

La teneur en protéines de la plupart des graines de légumineuses représente 20 à $25 \%$ du poids sec. Cette teneur peut atteindre $35 \%$ dans les graines de soja, d'arachide ou de pois ailé Psophocarpus tetragonolobus. Ces graines contiennent la plupart des acides aminés nécessaires à l'alimentation humaine, mais sont pauvres en acides aminés soufrés. Leur taux en protéines est deux à trois fois plus important que celui observé chez la majorité des céréales. C'est la source de protéines la moins onéreuse ; on estime au Nigéria méridional que leur coût est dix fois moins élevé que celui des protéines d'origine animale (Stanton, 1970).

La culture des légumineuses est la plus respectueuse de l'environnement puisque ce sont les seules plantes à assurer leur propre approvisionnement en azote grâce à l'activité de bactéries symbiotiques, les Rhizobium. Cette voie symbiotique permet de fournir 70 à $80 \%$ des besoins énergétiques de la plante et d'obtenir de bons rendements sans recourir à des apports d'azote minéral. L'activité de fixation symbiotique de l'azote est régulée, chez les légumineuses, par la plante et ajustée à ses besoins, ce qui réduit 
considérablement les risques de gaspillage et de lessivage de cette ressource (Gueguen et Duc, 2008). Cette aptitude à fixer l'azote permet de réaliser des cultures en consommant peu d'énergie non renouvelable. À titre de comparaison, l'utilisation d'engrais azotés (extraction, conditionnement, transport et épandage) contribue à environ $60 \% \mathrm{du}$ coût énergétique pour une culture de céréale. En limitant l'utilisation d'engrais azotés, la culture de légumineuses contribue à préserver la qualité des sols et des eaux. Après la récolte, les fanes sont utilisées pour la nutrition du bétail et apportent un supplément protéique très utile tant pour la croissance que pour la lactation.

\section{Les graines de légumineuses ont de très bonnes qualités nutritionnelles}

Les graines de légumineuses, à l'exception de l'arachide et du soja, sont pauvres en matières grasses et contiennent des quantités raisonnables de minéraux importants comme le fer et le calcium. Les teneurs élevées en amidon et en protéines digestibles leur donnent une valeur énergétique nette élevée, proche de celle du blé. Elles présentent un index glycémique bas et sont recommandées pour les diabétiques. Les graines de soja contiennent des isoflavones ; ces phyto-oestrogènes sont utilisés dans la prévention des troubles de la ménopause et interviennent dans le métabolisme lipidique en réduisant le taux de lipoprotéines à basse densité. Ils ont ainsi un effet cardioprotecteur. On trouve cependant à l'intérieur des graines de légumineuses des composés du métabolisme secondaire tels que des inhibiteurs de protéases, des lectines, des saponines, des acides aminés non protéiques qui ne permettent la consommation des graines qu'après une cuisson plus ou moins prolongée ou une préparation culinaire complexe comme dans le cas du soja.

Dans les pays d'Afrique subsaharienne, les régimes alimentaires se composent principalement de produits riches en glucides et relativement pauvres en protéines qui sont fournis par des céréales, des racines ou des tubercules. Les légumineuses sont consommées après cuisson, sous forme de graines ou de farines, et sont incorporées dans des préparations culinaires à base de céréales.

\section{L'association culturale céréales-légumineuses a des effets bénéfiques}

Les légumineuses vivrières sont très souvent cultivées en association avec du sorgho (Sorghum bicolor L.), du mil (Pennisetum glaucum L.) ou du maïs (Zea mays L.). Cette association se révèle bénéfique pour les deux plantes. Les racines des légumineuses libèrent dans le sol des composés azotés qui vont être utilisés par les céréales et améliorent les rendements. Elle limite l'emploi des engrais azotés d'origine minérale ou organique. Cette aptitude à fixer l'azote atmosphérique est un atout environnemental important dans le contexte actuel de préoccupation vis-à-vis du changement climatique. Malgré l'imprécision des données relatives aux émissions gazeuses, il est probable qu'une proportion de $25 \%$ de légumineuses dans les rotations de grandes cultures en Europe contribuerait à une réduction de l'ordre de $1 \%$ des émissions des gaz à effet de serre. Une telle diminution ne serait pas négligeable au regard des objectifs de réduction de ces émissions définis dans le protocole de Kyoto (Munier-Jolain et Carrouée, 2003). Ceci montre l'intérêt de poursuivre ce type d'association ou de procéder à des rotations culturales lorsque les céréales ou les légumineuses ne sont pas associées. L'association culturale permet aussi une économie de l'espace en produisant deux plantes vivrières sur 
une même parcelle. Le transfert d'azote de la légumineuse à la céréale se traduit par une augmentation du taux de protéines dans les graines produites par cette plante, ce qui peut avoir des conséquences alimentaires non négligeables. Elle assure également une certaine protection phytosanitaire, les céréales formant une canopée qui rendrait plus difficile la découverte de la légumineuse par les insectes ravageurs.

\section{Les principales légumineuses consommées en Afrique}

Un certain nombre d'espèces présentent une grande importance économique et alimentaire ; ce sont des cultures vivrières ou des cultures d'exportation. Les principales légumineuses cultivées sont :

- en Afrique de l'Ouest, le niébé (Vigna unguiculata Walp.), l'arachide (Arachis hypogaea L.), le voandzou (Voandzeia subterranea Thouars), le soja (Glycine max L.) et le haricot (Phaseolus vulgaris L.) ;

- en Afrique centrale et en Afrique de l'Est, le haricot, le haricot de Lima (Phaseolus lunatus L.), le pois cajan (Cajanus cajan L.) et l'arachide ;

- en Afrique du Nord, la fève (Vicia faba L.), le pois chiche (Cicer arietinum L.), la lentille (Lens esculenta Moench), le pois (Pisum sativum L.) et le haricot.

Les graines de la plupart de ces espèces sont consommées localement. Le haricot est à la fois une culture vivrière et une culture de rente dans la plupart des pays africains. Il est exclusivement cultivé pour la production de gousses vertes destinées à l'exportation en Afrique de l'Ouest. La production d'arachide est également une culture de rente dédiée à la production d'huile et de tourteaux riches en protéines utilisés pour l'alimentation du bétail.

\section{Le niébé, Vigna unguiculata Walp. subsp. unguiculata}

Le niébé est une légumineuse de la famille des Fabaceae originaire d'Afrique. On trouve sur ce continent une grande diversité génétique, aussi bien chez les sous-espèces sauvages que parmi celles qui sont sélectionnées. Le niébé est maintenant présent dans toutes les zones tropicales, mais les pays d'Afrique de l'Ouest en ont été les principaux producteurs de 1999 à 2003 avec 3,3 millions de tonnes par an. Le Nigeria est le premier d'entre eux avec 2,2 millions de tonnes par an.

Le niébé est un aliment important pour les populations locales. Les gousses vertes et les graines entrent dans la composition de nombreux mets. Les graines sont consommées sous forme de farine après cuisson; elles sont riches en protéines $(23,5 \mathrm{~g}$ pour $100 \mathrm{~g}$ de graines) et contiennent la plupart des acides aminés essentiels. Les régimes alimentaires à base de céréales et de niébé fournissent aux jeunes enfants les calories et les acides aminés nécessaires à leur croissance. Les fanes, ramassées après la récolte des gousses, servent de nourriture au bétail.

Le niébé s'adapte à différents environnements des zones semi-arides aux zones humides. Il est généralement cultivé en association avec une céréale, le mil ou le maïs. Les rendements sont supérieurs à $1000 \mathrm{~kg}$ par hectare lorsqu'il est cultivé en conditions pluviales sous irrigation dans des sols limoneux. Certaines variétés de niébé peuvent tolérer la sécheresse et se développer dans des sols sablonneux et pauvres, mais les rendements sont alors de l'ordre de 200 à $400 \mathrm{~kg}$ par hectare. La culture du niébé ne demande 
pas d'engrais azotés et cette plante peut laisser dans les sols de 75 à $150 \mathrm{~kg}$ par hectare d'azote qui profiteront à la culture suivante. En revanche, l'apport d'engrais phosphatés favorise les processus de nodulation et donc la fixation d'azote.

Le niébé a été sélectionné par les nutritionnistes de l'Agence spatiale américaine (Nasa) pour sa valeur alimentaire, afin de servir de source de protéines végétales lors des vols spatiaux de longue durée. Le niébé pourrait être cultivé dans des serres à l'intérieur des vaisseaux spatiaux et être consommé sous forme de graines ou de feuilles. Des recherches sont actuellement entreprises afin de déterminer les conditions optimales de développement de certaines lignées de niébé dans ces serres (Nelson et al., 2008).

Le niébé est attaqué par de nombreux ravageurs au stade végétatif, puis lors de la phase de floraison et de fructification. Ces ravageurs peuvent provoquer d'importantes pertes de rendement (Jackai et Daoust, 1986). Plus de 100 espèces d'insectes ont été trouvées dans les cultures de niébé en Afrique, mais le puceron Aphis craccivora Koch, le thrips des fleurs Megalurothrips sjostedti Trybom, les lépidoptères Maruca vitrata Fab. (Syn., Maruca testulalis Geyer) et les punaises suceuses de gousses sont les insectes qui provoquent les pertes les plus importantes en Afrique de l'Est durant la phase végétative (Adipala et al., 2000). Après la récolte, puis le stockage des graines, ce sont les Coléoptères Bruchinae qui deviennent les principaux ravageurs.

Le niébé a fait l'objet d'un important effort de sélection et de nombreuses lignées sont actuellement diffusées en Afrique de l'Ouest par l'Institut international d'agronomie tropicale (IITA) à Ibadan au Nigeria. Elles diffèrent :

- par leurs cycles de développement (variétés précoces, intermédiaires ou tardives);

- par leur productivité en fonction de leur usage (graines ou fourrage) ;

- par leur résistance aux insectes, aux maladies virales ou cryptogamiques ;

- par leur résistance à la sécheresse.

Une carte de liaison génétique a été établie en analysant la ségrégation de plusieurs types de marqueurs génétiques et de caractères de résistance. Elle sera utile en vue du développement d'outils pour la sélection assistée du niébé (Muchero et al., 2009).

Des lignées de niébé transgéniques résistantes vis-à-vis des insectes sont en cours d'expérimentation. Une lignée transgénique résistante vis-à-vis de larves de bruches a été également obtenue en Inde (Solleti et al., 2008). Tous ces efforts de sélection et de biotechnologie ont pour but d'améliorer la productivité du niébé, de réduire les pertes dans les cultures, puis dans les stocks, et de limiter les traitements chimiques.

\section{Le haricot, Phaseolus vulgaris L.}

La domestication du haricot commun serait intervenue dans deux centres distincts, d'une part en Amérique centrale (variété vulgaris) et d'autre part en Amérique du Sud dans la région andine (variété aborigineus). L’Amérique centrale, où se développent de nombreuses lignées sauvages, semble être le centre principal de diffusion des haricots à travers le monde. Le haricot aurait été introduit en Afrique par les navigateurs portugais revenant d'Amérique au XVI ${ }^{\mathrm{e}}$ siècle. La culture du haricot s'est surtout développée en Afrique au début du $\mathrm{XX}^{\mathrm{e}}$ siècle grâce à l'introduction de lignées provenant d'Europe ou d'Amérique du Nord. C'est à la fois une culture de rente et une culture vivrière.

Cette plante est cultivée en plein champ dans de nombreux pays d'Afrique subsaharienne et en Afrique du Nord, afin de produire des gousses vertes qui sont exportées vers l'Europe. L'Afrique a exporté, en 2008, 197000 tonnes de gousses de 
haricots verts ; le Maroc en est le principal producteur. Les haricots verts sont produits durant toute l'année au Maroc, en Égypte et au Kenya. Ils sont cultivés en contre-saison dans les pays sahéliens qui écoulent ainsi leur production durant la période hivernale en Europe. Cette production nécessite de nombreux traitements insecticides et fongicides.

Les haricots sont cultivés pour la production de graines en Afrique centrale et orientale, et à Madagascar dans des zones jouissant d'un climat tempéré. Cette culture vivrière est surtout réalisée par les agriculteurs sur de petites surfaces, en association avec une céréale. Les haricots nains sont produits dans des zones basses; les haricots volubiles le sont dans des zones agroécologiques situées entre 1000 et 2300 mètres. Les surfaces cultivées en Afrique sont estimées à 4 millions d'hectares. Les graines de haricot représentent une source d'alimentation pour plus de 100 millions d'Africains. La consommation annuelle est estimée à $50 \mathrm{~kg}$ par habitant en Afrique de l'Est. Les graines de haricot représentent une source de protéines ( $22 \%$ du poids sec), de fer, de zinc, de fibres et des sucres lents. Les pertes dues aux ravageurs sont souvent très importantes et diminuent les rendements en graines. Des lignées résistantes aux maladies cryptogamiques et adaptées aux différentes conditions culturales rencontrées dans ces régions ont été mises à la disposition des agriculteurs afin d'accroître les rendements.

\section{L'arachide, Arachis hypogaea L.}

C'est une plante originaire d'Amérique du Sud dont la culture s'est développée en Afrique. Cette plante est cultivée dans plus de cent pays à travers le monde, mais $71 \%$ de la production mondiale est réalisée en Chine, en Inde et en Indonésie. La plupart des pays de l'Afrique subsaharienne produisent de l'arachide qui est soit une culture vivrière soit une culture de rente. On estime que $18 \%$ de la production mondiale d'arachide provient de ce continent. Les cultures vivrières d'arachide sont réalisées sur de petites surfaces en association avec d'autres plantes; les rendements sont inférieurs à 0,5 tonne par hectare. Les graines d'arachide sont directement consommées ou sont transformées puis incorporées dans des préparations culinaires. Elles apportent des compléments protéiques et lipidiques à des régimes alimentaires à base de céréales. L'huile d'arachide est utilisée sur place ou est exportée. Après extraction de l'huile, les tourteaux d'arachide sont utilisés en nutrition animale. Les fanes sont récoltées et servent à l'alimentation du bétail. Les monocultures d'arachide destinées à la production d'huile et à l'exportation sont réalisées sur de grandes surfaces et nécessitent des apports d'engrais pour accroître les rendements.

La culture d'arachide doit être réalisée dans des sols sablonneux, bien drainés et aérés afin de permettre la pénétration des gynophores dans le sol, puis le développement des gousses. Les conditions thermiques prévalant dans les zones tropicales $\left(25-35^{\circ} \mathrm{C}\right)$ sont favorables au développement de l'arachide. La phase de floraison, puis de formation des gousses nécessite un apport d'eau tandis que la phase finale de maturation est favorisée par une sécheresse relative. Une pluviométrie comprise entre 500 et $1000 \mathrm{~mm}$ pendant la saison de culture permet d'obtenir une bonne récolte. Les gousses sont arrachées dès le début de la saison sèche et mises à sécher au soleil dans les champs avant d'être stockées ou utilisées en huilerie.

L'arachide est attaquée durant sa phase de croissance, de floraison et de fructification par des virus, des bactéries et des champignons qui réduisent de façon importante les rendements. De nombreuses espèces d'invertébrés s'attaquent aux jeunes plants (nématodes, myriapodes), aux feuilles (pucerons, larves de lépidoptères, thrips, etc.), aux tiges, aux 
gousses et aux graines (termites et Coléoptère Bruchinae Careydon serratus). Le contrôle de ces ravageurs nécessite des traitements insecticides et fongicides en plein champ.

\section{Le voandzou, Voandzeia subterranea Thouars}

Cette légumineuse est surtout cultivée en Afrique dans des régions où le sol est pauvre et sablonneux ou dans celles où la pluviosité est incertaine. Elle est en effet particulièrement tolérante à la sécheresse et résistante aux insectes et aux maladies cryptogamiques. Elle est voisine des espèces du genre Vigna. C'est une plante de petite taille avec beaucoup de feuilles ramifiées trifoliées. Les fleurs s'épanouissent au niveau du sol et les fruits sont enfouis dans le sol comme l'arachide. Les gousses, après la récolte, sont mises à sécher au soleil avant d'être stockées dans des greniers. Les rendements sont généralement faibles et varient entre 100 et $500 \mathrm{~kg}$ par hectare.

$V$. subterranea est une plante dont les centres d'origine seraient le nord-est du Nigéria et le nord du Cameroun. On la trouve d'ailleurs à l'état sauvage dans ces zones. Cette légumineuse est maintenant cultivée dans une grande partie de l'Afrique et à Madagascar pour ses graines qui sont consommées après avoir été bouillies à l'eau ou grillées. Les graines de $V$. subterranea contiennent beaucoup d'amidon (50 à $60 \%$ du poids sec) et des protéines (17 à $25 \%$ du poids sec); elles sont pauvres en lipides, mais riches en tanins. C'est un aliment assez énergétique qui est surtout consommé à la fin du cycle agricole lorsque les greniers sont vides et les cultures ne sont pas encore prêtes à être récoltées. Comme pour les autres légumineuses, les fanes sont utilisées après la récolte pour la nourriture du bétail.

\section{La fève, Vicia faba L.}

Cette Fabaceae est cultivée dans tout le Bassin méditerranéen pour ses graines qui sont utilisées soit pour l'alimentation humaine, soit pour l'alimentation animale. Cette plante a été cultivée dès la plus haute antiquité ; des graines de fève ont été trouvées en Égypte dans des tombes de la XXII ${ }^{\mathrm{e}}$ dynastie des pharaons (2002-2400 av. J.-C.). La fève s'accommode de tous les types de sols; ses besoins en eau sont faibles au début de la croissance puis augmentent lors de la phase de floraison et de fructification. L'apport d'engrais potassiques et phosphatés facilite son développement. Les fèves sont cultivées en Afrique dans tout le Maghreb, en Égypte et en Éthiopie. La FAO estimait que la récolte mondiale de fèves était de 4,75 millions de tonnes en 2002, la Russie étant le principal producteur. Les graines de fève sont riches en glucides et en protéines $(30 \%$ du poids sec), mais contiennent deux glucosides, la vicine et la convicine, qui peuvent être à l'origine du favisme. Ces deux composés sont hydrolysés par les $\beta$-glucosidases produites par la microflore intestinale en deux aglycones, la divicine et l'isouramil, qui inhibent l'activité de la glucose-6-phosphate déshydrogénase (G-6 PDH) au niveau des hématies entraînant une hémolyse. Le favisme atteint des individus qui présentent un déficit héréditaire en G-6 PDH.

Les cultures de fève sont attaquées par des nématodes et par plusieurs espèces d'insectes consommant les tiges et les feuilles (le coléoptère Sitonia lineatus), la sève (les pucerons Aphus fabae et Acyrthosiphon pisum) et les graines (la bruche Bruchus pisorum). Différentes maladies cryptogamiques dues au botrytis, à l'anthracnose et à la rouille peuvent réduire les rendements. 


\section{Deux espèces de légumineuses en voie de développement en Afrique}

La culture du soja (Glycine max L.) se développe en zone soudanienne ; le Nigeria en est l'un des principaux producteurs. Ses graines sont riches en protéines (35 à $40 \mathrm{~g}$ pour $100 \mathrm{~g}$ ) et en lipides (environ $20 \mathrm{~g}$ pour $100 \mathrm{~g}$ ) ; elles contiennent des acides gras polyinsaturés et des isoflavones qui ont des effets favorables sur la santé des consommateurs. Le soja est consommé sous forme de laitages, d'huiles ou est incorporé dans des mets traditionnels.

La lentille de terre (Macrotyloma geocarpum Harms) est une plante qui fructifie dans le sol. Elle est surtout cultivée dans les zones semi-arides d'Afrique de l'Ouest. C'est la légumineuse « de luxe » vendue sur tous les marchés africains ; sa culture est très rentable. Les graines sont riches en protéines $(21 \%)$ et pauvres en lipides $(1 \%)$; elles contiennent la plupart des acides aminés essentiels et leurs qualités nutritionnelles méritent d'être développées. Les composés secondaires présents dans les graines comme des tanins, des hémagglutinines et des phytates sont détruits lors de la cuisson.

Ces deux légumineuses subissent la pression des mêmes ravageurs que le niébé, leurs graines étant attaquées par plusieurs espèces de Coléoptères Bruchinae. 



\title{
Chapitre 3
}

\section{Évolution de la spécificité des relations entre les bruches et leurs plantes-hôtes et de leur aptitude à devenir des ravageurs}

\author{
GAËL J. KERGOAT
}

Avec près de 1300 espèces (Borowiec, 1987), les bruches constituent un groupe assez peu diversifié au regard des 135000 espèces connues de coléoptères phytophages (Lawrence, 1982). Depuis le milieu du XIX ${ }^{\mathrm{e}}$ siècle, ce groupe d'insectes a été traditionnellement considéré comme constituant une famille à part entière (Coleoptera: Bruchidae). Un tournant important eut lieu vers la fin des années 1990, période où la question du rang taxonomique du groupe fit l'objet d'un débat intense entre systématiciens (Kingsolver, 1995 ; Reid, 1996 ; Verma et Saxena, 1996 ; Duckett, 1997 ; Lingafelter et Pakaluk, 1997 ; Schmitt, 1998), en particulier en raison de l'apparentement supposé des Sagrinae (Chrysomelidae) avec les Bruchidae (Borowiec, 1987 ; Reid, 1995 ; Silvain et Delobel, 1998). Par la suite, un nombre croissant d'études moléculaires (Duckett et al., 2003 ; Farrell et Sequeira, 2004 ; Gomez-Zurita et al., 2007) vinrent soutenir cette hypothèse et mirent en évidence une position phylogénétique relativement dérivée des bruches au sein de représentants de la famille des Chrysomelidae. En conséquence, et en accord avec les principes utilisés dans les classifications modernes (Lecointre et Le Guyader, 2001), la plupart des études récentes portant sur le groupe traitent dorénavant les bruches comme une sous-famille de Chrysomelidae (Coleoptera : Chrysomelidae : Bruchinae). Bien que cette question du rang taxonomique à accorder aux bruches puisse sembler triviale aux yeux du non-spécialiste, elle demeure néanmoins fondamentale pour quiconque souhaite effectuer des recherches bibliographiques sur le groupe.

Malgré leur importance numérique toute relative, la biologie des bruches est assez bien connue (Southgate, 1979 ; Borowiec, 1987). Elles ont la particularité d'être strictement séminivores (à l'exception d'une espèce : Bruchidius cinerascens; Delobel et 
Delobel, 2003). Le développement larvaire se déroule à l'intérieur d'une seule et même graine (Kingsolver, 1995 ; Johnson, 1981a). Cependant, chez certaines espèces comme Acanthoscelides obtectus, il peut y avoir plusieurs larves par graine ; la réciproque est aussi possible et les larves de certaines espèces peuvent utiliser plusieurs graines pour leur développement (Kingsolver, 1995 ; Delobel et Delobel, 2006). La plupart des espèces de bruches sont oligophages ou monophages (Southgate, 1979 ; Johnson, 1981a ; Borowiec, 1987), ce qui se traduit par un spectre d'hôtes restreint et limité à un nombre réduit de plantes qui sont le plus souvent apparentées (c.-à-d. appartenant à un même genre ou à une même tribu botanique). Les plantes-hôtes de plus de $80 \%$ des espèces de Bruchinae appartiennent à la famille des légumineuses (Johnson, 1981a ; Borowiec, 1987). Elles peuvent également se développer sur des plantes appartenant à plus de 30 familles botaniques différentes (Johnson, 1981a ; Borowiec, 1987). Il est intéressant de noter que l'on peut déterminer avec précision leur spectre d'hôtes en collectant et identifiant des graines sur le terrain et en surveillant dans un second temps l'émergence des adultes (Johnson, 1981a). En raison de leur forte spécialisation et de la bonne connaissance que l'on peut avoir de leur régime alimentaire, les bruches constituent un modèle intéressant pour étudier l'évolution des relations entre plantes et insectes (Jermy et Szentesi, 2003 ; Kergoat, 2004 ; Morse et Farrell, 2005).

Ainsi, peu de temps après la parution des travaux pionniers d'Ehrlich et Raven (1964) sur la coévolution entre les insectes et leurs plantes-hôtes, les bruches servirent de groupe modèle pour étudier cette hypothèse dans de nombreuses études (par exemple, Janzen, 1967 ; Center et Johnson, 1974 ; Janzen et al., 1977 ; Johnson, 1990). Par ailleurs, les bruches ont fait l'objet d'un nombre important d'études en écologie où il a été mis en évidence l'existence de guildes qui diffèrent par leurs préférences pour le substrat d'oviposition (Johnson, 1981b). Certaines espèces préfèrent ainsi déposer leurs œufs sur la surface des gousses, d'autres pondent préférentiellement sur les graines au sein de gousses déhiscentes et un dernier groupe pond préférentiellement sur des graines matures qui sont tombées à même le sol (Johnson, 1981b). On retrouve dans ce dernier groupe la plupart des espèces qui s’attaquent aux denrées stockées (Delobel et Tran, 1993).

Certaines espèces polyvoltines sont faciles à élever au laboratoire (en particulier au sein du genre Callosobruchus), car elles se reproduisent de façon continue. Elles sont utilisées comme modèles biologiques pour des études portant par exemple sur la sélection sexuelle (Rönn et al., 2007 ; Hotzy et al., 2009), l'évolution de l'adaptation (Huignard et al., 1996 ; Teixeira et Zucoloto, 2003 ; Fricke et Arnqvist, 2007), ou la résistance aux composés toxiques (Bleiler et Rosenthal, 1988 ; Gatehouse et al., 1990 ; Rosenthal, 1990 ; Sales et al., 2005 ; Macedo et al., 2006).

Une vingtaine d'espèces de bruches sont économiquement nuisibles, car elles s'attaquent à des graines de légumineuses cultivées (Southgate, 1979 ; Delobel et Tran, 1993). Plusieurs espèces du genre Bruchus s'attaquent ainsi aux cultures de fève (Vicia faba), de lentille (Lens culinaris) et de pois (Pisum sativum) en occasionnant principalement des dégâts au champ. Les cultures de haricot (et plus particulièrement le haricot commun Phaseolus vulgaris) sont quant à elles préférentiellement attaquées par Acanthoscelides obtectus et Zabrotes subfasciatus. Les dégâts qui en résultent peuvent avoir lieu au champ, mais les plus importants ont lieu dans des greniers de stockage. En effet, les bruches sont parmi les rares insectes capables de s'attaquer aux stocks de graines de légumineuses et certaines espèces polyvoltines peuvent y causer des dégâts 
très importants, car elles sont capables de s'y reproduire de façon continue (Singh et Singh, 1990). C'est en particulier le cas de Caryedon serratus qui s'attaque à l'arachide (Arachis hypogaea) et de plusieurs espèces du genre Callosobruchus qui se développent aux dépens des graines de niébé (Vigna unguiculata), de pois bambara (Voandzeia subterranea) ou de pois d'Angole (Cajanus cajan). En plus des dégâts que ces espèces occasionnent aux cultures et aux denrées stockées, certaines espèces de bruches sont aussi considérées comme nuisibles, car elles peuvent limiter la régénération de certains arbres et arbustes (acacias en particulier) dans des régions menacées par la désertification (Southgate, 1979). Dans ce cadre, il importe de mieux comprendre les facteurs qui vont prédisposer certaines espèces de bruches à devenir des ravageurs des cultures. C'est d'autant plus important si l'on considère le contexte actuel qui voit émerger de nouveaux ravageurs en raison d'une intensification des échanges commerciaux et de l'introduction de plantes cultivées en dehors de leur aire d'origine.

\section{Apport de la phylogénie dans la compréhension des associations entre les bruches et leurs plantes-hôtes}

Il est vraisemblable que la radiation évolutive des différents groupes de Bruchinae a été facilitée, ou au contraire limitée, par la plus ou moins grande capacité de chacun de ces groupes à contourner les défenses des plantes (Janzen, 1967 ; Center et Johnson, 1974 ; Rosenthal, 1990 ; Siemens et al., 1991). Comme dans d'autres groupes d'insectes phytophages (Jaenike 1990 ; Farrell et al., 1991 ; Becerra 1997 ; Marvaldi et al., 2002), cette nécessaire adaptation aux particularités de la ressource alimentaire a probablement constitué pour les Bruchinae une contrainte évolutive majeure, conduisant certaines lignées à s'associer de manière très stricte à certaines familles, genres ou espèces botaniques aux dépens d'une exploitation plus large des ressources théoriquement disponibles. Afin de tester cette hypothèse, il est nécessaire de disposer d'un cadre historique (phylogénétique) pour l'échantillonnage le plus représentatif possible de la diversité du groupe et de ses associations. Actuellement plus de 200 espèces de Bruchinae ont fait l'objet d'études phylogénétiques et ont été séquencées pour différents marqueurs moléculaires, mitochondriaux ou nucléaires (Kergoat et al., 2008). Ce nombre est en constante progression comme le montrent des études récentes (Kato et al., 2010, Kergoat et al., à paraître).

La première étude phylogénétique portant sur les bruches s'est intéressée à seize espèces ouest-africaines du genre Caryedon (Silvain et Delobel, 1998). Cette étude a mis en évidence la parenté phylogénétique entre des espèces associées à des plantes-hôtes proches (respectivement des Caesalpinioideae, Mimosoideae et Combretaceae), et l'existence de changements d'hôtes indépendants chez les espèces actuellement associées aux Combretaceae. Les études qui suivirent (Kergoat et al., 2008) ont démontré l'existence de deux grandes tendances évolutives.

La première est que l'on observe des patrons d'associations très conservés au cours du temps entre les bruches et leurs plantes-hôtes. Les reconstructions phylogénétiques indiquent qu'au cours de leur diversification, les lignées évolutives de bruches se spécialisent durablement sur des plantes-hôtes apparentées appartenant à une même famille ou 
une même tribu botanique (figure 3.1, planche couleur IV). Ces associations ne sont pas exclusives ; ainsi il n'est pas rare de voir un même groupe de plantes dont les graines permettent le développement de lignées évolutives de bruches bien distinctes (Kergoat et al., 2005a ; Delobel et Delobel, 2006). On dénombre ainsi sept genres distincts de bruches qui se développent dans des graines d'acacias (Borowiec, 1987 ; Kergoat et al., 2007b). Dans certains genres, le conservatisme des associations est très marqué, à l'instar de ce que l'on observe dans le genre Bruchus où l'on a pu mettre en évidence l'extrême spécialisation de certains groupes d'espèces qui vont se nourrir préférentiellement sur des genres (voire même des sous-genres) botaniques de Vicieae (Kergoat et al., 2007a).

La seconde tendance évolutive qui se dégage des analyses phylogénétiques est que ce patron de conservatisme taxonomique des associations entre plantes et insectes n'est pas statique. Bien que des clades entiers soient associés à un même groupe de plantes pendant plusieurs dizaines de millions d'années, certaines lignées de bruches peuvent changer leurs préférences alimentaires au cours de leur diversification. Ainsi, dans de nombreux groupes, on observe des changements d'hôtes notables, avec la colonisation de tribus, voire de familles botaniques différentes (Kergoat et al., 2004 ; Morse et Farrell, 2005 ; Kergoat et al., 2005a, 2005b ; Delobel et Delobel, 2006 ; Kergoat et al., 2007b). Cette adaptation à un nouveau groupe de plantes hôtes s'accompagne presque systématiquement de l'abandon du groupe de plantes hôtes ancestral. Il n'y a donc pas d'évolution vers un élargissement du spectre d'hôtes chez les Bruchinae. La mise en évidence de ces changements d'hôtes indique également qu'une spécialisation marquée sur des groupes de plantes-hôtes spécifiques ne constitue pas nécessairement un cul-de-sac évolutif pour les bruches, à l'instar de ce qui a été observé pour d'autres groupes d'insectes phytophages (Termonia et al., 2001 ; Wahlberg 2001).

L'analyse de ces patrons phylogénétiques supporte l'hypothèse selon laquelle l'évolution des Bruchinae est soumise à d'importantes contraintes. Le degré d'apparentement entre plantes-hôtes constitue la contrainte qui explique le mieux les patrons d'associations actuellement observés. On peut supposer que les femelles pondent préférentiellement sur des plantes qui présentent des composés chimiques de surfaces similaires. C'est le cas des plantes apparentées qui produisent généralement les mêmes composés de surface induisant l'acte de ponte (Bernays et Chapman, 1994). C'est donc un groupe de plantes-hôtes apparentées qui pourra induire la ponte d'une femelle appartenant à une espèce de bruche (ou à un groupe d'espèces). Bien que cette hypothèse soit congruente avec les patrons observés, de nombreuses études écologiques et comportementales ont observé l'existence d'une certaine plasticité dans le choix du site d'oviposition chez les Bruchinae (Johnson, 1981c, 1988 ; Johnson et Siemens, 1991 ; Siemens et al., 1991 ; Delobel et al., 1995, 2000). Que ce soit au laboratoire ou dans le milieu naturel, on a pu ainsi observer de nombreux cas de pontes sur des plantes n'appartenant pas aux spectres d'hôtes habituels des espèces étudiées, voire même des pontes sur des substrats complètement inappropriés comme des pierres (Delobel et al., 2000). Dans la quasi-totalité des cas étudiés, les larves n’achèvent pas leur développement post-embryonnaire et dépérissent à des stades plus ou moins avancés de leur développement (Johnson, 1981c ; Delobel et al., 2000). Cependant, dans certains cas (y compris dans le milieu naturel), les larves arrivent au terme de leur développement, ce qui laisse penser que ces « erreurs de pontes » jouent vraisemblablement un rôle 
important dans la dynamique des changements d'hôtes observés chez les Bruchinae (Johnson et Siemens, 1991).

Les forts taux de mortalité larvaire observés dans des études où l'on fait pondre des femelles sur des plantes n'appartenant pas à leur spectre d'hôtes habituel s'expliquent principalement par la très grande diversité des composés secondaires toxiques des graines (Janzen et al., 1977 ; Janzen, 1981 ; Birch et al., 1986 ; Gatehouse et al., 1990 ; Rosenthal, 1990). Une espèce de bruche donnée présente un certain nombre d'adaptations qui lui permettent de détoxifier les composés secondaires, comme le font les Bruchinae se développant dans des graines contenant l'acide aminé non protéique L-canavanine (Bleiler et Rosenthal, 1988). Étant donné que des plantes apparentées possèdent souvent des composés secondaires toxiques identiques (voir Bisby et al., 1994 pour les légumineuses), on peut donc faire l'hypothèse que les patrons d'associations plantes-insectes chez les bruches sont également contraints par la nature chimique des composés secondaires toxiques des graines. On rejoint ici le patron évolutif dit « de spécialisation chimique » qui a été proposé pour décrire l'évolution de certains groupes d'insectes phytophages qui se diversifient sur des plantes-hôtes phylogénétiquement non apparentées, mais chimiquement similaires (Becerra, 1997 ; Garin et al., 1999 ; Termonia et al., 2001 ; Swigonova et Kjer, 2004). Pour certains groupes de bruches (par exemple, groupe rubicundus du genre Bruchidius), des analyses phylogénétiques ont démontré que le patron d'association plantes-insectes était dû à la nature des composés secondaires toxiques présents dans les graines (Kergoat et al., 2005b). Cependant, cette observation est loin d'être généralisable. Lorsque l'on étudie les lignées évolutives de bruches qui se développent dans des graines riches en $L$-canavanine, on peut observer que des espèces d'une même lignée évolutive se diversifient exclusivement sur des plantes phylogénétiquement proches. En revanche, elles ne se développent pas sur des plantes non apparentées, mais possédant de la $L$-canavanine (Kergoat et al., 2005a).

Le conservatisme du patron d'association plantes-insectes chez les bruches est donc vraisemblablement imputable au degré de parenté phylogénétique des plantes, mais également à la nature des composés secondaires toxiques contenus dans les graines. La réalité est très certainement plus complexe comme l'indiquent des études phylogénétiques récentes (Morse et Farrell, 2005 ; Tuda et al., 2006 ; Kato et al., 2010). Ces études ont mis en évidence l'influence de la nature du substrat d'oviposition dans la diversification de certains genres. Il existe des espèces phylogénétiquement proches au sein d'une même guilde d'oviposition appartenant aux genres Mimosestes et Stator (Morse et Farrell, 2005 ; Kato et al., 2010). Dans le cas du genre Callosobruchus, il a pu être mis en évidence un patron un peu similaire où l'on a un clade qui s'est spécialisé sur des graines sèches de Phaseoleae (Légumineuses), alors qu'un autre se développe préférentiellement sur des jeunes graines vertes (Tuda et al., 2006).

En résumé, toutes ces études suggèrent que le fort niveau de spécialisation et le conservatisme du patron d'association plantes-insectes chez les bruches ont pour principales causes :

- le comportement de choix de l'hôte, qui semble dicté à la fois par la chimie des plantes (et donc leur proximité phylogénétique) et par la nature du substrat d'oviposition ;

- la capacité de développement post-embryonnaire des larves, laquelle est surtout conditionnée par leur capacité à contourner les défenses physiques et chimiques des graines. 


\section{Facteurs pouvant expliquer le statut de ravageurs des denrées stockées de certaines espèces}

À partir des nombreuses études qui ont été conduites sur les Bruchinae, il est possible de dresser une liste de facteurs qui vont prédisposer certaines espèces à devenir des ravageurs des denrées stockées.

On peut distinguer tout d'abord certaines caractéristiques physiologiques, comme la tolérance à un climat semi-aride ou aride ou le fait d'avoir un cycle de vie de type polyvoltin. Ces deux attributs sont importants étant donné que les greniers de stockage constituent un milieu particulièrement sec où la ressource alimentaire est généralement disponible de façon continue.

Des prédispositions comportementales peuvent également jouer un rôle très important : ainsi des espèces pondant préférentiellement sur des graines mûres et sèches ou sur des graines dispersées au sol (par opposition à celles pondant sur des jeunes gousses ou dans des gousses déhiscentes) seront également mieux prédisposées à devenir des ravageurs des denrées stockées (Delobel et Tran, 1993 ; Tuda et al., 2006). Il a été également montré que certaines variétés de plantes cultivées, dont les graines sont plus rugueuses ou présentent une cuticule plissée, sont plus résistantes aux infestations, car moins attractives pour des femelles gravides (Delobel et Tran, 1993). Il faut aussi prendre en compte le fait que les greniers à grains constituent des milieux artificiels, ce qui peut influer sur le comportement de ponte des femelles en les conduisant à pondre sur des hôtes qui sortent du spectre d'hôtes habituel de l'espèce. Par exemple, plusieurs espèces de bruches (Acanthoscelides obtectus, Bruchidius spp., Callosobruchus spp.) infestent régulièrement des stocks de pois chiches, de soja (Delobel et Tran, 1993 ; Teixeira et Zucoloto, 2003) ou de fèves (Hamraoui et Regnault-Roger, 1994), alors que ces plantes ne correspondent pas à leur spectre d'hôtes habituel en milieu naturel. C'est également le cas de Caryedon serratus qui se développe en milieu naturel sur des plantes appartenant à une autre sous-famille de légumineuses (Caesalpinioideae). Dans leur milieu naturel, les gousses d'arachide sont protégées d'un nombre important de prédateurs potentiels, car elles sont hypogées alors qu'elles se retrouvent exposées dans les greniers de stockage. Il est donc vraisemblable que l'adaptation de $C$. serratus à cette nouvelle ressource a été favorisée à la fois par l'exposition des graines à l'air libre et le fait que les graines d'arachide ne possèdent pas de défenses chimiques notables (Bisby et al., 1994).

La capacité de développement post-embryonnaire des larves constitue également un facteur fondamental. Bien que des études aient pu mettre en évidence une certaine plasticité dans les voies métaboliques impliquées dans la détoxification des composés secondaires toxiques des graines (Oliveira et al., 2002), la très grande diversité des composés secondaires toxiques demeure une contrainte importante qui impose un fort niveau de spécialisation (Gatehouse et al., 1990). Ainsi, même si phylogénétiquement les plantes du genre Phaseolus et Vigna appartiennent à la même sous-tribu botanique (Phaseolineae), l'espèce Callosobruchus maculatus qui se développe sur Vigna spp. n'est pas à même de se développer dans des graines du genre Phaseolus ; réciproquement, l'espèce Zabrotes subfasciatus qui se développe sur Phaseolus spp. aura le plus grand mal à se développer dans des graines du genre Vigna (Gatehouse et al., 1990 ; Teixeira et Zucoloto, 2003). L'existence d'une possible hétérogénéité dans le degré de toxicité des graines est également à prendre en compte, en raison du fait qu'il existe de nombreuses 
variétés cultivées qui sont moins toxiques que les souches sauvages, comme cela a été démontré lors d'une étude portant sur le haricot (Phaseolus vulgaris) (van Schoonhoven et al., 1983). Enfin, des variations dans l'épaisseur de la cuticule ou du tégument des graines peuvent faciliter ou non la pénétration de la larve néonate dans la graine ; aussi des variétés à cuticule épaisse sont généralement plus résistantes aux infestations (Delobel et Tran, 1993).

L'exposé de ces facteurs suggère qu'un nombre limité d'espèces de bruches sont prédisposées à devenir des ravageurs des denrées stockées. On peut ainsi exclure la plupart des espèces appartenant à des groupes inféodés à des milieux tempérés ou humides et présentant une diapause reproductive. Les analyses phylogénétiques indiquent également qu'il est peu vraisemblable de voir émerger de nouveaux ravageurs des stocks dans des groupes connus pour avoir une préférence marquée pour certains substrats d'oviposition (jeunes gousses ou graines vertes) ou pour certains groupes de plantes très spécifiques et éloignées phylogénétiquement de plantes cultivées (cas par exemple de toutes les espèces de bruches associées aux Malvaceae).

\section{Remerciements}

Je tiens à remercier plus particulièrement Alex Delobel (MNHN, Paris, France), Bruno Le Rü (IRD/Icipe Nairobi, Kenya), Jean-François Silvain (IRD, Gif/Yvette, France) et Midori Tuda (université de Kyushu, Fukuoka, Japon) pour de nombreux échanges constructifs sur le sujet. 


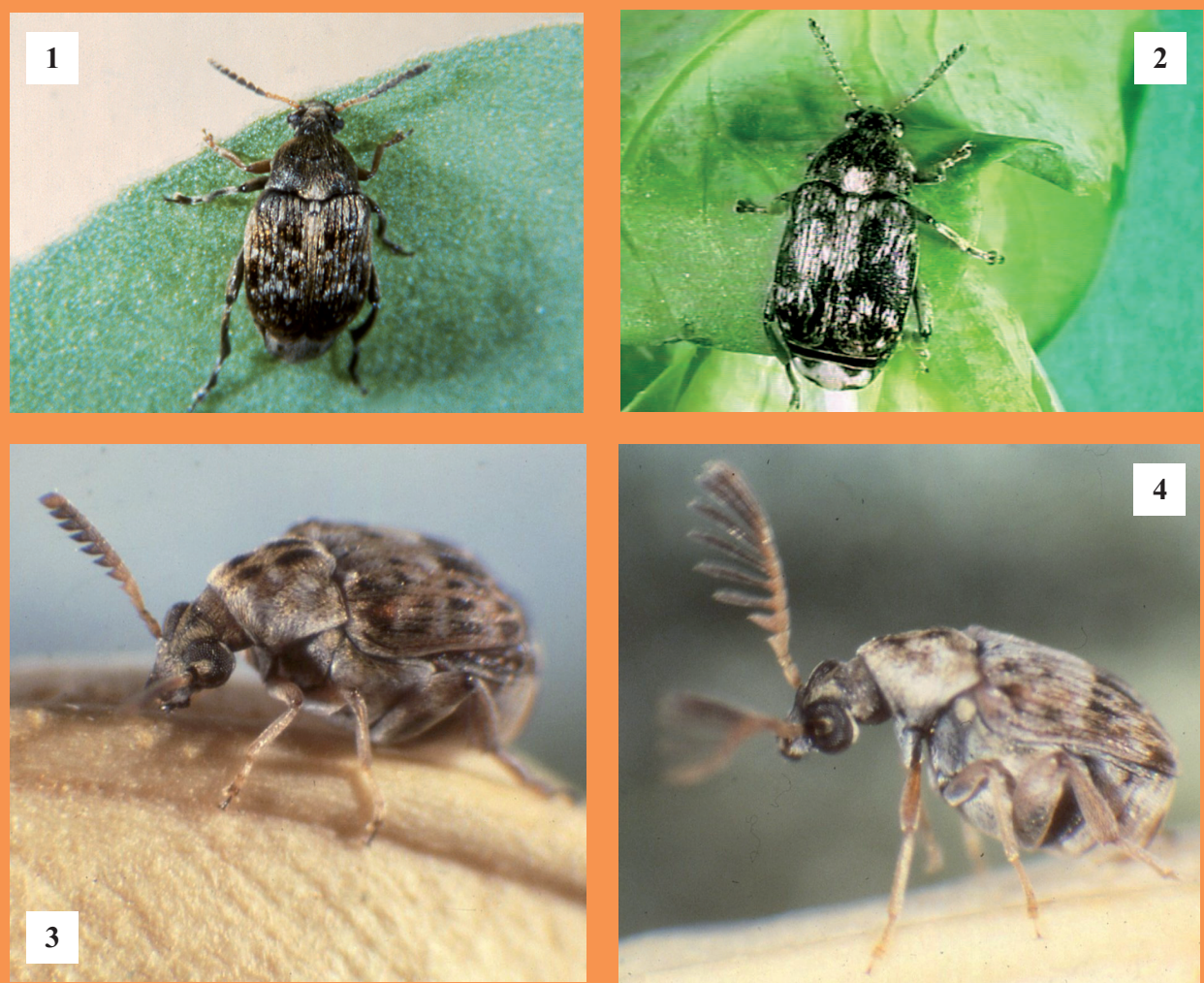

1. Adulte de Bruchus rufimanus L. (1:3,5 à $5 \mathrm{~mm})$. (C) Irbi Tours.

2. Adulte de Bruchus pisorum L. (1:3,5 à $5 \mathrm{~mm})$. C Irbi Tours.

3. Adulte femelle de Bruchidius atrolineatus Pic (1 : 2,5 à 3,5 mm). (C) J.-C. Biémont/Irbi, Tours.

4. Adulte mâle de Bruchidius atrolineatus Pic (1:2,5 à 3,5 mm). C J.-C. Biémont/Irbi, Tours. 

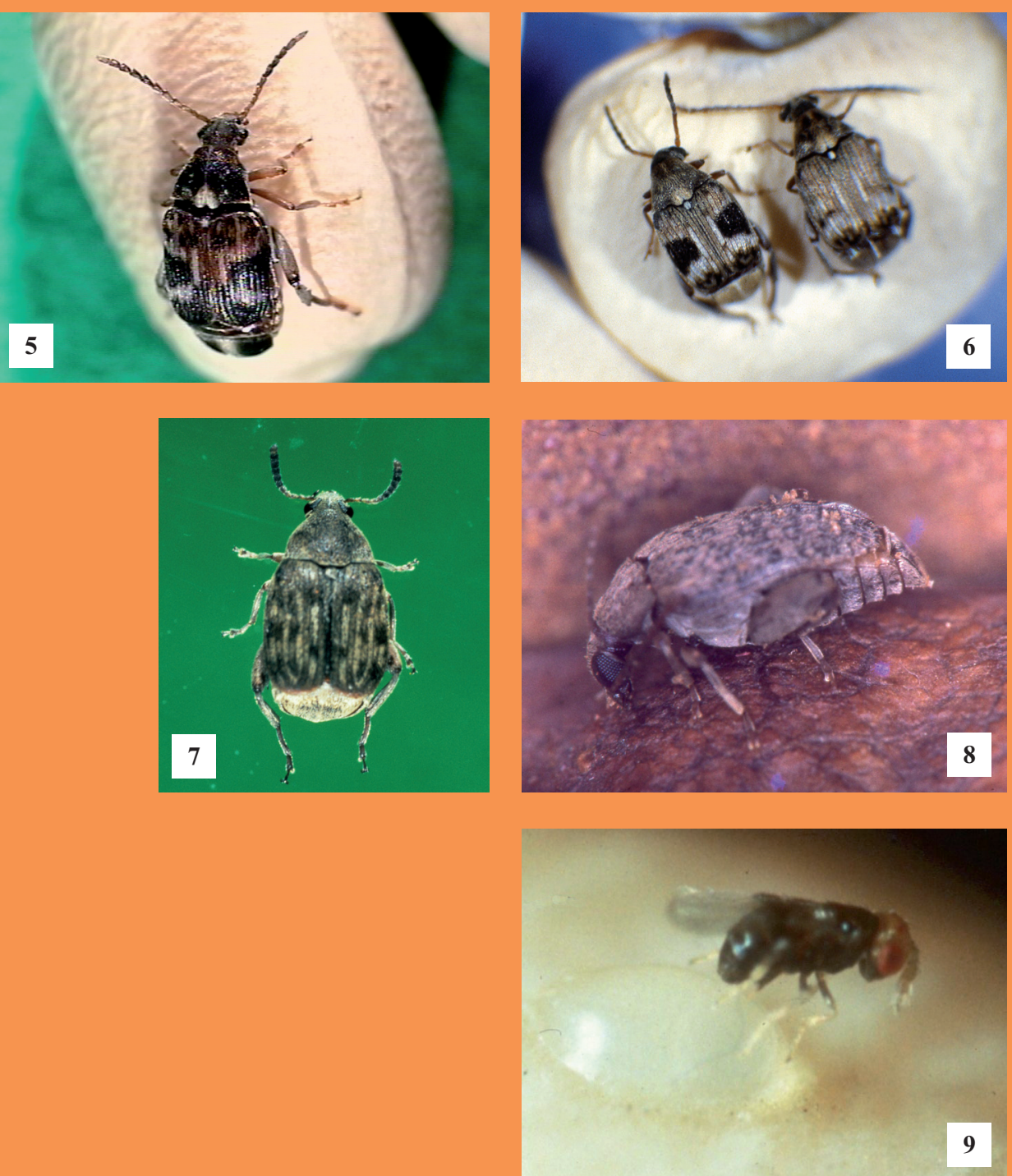

5. Adulte femelle de Callosobruchus maculatus F. du morphe non-voilier (1:3 ̀̀ $5 \mathrm{~mm})$.

(C) Irbi Tours.

6. Callosobruchus maculatus F., femelle (avec taches noires sur les élytres), mâle (sans taches sur les élytres), du morphe voilier. (C) Irbi Tours.

7. Acanthoscelides obtectus Say Femelle (1:2,5 à 3,5 mm). (C) F. Fleurat-Lessard/Inra.

8. Adulte de Caryedon serratus Ol. (1: 6 à $8 \mathrm{~mm})$. (C) M. Sembene.

9. Femelle d'Uscana lariophaga Steph. (1:0,4 mm). (C) Irbi Tours. 

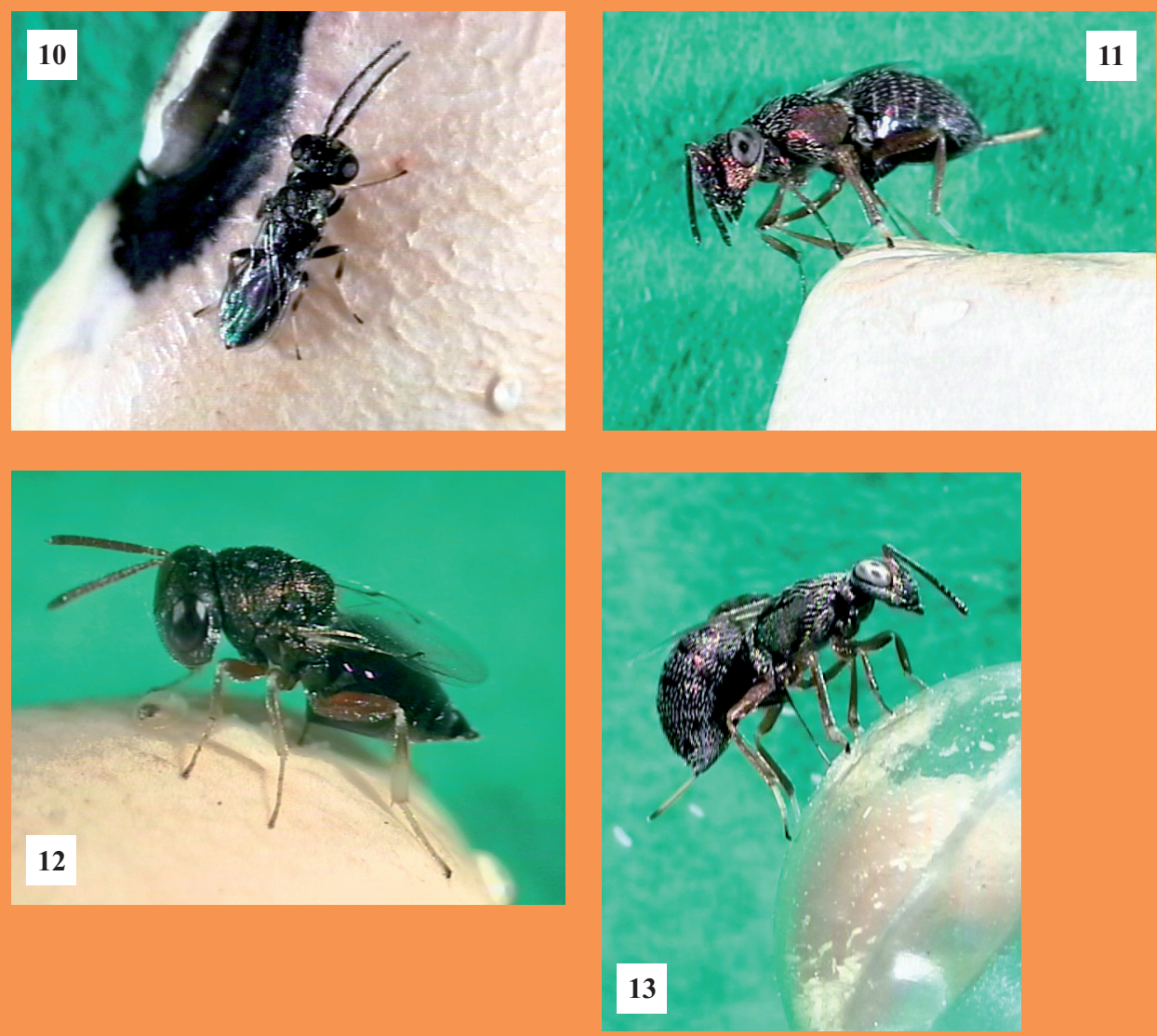

10. Mâle d'Eupelmus orientalis Crawford (1:2 à $4 \mathrm{~mm}$ ). (C) Irbi Tours.

11. Femelle d'Eupelmus orientalis Crawford (1:4 à $6 \mathrm{~mm})$. (C) Irbi Tours.

12. Femelle d'Eupelmus vuilleti (1:4 à $6 \mathrm{~mm})$. (C) Irbi Tours.

13. Femelle de Dinarmus basalis Rondani ( $1: 3$ à $3,5 \mathrm{~mm})$. (C) Irbi Tours. 


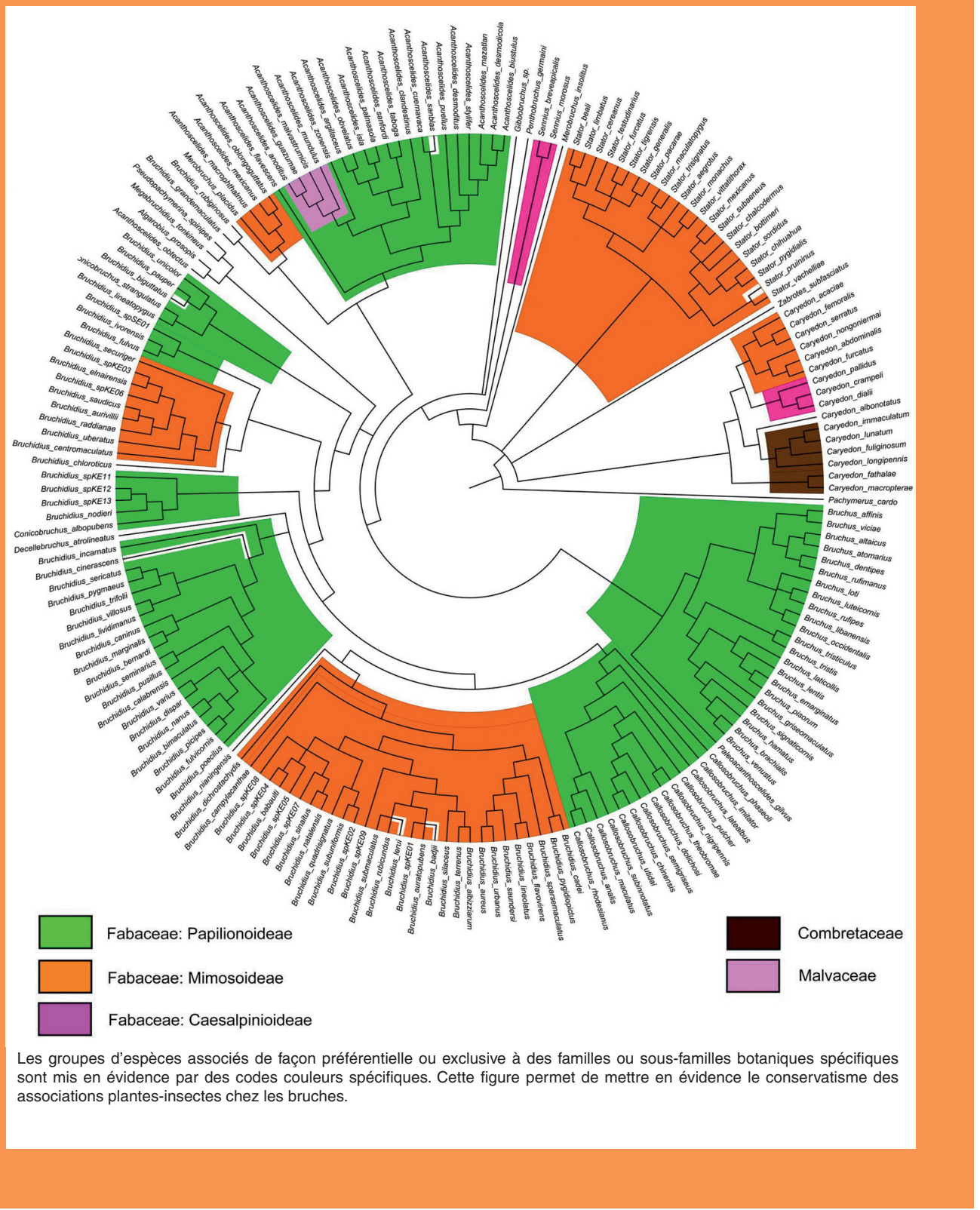

Figure 3.1. Schéma des résultats d'une analyse d'optimisation en parcimonie du caractère plantehôte sur un arbre phylogénétique (d'après Kergoat et al., 2008). 


\title{
Chapitre 4
}

\section{L'infestation des cultures puis des stocks de graines par les Coléoptères Bruchinae}

\author{
Jacques Huignard, Isabelle Adolé Glitho, Mbacke Sembene
}

Les Coléoptères Bruchinae sont des insectes séminivores qui se développent aux dépens des graines de légumineuses sauvages et cultivées. Ils sont spécialistes ou oligophages. Les femelles déposent leurs œufs sur les gousses et le premier stade larvaire de type chrysomélien est muni de pattes thoraciques. Ces larves, très mobiles, perforent le péricarpe de la gousse puis de la graine à l'aide de leurs mandibules. Peu après son entrée dans la graine, la larve $\mathrm{L}_{1}$ mue et se transforme en larve de type rhynchophorien dépourvue de pattes. Il y a généralement quatre stades larvaires au cours du développement post-embryonnaire. Chez la plupart des espèces, les larves $\mathrm{L}_{4}$ se transforment en nymphe dans la graine à l'intérieur d'une galerie tapissée d'acide urique. Après la mue imaginale, l'adulte découpe à l'aide de ses mandibules le tégument de la graine recouvrant la loge nymphale et mène une vie libre. Chez les espèces du genre Caryedon, les larves $\mathrm{L}_{4}$ sortent de la graine, tissent un cocon de soie et nymphosent à l'extérieur.

Ce sont les adultes qui doivent découvrir le substrat trophique des larves. Les femelles vont donc rechercher leur plante-hôte, puis les gousses qui serviront de substrat de ponte et qui contiennent les graines où aura lieu le développement des larves. Elles sont attirées par des composés volatils émis par leur plante-hôte comme chez de nombreux phytophages. Des composés chimiques présents à la surface des gousses et perçus par des chémorécepteurs gustatifs stimulent l'ovogenèse, puis induisent le comportement de ponte ; ils assurent la spécificité des relations entre l'insecte et sa plante-hôte. Ces informations issues du végétal permettent la synchronisation spatio-temporelle entre le stade adulte et le stade larvaire consommateur et sont à l'origine chez les spécialistes de la spécificité des relations entre le Bruchinae et sa plante-hôte (Jermy et Szentesi, 2003). Or, les gousses ne sont disponibles dans la nature que pendant une courte période de l'année. Certaines espèces vont entrer en diapause larvaire puis en diapause reproductrice, et survivre dans la nature pendant toute la période où le substrat de ponte ne sera pas disponible. D'autres espèces, plus opportunistes, vont exploiter les graines stockées 
par l'homme dans les greniers après la récolte. Elles deviennent alors capables de se reproduire et de se développer aux dépens de graines sèches dans des conditions environnementales très différentes des conditions naturelles. Ces espèces sont devenues des ravageurs des stocks et vont provoquer des pertes importantes pour les récoltes.

L'analyse du comportement de ponte permet de caractériser trois groupes de Bruchinae et de comprendre les mécanismes adaptatifs ayant permis à certaines espèces de devenir des insectes ravageurs de denrées stockées (Hoffmann et Labeyrie, 1962) :

- Premier groupe : les Bruchinae ne pondent que sur des gousses vertes et les larves réalisent une grande partie de leur développement dans des graines en cours de maturation. Ils ne disposent donc de leur substrat de ponte que pendant une courte période, car ils sont incapables de se reproduire et de se développer dans les systèmes de stockage. Il n'y a qu'une seule génération par an et les insectes sont en diapause durant toute la période où les gousses ne sont pas disponibles. Les espèces du genre Bruchus rencontrées au Maghreb et au Moyen-Orient appartiennent à ce groupe.

- Deuxième groupe : les Bruchinae qui colonisent les cultures pondent sur les gousses vertes puis sur les gousses sèches. Leurs larves se développent dans les graines en cours de maturation puis dans les graines sèches. Elles sont donc capables de se reproduire et de se développer dans les cultures, puis dans les systèmes de stockage après la récolte. Plusieurs générations peuvent ainsi se succéder à ce niveau, mais les capacités d'exploitation des stocks de graines varient suivant les espèces, comme le montrera l'analyse de la reproduction et du développement des différentes espèces de Bruchinae inféodées au niébé.

- Troisième groupe : les Bruchinae de ce groupe présentent une plasticité comportementale plus limitée, puisqu'ils ne pondent qu'en présence de gousses sèches dans les cultures à la fin de la phase de fructification de la plante-hôte, puis sur les graines sèches dans les systèmes de stockage après la récolte. Les espèces inféodées aux Phaseolus ou à l'arachide appartiennent à ce groupe.

Nous examinerons les conditions de reproduction et de développement des principales espèces de Bruchinae inféodées aux légumineuses cultivées en Afrique et tenterons de comprendre comment ces espèces se sont progressivement adaptées aux systèmes de stockage de graines et sont devenues des ravageurs des denrées stockées.

\section{Les Bruchinae du genre Bruchus}

Les espèces du genre Bruchus sont des insectes phytophages spécialistes qui colonisent les cultures au moment de la phase de floraison de leur plante-hôte et ne se reproduisent que sur les gousses vertes. Ce genre compte environ 300 espèces réparties dans toute la région eurasiatique et en Amérique. Les différentes espèces se développent aux dépens des légumineuses sauvages et cultivées. Ce sont des insectes monovoltins qui sont en diapause larvaire ou en diapause imaginale durant la période hivernale. Seule la biologie de quelques espèces s'attaquant aux légumineuses cultivées (pois, fève, lentille) ou ornementales (genêt, Lathyrus, etc.) a fait l'objet de recherches.

\section{La bruche de la fève: Bruchus rufimanus Boh.}

Cette bruche se développe aux dépens des graines de légumineuses du genre Vicia et particulièrement de la fève Vicia faba (planche couleur I photo 1). Cet insecte cosmopolite s'attaque aux cultures de fève en Europe, au Maghreb, au Moyen-Orient et 
aux États-Unis (Hoffmann et Labeyrie, 1962). Les femelles déposent leurs œufs sur les gousses vertes et les larves se développent dans les graines en cours de maturation. Les larves de B. rufimanus peuvent détruire de 20 à $50 \%$ des graines de fève récoltées au Moyen-Orient (Hariri, 1981).

\section{La colonisation des cultures de fève par $\mathrm{B}$. rufimanus}

Des études réalisées en France et au Maghreb ont permis de comprendre le cycle biologique de cette espèce. Les graines de fèveroles d'hiver (des variétés de fève utilisées pour l'alimentation animale) sont semées en automne et les plantes restent à l'état végétatif durant toute la période hivernale. Les adultes de B. rufimanus colonisent les cultures au début du mois de mai lorsque commence la phase de floraison de la fèverole. Les femelles sont toutes en diapause reproductive, leurs ovarioles sont réduits à leur germarium ; il n'y a aucune phase de vitellogenèse et elles ne présentent aucune activité sexuelle. La plupart des mâles sont sexuellement actifs (figure 4.1) ; les testicules contiennent de nombreux spermatozoïdes groupés en spermatodesmes et la lumière des glandes annexes contient d'abondantes sécrétions. Chez les mâles, qui sont encore en diapause reproductrice, la spermatogenèse est très ralentie et la lumière des glandes annexes est vide.

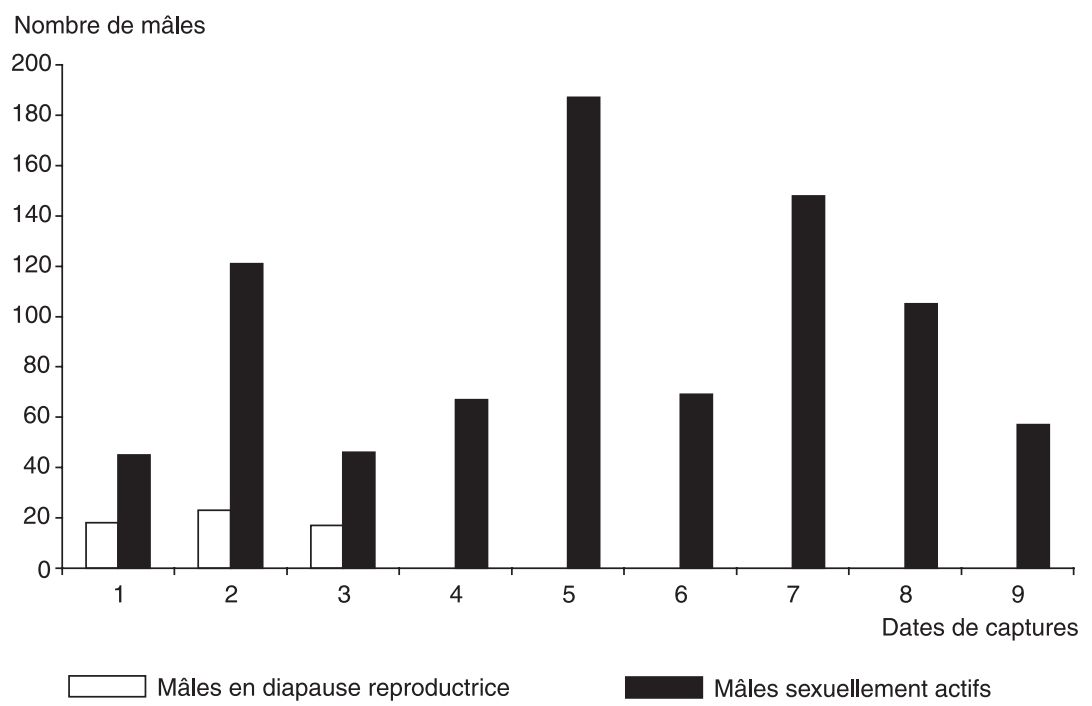

Figure 4.1. Évolution temporelle des effectifs d'adultes mâles de B. rufimanus capturés tous les quatre jours du 5 mai au 6 juin et analyse de leur état reproducteur.

Les femelles de B. rufimanus explorent les différentes parties de la plante durant la journée et consomment d'importantes quantités de pollen et de nectar. Elles deviennent progressivement sexuellement actives (figure 4.2); elles s'accouplent puis commencent à pondre sur les jeunes gousses dès que celles-ci apparaissent sur les pieds de fèverole. Les adultes restent présents dans la parcelle tant que des gousses vertes sont disponibles; ils se nourrissent de pollen de fèverole, puis à la fin de la phase de floraison de pollen d'autres espèces végétales afin de disposer de réserves suffisantes pour se reproduire. Lorsqu'il n'y a plus de gousses vertes, les insectes quittent les cultures et recherchent d'autres variétés de fèverole plus tardives où ils trouvent de nouveaux substrats de ponte. 


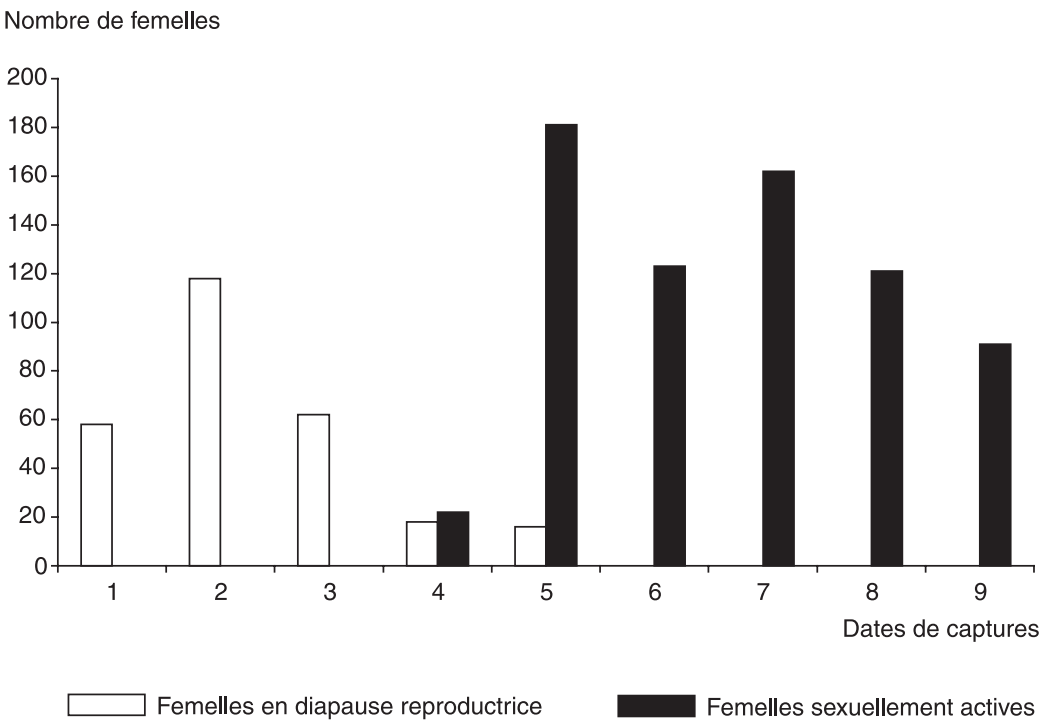

Figure 4.2. Évolution temporelle des effectifs d'adultes femelles de B. rufimanus capturés tous les quatre jours du 5 mai au 6 juin et analyse de leur état reproducteur.

Durant la période de fructification, les effectifs de B. rufimanus présents dans les cultures sont importants et les gousses vont recevoir des œufs (figure 4.3) qui sont collés au péricarpe grâce à des sécrétions produites par les cellules glandulaires des oviductes (figure 4.4).

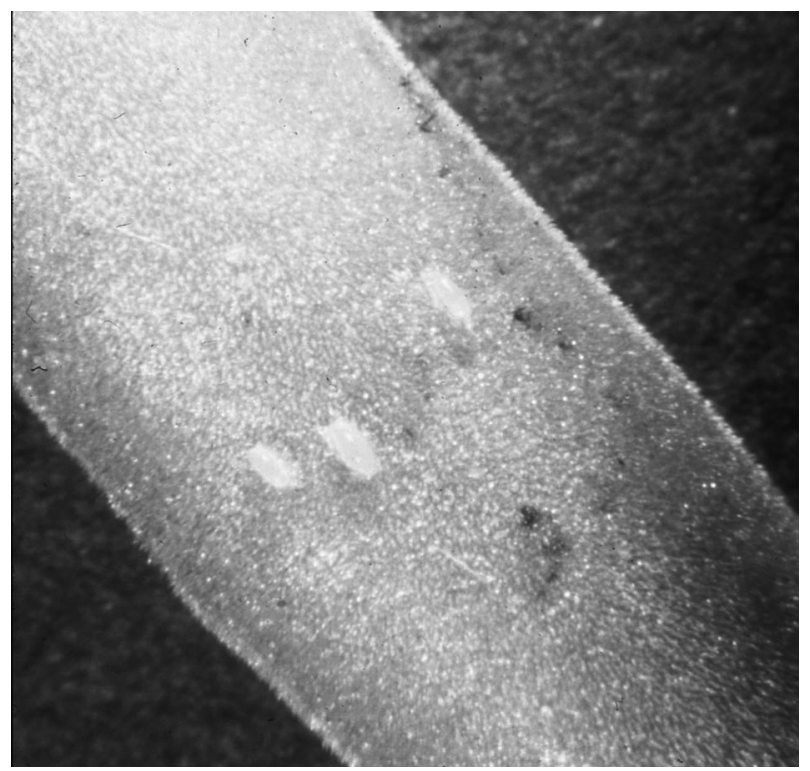

Figure 4.3. Pontes déposées sur le péricarpe des gousses vertes de $V$. faba par les femelles de B. rufimanus (longueur des œufs de couleur jaune : 0,8 mm). (C) J. Huignard. 


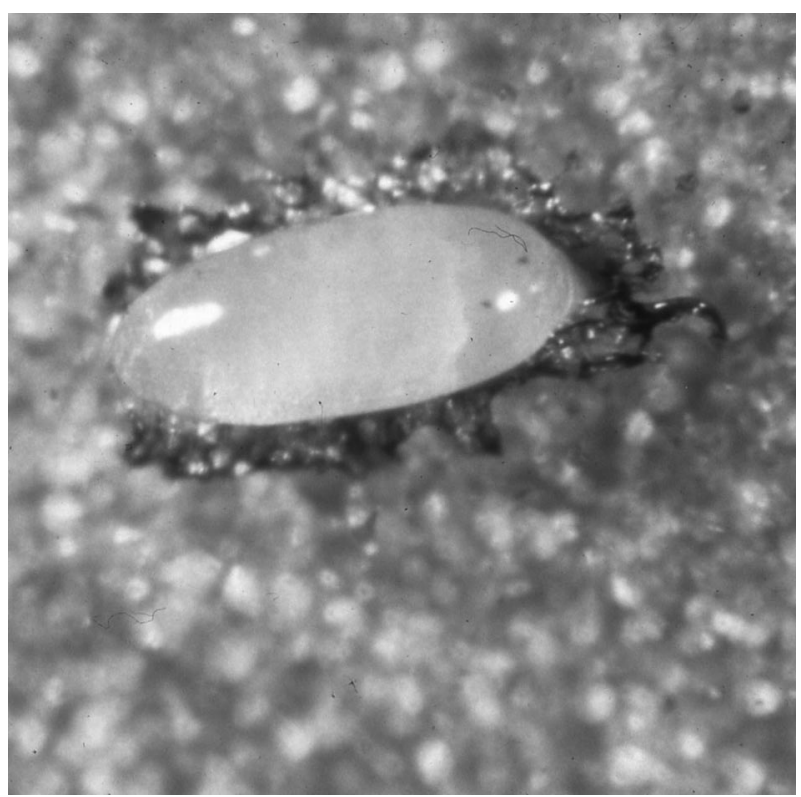

Figure 4.4. Sécrétions permettant l'adhésion d'un œuf de B. rufimanus sur la gousse de $V$. faba. (C) J. Huignard.

Les premières gousses formées sont généralement les plus contaminées. Des études réalisées par Medjdoub (2007) en Algérie montrent que 60 à $80 \%$ des gousses de fève formées au début de la phase de fructification ont reçu des œufs de B. rufimanus; le nombre d'œufs déposé sur chaque gousse est très variable, mais toujours inférieur à 10 . Les femelles ne déposent des œufs que sur les gousses vertes. Lorsque les gousses sont sèches, elles quittent les cultures et recherchent d'autres pieds de fève à floraison et fructification plus tardives pour se reproduire à nouveau. Les femelles pondent donc durant une période assez longue et leur fécondité peut être supérieure à 100 œufs.

\section{Les conditions de levée de la diapause reproductrice}

Chez B. rufimanus, la levée de la diapause a lieu au printemps lors de la phase de fructification de la plante-hôte. Des études expérimentales, réalisées dans une population de $B$. rufimanus originaire de la région Centre en France ont montré que la levée de la diapause était due à l'interaction de trois facteurs :

- La photopériode : il ne peut y avoir levée de la diapause reproductrice, quelles que soient les conditions expérimentales, si la photopériode est inférieure à 16:8h LD ${ }^{1}$. Le passage au régime photopériodique 18:6h LD permet la levée de la diapause reproductrice chez 60 à $70 \%$ des mâles, mais il n'a aucun effet chez les femelles.

- La présence des fleurs de la plante-hôte : ce facteur joue un rôle important dans le cycle biologique de B. rufimanus. Lorsque des femelles sont placées dans les conditions photopériodiques 18:6h LD en présence d'inflorescences de $V$. faba, plus de $90 \%$ d'entre

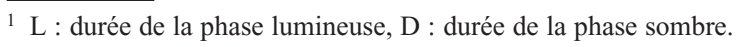


elles sont devenues reproductrices après dix jours d'exposition. La consommation du pollen de $V$. faba permet la levée de la diapause (Tran et Huignard, 1992). Le pollen d'autres légumineuses est ingéré par les adultes diapausants, mais n'a aucun effet. La consommation de substances contenues dans le grain de pollen de $V$. faba est suivie d'un accroissement du taux d'ecdysone, hormone qui induit probablement le démarrage de la reproduction (Medjdoub, 2007).

- La durée de la phase de diapause reproductrice : l'intensité de la diapause reproductrice décroît au cours du temps. Elle est élevée durant les premiers mois de diapause et les différents facteurs stimulants n'ont aucun effet. Ce n'est qu'après six à sept mois de diapause que les insectes réagissent à ces facteurs stimulants et peuvent devenir reproducteurs.

\section{Le développement de la nouvelle génération}

Les œufs déposés sur les gousses vertes donnent naissance à des larves qui perforent le péricarpe puis recherchent les graines. Un suivi régulier des effectifs d'adultes émergeant de gousses ayant reçu des pontes de B. rufimanus a été réalisé du mois d'août au mois d'avril dans les conditions de stockage. La majorité des larves qui ont pénétré à l'intérieur des graines débutent leur croissance, mais il y a deux stratégies de développement chez cette espèce (figure 4.5).

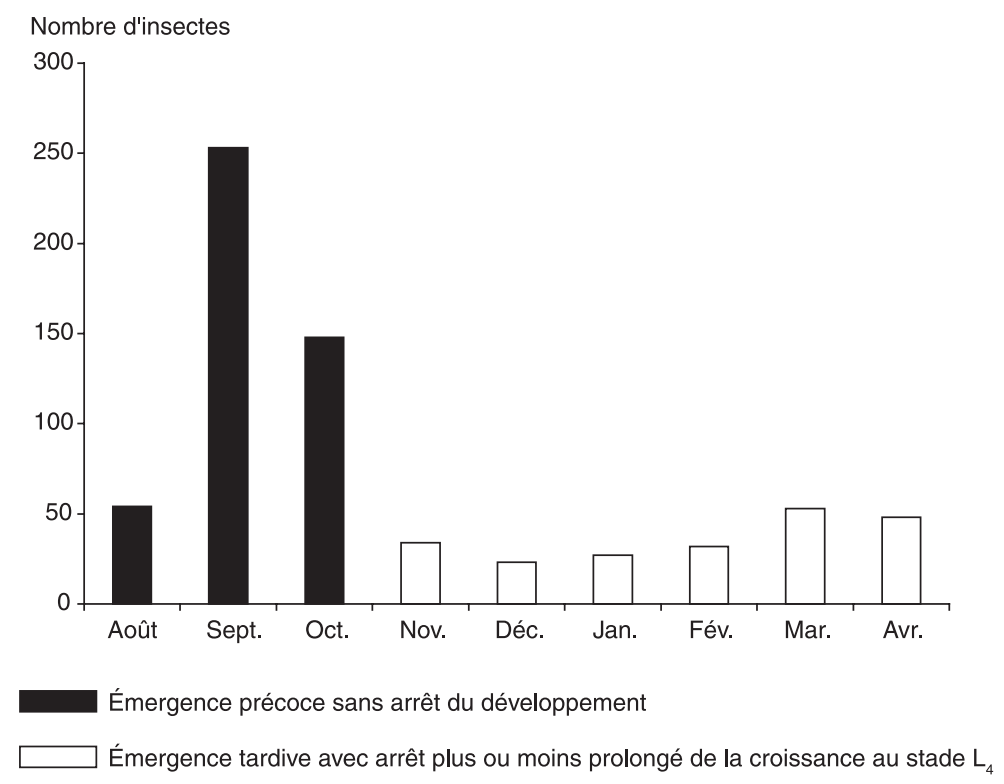

Figure 4.5. Évolution des effectifs d'adultes de B. rufimanus capturés chaque mois dans un stock de $10 \mathrm{~kg}$ de graines de fèves stockées pendant neuf mois.

- Première stratégie : émergence précoce d'adultes en diapause reproductrice. Il n'y a pas d'arrêt du développement et tous les insectes atteignent le stade adulte entre les mois d'août et d'octobre après une durée de développement post-embryonnaire de 75 à 80 jours. Les adultes, en diapause reproductrice, quittent les stocks de graines et sont 
capables d'effectuer des déplacements de plusieurs kilomètres. Ils volent à une altitude moyenne de 8 à 10 mètres et recherchent les bosquets entourant les zones de culture (Hoffman et Labeyrie, 1962). Ils hivernent dans les écorces des arbres, sous les lichens recouvrant les troncs ou le branchage. Ces adultes ne restent pas inactifs durant l'hiver et peuvent changer d'abris au cours des journées chaudes et ensoleillées. La mortalité au cours de l'hivernation dépend de la température et de la nature de l'abri. Les insectes peuvent supporter des températures inférieures à $-10^{\circ} \mathrm{C}$. La présence de sucres et notamment de tréhalose dans l'hémolymphe facilite la survie des insectes dans ces conditions thermiques. Durant la phase de diapause, les insectes possèdent un corps gras abondant et le taux de protéines de l'hémolymphe est élevé.

- Seconde stratégie : émergence tardive après une diapause larvaire. Il y a un arrêt plus ou moins prolongé de la croissance larvaire au stade $\mathrm{L}_{4}$ à l'intérieur des graines qui peut être assimilé à une diapause larvaire. Dans les conditions naturelles, l'accroissement de l'humidité de la graine au moment du semis permet la reprise du développement, puis la sortie des adultes qui sont en diapause reproductrice.

Cette double stratégie de développement permet à cette espèce de s'adapter à des variations climatiques aléatoires pendant la saison hivernale. Si la mortalité est importante au stade adulte durant la période hivernale, en raison d'une forte humidité ou de températures très basses, l'émergence d'adultes issus de larves diapausantes pourra permettre le maintien des populations au printemps suivant.

\section{Le devenir des adultes diapausants}

$\mathrm{Au}$ printemps, lorsque la température est supérieure à $15^{\circ} \mathrm{C}$ et que la photopériode s'allonge, les adultes commencent à voler à la recherche de plantes en fleur et se nourrissent du pollen et du nectar que ces fleurs produisent. Ils vont alors rechercher les cultures de fève et peuvent effectuer des déplacements de plusieurs kilomètres lorsque les sites d'hivernation sont éloignés des cultures. Les adultes colonisant la culture ont un comportement opportuniste et exploitent d'abord les pieds de fèves se trouvant à proximité d'arbres ayant servi de sites d'hivernation puis, dans un second temps, les pieds les plus éloignés.

\section{La bruche du pois : Bruchus pisorum L.}

C'est une espèce cosmopolite dont les dégâts sont signalés dans toutes les régions d'Eurasie, aux États-Unis et en Australie (planche couleur I photo 2). Les larves se développent dans les graines de pois (Pisum sativum L.) ; elles réduisent de façon importante leur valeur marchande et diminuent leur pouvoir germinatif. La biologie de B. pisorum est proche de celle décrite chez B. rufimanus.

Les adultes en diapause reproductrice quittent les sites d'hivernation lorsque la température est supérieure à $20{ }^{\circ} \mathrm{C}$ et colonisent les cultures de pois au moment de la phase de floraison. Ils pénètrent dans les fleurs durant la journée et consomment des quantités importantes de pollen. Cette consommation de pollen induit la levée de la diapause reproductrice chez les mâles comme chez les femelles (Pajni et Sood, 1975). Elle permet un apport énergétique important nécessaire à la recherche du substrat de ponte et à la phase de reproduction (Clement, 1992). Seule la consommation de pollen de pois peut permettre la levée de la diapause reproductive. La ponte commence neuf à dix jours après la consommation de pollen; les œufs de couleur jaune mesurent 1,5 x 0,6 mm et 
ne sont déposés que sur les gousses vertes. Les femelles ont une fécondité élevée durant leur vie imaginale lorsque les conditions climatiques et nutritionnelles sont favorables. Certaines d'entre elles peuvent pondre plus de 300 œufs. La période de ponte se prolonge durant toute la production des gousses. Le nombre d'œufs déposés sur une même gousse peut être de 20 à 30 ; certains œufs étant même déposés l'un au-dessus de l'autre, ce qui provoque une mortalité élevée.

Après une phase de développement embryonnaire d'une dizaine de jours, les larves perforent le péricarpe de la gousse, puis se déplacent à l'intérieur de celle-ci pour rechercher les graines vertes dans lesquelles ils se développent. Il y a là encore deux stratégies de développement durant la période hivernale :

- soit un développement direct avec survie dans la nature ou dans les entrepôts. La durée de développement est estimée à deux mois, mais peut varier en fonction de la température et de l'état de maturation des graines. Une période de sécheresse qui accélère la maturation des graines entraîne un ralentissement de la croissance et provoque une mortalité élevée ; - soit un développement ralenti à l'intérieur des graines avec l'arrêt du développement au stade $\mathrm{L}_{4}$ et au stade nymphal, puis l'émergence des adultes au printemps (Smith, 1990). Il est donc possible qu'il y ait aussi chez B. pisorum une diapause larvaire chez une partie des individus au cours de la période hivernale.

Les adultes quittent les graines de pois après la récolte et recherchent les forêts où ils passeront l'hiver. Ils volent vers leurs sites d'hivernation à des altitudes variant entre 9 et 20 mètres et hivernent dans la partie supérieure des arbres entre 5 et 7 mètres du sol. Ils se cachent au niveau des mousses ou des lichens recouvrant les écorces des troncs et des branches. Ils peuvent changer de sites d'hivernation au cours des journées chaudes et ensoleillées. Le taux de survie dans les sites d'hivernation est très variable et dépend des conditions climatiques, un hiver froid et humide provoquant une mortalité élevée (Hoffmann et Labeyrie, 1962). Tous les insectes survivant dans les sites d'hivernation sont en diapause reproductrice.

\section{Les bruches de la lentille}

Trois espèces se développent aux dépens des lentilles : Bruchus signaticornis Gyll., Bruchus lentis Fröel. et Bruchus ervi Fröel.

B. signaticornis et B. ervi sont présentes dans les cultures de lentille en Europe et dans les zones méditerranéennes, notamment en Syrie, en Turquie et en Iran. B. signaticornis peut détruire $80 \%$ des graines de lentilles au cours du stockage (Hariri, 1981). B. lentis est surtout présente dans le Bassin méditerranéen, au Moyen-Orient et en Asie.

La biologie de ces trois espèces est proche de celle des autres espèces du genre Bruchus. Les études les plus complètes ont été réalisées chez B. lentis en Algérie par De Luca (1956). Les adultes de $B$. lentis colonisent les cultures de lentille au cours du mois de mai lors de la phase de floraison; ils pénètrent dans les fleurs et consomment le pollen. Cette phase de nutrition permet probablement la levée de la diapause reproductrice. Les femelles devenues sexuellement actives recherchent activement les gousses au niveau desquelles ont lieu les accouplements puis la ponte. Les femelles pondent rarement plus d'un œuf par gousse ; celui-ci est généralement déposé à la base de la gousse. Elles évitent de pondre sur des gousses qui ont déjà reçu un œuf.

Après un développement embryonnaire d'une dizaine de jours, les larves $\mathrm{L}_{1}$ perforent le péricarpe de la gousse, puis pénètrent à l'intérieur des graines en cours de maturation. 
Tout le développement post-embryonnaire d'un insecte se réalise à l'intérieur d'une seule graine et il y a, selon De Luca (1956), six stades larvaires. La durée du développement est estimée selon cet auteur à 45 jours et les adultes sortent des graines mûres en juillet avant la récolte ou dans les centres de stockage, et gagnent des sites d'hivernation (silos, arbres, etc.). Il est possible qu'une partie de la population hiverne à l'intérieur des graines comme les autres Bruchinae, mais ceci n'est pas signalé. Tous les adultes de la nouvelle génération émergeant des graines de lentille sont en diapause reproductrice.

Lorsque les larves de $B$. lentis se développent dans les graines de lentille, elles produisent des protéines spécifiques fortement allergènes vis-à-vis des personnes manipulant ces graines et des consommateurs. Cette réaction allergique se manifeste par des troubles respiratoires, des rhinites et de l'asthme (Armentia et al., 2006). Il convient donc de se protéger lors de la manipulation de graines infestées par $B$. lentis dans les systèmes de stockage.

\section{Les Bruchinae inféodés au niébé Vigna unguiculata}

\section{Bruchidius atrolineatus (Pic)}

Bruchidius atrolineatus (Pic) est une espèce qui est largement distribuée en Afrique tropicale et subtropicale, particulièrement dans les zones sahéliennes (planche couleur I photos 3 et 4). Sa principale plante-hôte en Afrique de l'Ouest est Vigna unguiculata. Les femelles pondent sur les gousses vertes ou sur les gousses sèches des variétés sauvages et cultivées de cette légumineuse. Les larves se développent à l'intérieur des graines en voie de maturation ou des graines mûres. Les études présentées dans ce travail ont été réalisées en zone sahélienne dans la région de Niamey au Niger.

\section{La colonisation des cultures de V. unguiculata en zone sahélienne}

Les adultes de $B$. atrolineatus commencent à coloniser les cultures de niébé au cours du mois d'août pendant la saison des pluies lorsque les plantes sont encore au stade végétatif. Toutes les femelles et un fort pourcentage de mâles sont en diapause reproductrice. Ils consomment durant cette période du pollen et du nectar produits par les plantes qui sont en fleur dans l'agrosystème. Les effectifs d'adultes deviennent importants en septembre dès que les inflorescences apparaissent sur les pieds de V. unguiculata. Les insectes sont surtout présents dans les cultures à l'aube et au crépuscule; ils sont peu actifs durant la journée lorsque les températures sont très élevées. Au début de la phase de floraison, les mâles puis les femelles deviennent progressivement sexuellement actifs. Les insectes s'accouplent au niveau des plantes, puis les femelles commencent à pondre sur les gousses vertes dès que celles-ci se forment.

Les études expérimentales montrent que la levée de la diapause chez les femelles est due à l'interaction de trois facteurs : une photophase de 11:13h LD, une humidité relative élevée et la présence d'inflorescences ou de gousses vertes de V. unguiculata (Germain et al., 1985). Cette levée de la diapause n'est pas due à la consommation du pollen des fleurs de la plante-hôte, contrairement à ce que l'on observe chez les espèces du genre Bruchus. Le contact avec les fleurs ou les gousses vertes de V. unguiculata est seul nécessaire. Un stimulus gustatif spécifique (contact avec des substances présentes au niveau des pièces florales) induit le démarrage de l'activité reproductrice. 
Chez 70 à $80 \%$ des mâles, une photopériode de 11:13h LD et une humidité relative élevée permettent seules la levée de la diapause reproductrice. Chez les autres mâles, la présence des inflorescences de $V$. unguiculata est nécessaire.

\section{Caractérisation de l'état diapausant chez B. atrolineatus}

Les femelles en diapause reproductrice ont des ovarioles réduits à leur germarium (figure $4.6 \mathrm{~A}$ ). Elles ne synthétisent pas de vitellogénine, mais produisent une protéine de diapause qui s'accumule dans l'hémolymphe. Chez les femelles sexuellement actives (figure $4.6 \mathrm{~B}$ ), les ovarioles contiennent des ovocytes mûrs ou en voie de maturation. Il y a disparition de la protéine de diapause et synthèse de vitellogénine dans l'hémolymphe. La protéine de diapause pourrait être une importante source d'acides aminés permettant les synthèses tissulaires après la levée de la diapause (Denlinger, 2002). Les femelles diapausantes n'attirent pas les mâles, car elles ne produisent pas de phéromone sexuelle.
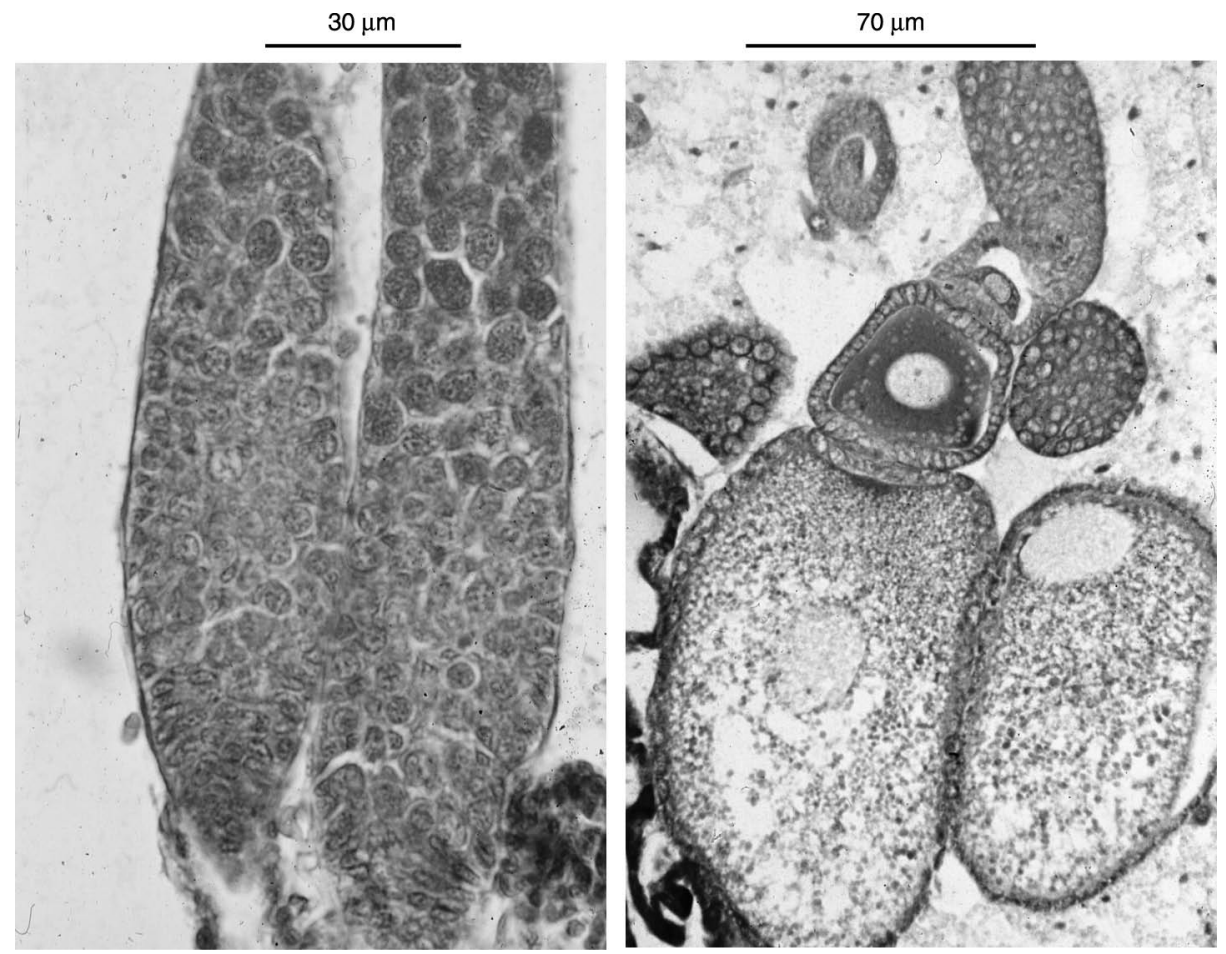

Figure 4.6 : Coupes histologiques des organes reproducteurs femelles. À gauche, ovarioles d'une femelle en diapause reproductrice ; à droite, ovarioles d'une femelle sexuellement active avec des ovocytes en voie de maturation. (C) J. Huignard.

Chez les mâles en diapause reproductrice, la spermatogenèse débute durant le stade nymphal et se poursuit très lentement au cours de la vie imaginale. Il n'y a qu'un nombre limité de spermatozoïdes qui s'accumulent dans les vésicules séminales. Les glandes 
annexes ne présentent aucune activité sécrétrice et leur lumière est vide. La spermatogenèse est en revanche très importante chez les mâles sexuellement actifs et les glandes annexes contiennent d'abondantes sécrétions (figure 4.7). Les mâles en diapause reproductrice ont synthétisé une protéine de diapause qui s'accumule dans l'hémolymphe, puis disparaît chez les insectes sexuellement actifs. Les mâles en diapause reproductrice sont insensibles aux phéromones sexuelles émises par les femelles sexuellement actives.

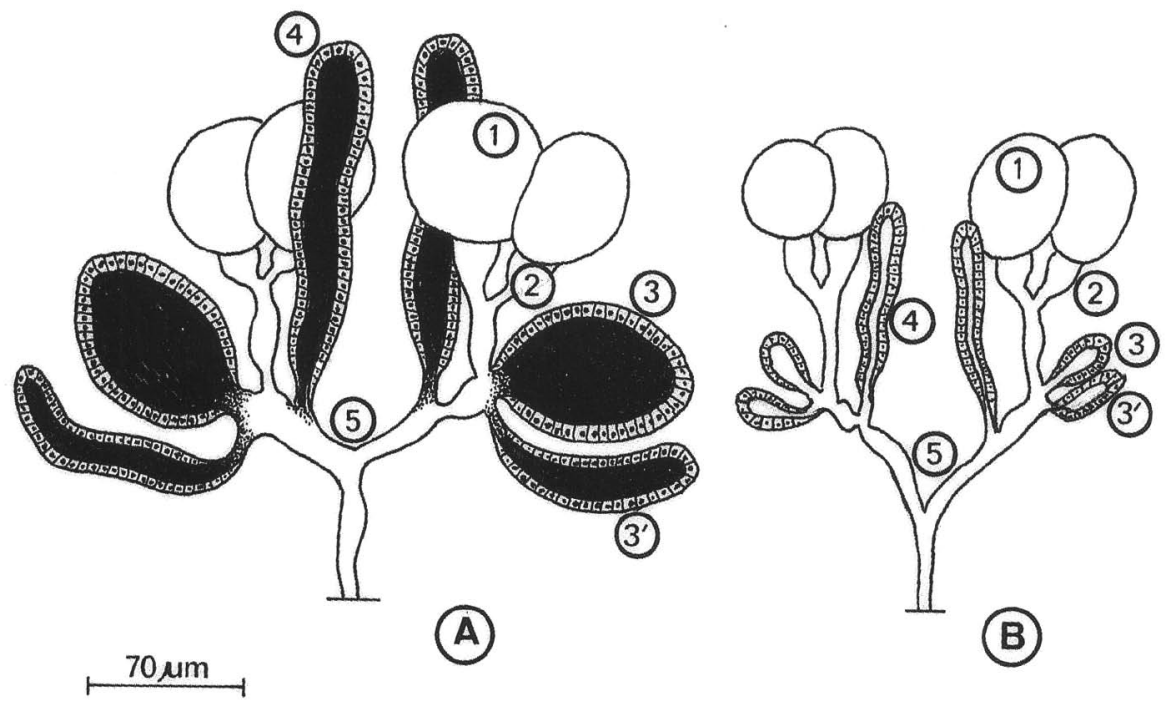

Figure 4.7. Appareil génital d'un mâle sexuellement actif (A) et d'un mâle en diapause reproductrice (B). 1. testicule, 2. vésicule séminale, 3. et 3'. glande latérale, 4. glande médiane, 5. canal déférent. Schéma J. Huignard.

\section{La reproduction et le développement dans les cultures}

Les insectes adultes restent présents dans les cultures durant toute la phase de floraison puis de fructification du niébé. Les femelles pondent sur les gousses vertes en voie de maturation, puis sur des gousses sèches. Les œufs sont déposés le long des deux sutures de la gousse (figure 4.8); ils adhèrent au péricarpe grâce à des pédicelles sécrétés lors de la phase de ponte par les cellules glandulaires des oviductes latéraux (figure 4.9).

Les études réalisées au Niger (Leroi et al., 1985) au cours de la saison des pluies montrent que durant toute la période de fructification du niébé, les femelles répartissent leurs œufs sur les gousses disponibles dans la culture quel que soit leur état de maturation. Ce sont les premières gousses formées au début du mois de septembre qui sont les plus contaminées ; plus de $70 \%$ d'entre elles reçoivent en moyenne 12 œufs. Les gousses formées plus tardivement sont moins contaminées, mais plus de $40 \%$ d'entre elles ont cependant reçu des pontes de $B$. atrolineatus. La mortalité au cours du développement embryonnaire et post-embryonnaire est très élevée puisque $75 \%$ des œufs déposés sur les gousses ne donneront naissance à aucune descendance. Cette forte mortalité est observée quelles que soient l'année et les dates de formation des gousses sur les pieds de V. unguiculata. Elle est due à différents facteurs : 
- un parasitisme des œufs provoqué par l'hyménoptère Uscana lariophaga (Stephan.) qui détruit suivant les années 6 à $10 \%$ des œufs ;

- la prédation essentiellement due à des hémiptères qui se nourrissent aux dépens des œufs et des larves néonates ;

- les pluies, fréquentes à cette période de l'année, qui provoquent le décollement des œufs puis leur chute ;

- un parasitisme larvaire dû aux hyménoptères Eupemidae, Eupelmus orientalis (CRW.) et Eupelmus (CRW.), et à l'hyménoptère Pteromalidae, Dinarmus basalis (Rond.). E. orientalis est l'espèce dominante et représente $82 \%$ des émergences d'hyménoptères. Les taux de parasitisme dus aux parasitoïdes larvaires sont toujours inférieurs à $10 \%$; - une mortalité d'origine non déterminée qui a lieu lorsque les larves perforent le péricarpe ou pénètrent dans les grains.

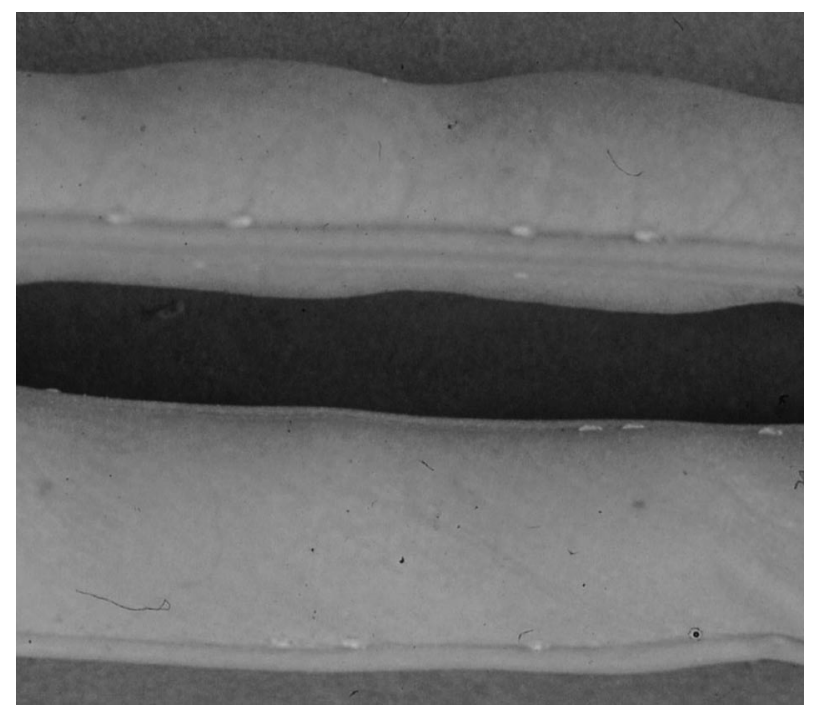

Figure 4.8. Eufs de B. atrolineatus déposés le long des sutures sur des gousses de V. unguiculata. $\mathrm{L}: 0,6 \mathrm{~mm}$. (C) J. Huignard.

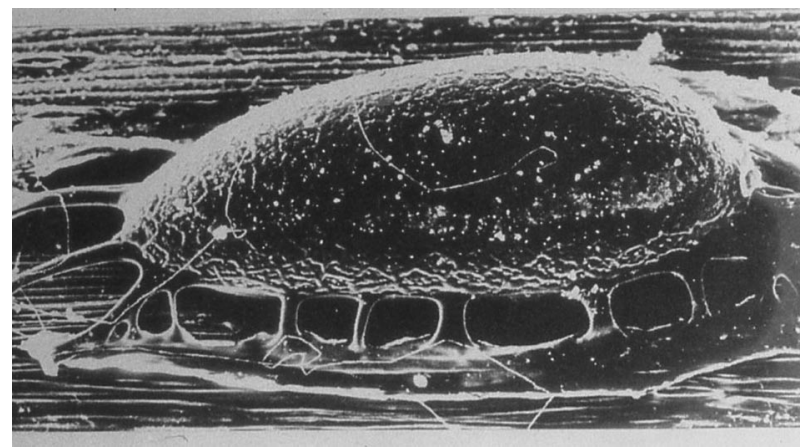

Figure 4.9. Vue en microscopie électronique à balayage du système d'adhésion d'un œuf de B. atrolineatus sur une gousse de V. unguiculata. (C) J. Huignard. 
Lorsqu'elles ont pénétré la graine, les larves de $B$. atrolineatus, qui ne sont pas parasitées, sont capables de se développer sans mortalité importante dans des graines en voie de maturation, puis dans les graines sèches.

Les femelles de $B$. atrolineatus ne vont disposer de leur substrat de ponte, c'est-à-dire des gousses de $V$. unguiculata, que pendant une courte période de l'année (au maximum un mois et demi). Elles doivent donc avoir une activité reproductrice importante, afin d'exploiter au mieux les gousses disponibles pour optimiser les chances de développement de la descendance. Cette stratégie permet, malgré une mortalité élevée, le développement d'une population importante dans les systèmes de stockage.

\section{Évolution des populations de B. atrolineatus dans les systèmes de stockage}

Des gousses de niébé récoltées dans des cultures à la fin du mois d'octobre sont stockées dans des structures en terre séchée ressemblant à des greniers à grains traditionnels. Ces greniers sont placés dans les conditions naturelles. Ils sont munis d'un piège permettant l'évasion des insectes hors de la structure de stockage (figure 4.10). Le dénombrement hebdomadaire des $B$. atrolineatus adultes trouvés dans ces pièges permet d'estimer l'évolution des effectifs de bruches adultes présents dans les structures de stockage et leur état reproducteur (Germain et Monge, 1987).

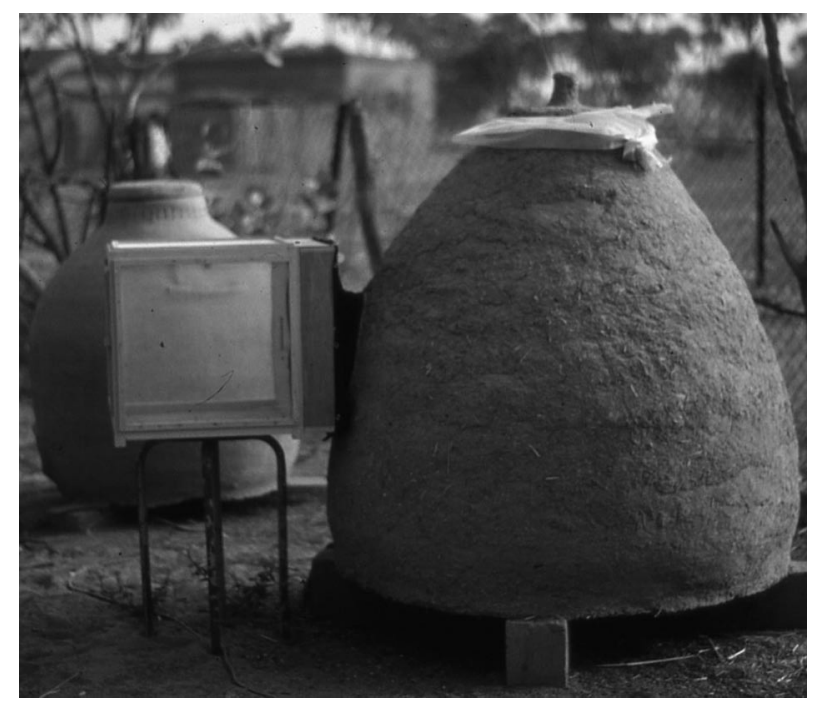

Figure 4.10. Grenier traditionnel en terre cuite muni d'un piège permettant de suivre les effectifs de $B$. atrolineatus durant la période de stockage. (C) J. Huignard.

On constate que deux générations de bruches se sont succédé dans les systèmes de stockage (figure 4.11) :

- la première génération est issue des œufs pondus dans la nature. Les adultes émergent des graines en novembre et décembre ; $82 \%$ d'entre eux ont des organes reproducteurs fonctionnels et se reproduisent dans le système de stockage. Les femelles déposent alors leurs œufs sur les gousses sèches stockées ou sur les graines sèches ; 
- la seconde génération se développe dans les stocks et commence à émerger à la fin du mois de décembre. Elle se caractérise par l'apparition d'un fort taux d'insectes en diapause reproductrice et par une très grande variabilité de la durée du développement post-embryonnaire puisque les émergences s'étalent sur sept mois. Seuls 15 à $20 \%$ des adultes émergeant en décembre sont reproducteurs. Le ralentissement du développement post-embryonnaire se fait essentiellement au cours des derniers stades larvaires $\left(\mathrm{L}_{3}\right.$ ou $\mathrm{L}_{4}$ ) et peut être assimilé à une diapause larvaire comme cela est observé chez d'autres Bruchinae.

Il est probable que dans la nature les insectes émergeant des stocks quittent les greniers mal clos ou s'envolent lorsque les greniers sont ouverts afin de prélever de la nourriture. Les conditions de survie de ces insectes pendant la saison chaude sont inconnues. Ils peuvent se cacher dans des anfractuosités rocheuses ou sous des végétaux et rechercher de la nourriture au niveau des végétaux en fleurs pendant cette période. C'est ainsi que des adultes ont été trouvés dans les fleurs de certaines légumineuses pendant la saison sèche.

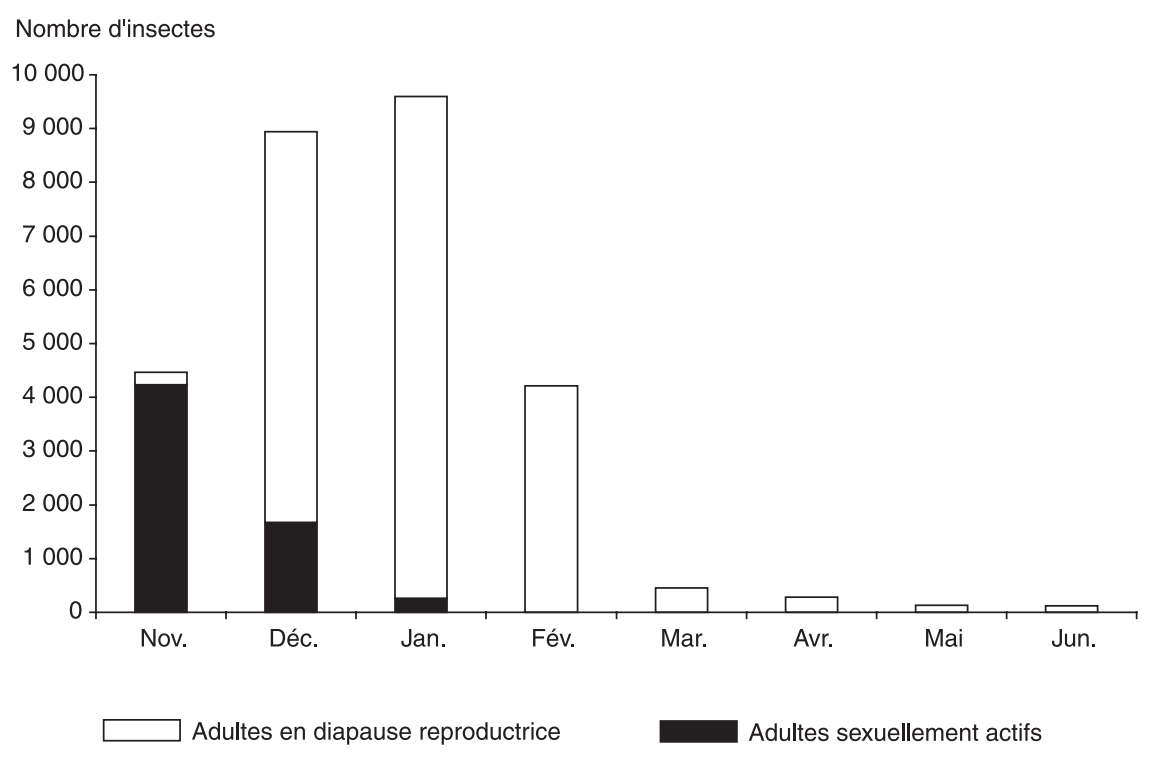

Figure 4.11. Évolution des effectifs d'adultes de B. atrolineatus capturés dans une structure de stockage expérimentale contenant $30 \mathrm{~kg}$ de gousses de niébé et analyse de leur état reproducteur.

\section{Comment expliquer l'émergence d'adultes reproducteurs ou diapausants ?}

Une analyse des conditions de développement de B. atrolineatus (Monge et al., 1989) montre l'importance des facteurs climatiques au cours de la croissance postembryonnaire sur l'état physiologique des adultes à l'émergence.

L'état reproducteur des adultes dépend des conditions photopériodiques prévalant au début du développement. B. atrolineatus est donc un insecte de jour court ; il y a émergence d'un fort taux d'adultes reproducteurs lorsque le développement postembryonnaire a lieu dans les conditions 11:13h LD. Inversement, les conditions 13:11h LD 
favorisent l'émergence d'un fort taux d'adultes en diapause reproductrice. Cette sensibilité vis-à-vis de la photopériode a été retrouvée chez une espèce japonaise Bruchidius dorsalis (Kurota et Shimada, 2007). Chez ces deux espèces, la larve de stade $\mathrm{L}_{1}$, qui représente le seul stade externe, est le stade sensible aux variations de la photopériode.

Les conditions thermiques du développement à deux périodes du stockage ont été reproduites au laboratoire. Des études expérimentales montrent que lorsque le développement a lieu dans les conditions thermiques reproduisant celles du début du stockage, à savoir $35: 25^{\circ} \mathrm{C}, 12: 12 \mathrm{~h} \mathrm{DD}^{2}, 89 \%$ des adultes émergeant des graines sont sexuellement actifs. Les adultes en diapause reproductrice ont un développement post-embryonnaire plus long (figure 4.12).

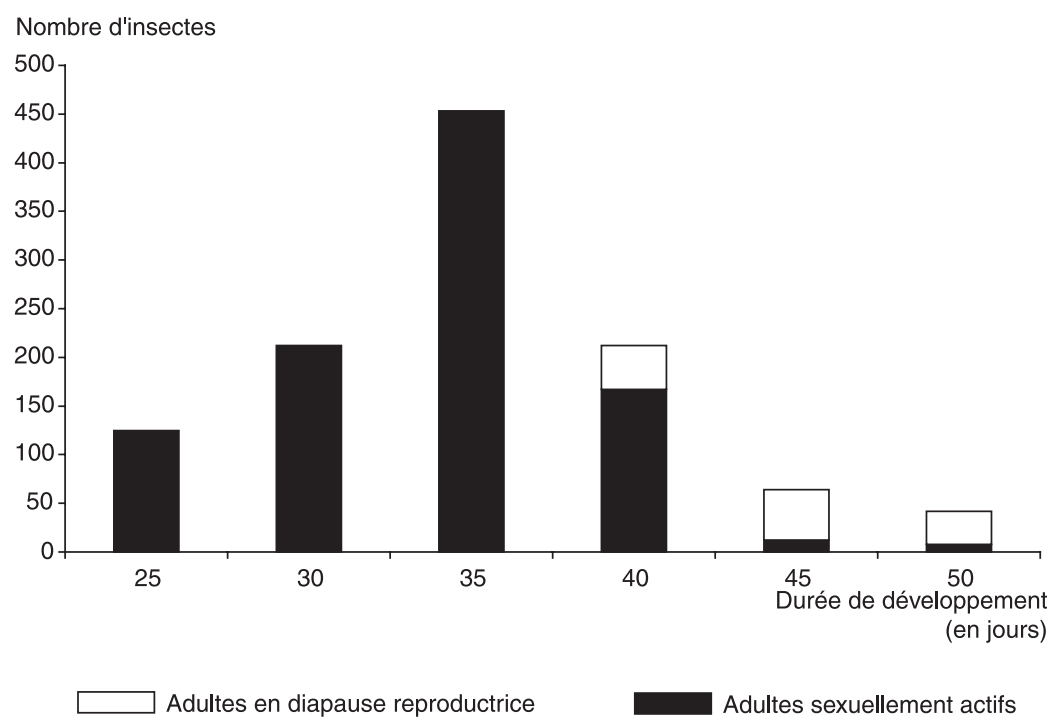

Figure 4.12. État reproducteur des adultes de $B$. atrolineatus après développement à l'obscurité dans les conditions thermopériodiques $\left(12 \mathrm{~h} 35^{\circ} \mathrm{C}: 12 \mathrm{~h} 25^{\circ} \mathrm{C}\right)$.

Lorsque le développement a lieu dans les conditions $25: 20^{\circ} \mathrm{C}, 12: 12 \mathrm{~h} \mathrm{DD}$, reproduisant les températures observées au Niger en décembre, la durée du développement est très variable suivant les individus (figure 4.13). Les premiers individus émergeant des graines (16\% des insectes adultes) sont sexuellement actifs. Les autres adultes sont en diapause reproductrice et les durées de développement s'étalent entre 90 et 290 jours. Il y a, comme dans les conditions naturelles, un ralentissement de la croissance aux stades $\mathrm{L}_{3}$, $\mathrm{L}_{4}$ qui peut être assimilé à une diapause larvaire.

B. atrolineatus peut donc être polyvoltin si les conditions de développement des 1 arves ont lieu dans les conditions favorables à l'émergence des insectes reproducteurs. Dans les conditions de stockage observées au Niger, l'abaissement des températures de décembre à février est le principal facteur induisant l'apparition de la diapause reproductrice.

$212 \mathrm{~h}$ à $35^{\circ} \mathrm{C}, 12 \mathrm{~h}$ à $25^{\circ} \mathrm{C} ; \mathrm{DD}$ : obscurité pendant $24 \mathrm{~h}$. 


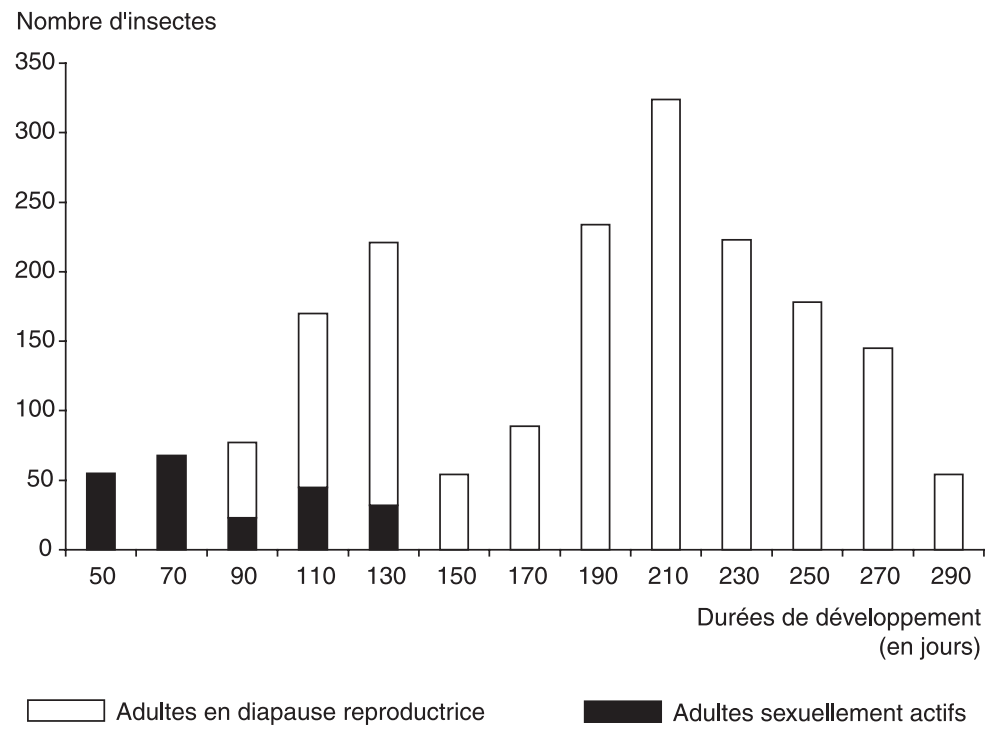

Figure 4.13. État reproducteur des adultes de $B$. atrolineatus après développement à l'obscurité dans les conditions thermopériodiques $\left(12 \mathrm{~h} 25^{\circ} \mathrm{C}: 12 \mathrm{~h} 20^{\circ} \mathrm{C}\right)$.

Cette adaptation physiologique favorise la survie des adultes pendant la saison sèche, tant que les gousses de la plante-hôte ne sont pas disponibles dans la nature. Il existe à l'intérieur des populations observées dans cette zone sahélienne une importante variabilité interindividuelle avec des individus qui sont toujours sexuellement actifs ou en diapause reproductrice, quelles que soient les conditions climatiques, tandis que d'autres sont

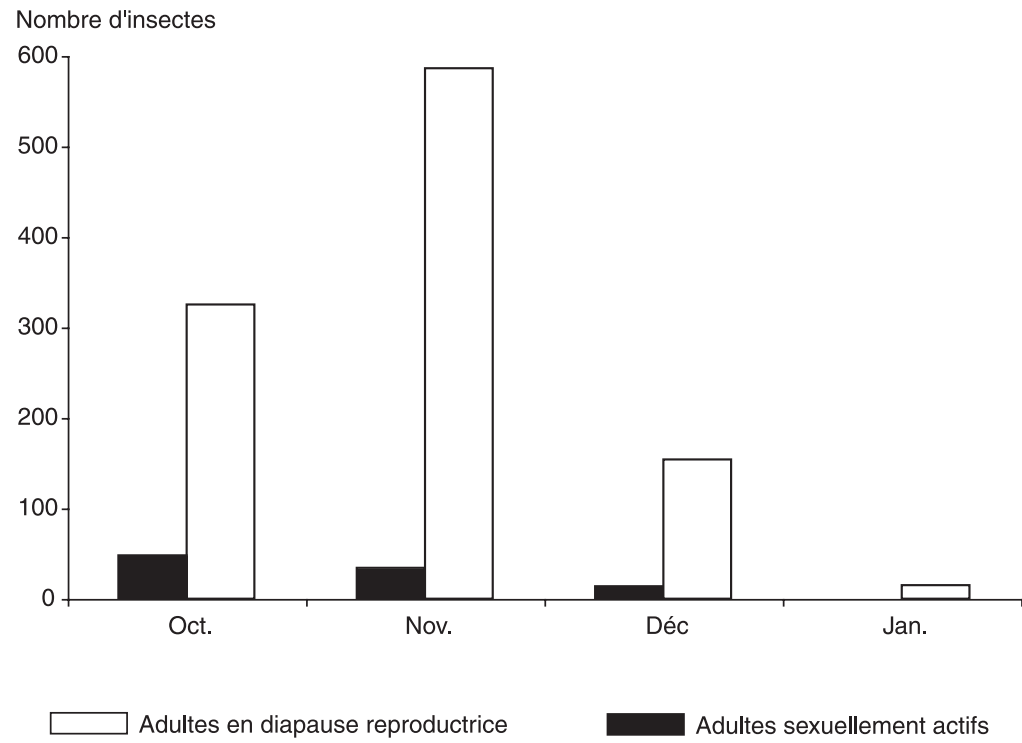

Figure 4.14. Évolution des effectifs de B. atrolineatus capturés dans un grenier contenant un stock de graines de niébé dans la région de Lomé ( $\left.4^{\circ} \mathrm{LN}\right)$ au Togo. 
sensibles à ces variations. Ces différences de sensibilité sont génétiquement déterminées (Lenga et al., 1991). Glitho (1990) constate que cette variabilité, observée dans des populations d'origine sahélienne, ne se retrouve pas dans des populations de B. atrolineatus étudiées en zone guinéenne plus humide, puisque $90 \%$ des individus de la première génération émergeant dans les systèmes de stockage sont en diapause reproductrice (figure 4.14). On peut considérer que cette espèce est pratiquement univoltine en zone guinéenne. Des différences génétiques entre les populations pourraient expliquer ces résultats.

\section{Callosobruchus maculatus (F.)}

Ce Bruchinae est présent dans toutes les zones tropicales (planche couleur II photos 5 et 6 ). Le niébé ( $V$. unguiculata) est sa principale plante-hôte. Il peut également se développer dans les graines d'autres légumineuses comme Cajanus cajan, Cicer arietinum, Lablab pupureus, Pisum sativum, Macrostyloma geocarpum et Glycine max.

Les femelles pondent sur les gousses en voie de maturation, sur les gousses sèches ou sur les graines aussi bien dans les cultures que dans les systèmes de stockage. Les pontes sont dispersées le long du péricarpe (figure 4.15) ; les œufs adhèrent fortement sur celui-ci grâce à une sécrétion qui recouvre complètement le chorion et s'étale sur la gousse. Les larves se développent dans les graines sèches. C. maculatus est parfaitement adapté aux systèmes de stockage de graines de niébé ; c'est le Bruchinae qui provoque les pertes les plus importantes en zones tropicales.

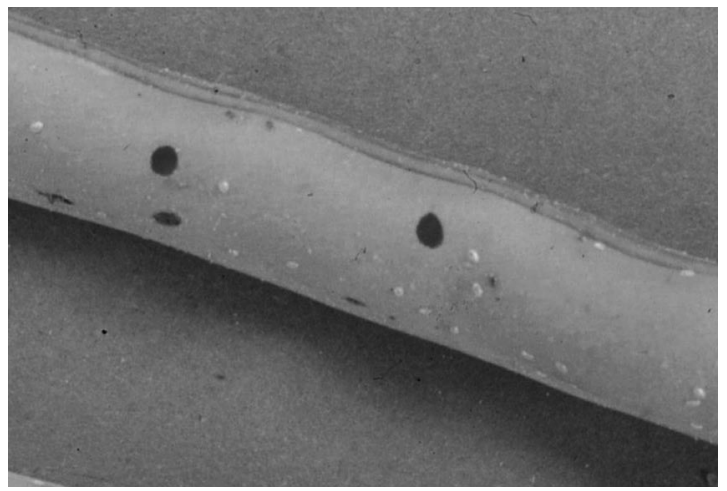

Figure 4.15. Pontes déposées par les femelles de C. maculatus sur une gousse de V. unguiculata. L : 0,4 mm. (C) J. Huignard.

Cet insecte a fait l'objet de nombreuses études analysant notamment son comportement de ponte, ses capacités de développement et son polymorphisme imaginal. Il existe en effet, au stade adulte, deux morphes : le morphe voilier et le morphe non-voilier, différant par des caractéristiques morphologiques, physiologiques et comportementales (Utida, 1972).

Les adultes du morphe non-voilier (planche couleur I photo 3) sont de couleur brun rougeâtre et il y a deux taches noires sur leur pygidium. Ils sont en effet incapables de voler ; leurs muscles alaires, bien que présents, ne sont pas fonctionnels. Ils ont des organes reproducteurs fonctionnels dès le début de leur vie imaginale.

Les adultes du morphe voilier sont de couleur brun noir à gris noir et ils n'ont pas de taches sur le pygidium (planche couleur I photo 4). Leur corps et les antennes sont plus 
courts que chez les adultes non-voiliers. Ils sont très actifs et s'envolent dès l'ouverture du grenier. Ils représentent des formes de dispersion adaptées à la colonisation de la plante-hôte dans l'agrosystème. Leur activité reproductrice est beaucoup plus faible que celle des non-voiliers (tout au moins dans les conditions de laboratoire) et très variable suivant les individus.

Il existe également des différences génétiques entre les individus des deux morphes comme l'ont montré des études de biologie moléculaire (Gill et al., 2006).

\section{Conditions d'apparition des deux morphes dans des systèmes de stockage en zone sahélienne sèche}

Des gousses portant de 1 à 3 œufs de $C$. maculatus ont été récoltées dans les cultures de niébé dans la région de Ouagadougou au Burkina Faso à la fin de la saison sèche, puis ont été stockées dans des jarres en terre cuite de $1 \mathrm{~m}^{3}$ pendant huit mois (de décembre à juillet). Les effectifs d'adultes (figure 4.16) s'accroissent de manière importante durant les trois premiers mois et atteignent une valeur maximale en mars. Les générations qui se succèdent durant cette période sont toutes composées d'adultes du morphe non-voilier ayant des organes reproducteurs fonctionnels. À partir du mois d'avril, les adultes du morphe voilier apparaissent et leur nombre augmente progressivement. Tous les insectes du morphe voilier, quel que soit leur sexe, ont des organes reproducteurs non fonctionnels. Il y a apparition d'adultes du morphe voilier lorsque la teneur en eau des graines devient importante au cours de la saison des pluies (Ouedraogo et al., 1991).

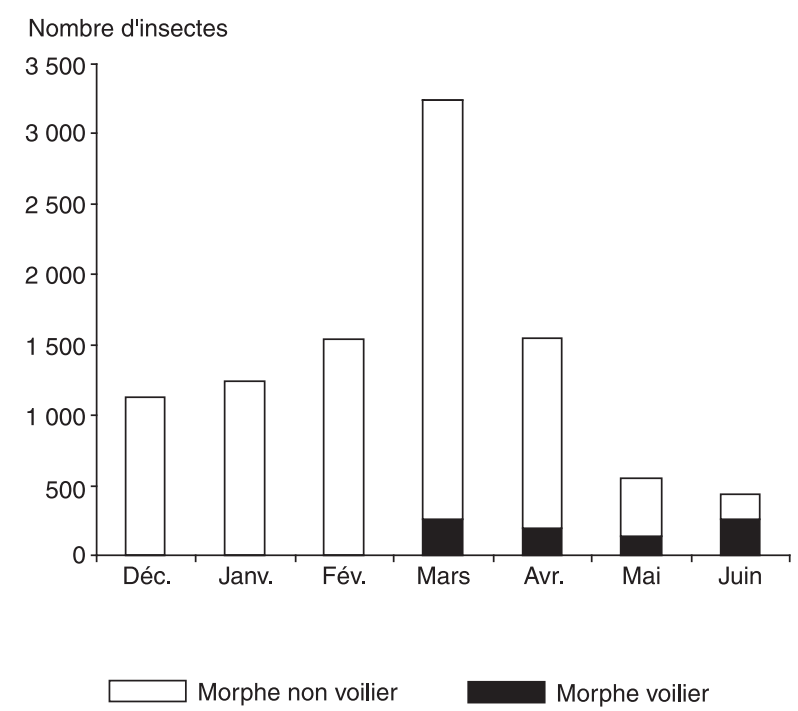

Figure 4.16. Variations temporelles des effectifs d'adultes de C. maculatus du morphe non-voilier et du morphe voilier émergeant des gousses en zone sahélienne.

Conditions d'apparition des deux morphes dans des systèmes de stockage en zone tropicale humide

Les études ont été réalisées dans la région de Cotonou au Bénin dans des conditions expérimentales proches de celles décrites précédemment au Burkina Faso. Durant la 
période de stockage, de septembre à février, les températures varient peu (entre 28 et $30{ }^{\circ} \mathrm{C}$ ) et l'atmosphère est toujours saturée en eau à l'intérieur des jarres. Les effectifs d'adultes de C. maculatus s'accroissent rapidement à partir du mois d'octobre ; les premiers adultes voiliers commencent à apparaître en novembre dès le troisième mois de stockage et ils deviennent rapidement dominants (figure 4.17).

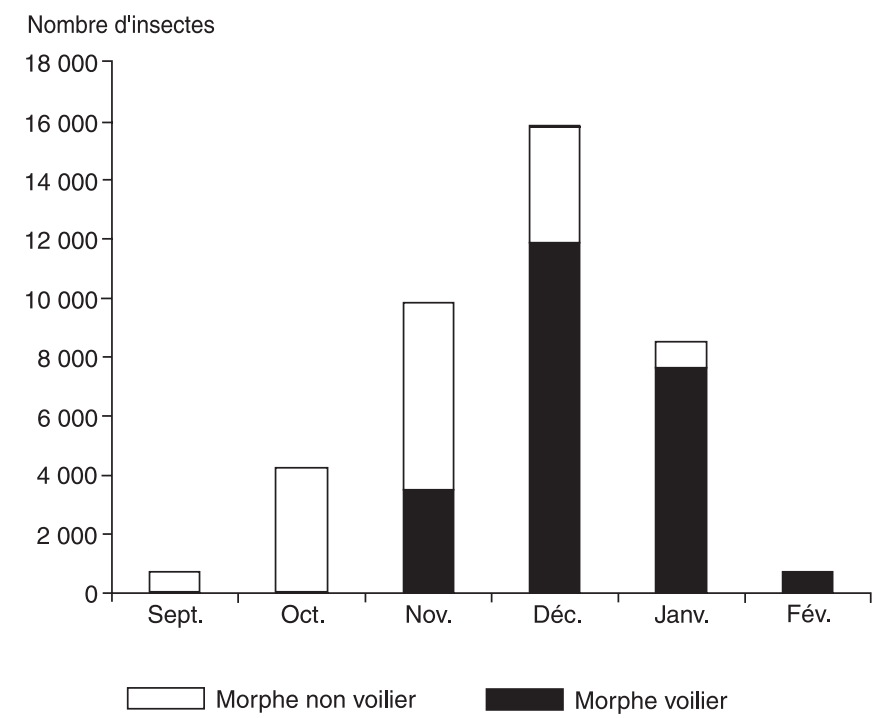

Figure 4.17. Variations temporelles des effectifs d'adultes de C. maculatus du morphe non-voilier et du morphe voilier émergeant des gousses en zone guinéenne.

L'accroissement de la densité larvaire à l'intérieur des graines semble être le principal facteur expliquant l'émergence précoce des adultes voiliers (Zannou et al., 2003). Il existe à l'intérieur de la population d'adultes du morphe voilier émergeant des graines trois types de femelles différant par leur activité reproductrice. Un fort pourcentage de femelles (environ $70 \%$ ) est en diapause reproductrice. Les autres femelles sont capables de se reproduire, mais elles le font soit durant les premiers jours de la vie imaginale, soit après un temps de latence de 14 à 25 jours. Leur fécondité, dans les conditions expérimentales, est toujours plus faible que celle observée chez les femelles du morphe non-voilier. Ce sont les mâles et les femelles du morphe voilier en diapause reproductrice qui colonisent ces cultures au début de la phase de floraison. Les adultes des deux sexes deviennent reproducteurs dès que débute la phase de floraison de V. unguiculata (Zannou et al., 2003). Les femelles se reproduisent sur les gousses en voie de maturation, puis sur les gousses sèches. Les pontes sont bien dispersées sur ces gousses qui ne portent à la récolte qu'un faible nombre d'œufs. Les adultes colonisateurs ont dû se maintenir pendant une durée plus ou moins longue dans l'agrosystème avant la phase de floraison de la plante-hôte. Les conditions de survie de ces insectes dans la nature sont inconnues.

\section{Analyse expérimentale du polymorphisme imaginal chez C. maculatus}

Les études de laboratoire montrent que l'existence du polymorphisme imaginal chez C. maculatus dépend des conditions du développement post-embryonnaire (Utida, 1972 ; Sano-Fujii, 1981 ; Ouedraogo et al., 1991). 
Il y a émergence d'un fort taux d'adultes voiliers lorsque les larves de C. maculatus se développent dans les conditions thermopériodiques $35: 25^{\circ} \mathrm{C}, 12: 12 \mathrm{~h}$ dans des graines dont la teneur en eau est élevée (14 à $16 \%$ ). Le taux d'adultes du morphe voilier est faible lorsque les larves se développent dans des graines sèches ou dans un régime thermopériodique caractérisé par des températures plus basses (figure 4.18). Une forte densité larvaire à l'intérieur des graines favorise l'émergence d'adultes voiliers. Dans ces conditions, l'apparition des adultes voiliers est due à l'augmentation de la teneur en eau des graines liée au métabolisme des larves (Ouedraogo et al., 1991).

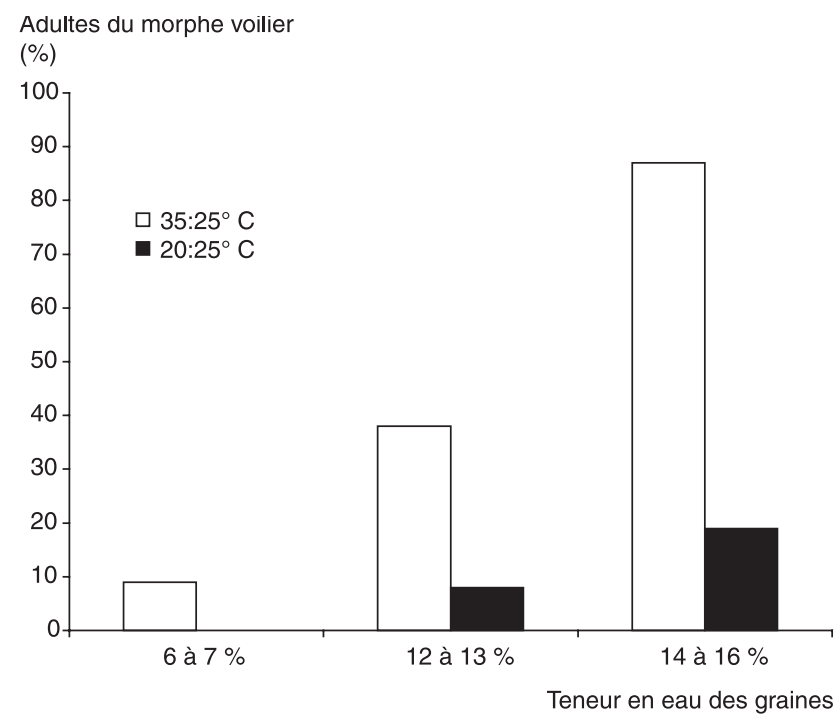

Figure 4.18. Importance des conditions thermiques et hygrométriques au cours du développement post-embryonnaire sur le taux de C. maculatus adultes du morphe voilier émergeant des graines.

Sano-Fujii (1986) démontre que ce polymorphisme imaginal résulte d'une interaction entre des facteurs de l'environnement et des facteurs génétiques. Ce chercheur a pu sélectionner au laboratoire, à partir d'adultes non-voiliers, des souches de C. maculatus incapables de produire des adultes voiliers, même lorsque les conditions sont favorables à l'apparition de ce morphe. De la même façon, en sélectionnant les descendants d'adultes voiliers, il est possible d'obtenir des souches produisant à chaque génération un fort taux d'adultes voiliers. Des croisements entre souches de laboratoire ayant une faible aptitude à produire des voiliers et des souches capables de produire un fort taux de voiliers montrent que le déterminisme de ce polymorphisme est polygénique. Il y aurait en plus un effet maternel; les œufs pondus à la fin de la période de ponte donnant naissance à plus de voiliers que ceux émis au début de la phase de ponte.

\section{Les caractéristiques du morphe non-voilier}

Les femelles du morphe non-voilier sont parfaitement adaptées aux conditions de stockage et peuvent en quelques générations provoquer des pertes élevées.

L'ovogenèse débute dès le premier jour de la vie imaginale. L'activité de ponte se poursuit durant une grande partie de la vie ; elle permet l'émission de 80 à 110 œufs 
lorsque les femelles sont maintenues à $30{ }^{\circ} \mathrm{C}$ et disposent en permanence d'un substrat de ponte. La présence des graines ou des gousses de niébé stimule l'ovogenèse et induit le comportement de ponte. C'est un mélange complexe d'acides gras se trouvant dans les cires épicuticulaires de la gousse ou de la graine qui induit la fonction reproductrice. Ces acides gras sont reconnus par les chémorécepteurs de contact situés au niveau des pièces buccales et de l'ovipositeur des femelles (Parr et al., 1998).

Les femelles produisent au début de la vie imaginale une phéromone sexuelle qui permet la rencontre des deux sexes. Cette phéromone, identifiée par Philipps et al. (1996), est formée par de courtes chaînes d'acides gras. Elle est produite par des glandes situées à l'extrémité de l'abdomen des femelles. Elle est émise au début de la vie imaginale et est perçue par les récepteurs sensoriels antennaires comme l'ont montré les études électrophysiologiques. Les études comportementales montrent qu'il y a deux composés actifs qui attirent les mâles, le (Z)-3-methyl-2-heptenoic acid (Z32A) et le (Z)-3-methyl3-heptenoic acid (Z33A). Le composé Z33A induit une réponse plus importante que le composé Z32A.

Lorsqu'elles sont au contact des mâles, les femelles émettent une seconde phéromone appelée érectine qui stimule le comportement d'accouplement des mâles. Sa composition chimique (acide 2,6-dimethyloctane-1,8-dioic) a été déterminée (figure 4.19) et plusieurs isomères ont été synthétisés par Nojima et al. (2007).

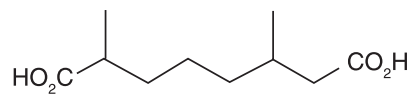

Figure 4.19. Structure de la copulation release pheromone de C. maculatus (d'après Nakai et al., 2005).

Les œufs sont bien dispersés sur les gousses ou les graines disponibles lors de la phase de ponte. Les femelles sont capables de détecter à la surface d'un substrat de ponte la présence d'un œuf pondu par elles-mêmes ou par une conspécifique et évitent de pondre sur ce substrat. Des signaux chimiques présents à la surface de l'œuf ou des informations tactiles permettent une discrimination de la qualité du substrat de ponte et limitent la compétition larvaire à l'intérieur des graines qui peut entraîner une mortalité élevée (Messina, 1990).

Le développement post-embryonnaire se réalise sans arrêt du développement et il est possible d'avoir à $30{ }^{\circ} \mathrm{C}$ une génération par mois. Les larves de C. maculatus en situation de compétition interspécifique avec d'autres larves de Bruchinae, telles que Bruchidius atrolineatus ou Callosobruchus rhodesianus sont très agressives vis-à-vis de leurs compétiteurs et éliminent ces derniers.

\section{Callosobruchus rhodesianus (Pic)}

Cet insecte a tout d'abord été trouvé en Afrique du Sud, puis a franchi l'équateur pour atteindre l'Afrique de l'Est, puis de l'Ouest (Southgate, 1979). Il est en train de coloniser progressivement les régions tropicales d'Afrique de l'Ouest. Il est régulièrement présent dans les cultures de niébé en Côte d'Ivoire (Delobel et Tran, 1993), au Togo et au Bénin (Amévoin et al, 2005). C. rhodesianus se développe aux dépens de diverses espèces de 
légumineuses : V. unguiculata, V. radiata, V. angularis et Cajanus cajan. Il est bien adapté aux conditions tropicales chaudes ; les conditions optimales de développement sont observées lorsque les insectes sont élevés à $30^{\circ} \mathrm{C}$ et $70 \% \mathrm{HR}$ (Giga et Smith, 1987).

Les adultes de $C$. rhodesianus colonisent les cultures de niébé au Togo lors de la phase de fructification. Les femelles se reproduisent sur les gousses en voie de maturation, puis sur les gousses sèches, et les larves se développent dans les graines en cours de maturation. Elles déposent avec les œufs une phéromone de marquage qui permet la reconnaissance des graines déjà infectées et réduit la compétition larvaire (Giga et Smith, 1985). Les adultes de la nouvelle génération, émergeant dans les systèmes de stockage, sont peu adaptés à cet environnement. Les effectifs d'adultes émergeant des graines régressent rapidement au cours du stockage, puis se maintiennent à un faible niveau. Cette diminution des effectifs est tout d'abord une conséquence de la faible activité reproductrice des femelles se développant dans cet habitat. Une analyse des femelles de la première génération de stockage (figure 4.20) montre que les femelles sexuellement actives (lot A) commencent à pondre au début de leur vie imaginale, mais leur fécondité moyenne est de 30 œufs. Les femelles du lot B produisent également des ovocytes après un long temps de latence, mais leur fécondité est inférieure à 10 œufs. Les autres femelles (lot C) sont en diapause reproductrice. Contrairement à ce qui a été observé chez B. atrolineatus, les durées de développement des femelles reproductrices et des femelles en diapause ne sont pas différentes; les deux types de femelles étant observées dès les premières dates d'émergence (figure 4.20). Les femelles reproductrices donnent naissance à une nouvelle génération qui présente la même hétérogénéité au niveau reproducteur.

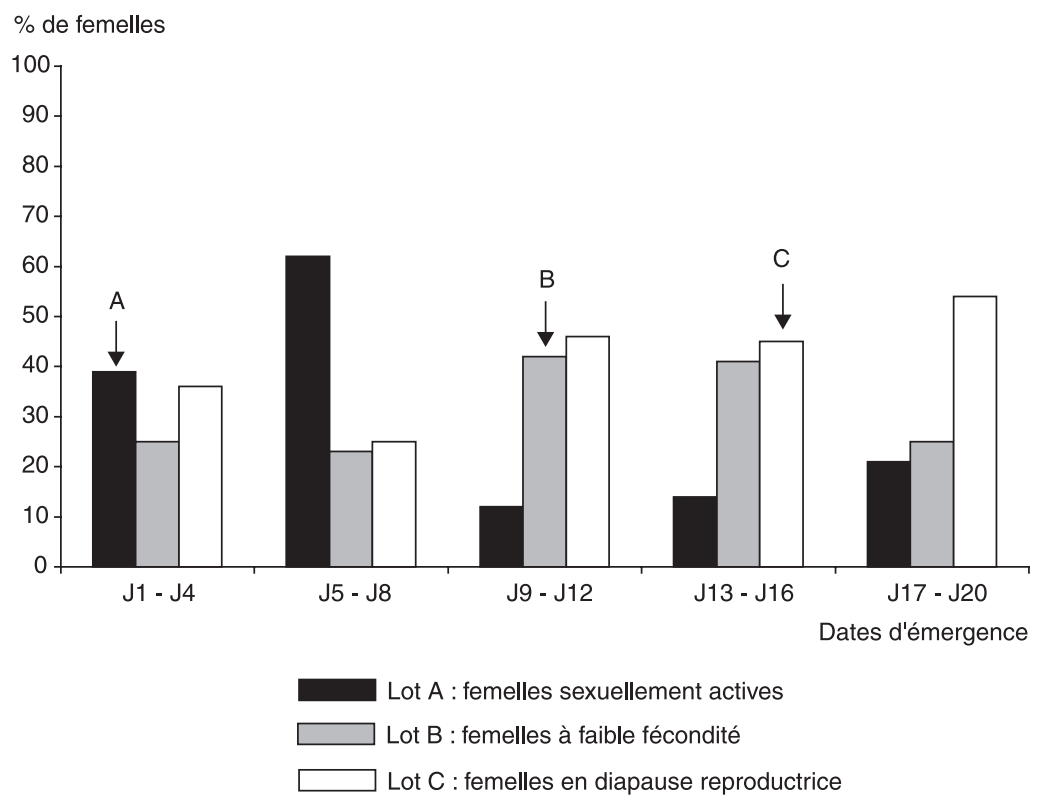

Figure 4.20. Pourcentages de femelles de $C$. rhodesianus émergeant des graines au cours du temps.

La compétition interspécifique avec $C$. maculatus au cours du développement larvaire à l'intérieur des graines explique également la régression des effectifs de $C$. rhodesianus. 
Cette compétition est toujours favorable à $C$. maculatus, mais $C$. rhodesianus n'est pas complètement éliminé et une faible population résiduelle se maintient à l'intérieur du système de stockage (Amévoin et al., 2007).

Il est probable que les femelles de $C$. rhodesianus en diapause reproductrice quittent les systèmes de stockage et survivent dans la nature pendant toute la période où les gousses de la plante-hôte ne sont pas disponibles. Une autre partie de la population se maintient dans les systèmes de stockage et peut permettre à cette espèce de devenir un ravageur important des graines de niébé. C'est probablement cette aptitude au polyvoltinisme qui explique l'extension de cette espèce en Afrique de l'Ouest.

\section{Callosobruchus subinnotatus (Pic)}

Ce Bruchinae se développe essentiellement aux dépens des graines de voandzou (Vigna subterranea) dans toute l'Afrique de l'Ouest. Les femelles pondent sur les gousses ou les graines et les larves consomment les réserves contenues dans les cotylédons. C. subinnotatus peut provoquer des pertes importantes après plusieurs mois de stockage (Mbata, 1994) et réduire les potentialités alimentaires de $V$. subterranea dont les graines ont une valeur nutritionnelle élevée en raison de leur richesse en protéines. La contamination débute dans les champs avant la récolte, les femelles pondant sur les gousses sèches qui se trouvent près de la surface du sol. Elle se poursuit dans les stocks après la récolte. La croissance post-embryonnaire à $30{ }^{\circ} \mathrm{C}, 70 \% \mathrm{HR}$ dure six à sept semaines. C. subinnotatus peut également se développer aux dépens de l'arachide et du niébé et pourrait causer des pertes importantes à ces deux légumineuses.

Appleby et Credland (2001) ont mis en évidence un polymorphisme imaginal chez cette espèce avec émergence d'adultes normaux et d'adultes actifs. Ces deux morphes diffèrent par des critères :

- morphologiques : la forme du corps, la couleur et les dessins des élytres, la forme et la couleur du pygidium sont différents selon les morphes, particulièrement chez les femelles. Une analyse discriminante de 22 caractères biométriques a permis de séparer les mâles et les femelles de deux groupes d'insectes ;

- physiologiques : les femelles du morphe normal ont une fécondité élevée (107 œufs), une durée de vie de l'ordre de 10 jours. Les adultes du morphe actif ont une vie imaginale plus longue (de l'ordre de 23 jours dans les conditions expérimentales). Ils sont en diapause reproductrice ;

- comportementaux : les adultes du morphe normal sont sédentaires, ceux du morphe actif ont tendance à quitter le stock de graines et à se disperser.

Appleby et Credland (2001) pensent que le morphe actif est adapté à la colonisation des cultures et permet la survie de l'espèce pendant la période où les gousses de la plantehôte ne sont pas disponibles dans la nature. Les conditions d'induction du polymorphisme imaginal sont inconnues chez cette espèce.

\section{Callosobruchus chinensis (F.)}

Cette espèce est originaire d'Asie et provoque surtout des dégâts importants sur ce continent. Elle est présente en Afrique et à Madagascar, mais elle est peu répandue et cause des dégâts assez limités. Elle se développe aux dépens des graines de Cajanus cajan, Cicer arietinum et de plusieurs espèces de Vigna : V. unguiculata, V. radiata, $V$. angularis. Cette dernière espèce est sa principale plante-hôte en Asie. 
Des études montrent que cette espèce présente au Japon deux stratégies de développement (Shinoda et Yoshida, 1990) :

- Une partie de la population est polyvoltine. Les adultes sont présents dans les cultures de $V$. angularis (azuki bean) de juillet à octobre et se reproduisent sur les gousses disponibles. Les graines contenant des larves de bruches se retrouvent dans les systèmes de stockage. Les adultes se reproduisent au niveau des graines stockées et plusieurs générations vont se succéder à ce niveau provoquant des pertes importantes. Le renouvellement des générations est rapide; la durée du développement dans les graines de $V$. angularis est en moyenne de 24 jours, lorsque les insectes sont élevés à une température constante de $30{ }^{\circ} \mathrm{C}$ et une humidité relative de $70 \%$.

- Une autre partie de la population est univoltine. Elle se reproduit sur les gousses de $V$. angularis non récoltées, puis sur les gousses de $V$. angularis var. nipponensis et Dunbaria villosa qui se forment plus tardivement que celles des plantes cultivées. Les insectes passent l'hiver au stade larvaire, puis émergent au printemps. La consommation de pollen et de moisissure accroît la durée de leur vie imaginale et favorise la survie des insectes dans la nature jusqu'à ce que les gousses apparaissent. Ce sont surtout ces adultes, très actifs, excellents voiliers, qui coloniseraient les cultures de V. angularis au cours du printemps.

Les adultes s'accouplent dès leur émergence des graines, car les femelles émettent une phéromone sexuelle qui attire les mâles. Les deux composés actifs appartiennent à la famille des homofarnesals, $(2 Z, 6 E)$ et $(2 E, 6 E)$-7-ethyl-3,11-dimethyl-2,6,10-dodecatriennal (Shimonura et al., 2008), et influencent le comportement des mâles comme le montre la figure 4.21 .

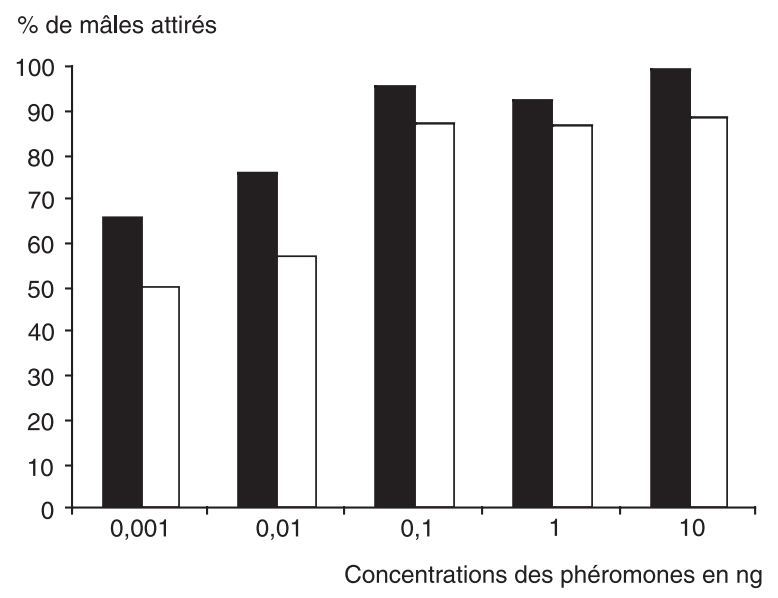

$2 \mathrm{Z}, 6 \mathrm{E} \square 2 \mathrm{E}, 6 \mathrm{E}$

Figure 4.21. Analyse en olfactométrie du pourcentage de mâles de $C$. chinensis attirés par deux formes isomèriques de la phéromone sexuelle sécrétée par les femelles, la forme $2 Z, 6 E$ et la forme $2 E, 6 E$. Le comportement des mâles est analysé en fonction de concentrations croissantes (en nanogrammes : ng) de phéromones sexuelles (d'après Shimonura et al., 2008).

Les femelles libèrent également une copulation release pheromone qui induit un comportement d'accouplement dès que les mâles sont à proximité des femelles. C'est 
selon Yamamoto (1990) un mélange complexe de monterpènes et d'hydrocarbones (3,7-dimethyl-2-octène-1,8-dioicacid) dont la structure est représentée sur la figure 4.22.<smiles>C/C(=C\CCC(C)CC(=O)O)C(=O)O</smiles>

Figure 4.22. Structure chimique de la copulation release pheromone de C. chinensis (d'après Nakai et al., 2005).

Les femelles émettent lors de la ponte une phéromone de marquage qui permet une bonne répartition des œufs sur les différentes graines disponibles. Cette substance de nature lipidique est un mélange complexe d'acides gras, d'hydrocarbones, de triglycérides, et à faible concentration de mono et de diglycérides (Yamamoto, 1990). Lorsqu'il y a ponte de plusieurs œufs sur une même graine, dans des conditions de forte densité, la concentration de phéromone de marquage à ce niveau exerce un effet ovicide sur un certain nombre d'œufs et limite la compétition intraspécifique au niveau larvaire.

Une analyse de populations de $C$. chinensis, différant par leur origine géographique (Japon, Corée, Taiwan) et leur habitat, à l'aide d'ADN mitochondrial a permis de mettre en évidence une base génétique à ce polymorphisme imaginal (Tuda et al., 2006). Six haplotypes ont pu être distingués. L'un d'entre eux, l'haplotype U, est dominant dans toutes les populations colonisant les plantes cultivées et les stocks de graines. Il est en revanche absent dans les populations monovoltines se développant aux dépens des légumineuses sauvages au Japon.

Nahdy et al. (1999) ont analysé des populations de C. chinensis se développant en Ouganda aux dépens de Cajanus cajan et ont décrit chez cette espèce un polymorphisme proche de celui observé chez C. maculatus. Les adultes des deux morphes diffèrent par des critères morphologiques et comportementaux (aptitude ou non au vol). Les adultes du morphe voilier émergent lorsque le développement a eu lieu dans les cultures, tandis que ceux du morphe non-voilier apparaissent dans des stocks où les graines sont sèches.

\section{Les Bruchinae inféodés au haricot (Phaseolus vulgaris)}

\section{Acanthoscelides obtectus (Say)}

Ce Bruchinae est originaire des régions andines équatoriales en Amérique du Sud. Il a suivi l'extension des cultures de haricot (Phaseolus vulgaris) en Amérique du Nord, en Europe, puis en Afrique (planche couleur II photo 7). Cette plante a été introduite il y a environ quatre cents ans en Afrique. Le haricot est surtout présent dans les zones à climat tempéré en Afrique de l'Est, en Afrique du Sud, en Afrique centrale et à Madagascar. A. obtectus est observé dans toutes ces zones où il provoque des pertes importantes au cours du stockage (Abate et Ampofo, 1996).

\section{La reproduction d'A. obtectus}

Les femelles colonisent les cultures de haricot lorsque les gousses sont mûres. Elles sont attirées par les mâles qui produisent une phéromone sexuelle composée de 
méthyle(E)-2,4,5-tetradecatrienoate (Horler,1970). Cette phéromone a été synthétisée et peut être utilisée en lutte intégrée contre cet insecte. Lors de l'accouplement, le mâle dépose dans la bourse copulatrice de la femelle un spermatophore contenant des spermatozoïdes et des sécrétions mâles. Les femelles inséminées explorent les gousses à l'aide de leurs palpes maxillaires qui sont en permanence au contact du végétal. La stimulation de l'ovogenèse est due à l'influence de deux facteurs : l'accouplement et la présence de la plante-hôte. Des sécrétions produites par les glandes annexes mâles et contenues dans le spermatophore déposé lors de l'accouplement sont transférées dans l'hémolymphe des femelles et provoquent le démarrage de l'activité reproductrice. Des peptides contenus dans ces sécrétions mâles seraient responsables de cet effet stimulant (Huignard, 1974). Des substances présentes à la surface des gousses ou des graines, perçues par des récepteurs sensoriels situés au niveau des palpes labiaux et maxillaires, complètent l'influence de l'accouplement et induisent l'acte de ponte.

Lorsque les femelles atteignent la suture dorsale des gousses, elles perforent le péricarpe à l'aide de leurs mandibules, introduisent leur ovipositeur dans l'orifice ainsi ménagé, puis déposent leurs œufs à l'intérieur de la cavité carpellaire (figure 4.23). Les œufs n'adhèrent jamais aux graines. Les larves néonates issues de ces œufs se déplacent à l'intérieur de la gousse, puis perforent le tégument des graines et se développent aux dépens des cotylédons. Les taux de contamination des gousses dans les cultures peuvent être importants lorsque celles-ci se trouvent à proximité des centres de stockage des graines de haricot.

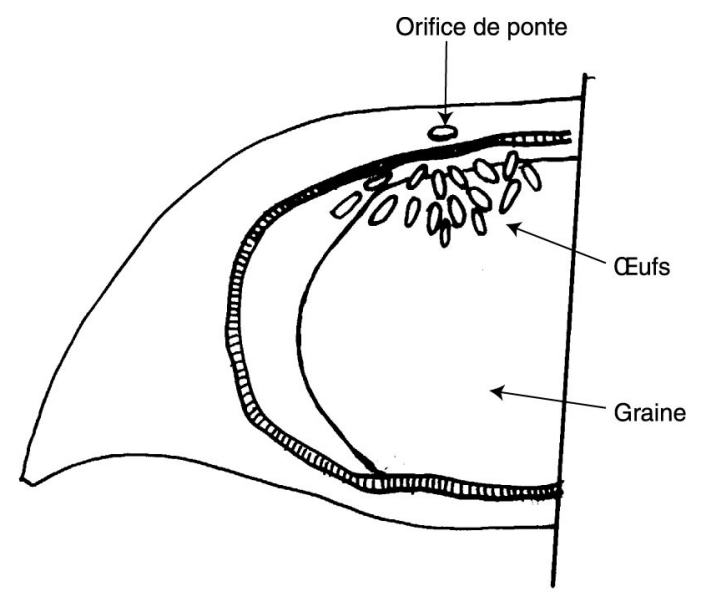

Figure 4.23. Ponte d'une femelle d'A. obtectus à l'intérieur d'une gousse de haricot. Schéma J. Huignard.

\section{Cycle biologique d'A. obtectus}

Cette espèce est polyvoltine et ne présente aucune diapause ni au stade adulte ni au stade larvaire. Alvarez et al. (2005) ont analysé des populations d'A. obtectus originaires des régions andines et des différentes régions de l'aire de dispersion de cette espèce (Amérique centrale, Amérique du Nord, Europe et Afrique équatoriale), à l'aide de marqueurs mitochondriaux (mt DNA) et de marqueurs microsatellites nucléaires. Ces 
auteurs démontrent que le polyvoltinisme n'est pas une adaptation à la domestication de $P$. vulgaris par l'homme. Les populations ancestrales d'A. obtectus se développent dans des zones équatoriales où des espèces de Phaseolus fleurissent et produisent des gousses durant toute l'année. Les insectes disposent donc en permanence d'un substrat leur permettant de se reproduire, puis de se développer. Ce trait adaptatif ancien a permis à cette espèce de coloniser $P$. vulgaris dans les cultures, puis dans les systèmes de stockage créés par l'homme, et de suivre l'extension de cette plante au Mexique. Les populations ayant colonisé l'Europe et l'Afrique sont phylogénétiquement proches des souches mexicaines et proviendraient donc de cette zone (Alvarez et al., 2005). Dans les zones tempérées où la plante-hôte n'est disponible que pendant une courte période de l'année, A. obtectus doit donc obligatoirement passer par le système de stockage pour réaliser son cycle biologique.

Les graines de haricot contenant des larves de bruches sont stockées dans des greniers ; les adultes qui émergent peuvent se reproduire et déposent leurs œufs à proximité des graines. Schmale et al. (2002) ont suivi l'infestation des stocks de graines de haricot en Colombie. Ils constatent que les taux d'infestation des graines sont faibles à la récolte et s'accroissent rapidement au cours des générations. Lorsque le taux de contamination initiale est de $10 \%$, un stock de graines peut être rendu inconsommable après le développement de trois générations d'A. obtectus. Des températures de stockage proches de $25^{\circ} \mathrm{C}$ sont très favorables au développement des larves et il peut y avoir une nouvelle génération tous les 30 ou 40 jours. Des températures supérieures à $30^{\circ} \mathrm{C}$ limitent le potentiel reproducteur des adultes et causent une mortalité élevée chez leurs descendants. Schmale et al. (2002) estiment que 35 à $40 \%$ des récoltes de haricot sont détruites par A. obtectus en Amérique latine. Les pertes sont du même ordre en Afrique de l'Est et en Afrique centrale où les cultures de haricot sont largement développées (Paul et al., 2010).

La colonisation des cultures de haricot est due à des adultes qui ont quitté les centres de stockage ; elle a lieu à la fin de la phase de fructification lorsque les gousses sont mûres (Hoffmann et Labeyrie, 1962 ; Schmale et al., 2002). Les conditions d'évasion des systèmes de stockage des insectes et de survie dans la nature sont mal connues. En Europe, l'accroissement des températures à l'intérieur du stock semble être le principal facteur permettant l'évasion des adultes. Ceux-ci peuvent survivre plusieurs mois dans la nature jusqu'à l'apparition des gousses sèches. Les adultes se nourrissent de pollen et de nectar de plantes rencontrées dans l'écosystème. En zone équatoriale tempérée, où plusieurs cultures de haricot peuvent se succéder au cours de l'année, il est possible qu'une partie de la population puisse se maintenir dans la nature sans passer par les systèmes de stockage.

\section{Zabrotes subfasciatus (B.)}

Cette espèce provoque, comme $A$. obtectus, des pertes importantes lors du stockage des graines de $P$. vulgaris et $P$. lunatus qui sont ses principales plantes-hôtes. Z. subfasciatus est également originaire d'Amérique du Sud, mais se développe surtout dans les zones plus chaudes et plus humides que celles où l'on rencontre A. obtectus. Elle a été trouvée en Afrique dès le début du $\mathrm{XX}^{\mathrm{e}}$ siècle et provoque des pertes aux récoltes en Afrique équatoriale, en Afrique de l'Ouest et à Madagascar (Decelle, 1981). Dans ces zones, où les plantes-hôtes ne sont pas disponibles durant toute l'année dans la nature, il 
semble que cette espèce doive obligatoirement passer par les systèmes de stockage pour réaliser son cycle biologique.

Les femelles de Z. subfasciatus déposent leurs œufs de forme hémisphérique uniquement sur les graines. Il n'y a aucune ponte sur le péricarpe des gousses lorsqu'elles sont indéhiscentes. Les femelles qui colonisent les cultures ne le font que sur des variétés de Phaseolus ne produisant que des gousses déhiscentes. Elles pénètrent alors à l'intérieur des gousses grâce aux zones de déhiscence, puis se reproduisent sur les graines qu'elles contiennent. La contamination se poursuit dans les stocks ; elle provient soit des graines contaminées dans les champs, soit des stocks de graines anciens non désinsectisés. Des études réalisées dans des stocks de graines de haricot en Tanzanie évaluent les pertes dues à cet insecte à $40 \%$ après plusieurs mois de stockage (Mulungu et al., 2007).

Chez Z. subfasciatus, la présence de graines provoque chez la femelle l'émission d'une phéromone sexuelle qui attire le mâle, permet la rencontre des sexes, stimule l'ovogenèse et induit la ponte (Pimbert, 1987). Lorsque les femelles sont élevées à $30^{\circ} \mathrm{C}$, $70 \% \mathrm{HR}$, elles pondent en moyenne 60 œufs sur des graines de $P$. lunatus durant leur vie imaginale dont la durée varie de 8 à 12 jours (Pimbert, 1987 ; Aparecida et al., 2004). Il existe en Inde deux morphes différant par des critères morphologiques et reproducteurs. Le morphe dit «normal », qui est adapté aux systèmes de stockage, possède un pygidium noir barré d'une bande transversale de soies blanches et a une fécondité élevée. Le morphe dit « anormal » possède un pygidium complètement recouvert de soies blanches et est beaucoup moins fécond. Ce morphe apparaît surtout pendant les mois les plus chauds et correspond sans doute à une forme de dissémination (Kaur et al., 1999). Il ne semble pas que la signification adaptative de ce polymorphisme ait été étudiée.

\section{La bruche de l'arachide : Careydon serratus OI.}

\section{Systématique et répartition géographique}

C. serratus est une espèce d'origine africaine qui est surtout présente dans les régions de savanes arborées d'Afrique tropicale (planche couleur II photo 8). Ce Bruchinae a été décrit pour la première fois en 1790 sous le nom de Bruchus serratus par Olivier à partir d'exemplaires récoltés au Sénégal, mais la plante-hôte de cet insecte n'est malheureusement pas spécifiée. Cette espèce a ensuite été retrouvée par différents auteurs en Afrique et en Inde sur plusieurs espèces de légumineuses sauvages et particulièrement le tamarinier, avant d'être définitivement appelée Careydon serratus par Decelle (1981). Le genre Caryedon, qui comporte une trentaine d'espèces morphologiquement très voisines, est réparti dans une vaste zone qui s'étend de la pointe occidentale de l'Afrique aux îles Moluques, du sud de la Méditerranée à Madagascar. À la lumière des informations apportées par les descriptions des anciens auteurs, on peut estimer qu'au début du $\mathrm{xx}^{\mathrm{e}}$ siècle, l'aire d'extension de C. serratus était presque identique à celle du genre.

Careydon serratus est un Bruchinae oligophage qui peut se développer aux dépens des graines de différentes espèces de légumineuses arbustives sauvages de la famille des Caesalpiniaceae : Bauhinia rufescens Lam., Bauhinia monandra Kurz, Cassia arereh Del, Cassia sieberiana DC., Piliostigma reticulatum (DC.) Hochst., Piliostigma thonningii (Schum.), Tamarindus indica Linn. En revanche, aucune Mimosoideae (sauf peut-être Prosopis africana) ne peut être considérée de manière certaine comme hôte 
de C. serratus dans la nature. Toutes ces plantes-hôtes diffèrent par l'aspect de leurs organes végétatifs, la structure de leurs gousses (taille, couleur, présence ou non de pulpe ou de tissu fibroligneux, disposition des graines), par la taille, la texture et probablement la composition chimique des graines. La phénologie des différentes espèces de Caesalpiniaceae rencontrées en zone sahélienne n'est pas identique, mais on peut cependant en tirer une règle générale. Toutes ces plantes, à l'exception de $B$. rufescens, fleurissent pendant la saison des pluies d'août à octobre et les gousses mûrissent au début de la saison sèche (de novembre à décembre). Elles restent longtemps présentes sur l'arbre avant de tomber sur le sol, puis de se dégrader lentement. En revanche, B. rufescens produit des fleurs et des gousses durant toute l'année.

\section{Adaptation de C. serratus sur l'arachide}

C. serratus a pu s'adapter sur l'arachide Arachis hypogaea L. (Fabacae) lorsque la culture intensive de cette plante, originaire d'Amérique du Sud, a été développée en Afrique et notamment au Sénégal à la fin $\mathrm{du} \mathrm{XVI}^{\mathrm{e}}$ siècle. C'est dans ce pays que furent signalées les premières attaques des stocks d'arachide par C. serratus (Roubaud, 1916) et les pertes provoquées par cette bruche deviennent de plus en plus importantes comme le constatent au Sénégal Sagot et Bouffil (1935). Ces auteurs observent que des adultes de C. serratus issus de graines d'arachide se développent très bien dans les graines de tamarinier et que cet hôte sauvage est infesté dans la nature par ce Bruchinae. Ils constatent que l'infestation de l'arachide se produit au champ, pendant le séchage en andains.

Les dégâts dus à cet insecte sont restés limités à l'Afrique de l'Ouest pendant une longue période. À partir de 1970, C. serratus a été retrouvé dans des stocks d'arachide en Afrique centrale et est devenu un ravageur important dans cette zone (Delobel, 1989a). C. serratus a maintenant suivi l'extension des cultures d'arachide dans toute l'Afrique, l'Asie et l'Amérique du Sud (Delobel et Tran, 1993).

Les adultes de $C$. serratus, qui colonisent les gousses d'arachide lorsque celles-ci sont mises à sécher en andains dans les champs après l'arrachage, proviennent soit des plantes-hôtes sauvages, soit des entrepôts mal nettoyés où ont été conservées des gousses de la récolte précédente. La contamination se poursuit dans les stocks et les différentes générations qui se succèdent peuvent provoquer des pertes quantitatives et qualitatives, et détruire la récolte en quelques mois. De plus, les orifices de pénétration des larves favorisent l'attaque d'autres insectes, tels que Trogoderma spp., Tribolium spp., Oryzaephilus mercator, Ephestia cautella, et facilitent le développement d'une moisissure (Aspergillus flavus) productrice d'une substance cancérigène : l'aflatoxine. C. serratus provoque des pertes importantes aussi bien chez le producteur que chez les commerçants en endommageant les stocks de gousses destinées à la consommation ou à la production de semences.

\section{Reproduction et développement de C. serratus en présence de gousses d'arachide}

Les adultes de C. serratus émergeant des cocons sont sexuellement mûrs et s'accouplent dès les premières heures de la vie imaginale. Les mâles déposent un spermatophore dans la bourse copulatrice des femelles contenant des spermatozoïdes et des sécrétions des glandes annexes. Les spermatozoïdes migrent vers la spermathèque 
et des substances contenues dans les sécrétions mâles sont utilisées lors des phases d'ovogenèse. Les adultes se reproduisent durant la phase nocturne et déposent leurs œufs de couleur blanche et de forme ovoïde sur les gousses, de préférence dans les creux et crevasses. La présence des gousses d'arachide stimule l'ovogenèse et induit une phase de ponte. En absence de nourriture, la fécondité moyenne des femelles varie de 20 à 115 œufs, suivant les conditions de température et d'humidité. Lorsque les femelles sont nourries avec du pollen, leur fécondité est plus élevée et peut atteindre 650 œufs (Delobel, 1989a). L'œuf éclot au bout d'une semaine environ ; la larve $\mathrm{L}_{1}$ perfore la cosse de la gousse, traverse le péricarpe, perce le tégument et pénètre dans la graine dont elle se nourrit. Le développement larvaire dure deux à trois semaines lorsqu'il s'effectue à des températures de 35 ou $40{ }^{\circ} \mathrm{C}$. Une même larve peut utiliser une ou plusieurs graines pour se développer. Il y a quatre stades larvaires comme chez les autres Bruchinae. La nymphose a lieu à l'extérieur de la graine dans un cocon de soie tissé par la larve $\mathrm{L}_{4}$, puis collé à la surface de la gousse ou déposé dans le sol (figure 4.24). Les adultes émergent des cocons environ deux semaines après le début de la nymphose, mais la durée de cette phase de développement peut être plus longue et même atteindre quatre mois. Il pourrait s'agir d'un mécanisme de quiescence à l'intérieur du cocon, qui serait lié à l'humidité (Robert, 1985).

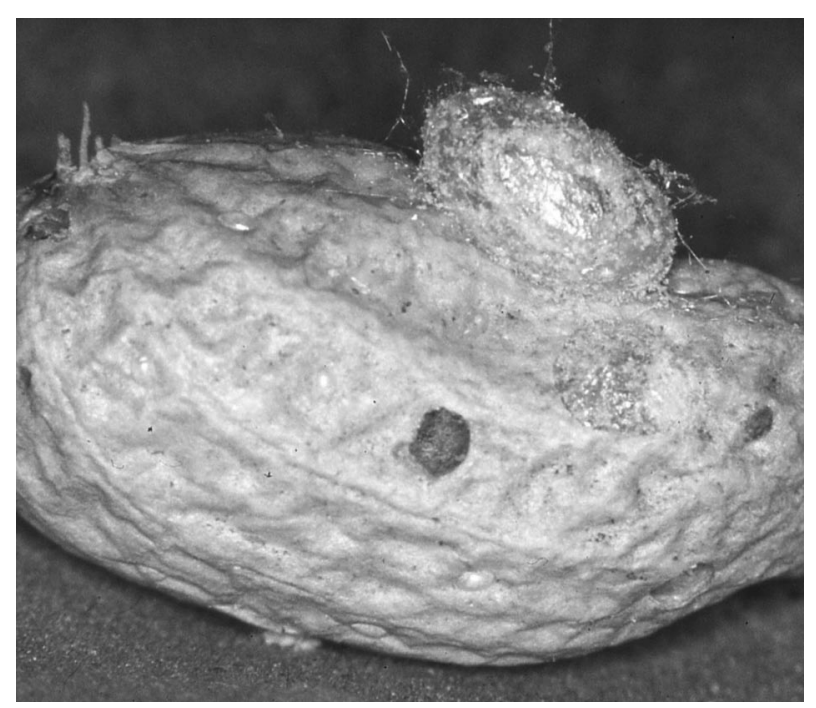

Figure 4.24. Gousse d'arachide attaquée par les larves de C. serratus sur laquelle se trouve un cocon de soie tissé par les larves $\mathrm{L}_{4}$. (C) Irbi Tours.

\section{Analyse des différentes populations de C. serratus}

Les adultes de $C$. serratus sont capables de se reproduire sur les gousses des différentes plantes-hôtes et les larves se développent sans mortalité importante aux dépens des graines quelle que soit l'espèce végétale où a eu lieu le développement post-embryonnaire. Ali-Diallo et Huignard (1992) ont montré l'importance des condi- 
tions de développement lorsque les femelles ont le choix entre les gousses des différentes Caesalpiniaceae. Lorsque des femelles ont été collectées dans la nature sur une espèce végétale, elles pondent préférentiellement sur les gousses de cette espèce lorsqu'elles sont en situation de choix. Un tel comportement pourrait être lié à une mémorisation des conditions de développement par les adultes. En revanche, des femelles s'étant développées aux dépens des gousses d'arachide ne présentent pas un tel comportement de ponte et répartissent leurs œufs sur les différentes gousses disponibles sans choix très net.

Les résultats obtenus à partir d'études effectuées sur des populations sympatriques et allopatriques de C. serratus au Sénégal et portant sur la caractérisation morphométrique (Sembene et Delobel, 1996), la variabilité allozymique (Sembene et al., 1998 ; Sembene et Delobel, 1998), le séquençage de gènes mitochondriaux et nucléaires (Sembene, 2006), et enfin sur le polymorphisme des loci microsatellites (Sembene et al ., 2008) révèlent qu'il existe plusieurs populations de C. serratus. Chacune d'elles étant inféodée à une plante ou un groupe de plantes-hôtes, mais l'isolement entre elles n'est que partiel. Les flux géniques sont très importants entre la souche infestant l'arachide et celle inféodée à Piliostigma reticulatum. Le cycle biologique de cette plante qui ne produit des gousses que pendant la saison des pluies favoriserait le passage de C. serratus sur l'arachide lorsque les gousses sont récoltées, puis mises à sécher dans les champs à proximité de ces arbres (Sembene et al., 2008). Il est noté une forte différenciation génétique entre les $C$. serratus issus de Cassia sieberiana et ceux inféodés aux quatre autres plantes-hôtes (Sembene et al., 2010). Cette forte différenciation pourrait être liée, selon ces auteurs, à une compétition interspécifique avec une autre espèce, Caryedon crampeli, qui est défavorable à $C$. serratus. La forte réduction des effectifs de cette population entraînerait une limitation de la variabilité génétique et donc des capacités d'adaptation sur de nouvelles plantes-hôtes. Elle pourrait être à l'origine de phénomènes de spéciation.

Les valeurs de différenciation génétique à différents niveaux hiérarchiques et les reconstructions phylogénétiques à partir des distances génétiques montrent que la structuration génétique est liée au fait que la bruche de l'arachide se développe sur plusieurs plantes-hôtes différant aussi bien par les caractéristiques physiques de leurs gousses et graines que par leur nature chimique. Il existe donc chez C. serratus différentes populations, chacune d'entre elles étant adaptée à une ou plusieurs espèces de Caesalpinaceae. Il y a maintien d'une certaine variabilité génétique à l'intérieur de chaque population permettant à certains individus de se reproduire, puis de se développer aux dépens d'une autre espèce végétale rencontrée dans l'écosystème. Ceci implique que ces individus possèdent tout un ensemble d'enzymes leur permettant de détoxifier les composés secondaires plus ou moins spécifiques présents dans les graines de chaque espèce de Caesalpinaceae. Cette variabilité génétique intra-populationnelle a permis à certains individus de se reproduire sur l'arachide, puis de se développer dans des graines de cette légumineuse qui sont pauvres en composés secondaires. La présence prolongée de gousses sur les légumineuses sauvages sur les arbres ou sous les arbres et la possibilité de transferts d'individus entre les différentes plantes-hôtes différant par leurs cycles de floraison et de fructification permettent aux différentes générations de $C$. serratus de se reproduire et de se développer toute l'année. Grâce à cette aptitude au polyvoltinisme, $C$. serratus peut se maintenir dans les stocks après la récolte des gousses d'arachide et devenir un ravageur causant des pertes élevées. 


\section{Conclusion}

Les principales espèces de Bruchinae, qui sont devenues des ravageurs importants des stocks de graines, présentent un certain nombre de caractères communs.

Ces espèces sont toutes étroitement dépendantes des cycles de floraison et de fructification de leur plante-hôte. La présence de gousses stimule l'ovogenèse et induit la ponte. Lorsque ces gousses ne sont pas disponibles dans la nature, deux stratégies sont possibles :

- soit les insectes entrent en diapause larvaire et surtout reproductrice, et doivent survivre dans la nature pendant une période plus ou moins longue. Dans tous les cas, la présence des fleurs de la plante-hôte, qui permet chez les femelles la levée de la diapause reproductrice, assure la synchronisation spatio-temporelle entre le stade reproducteur de la plante et celui de l'insecte ;

- soit les insectes s'adaptent aux conditions culturales imposées par l'homme et deviennent capables de se développer dans les systèmes de stockage où un grand nombre de graines sont disponibles. Cette adaptation à ce nouvel environnement, s'accompagnant parfois de modifications morphologiques et physiologiques, va permettre à ces populations d'insectes de s'accroître même en dehors des périodes de fructification de la plante-hôte et de survivre pendant de longues périodes sèches dans des zones arides. Ce polymorphisme imaginal est particulièrement observé chez les espèces du genre Callosobruchus. L'existence de deux morphes, l'un adapté aux conditions de stockage, l'autre adapté à la dispersion et à la recherche de la plante-hôte dans la nature, a permis à ces insectes de devenir des ravageurs redoutables qu'il est très difficile de contrôler.

Ils réalisent tous le même type de développement larvaire à l'intérieur des graines, mais nymphosent soit dans la graine soit à l'extérieur de la graine. Certaines espèces sont capables de se développer à l'intérieur de graines en voie de maturation dont la texture et la composition chimique évoluent au cours du temps, tandis que d'autres ne se développent que dans les graines sèches. La mortalité larvaire à l'intérieur des graines est généralement limitée, car ces insectes ont souvent de remarquables capacités de développement dans des substrats très secs et riches en composés secondaires, même si leur concentration est plus réduite dans ces plantes cultivées. 


\title{
Chapitre 5
}

\section{Biologie des hyménoptères parasitoïdes des larves et des nymphes de Bruchinae}

\author{
Jean-Paul Monge, Jacques Huignard
}

Il existe un important cortège parasitaire se développant aux dépens des œufs et des larves de Coléoptères Bruchinae, Bruchidius atrolineatus et Callosobruchus maculatus, inféodés au niébé Vigna unguiculata. Ces espèces sont parasitées en Afrique de l'Ouest par plusieurs espèces d'hyménoptères. Les parasitoïdes les plus fréquents sont l'oophage Trichogrammatidae, Uscana lariophaga Steffan (planche couleur II photo 9), et les ectoparasitoïdes solitaires : les Eupelmidae, Eupelmus orientalis CRW. (planche couleur III photos 10 et 11), Eupelmus vuilleti CRW. (planche couleur III photo 12), et le Pteromalidae Dinarmus basalis Rondani (planche couleur III photo 13). Seuls $D$. basalis et $E$. vuilleti sont capables de se reproduire et de se développer à la fois dans les cultures de niébé et dans les stocks de graines. Ce sont des parasitoïdes solitaires, un seul parasitoïde pouvant se développer sur une larve ou une nymphe hôte. D. basalis est une espèce tropicale cosmopolite, se développant aux dépens des larves et nymphes de plusieurs espèces de Bruchinae appartenant aux genres Bruchidius, Callosobruchus, Acanthoscelides et Zabrotes. E. vuilleti a une aire de répartition beaucoup plus limitée ; il est présent sur le continent africain de Madagascar au Sénégal et semble surtout adapté au climat sahélien. C'est un parasitoïde de bruches des genres Callosobruchus et Bruchidius.

Ces deux espèces sont des parasitoïdes synovigéniques. Les femelles produisent des ovocytes mûrs dès le début de la vie imaginale, en utilisant les réserves stockées durant la vie larvaire. Ces réserves étant limitées, les femelles de ces deux espèces doivent consommer l'hémolymphe de leurs hôtes pour être capables de former de nouveaux ovocytes au cours de leur vie.

Nous analyserons dans ce chapitre les stratégies de reproduction et de développement d'E. vuilleti et de D. basalis qui vivent en sympatrie en zone sahélienne et exploitent les 
mêmes hôtes (B. atrolineatus et $C$. maculatus), aussi bien dans les cultures de niébé que dans les systèmes de stockage.

\section{La découverte de l'hôte}

Les femelles adultes doivent découvrir, pour se reproduire, les larves de bruches qui se développent dans une graine à l'intérieur d'une gousse. Cette recherche va se faire en deux temps. Elles doivent tout d'abord rechercher la plante susceptible d'héberger les larves de bruches, puis localiser l'hôte lorsque la plante aura été découverte.

Le comportement des femelles de D. basalis et d'E. vuilleti, qui se sont développées aux dépens de larves de $C$. maculatus dans des graines de niébé, a été étudié en olfactométrie. Ces femelles sont attirées par les composés volatils émis par les graines, les gousses sèches et dans une moindre mesure par les feuilles de niébé et par les larves de C. maculatus ou par leurs fèces. Elles ne sont pas attirées par les composés volatils émis par les graines ou les gousses d'autres espèces végétales du genre Vigna ou par les larves de B. atrolineatus (Cortesero et al., 1993).

Cette sensibilité n'est pas génétiquement déterminée, mais acquise au cours d'un apprentissage précédant l'émergence des graines. Il a lieu lorsque les jeunes adultes sont en contact dans la loge nymphale avec la graine et la larve de bruche. De jeunes femelles, placées à cette phase de leur développement en présence de graines de Vigna radiata ou de larves de $B$. atrolineatus, deviennent sensibles aux composés volatils qu'ils émettent et sont attirés par ces composés (Cortesero et al., 1995).

\section{La phase d'exploration de la graine puis de l'hôte}

\section{Chez E. vuilleti}

Lorsque la femelle d'E. vuilleti a découvert la gousse ou la graine contenant la larve-hôte, elle va tout d'abord l'examiner à l'aide de ses antennes afin de localiser soit un œuf de bruche ayant achevé son développement embryonnaire, soit l'emplacement d'une loge nymphale. Quand la femelle a découvert un œuf, avec sa tarière, elle perce le chorion, introduit son ovipositeur dans la galerie de pénétration de la larve, jusqu'à atteindre l'hôte. La femelle d'E. vuilleti peut également atteindre directement l'hôte en perforant le tégument de la graine à l'aide des valves de l'ovipositeur. Ce comportement de perforation active qui demande beaucoup plus de temps et d'énergie n'est observé que dans $30 \%$ des cas (Jaloux et al., 2007). La femelle ne pond qu'après avoir examiné la loge et le tégument de l'hôte à l'aide des récepteurs sensoriels se trouvant à l'extrémité de l'ovipositeur. Cette phase de prospection qui lui permet d'évaluer la qualité de l'hôte peut être suivie :

- soit par le dépôt d'un œuf sur le tégument de l'hôte. Avant de pondre la femelle pique l'hôte à l'aide de son ovipositeur, puis injecte un venin sécrété par les glandes annexes de l'appareil reproducteur. Ce venin paralyse l'hôte, mais ne le tue pas. Après injection du venin, la femelle dépose ensuite son œuf sur le tégument de l'hôte ;

- soit par le retrait de l'ovipositeur si l'hôte ne lui a pas semblé propice au développement de sa larve ; 
- soit par une phase de nourrissage. Après la piqûre de l'hôte, le retrait progressif de l'ovipositeur permet de construire un tube de nutrition par lequel l'hémolymphe remonte à la surface de la graine, puis est alors consommée par la femelle.

\section{Chez D. basalis}

Les femelles effectuent également une phase d'exploration antennaire de la gousse ou de la graine, si elle est accessible, afin de déterminer l'emplacement de la loge nymphale. Elles n'utilisent pas les galeries de pénétration larvaires pour atteindre leurs hôtes. Elles perforent le tégument de la graine à l'aide des deux valves de leur ovipositeur. Comme chez E. vuilleti, cette perforation est suivie d'une phase de prospection interne de la larve de bruche effectuée avec l'ovipositeur. Il y a ensuite ponte, mais l'émission d'un œuf est rarement précédée d'une piqûre et de l'injection d'un venin. Si les conditions de développement des larves ne sont pas favorables, il y a retrait de l'ovipositeur. Chez D. basalis, les phases de nourrissage sont plus rares que chez E. vuilleti.

\section{Le comportement en situation de compétition}

$E$. vuilleti et $D$. basalis étant des ectoparasitö̈des solitaires, l'émission de deux œufs sur un même hôte va se traduire par des combats entre les larves avec élimination de l'un des deux compétiteurs.

Il y a superparsitisme lorsqu'il y a émission de deux œufs pondus par les femelles d'une même espèce sur une larve-hôte, entraînant une compétition intraspécifique entre deux larves.

Il y a multiparasitisme lorsqu'une femelle pond un œuf déjà parasité par une autre espèce. D. basalis et E. vuilleti qui exploitent les mêmes hôtes dans un habitat confiné, comme celui des systèmes de stockage, ont adopté des stratégies différentes en situation de compétition interspécifique.

\section{$D$. basalis évite la compétition intra et interspécifique}

Les femelles de D. basalis sont capables de discrimination intraspécifique et évitent de pondre sur des larves de bruches déjà parasitées par elles-mêmes ou par des congénères. Lorsqu'une femelle détecte lors de la phase d'exploration de l'hôte une larve, un œuf âgé de plus d'une heure ou une larve provenant de sa propre descendance ou de celle d'un congénère, il y a arrêt de la phase de prospection et retrait de l'ovipositeur. Cette discrimination est effectuée grâce à la perception d'un facteur chimique qui est déposé sur le tégument de l'hôte par l'œuf en développement ou par la larve du parasitoïde. La nature chimique de ce facteur n'est pas connue (Gauthier et al., 1996). Ce comportement d'évitement empêche l'émission d'un œuf sur un hôte où ses chances de développement sont limitées. Les larves plus âgées sont en effet très agressives et tuent les œufs ou les jeunes larves qui débutent leur croissance sur les hôtes.

Des femelles de D. basalis, appartenant à des populations sahéliennes et vivant en sympatrie avec E. vuilleti dans les cultures et dans les stocks, sont placées en présence d'hôtes sains et d'hôtes déjà parasités par E. vuilleti. Elles pondent sur les hôtes sains et évitent les hôtes parasités quel que soit le stade de développement de la larve d'E. vuilleti. 
Lorsqu'elles sont placées en présence de graines contenant des hôtes parasités par E. vuilleti, les femelles de $D$. Basalis explorent la graine à l'aide de leurs antennes et peuvent avoir deux comportements :

- soit elles perçoivent un signal chimique à l'emplacement de l'orifice de pénétration de la larve d'E. vuilleti et quittent la graine;

- soit elles perforent le tégument de la graine et explorent l'hôte. La détection de la larve d'E. vuilleti et sans doute d'un signal chimique lié à la présence de cette larve entraîne le retrait de l'ovipositeur sans qu'il y ait eu de ponte (figure 5.1).

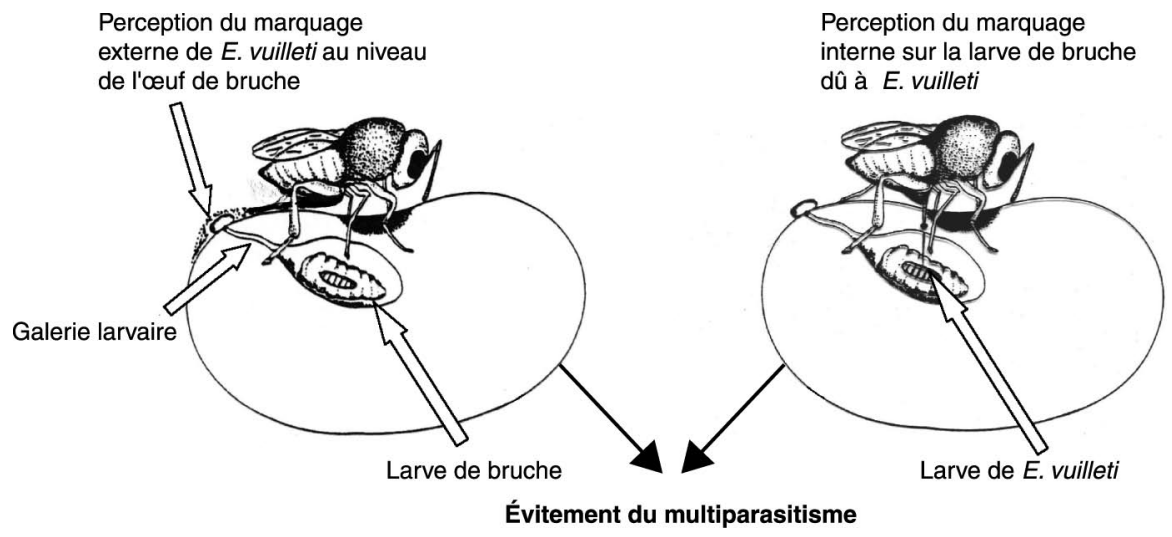

Figure 5.1. Analyse du comportement d'une femelle de D. basalis en situation de compétition interspécifique avec E. vuilleti.

Ce comportement d'évitement du multiparasitisme accroît les probabilités de survie des larves de $D$. basalis. Elles ont, en effet, de très faibles chances de survie lorsqu'elles sont en présence de larves d'E. vuilleti. Ces larves sont très agressives ; elles se dirigent vers leurs compétitrices, les mordent à l'aide de leurs mandibules et injectent un venin très toxique qui provoque leur mort.

La présence des deux espèces de parasitoïdes dans un même stock de graines qui est un milieu fermé va défavoriser $D$. basalis, ce qui aura des conséquences en lutte biologique.

\section{E. vuilleti recherche la compétition}

Les femelles d'E. vuilleti ne présentent pas de stratégie d'évitement de la compétition intraspécifique ; le taux de superparasitisme est toujours important même si le nombre d'hôtes sains est élevé. Elles recherchent même les hôtes déjà parasités et pondent préférentiellement sur ces hôtes. Elles vont pondre plus d'œufs mâles non inséminés que d'œufs femelles sur des hôtes déjà parasités (Darrouzet et al., 2002). Il existe donc chez cette espèce un système performant de reconnaissance intraspécifique dont les modalités sont encore inconnues. Cette tendance au superparasitisme chez E. vuilleti va provoquer une forte mortalité au cours du développement post-embryonnaire.

Lorsque les femelles d'E. vuilleti se trouvent en présence d'hôtes parasités par D. basalis et d'hôtes sains, elles pondent préférentiellement sur les hôtes parasités par 
l'espèce concurrente. Elles sont attirées à courte distance par les graines hébergeant ces hôtes et entreprennent une phase de ponte après avoir introduit leur ovipositeur dans l'orifice de pénétration perforé par les larves de D. basalis. Les femelles d'E. vuilleti sont attirées par des sécrétions déposées sur la graine de niébé par les femelles de D. basalis lors de la phase d'exploration des graines. Ces sécrétions sont des hydrocarbures, sécrétés par une glande accessoire de l'appareil génital femelle de D. basalis : la glande de Dufour (figure 5.2). Elles sont déposées sur la cuticule par les femelles lors des phases d'exploration (Jaloux et al., 2005, Jaloux et Monge, 2006).

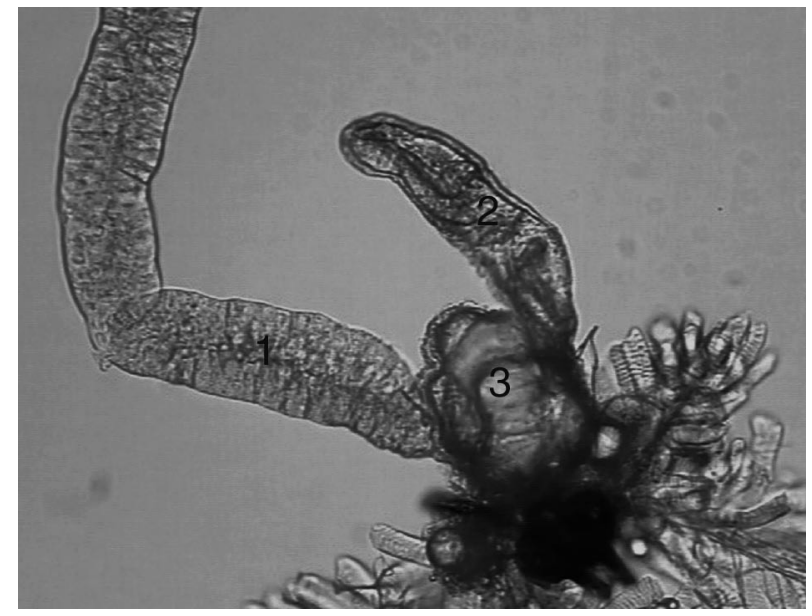

Figure 5.2. Glandes annexes de l'appareil génital femelle de $D$. basalis. Les sécrétions de la glande de Dufour (2) attirent les femelles d'E. vuilleti; celles de la glande à venin (1) qui déverse ses sécrétions dans le réservoir de la glande (3) stimulent le comportement de ponte d'E. vuilleti. (C) Irbi Tours.

Les femelles de $D$. basalis déposent également une autre sécrétion de nature protéique produite par la glande à venin. Ces protéines dont les poids moléculaires varient de 6,5 à 100 kilodalton $(\mathrm{kDa})$ stimulent le comportement de ponte des femelles d'E. vuilleti au contact de l'hôte parasité. Les femelles d'E. vuilleti utilisent donc un certain nombre de signaux résultant de l'activité de l'espèce concurrente pour découvrir les hôtes qu'elle a parasités et les éliminer. Grâce à ce comportement agressif, E. vuilleti peut se maintenir dans un système de stockage lorsqu'il se trouve en présence d'un concurrent comme D. basalis dont les capacités de reproduction et de développement sont nettement plus importantes (Sanon et al., 1998 ; Jaloux et Monge, 2006).

Cette discrimination interspécifique n'est observée que lorsque E. vuilleti a évolué en zone sahélienne dans les cultures et dans les stocks avec D. basalis. Dans d'autres zones géographiques, telles que la zone guinéenne ou l'Amérique latine, E. vuilleti est absent dans les stocks de graines de niébé et $D$. basalis est le parasitoïde larvaire dominant. Les femelles d'E. vuilleti, issues de populations sahéliennes, ne sont pas attirées par les hydrocarbures cuticulaires déposés sur les graines par des femelles de D. basalis collectées au Togo, au Bénin et au Mexique. Des différences quantitatives entre les profils 
d'hydrocarbures produits par la glande de Dufour dans ces trois populations et dans la population sahélienne pourraient expliquer ces résultats. Cette capacité de discrimination du multiparasitisme observée dans la population sahélienne d'E. vuilleti est la conséquence d'un phénomène d'apprentissage au stade adulte, résultant de la longue cohabitation entre les deux espèces dans cette zone (Jaloux et al., 2007).

\section{La régulation du taux sexuel}

Comme tous les hyménoptères, les femelles d'E. vuilleti et de D. basalis pondent soit des œufs fécondés diploïdes qui donnent naissance à des femelles, soit des œufs non fécondés se développant par parthénogenèse arrhénotoque qui donnent naissance à des mâles haploïdes. Cette capacité de régulation permet aux femelles d'ajuster le taux sexuel aux capacités de développement, puis de reproduction de la descendance, comme l'ont montré de nombreux travaux réalisés chez les hyménoptères parasitoïdes.

\section{Influence du stade de développement de l'hôte}

Les femelles d'E. vuilleti et de D. basalis pondent une majorité d'œufs mâles sur des larves de bruches de stade $\mathrm{L}_{3}$. Le taux sexuel de la descendance est équilibré lorsque les œufs sont pondus sur des larves de stade $\mathrm{L}_{4}$ et est en faveur des femelles lorsqu'il y a ponte sur des nymphes (figure 5.3). Ces derniers stades de développement, de plus grande taille, fournissent probablement plus d'alimentation et donc plus de réserves à leur descendance. Il est donc avantageux de déposer sur ces hôtes des œufs femelles qui donneront naissance à des larves ayant besoin de plus de réserves pour assurer leur développement, puis la reproduction des adultes.

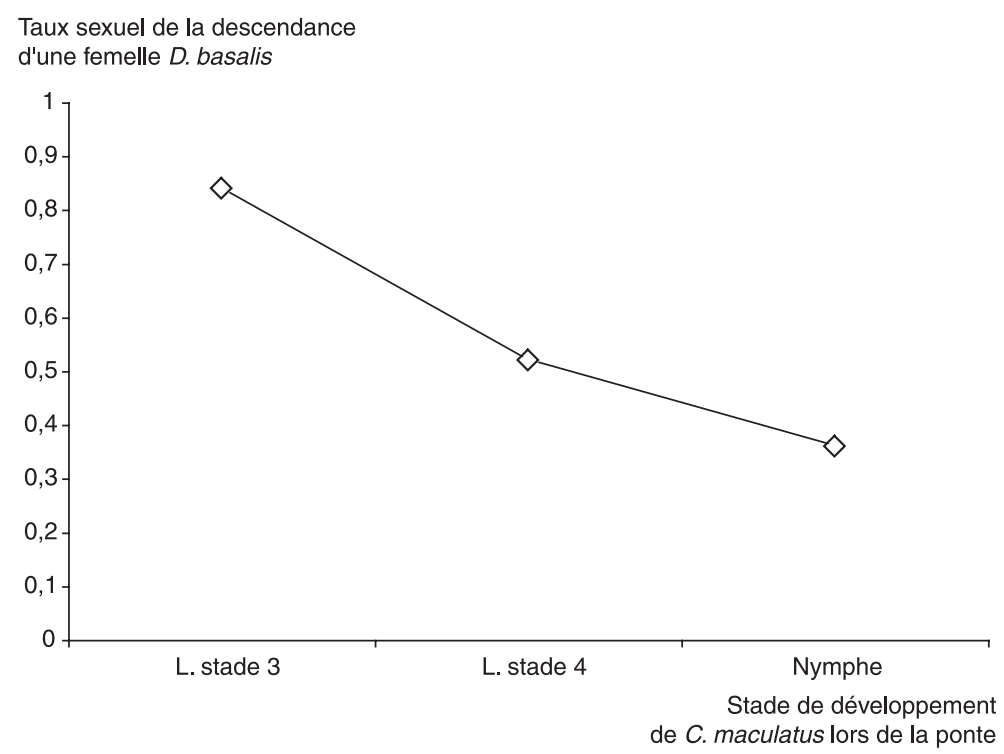

Figure 5.3. Étude du taux sexuel de la descendance d'une femelle de D. basalis (mâles/mâles + femelles) en fonction du stade de développement de $C$. maculatus sur lequel a eu lieu la ponte. 


\section{Influence de la densité de femelles exploitant l'hôte}

Lorsqu'un petit nombre de femelles de D. basalis exploitent les hôtes, le taux sexuel de la descendance est biaisé en faveur des femelles. Il s'équilibre, puis s'inverse en faveur des mâles lorsque le nombre de femelles exploitant les hôtes augmente (Gauthier, 1996). Ces résultats sont conformes aux prédictions de la théorie de la «local mate competition » d'Hamilton (1967).

\section{Influence de l'activité sexuelle des femelles}

Lorsqu'une femelle de D. basalis ne s'accouple qu'une seule fois au cours de sa vie, elle pond une majorité d'œufs femelles au début de la vie imaginale, puis un nombre de plus en plus important d'œufs mâles, parthénogénétiques à la fin de sa vie. Cet accroissement du taux sexuel en faveur des mâles est lié à un épuisement progressif du nombre de spermatozoïdes stockés dans la spermathèque (Chevrier et Bressac, 2002). Un second accouplement, permettant un apport de spermatozoïdes à l'intérieur de la spermathèque, assure à nouveau la production d'une majorité de femelles (figure 5.4).

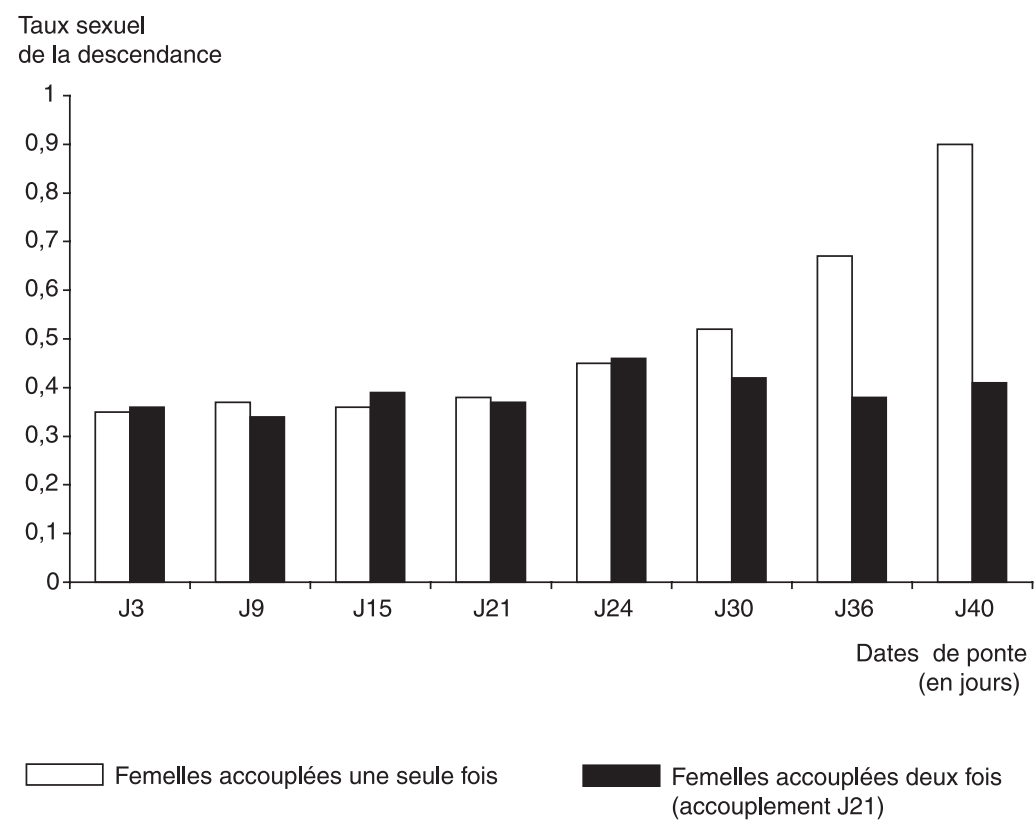

Figure 5.4. Évolution du taux sexuel de la descendance (mâles/mâles + femelles) chez des femelles de $D$. basalis accouplées une seule fois ou deux fois.

\section{La ponte et le développement des larves}

Lorsque les femelles ont découvert un hôte susceptible de permettre le développement de la descendance, elles entreprennent une phase de ponte et déposent un œuf sur cet hôte. L'œuf d'E. vuilleti de forme ovoïde est lisse et translucide ; il mesure $800 \mu \mathrm{m}$ 
de long et $200 \mu \mathrm{m}$ de large et porte un pédicelle d'environ $350 \mu \mathrm{m}$ (figure 5.5) ; celui de D. basalis est de forme oblongue et mesure $600 \mu \mathrm{m}$ de long et $150 \mu \mathrm{m}$ de large, il est dépourvu de pédicelle (figure 5.6).

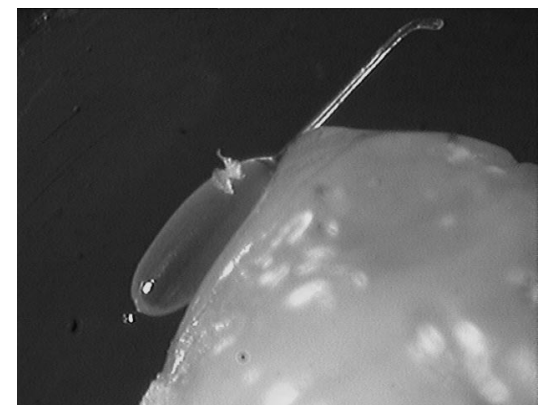

Figure 5.5. Euf d'E. vuilleti (L : $800 \mu \mathrm{m}, 1: 200 \mu \mathrm{m}$ ) avec un pédicelle de $350 \mu \mathrm{m}$ et un court pédoncule à son pôle micropylaire. (C) Irbi Tours.

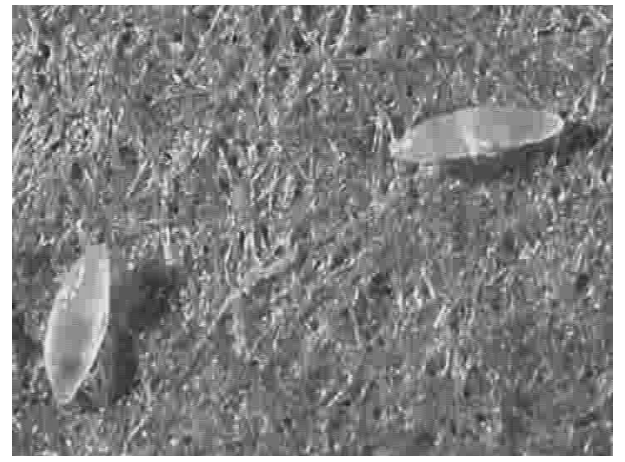

Figure 5.6. Eufs de D. basalis (L : $600 \mu \mathrm{m}, 1: 150 \mu \mathrm{m})$. C Irbi Tours.

La fécondité moyenne des femelles des deux parasitoïdes a été estimée au laboratoire dans les conditions $35: 25^{\circ} \mathrm{C}, 12: 12 \mathrm{~h}$, en présence d'hôtes régulièrement renouvelés. E. vuilleti pond en moyenne 60 œufs durant une vie imaginale de 12 jours ; D. basalis est plus fécond et pond en moyenne 100 œufs durant une vie imaginale de 30 jours. L'ovogenèse se réalise durant un premier temps en utilisant les réserves glucidiques, protéiques et lipidiques accumulées durant la vie larvaire, mais ces réserves sont en quantité limitée et elles ne permettent pas d'assurer la reproduction durant toute la vie imaginale. Dans un second temps, les femelles doivent se nourrir pour que l'ovogenèse puisse se poursuivre. Les femelles d'E. vuilleti et de D. basalis consomment le nectar de fleurs rencontrées dans l'écosystème lorsqu'elles se trouvent dans les cultures ou l'hémolymphe de leurs hôtes lorsqu'elles sont présentes dans les stocks de graines. L'hémolymphe leur apporte des glucides et particulièrement du tréhalose et du saccharose, ainsi que des protéines, mais est pauvre en lipides et en glycogène. Les glucides permettent la survie des femelles, tandis que les protéines et les lipides sont utilisés pour la reproduction 
(Giron et al., 2004). Il n'y a pas de synthèses de lipides à partir des glucides ou celles-ci sont très limitées. Les stérols stockés au cours de la vie larvaire d'E. vuilleti sont essentiellement utilisés lors des phases d'ovogenèse, mais ils ne permettent la production que de $30 \%$ des œufs pondus au cours de la vie. La femelle trouve lors de la nutrition le reste des lipides nécessaires à la production d'ovocytes viables (Mondy et al., 2006). Cette contrainte biochimique contribue à expliquer l'ajustement précis de l'activité de ponte, en fonction de la qualité du substrat de ponte et de son aptitude à permettre le développement de la descendance, pour utiliser à bon escient ces réserves.

La phase de nutrition, suivie ou non d'une ponte chez E. vuilleti, provoque l'émission d'un pic d'ecdysone dans l'hémolymphe, qui induit une nouvelle phase d'ovogenèse (Casas et al., 2009). Cette hormone est probablement synthétisée par les glandes endocrines rétrocérébrales à partir des précurseurs stéroliques provenant des réserves larvaires, puis de l'hémolymphe de l'hôte.

Lorsque les femelles ne disposent pas d'hôtes pendant un certain temps, on observe à l'intérieur de chaque ovariole une résorption des ovocytes en cours de vitellogenèse, mais le dernier ovocyte mûr ne subit aucune transformation. Lors de cette phase de résorption, les composés du vitellus sont transférés vers l'hémolymphe. Ils seront alors disponibles dès que les conditions de reproduction redeviendront favorables pour permettre la formation de nouveaux ovocytes. L'ecdysone joue également un rôle important dans le transfert de nutriments (Bodin et al., 2009).

La stratégie de reproduction observée chez E. vuilleti est caractéristique d'espèces synovigéniques qui disposent d'un stock limité d'ovocytes et vivent en zone sahélienne dans un écosystème où les ressources peuvent être rares, dispersées et ne sont disponibles que durant une courte période de l'année, ce qui est le cas d'E. vuilleti dans les cultures de niébé. Les stratégies de reproduction mises en place lui permettent d'exploiter ses hôtes dès que ceux-ci sont découverts.

Il y a cinq stades larvaires au cours du développement post-embryonnaire chez ces deux espèces. Les larves apodes possèdent des mandibules sclérifiées, acérées, creusées d'un canal relié aux glandes salivaires. Ces mandibules permettent la fixation sur le tégument de l'hôte durant la phase de nutrition et jouent un rôle important pendant les combats larvaires. La durée du développement embryonnaire et post-embryonnaire moyenne est de 16 jours chez E. vuilleti et de 12 jours chez D. basalis dans les conditions $35: 25^{\circ} \mathrm{C}$.

Doury et al. (1997) ont analysé les conditions d'établissement des larves d'E. orientalis; elles perforent le tégument à l'aide de leurs mandibules et injectent un venin sécrété par les glandes salivaires. Ce venin contient des neurotoxines qui provoquent une paralysie permanente de la larve ou de la nymphe de bruche. Il ne les tue pas et les tissus conservent leur intégralité ; les synthèses protéiques sont bloquées, mais il n'y a aucune dégradation de l'ADN. Lors des phases d'alimentation, la larve injecte du venin qui contient également des enzymes ayant une activité histolytique et cytolytique, transformant progressivement les tissus de l'hôte afin de faciliter leur absorption, puis leur digestion par le parasitoïde.

\section{Conclusion}

Les femelles de D. basalis et d'E. vuilleti doivent rechercher dans la nature des hôtes qui se développent à l'intérieur de graines et qui ne sont disponibles que pendant une 
courte période de l'année. Elles ne disposent que de réserves limitées, accumulées durant la vie larvaire pour survivre, se déplacer, puis se reproduire lorsque les hôtes sont découverts. Elles ne présentent pas de phénomènes de diapause ni au stade larvaire ni au stade adulte. Elles doivent donc soit rechercher des hôtes alternatifs lorsque C. maculatus et B. atrolineatus ne sont pas disponibles dans la nature, soit suivre les hôtes habituels dans les systèmes de stockage et s'adapter à de nouvelles conditions environnementales. Les études réalisées montrent que ces deux parasitoïdes se sont particulièrement bien adaptés aux conditions de stockage et ont mis en place un ensemble de stratégies leur permettant d'exploiter leurs hôtes. Les femelles des deux espèces peuvent découvrir, puis localiser leurs hôtes, même lorsqu'ils sont rares et très dispersés. Elles peuvent devenir sensibles à de nouvelles espèces-hôtes rencontrées (tout au moins dans certaines limites), grâce à des capacités d'apprentissage. Elles ont mis en place des stratégies de reproduction leur permettant d'apprécier la qualité de l'hôte avant l'émission d'un œuf, en évitant la compétition intra et interspécifique chez D. basalis ou en la recherchant chez E. vuilleti. Ces deux stratégies permettent le maintien des deux espèces exploitant une même niche écologique dans des environnements confinés, comme le sont les systèmes de stockage. Il y a de plus chez $E$. vuilleti, une régulation endocrine de la reproduction dès que la femelle se trouve en présence de son hôte. Cette régulation lui permet de mobiliser rapidement les réserves, puis de produire des ovocytes mûrs dès que les conditions favorables à la reproduction sont réunies.

La compréhension de ces mécanismes comportementaux et physiologiques assurant la reproduction, puis le développement de ces deux espèces, a permis le développement de méthodes de lutte biologique afin de contrôler les populations de C. maculatus dans les cultures, puis dans les systèmes de stockage, qui seront présentés dans le chapitre 9. 


\section{Chapitre 6 \\ Les stratégies de lutte chimique en pré- et post-récolte en Afrique}

Francis Fleurat-Lessard

" La technologie industrielle est universelle. La technologie agricole est, par contre, en premier lieu, écologiquement déterminée. " Vincent Labeyrie, 1981

La culture de légumineuses en Afrique est principalement assurée par des petits producteurs ; elle est surtout concentrée sur trois espèces végétales majeures : l'arachide, le niébé et le haricot. Les productions moyennes annuelles de ces trois légumineuses sont respectivement de 8 millions, 3 millions et 2 millions de tonnes selon la FAO en 2006. Les légumineuses sont primordiales au niveau de la population rurale des pays d'Afrique tropicale pour assurer la continuité de la ressource alimentaire des familles qui vivent de leur production agricole tout au long de l'année. Elles pallient en effet l'épuisement temporaire de cultures vivrières traditionnelles comme les céréales (mil, sorgho et maïs) ou les racines et tubercules (igname, patate douce et manioc). Qu'elles soient autoconsommées, écoulées sur les marchés locaux ou destinées à l'exportation, les légumineuses contribuent à la sécurité alimentaire des régions de savane de l'Afrique subsaharienne (zone climatique soudano-sahélienne et guinéosoudanaise) et de toute l'Afrique orientale (Brink et Belay, 2006). En plus de cette contribution essentielle à l'alimentation au quotidien des populations rurales, elles permettent une diversification des sources de revenu des exploitations agricoles qui produisent des cultures « de rente » (coton, soja, arachide, palmiste) ou des productions végétales destinées à l'exportation (ananas, banane, mangue, café, cacao). Mais pour obtenir une production marchande qui satisfait aux standards de qualité sanitaire, la culture de légumineuses nécessite une bonne protection contre les attaques parasitaires, et en particulier les infestations par les insectes nuisibles au champ et en période de conservation des graines après récolte. 
La capacité des producteurs à prévenir les risques d'infestation des cultures à l'approche de la récolte ou des stocks de graines de légumineuses par les ravageurs nuisibles ou déprédateurs (insectes, rongeurs, oiseaux, etc.) est le facteur clé de la prévention des pertes à la récolte, de la dépréciation de la valeur marchande ou de la réduction de qualité des graines conservées pour la consommation familiale ou la semence. Dans les régions à forte pression parasitaire (c'est-à-dire dans les zones climatiques à forte pluviométrie), la protection phytosanitaire par voie chimique constitue une nécessité pour assurer la préservation des critères de qualité sanitaire exigés par le marché. Ainsi, dans ces situations particulières, l'utilisation des pesticides peut conditionner le niveau de production des légumineuses des exploitations agricoles qui dépendent de la commercialisation d'une partie de leur récolte pour assurer autonomie financière et ressource alimentaire en parallèle (Muthomi et al., 2008 ; Sharah et Ali, 2008).

La protection des légumineuses pré- et post-récolte par des traitements insecticides a notablement été encouragée des années 1980 à 2000 (Bernard, 2008). Cependant, lorsqu'ils sont utilisés comme seul moyen de lutte contre les ravageurs, les pesticides peuvent engendrer des effets secondaires néfastes et même nuisibles à long terme. Leur prise en compte impose une gestion plus rationnelle et raisonnée de la protection phytosanitaire et de ses conséquences pour les applicateurs, les consommateurs et l'environnement du champ cultivé. Par ailleurs, dans le contexte des pays en développement et en dehors des cultures de rente, la disponibilité des produits de protection phytosanitaire pour les cultures vivrières largement autoconsommées (céréales, maïs, légumineuses, tubercules, manioc, etc.) n'est pas convenablement assurée dans les régions éloignées des grands centres urbains, ce qui rend l'approvisionnement en pesticides chimiques peu fiable au niveau du petit producteur. De plus, l'ensemble des zones de production ne nécessitent pas d'intervention avec des pesticides chimiques, eu égard au faible impact des ravageurs des légumineuses en région aride (ex. : savane soudanaise subsaharienne) ou dans les cultures de saison sèche en zone climatique propice à plusieurs cycles de cultures au cours de l'année.

La combinaison de la lutte chimique et des alternatives qui tendent à se développer aujourd'hui en parallèle ou en association est dorénavant à aborder dans le cadre nouveau d'une protection phytosanitaire durable et compatible avec le marché global des légumineuses alimentaires. Les itinéraires rationnels de protection des stocks de graines de légumineuses, avec un usage raisonné des pesticides, une fois replacés dans le contexte particulier de l'agriculture vivrière des pays d'Afrique tropicale, devraient permettre de mieux appréhender les écarts à combler entre les bonnes pratiques exposées ci-après et leur application au quotidien par le producteur africain.

\section{Pratique raisonnée de protection des cultures et des stocks de graines par des pesticides chimiques}

Il sera principalement question ici de la protection chimique des légumineuses après récolte. Mais l'incidence des événements antérieurs à la récolte qui interfèrent sur la protection des stocks de graines sera également évoquée. Ainsi, deux stratégies différentes de lutte peuvent être mises en œuvre selon que l'infestation est causée par des espèces de bruches monovoltines ou par des bruches polyvoltines. 


\section{La protection des graines après récolte}

Les pertes après récolte dues aux attaques des insectes ravageurs nuisibles peuvent être considérées sous deux aspects différents : au plan quantitatif (ou perte pondérale) et au plan qualitatif. La perte pondérale se traduit par la réduction du poids et du volume des graines attaquées par les insectes pour s'en nourrir. La partie de l'albumen des graines attaquées par les bruches est détruite après le développement des larves et les graines fortement endommagées se délitent (avec la prise en masse possible en cas de développement de moisissures qui peuvent être éventuellement productrices de mycotoxines dangereuses pour la santé du consommateur régulier). Sur le plan qualitatif, les attaques d'insectes se traduisent généralement par une diminution de la valeur nutritive et de la capacité germinative (en particulier dans les cas de développement abondant de moisissures de stockage). Comme dans la plupart des cas, il est traditionnellement gardé par le producteur une fraction de la récolte de légumineuses pour servir de semence à la prochaine mise en culture ; cette fraction peut faire l'objet d'un traitement particulier pour la protéger efficacement contre l'attaque des bruches et de la contamination par les moisissures qu'elle pourrait favoriser.

Selon les espèces et les types de bruches qui s'attaquent aux graines de légumineuses, les scénarios d'infestation sont assez différents.

Le cas des bruches monovoltines (Bruchus rufimanus, B. pisorum, B. lentis) est particulier : elles terminent leur développement après la récolte, mais après avoir émergé, les larves étant incapables de s'installer dans les graines sèches; les adultes quittent les zones de stockage pour aller regagner les champs et commencer un nouveau cycle de développement. Dans tous les cas, il n'y a pas de nouvelle contamination des graines sèches. Dans cette situation, la lutte contre ces bruches monovoltines passe par un traitement au champ avant la récolte au moment de la floraison ou au début de la formation des gousses (fructification) avec des insecticides a durée d'action prolongée comme la deltaméthrine, la cyperméthrine ou la lambda-cyhalothrine (Hardie et Clement, 2001). En conséquence, il n'y a pas de nécessité de lutter contre ces espèces après récolte, sauf à les empêcher de regagner les cultures en enfermant les graines dans des contenants ou des emballages étanches aux insectes.

Les bruches polyvoltines (Acanthoscelides obtectus, Callosobruchus spp., Caryedon serratus, etc.) s'introduisent indifféremment dans les graines vertes au champ et dans les graines sèches au cours du stockage, période pendant laquelle elles peuvent accomplir plusieurs générations, ce qui peut entraîner des taux de contamination élevés avec une dépréciation des qualités organoleptiques et de la valeur alimentaire. Le développement des générations successives va provoquer une perte corrélée à la durée de conservation. Les moyens traditionnels de stockage au niveau paysan sont souvent conçus de façon à réduire au minimum les risques d'infestation par les espèces nuisibles après récolte. De plus, les producteurs de légumineuses sont généralement en mesure d'évaluer le risque de pertes dues aux insectes à travers quelques critères fondés sur l'expérience (par exemple, connaissance de la sensibilité relative des différentes variétés cultivées aux ravageurs courants des graines stockées, du niveau de risque d'infestation selon la période de l'année, des mesures à prendre dans la construction des greniers). Même si les producteurs de légumineuses estiment difficilement le niveau des pertes causées par les bruches dans leurs stocks de réserve, ils affirment que ce sont les insectes qui causent le plus de dégâts (Boxall, 1998). 


\section{L'évaluation des pertes pendant la conservation: un outil d'aide à la décision de traiter}

L'évaluation précise des pertes après récolte peut se faire selon des méthodes simples à mettre en pratique et largement diffusées entre 1975 et 1995 par le programme de prévention des pertes après récolte de la FAO et par des ONG responsables de programmes d'amélioration des ressources alimentaires des pays en développement.

Deux méthodologies de mesure des pertes de poids causées par les insectes des grains et graines après récolte peuvent être pratiquées en milieu rural : la méthode poids des 1000 grains et la méthode de comptage et pesée (Boxall, 1998 ; Compton et al., 1998). La seconde méthode de « comptage et pesée » est de loin la plus pratique. L'évaluation des pertes pondérales par cette méthode est réalisée à partir d'un échantillon de 400 à 500 graines prélevées dans le lot à évaluer. Ces graines sont examinées soigneusement pour être triées en deux catégories : les graines infestées ou présentant des trous d'émergence d'adultes et les graines apparemment saines. Après le comptage précis des graines de chaque série, l'ensemble de chaque catégorie est pesé avec précision pour déterminer le poids moyen d'une graine saine (PGs) et d'une graine endommagée (PGe). La perte de poids due aux insectes est calculée selon la formule suivante (Boxall, 1998) :

$$
\% \text { perte pondérale }=\frac{\text { NGe } \times \text { PGs }}{(\mathrm{NGe}+\mathrm{NGs}) \mathrm{PGs}} \times 100
$$

NGe étant le nombre de graines endommagées ; PGs, le poids moyen d'une graine saine et NGs, le nombre de graines saines.

La perte peut aussi être exprimée plus simplement par la formule de Compton et al. (1998) :

$$
\% \text { perte pondérale }=\frac{\text { PGs }-\mathrm{PGe}}{\mathrm{PGs}} \times 100
$$

En séparant les graines de l'échantillon global en deux classes de taille (grande ou petite), il a été montré que l'on pouvait améliorer sensiblement la précision du taux de pertes (Ratnadass et Fleurat-Lessard, 1991). En associant la pesée avec la mesure de la teneur en eau moyenne des graines de l'échantillon (avec un appareil autonome portable, par exemple), ces mêmes auteurs ont montré que la perte pondérale peut être convertie en perte de matière sèche avec la même précision.

Dans le cadre de la protection intégrée des stocks de grains et graines (Vincent et al., 2009), l'estimation de la perte au moment d'une inspection du grenier ou du magasin permet de conditionner le déclenchement d'un traitement à partir du seuil de perte jugé tolérable. Ce seuil de dommage économique tolérable est déterminé empiriquement en tenant compte de plusieurs contraintes : la nécessité de conserver les graines à plus ou moins long terme, la date prévisible de la prochaine récolte de ressources alimentaires et d'autres facteurs liés au climat ou aux habitudes et standards alimentaires locaux. Ainsi, dans l'enquête sur les pertes de céréales stockées au niveau paysan en République centrafricaine et en Côte d'Ivoire, réalisée sur plusieurs saisons, il a été montré que les pertes pondérales dépassent rarement $6 \%$ dans tous les cas où une gestion rigoureuse du turn over des stocks de denrées disponibles (céréales ou légumineuses pour l'essentiel) est pratiquée. Cette gestion permet de conserver sur le long terme le stock minimum nécessaire pour atteindre la période de récolte des autres denrées alimentaires de base qui prennent le relais avant épuisement du stock en cours de consommation. 
L'intérêt de suivre l'évolution des pertes pendant la conservation des lots de graines a été relancé récemment grâce aux outils modernes de communication (liaison Internet, téléphonie portable multimédia, par exemple) qui deviennent accessibles en Afrique et qui peuvent devenir des outils d'aide à la décision. Ainsi, dans l'ensemble des pays de l'Afrique centrale et orientale, du Soudan à l'Afrique du Sud (incluant Madagascar), un réseau d'information sur les pertes après récolte de céréales a été construit avec l'aide de la Commission des Communautés européennes et est ouvert à la consultation sur un site Internet dédié : African Postharvest Losses Information System Network (Aphlis) (http:www.phlosses.net) (Hodges et al., 2010). Un tel système de partage d'informations sur les pertes après récolte pourrait être mis en place dans le cas des légumineuses.

\section{La lutte chimique raisonnée selon le risque de perte après la récolte}

La préservation des stocks de graines de légumineuses contre les attaques d'insectes nuisibles se limite à la lutte contre les bruches polyvoltines qui s'installent aussi bien dans les graines immatures au champ au moment de la formation et du développement des gousses, qu'en cours de conservation dans les graines sèches. Deux approches de la lutte chimique contre les insectes de la post-récolte sont régulièrement pratiquées partout dans le monde :

- l'application de spécialités insecticides liquides ou en poudre ayant un effet létal par simple contact des ravageurs cibles avec les dépôts de la substance active sur les graines ; - le gazage dans une enceinte étanche avec un fumigant, c'est-à-dire un gaz à propriétés insecticides reconnues comme le phosphure d'hydrogène $\left(\mathrm{PH}_{3}\right)$.

\section{Utilisation des insecticides liquides}

L'application d'un insecticide au moment propice sur les cultures en plein champ peut réduire les populations de bruches polyvoltines présentes dans les graines à la récolte, mais ne permet pas de contrôler efficacement la multiplication une fois la récolte passée, au cours de la période de conservation des graines. La lutte contre les insectes déjà présents à l'intérieur des graines à la récolte doit donc débuter aussitôt que possible pour éviter la détérioration irréversible des graines infestées au champ.

Les insecticides de contact persistants préservent les graines pendant plusieurs mois en tuant les adultes qui émergent des graines déjà infestées et ceux arrivant de l'extérieur. L'efficacité de la protection par des insecticides peut être améliorée par un confinement dans un contenant ou une structure étanche aux insectes (jarre, bidon métallique, grenier entièrement fermé, aérien ou souterrain, technique du triple sac plastique, etc.) (Delobel et Matokot, 1991 ; Murdock et al., 1997).

\section{Mise en œuvre de la fumigation}

Dans le cas où une structure étanche aux gaz est disponible, la désinfestation par gazage (appelée plus couramment fumigation) d'un stock de graines est réalisable en vue d'une éradication complète des insectes, quel que soit leur stade de développement : le gaz pénètre profondément à l'intérieur des graines et tue les formes cachées (larves, nymphes et adultes pré-émergents), sans laisser de résidus dans la graine. La fumigation proprement dite consiste à maintenir la denrée à désinsectiser dans une enceinte étanche, le temps nécessaire pour l'intoxication complète (par inhalation du gaz) des insectes présents dans les lots de graines à désinsectiser. Le gazage peut s'effectuer en enceinte 
étanche spécialisée (chambre de fumigation homologuée, autoclave de désinsectisation, chambre de gazage) ou non spécialisée (fût ou conteneur en plastique à fermeture hermétique, sous bâche plastique étanche spéciale gazage et recouvrant intégralement le lot de graines à désinsectiser), ou dans un local ou une pièce étanchée temporairement (avec des bandes adhésives plastifiées ou de la mousse de polyuréthane expansée, par exemple).

Les gaz homologués pour le traitement des grains étant aussi toxiques pour l'homme, la fumigation est le plus souvent réservée à des opérations de grande ampleur dans des stocks importants de denrées alimentaires. Elle doit se réaliser dans des conditions drastiques de protection afin d'éviter tout risque d'intoxication du personnel par voie respiratoire. La fumigation est généralement exécutée par des sociétés spécialisées, implantées dans les grands centres urbains ou dans les ports de commerce.

Selon la règle du commerce international, un lot de graines n'est « sain, loyal et marchand » que s'il est indemne d'infestation par des insectes vivants. Après l'interdiction du bromure de méthyle, la phosphine $\left(\mathrm{PH}_{3}\right)$ est devenue le fumigant le plus courant de la désinsectisation des lots de grains et graines stockées. D'autres gaz sont également disponibles ou sont en cours d'homologation afin de remplacer le bromure de méthyle ou de pallier les difficultés d'éradication des populations locales d'insectes devenues résistantes aux insecticides. De nouveaux produits sont arrivés jusqu'au stade de l'homologation notamment en Australie. Le fluorure de sulfuryle $\left(\mathrm{SO}_{2} \mathrm{~F}_{2}\right)$ a l'inconvénient d'être très peu actif à température ordinaire sur les stades à faible niveau de respiration comme l'œuf ou le stade nymphal. Le sulfure de carbonyle (COS) manque d'efficacité sur les œufs d'insectes et le formiate d'éthyle $\left(\mathrm{C}_{3} \mathrm{H}_{6} \mathrm{O}_{2}\right)$ doit être dilué dans le dioxyde de carbone pour limiter les risques d'explosion (Rajendran, 2001). Ces nouveaux gaz n'ont pas encore les caractéristiques et les propriétés requises pour remplacer le bromure de méthyle dans les conditions économiques des pays en développement.

\section{Produits insecticides de contact, fumigants et bonnes pratiques d'utilisation}

\section{Molécules homologuées pour le traitement des graines après la récolte}

Les produits insecticides contenant une substance active autorisée pour le traitement des grains et graines alimentaires sont des organo-phosphorés et des pyréthrinoïdes. Dans chacune de ces catégories, un nombre très limité de substances actives est homologué pour le traitement des graines brutes (tableau 6.1). Des substances insecticides d'origine minérale ou biologique (Dryacide ${ }^{\mathrm{TM}}$, Spinosad ${ }^{\mathrm{TM}}$ ) sont venues compléter la gamme des matières actives autorisées en application directe sur les graines de légumineuses (DEAPEA, 2005).

\section{Formulations disponibles et matériel d'application}

Les formulations liquides ou en poudre des pesticides disponibles sur le marché sont diverses, en relation avec un mode et un matériel d'application spécifique.

Les formulations liquides les plus courantes, à diluer dans l'eau au moment de l'emploi, sont le concentré émulsionnable (CE), la suspension concentrée (SC), qui est une dispersion stable de particules solides et de gouttelettes en phase aqueuse, et le concentré soluble (SL). Elles sont utilisées à la fois dans les cultures de légumineuses et dans les stocks. Les traitements sont effectués à l'aide de pulvérisateurs à pression de toutes 
tailles, allant du pulvérisateur à dos à action manuelle, au pulvérisateur à rampe de buses de pulvérisation actionné par tracteur agricole, en passant par les atomiseurs à moteur thermique transportables à dos d'homme.

Pour les traitements à grande échelle, les formulations liquides prêtes à l'emploi sont privilégiées (UL). Elles utilisent sans dilution une quantité de liquide extrêmement faible (très faible volume ou ULV) grâce à des nébulisateurs produisant un aérosol à très fines particules (5 à $20 \mu \mathrm{m}$, transportées dans un flux d'air chaud ou froid, généré par une turbine à propulsion thermique ou électrique, respectivement).

Les doses d'application des insecticides liquides en système post-récolte peuvent varier de $0,1 \mathrm{~L}$ par quintal, avec un pulvérisateur classique utilisant un concentré émulsionnable dilué dans l'eau, à $0,01 \mathrm{~L}(10 \mathrm{~mL})$ par quintal, avec les spécialités prêtes à l'emploi, mises en œuvre exclusivement avec un nébulisateur à très bas volume.

Les formulations de pesticides les plus utilisées en Afrique dans le traitement des grains et graines stockées ou des sacs (vides ou remplis de graines) sont les poudres pour poudrage (PP). Les insecticides pour poudrage sont d'utilisation facile sur les graines après récolte et nécessitent des systèmes d'application rudimentaires comme des boîtes métalliques perforées pour saupoudrer les graines lorsque la récolte est en quantité limitée ou pour imprégner d'insecticide les sacs de graines (Koona et al., 2007). Toutefois, il existe également des poudreuses manuelles (à soufflet actionné à la main ou à entraînement par manivelle) qui permettent généralement un meilleur contrôle des doses à appliquer. Les spécialités commerciales homologuées contiennent entre 2,5 et $7,5 \%$ de substance active insecticide, les doses par quintal peuvent varier de 2 à $5 \mathrm{~g}$ par quintal (tableau 6.1).

\section{Bonnes pratiques d'application des pesticides de protection des graines après la récolte}

Les bonnes pratiques d'application et les risques inhérents à l'utilisation et l'épandage des pesticides en formulation liquide ont fait l'objet d'une revue de synthèse qui fait référence pour les pays en développement (Boland et al., 2007).

Les formulations en poudre sont encore largement utilisées au niveau villageois pour le traitement des grains et graines stockées (Reuben et al., 2006). Lorsque des quantités importantes de graines sont stockées en vrac dans les greniers, la poudre insecticide est répartie de façon plus ou moins homogène par pelletage. Ce type de traitement présente cependant de nombreux inconvénients. L'activité insecticide des organophosphorés les plus souvent utilisés décroît avec le temps. Il est difficile d'ajuster les doses recommandées à la quantité de graines et d'homogénéiser la répartition des produits. Le traitement des graines en sacs est souvent moins efficace que le traitement des graines en vrac. Le traitement des graines en vrac avec des insecticides liquides dilués juste avant l'emploi présente davantage de garanties d'efficacité que le poudrage.

La stratégie consistant à traiter les lots de graines à des dates pré-établies, comme souvent en protection des cultures, n'est pas applicable à la protection des graines après récolte et seule la surveillance continue du stock avec une évaluation périodique du niveau de pertes est susceptible d'apporter les éléments d'information suffisants pour déclencher un traitement. 
Tableau 6.1. Substances actives insecticides homologuées pour le traitement des grains et graines pour les protéger sur le long terme des attaques des insectes nuisibles après la récolte.

\begin{tabular}{|c|c|c|c|c|c|}
\hline $\begin{array}{l}\text { Famille } \\
\text { chimique }\end{array}$ & $\begin{array}{l}\text { Substance } \\
\text { active (s.a.) }\end{array}$ & $\begin{array}{l}\text { Principales } \\
\text { spécialités } \\
\text { commerciales } \\
\text { (Spec)* }\end{array}$ & $\begin{array}{l}\text { Limite } \\
\text { maximale de } \\
\text { résidus de } \\
\text { s.a. }(\mathrm{mg} / \mathrm{kg})\end{array}$ & $\begin{array}{l}\text { Dose } \\
\text { d'application } \\
\text { Spec en } \\
\text { poudre }\end{array}$ & $\begin{array}{l}\text { Dose } \\
\text { d'application } \\
\text { Spec après } \\
\text { dilution } \\
\text { dans l'eau } \\
\text { (mL/quintal) }\end{array}$ \\
\hline \multirow[t]{5}{*}{$\begin{array}{l}\text { Organo- } \\
\text { phosphorés }\end{array}$} & $\begin{array}{l}\text { Pyrimiphos- } \\
\text { méthyl }\end{array}$ & $\begin{array}{l}\text { Actellic }^{(2)} \\
\text { Pirigrain }^{(2)}\end{array}$ & Non fixée ${ }^{(1)}$ & & \\
\hline & $\begin{array}{l}\text { Chlorpyriphos- } \\
\text { méthyl }\end{array}$ & Nuvan durée $e^{(2)}$ & Non fixée ${ }^{(1)}$ & & \\
\hline & $\begin{array}{l}\text { Chlorpyriphos- } \\
\text { éthyl* }\end{array}$ & Dursban $^{(2) *}$ & $\begin{array}{l}0,1 \text { (soja } \\
\text { seulement) }\end{array}$ & & \\
\hline & Fénitrothion* & $\begin{array}{l}\text { Nuvanol }^{(2) *} \\
\text { Sumithion }^{(2) *}\end{array}$ & $\begin{array}{l}0,1 \text { (soja } \\
\text { seulement) }\end{array}$ & & \\
\hline & Malathion* & $\begin{array}{l}\text { Zithiol* } \\
\text { Cythion } \\
\text { Malatox }\end{array}$ & $\begin{array}{l}2 * \text { (haricot } \\
\text { sec } \\
\text { seulement) }\end{array}$ & $\begin{array}{l}4 \text { à } 5 \mathrm{~g} / \\
\text { quintal }\end{array}$ & 50 à 80 \\
\hline \multirow[t]{4}{*}{ Pyréthrinoïdes } & Deltaméthrine & K-Obiol & $\begin{array}{l}1 \text { (toutes } \\
\text { légumi- } \\
\text { neuses) }\end{array}$ & $\begin{array}{l}2 \text { à } 3 \mathrm{~g} / \\
\text { quintal }\end{array}$ & 25 à 40 \\
\hline & Cyperméthrine & Talisma $^{(2)}$ & $\begin{array}{l}0,05 \\
\text { (arachide et } \\
\text { soja) }\end{array}$ & & \\
\hline & Perméthrine ${ }^{(1)}$ & Ambush $^{(1)}$ & $\begin{array}{l}0,1 \text { (haricot } \\
\text { et arachide) }\end{array}$ & & \\
\hline & & & 0,05 (soja) & & \\
\hline \multirow[t]{2}{*}{$\begin{array}{l}\text { Fumigants } \\
\text { (gaz) }\end{array}$} & $\begin{array}{l}\text { Phosphure } \\
\text { d'alumi- } \\
\text { nium ou de } \\
\text { magnésium }\end{array}$ & $\begin{array}{l}\text { Fumitoxin } \\
\text { Phostoxin } \\
\text { Quick-fume } \\
\text { Fumi-cell }\end{array}$ & $\begin{array}{l}0,01 \\
\text { (arachide et } \\
\text { toutes légu- } \\
\text { mineuses) }\end{array}$ & $\begin{array}{l}3 \mathrm{~g} / \mathrm{m}^{3} \mathrm{de} \\
\text { graines, soit } \\
4 \mathrm{~g} / \text { tonne }\end{array}$ & - \\
\hline & $\begin{array}{l}\text { Fluorure de } \\
\text { sulfuryle }\end{array}$ & $\begin{array}{l}\text { Vikane } \\
\text { Profume }\end{array}$ & & & \\
\hline Biopesticides & Spinosad & & $\begin{array}{l}0,01 \text { (soja } \\
\text { seulement) }\end{array}$ & & 50 à 80 \\
\hline \multirow[t]{2}{*}{$\begin{array}{l}\text { Matières } \\
\text { minérales }\end{array}$} & $\begin{array}{l}\text { Terre de } \\
\text { diatomées }\end{array}$ & $\begin{array}{l}\text { Dryacide } \\
\text { (liquide) }\end{array}$ & Non fixée ${ }^{(1)}$ & $\begin{array}{l}30-50 \mathrm{~g} / \\
\text { quintal }\end{array}$ & 50 à 80 \\
\hline & & $\begin{array}{l}\text { Diatomite } \\
\text { (poudre) }\end{array}$ & & & \\
\hline $\begin{array}{l}\text { * pour indication (s } \\
\text { (1) pas d'autorisatio } \\
\text { (2) spécialités comm }\end{array}$ & $\begin{array}{l}\text { s garantie du fabric } \\
\text { l'emploi sur légum } \\
\text { ciales homologuées }\end{array}$ & céréales en grain & & & \\
\hline
\end{tabular}




\section{Domaine d'utilisation de la fumigation et perspectives}

Actuellement, il n'y a pratiquement plus qu'un seul gaz utilisable pour la désinsectisation des stocks de graines dans le monde : le phosphure d'hydrogène ou " phosphine » $\left(\mathrm{PH}_{3}\right)$. Cette substance n'est pas introduite directement sous forme gazeuse dans l'enceinte de fumigation, mais par l'intermédiaire d'un générateur solide (pilule, comprimé ou sachet) à base de phosphure d'aluminium ou de magnésium qui, au contact de l'humidité de l'air, dégage progressivement le gaz en laissant après diffusion un résidu inerte de sels d'aluminium ou de magnésium. La répartition du gaz qui se dégage des générateurs peut être accélérée à l'aide d'un système de recirculation extérieur (figure 6.1).

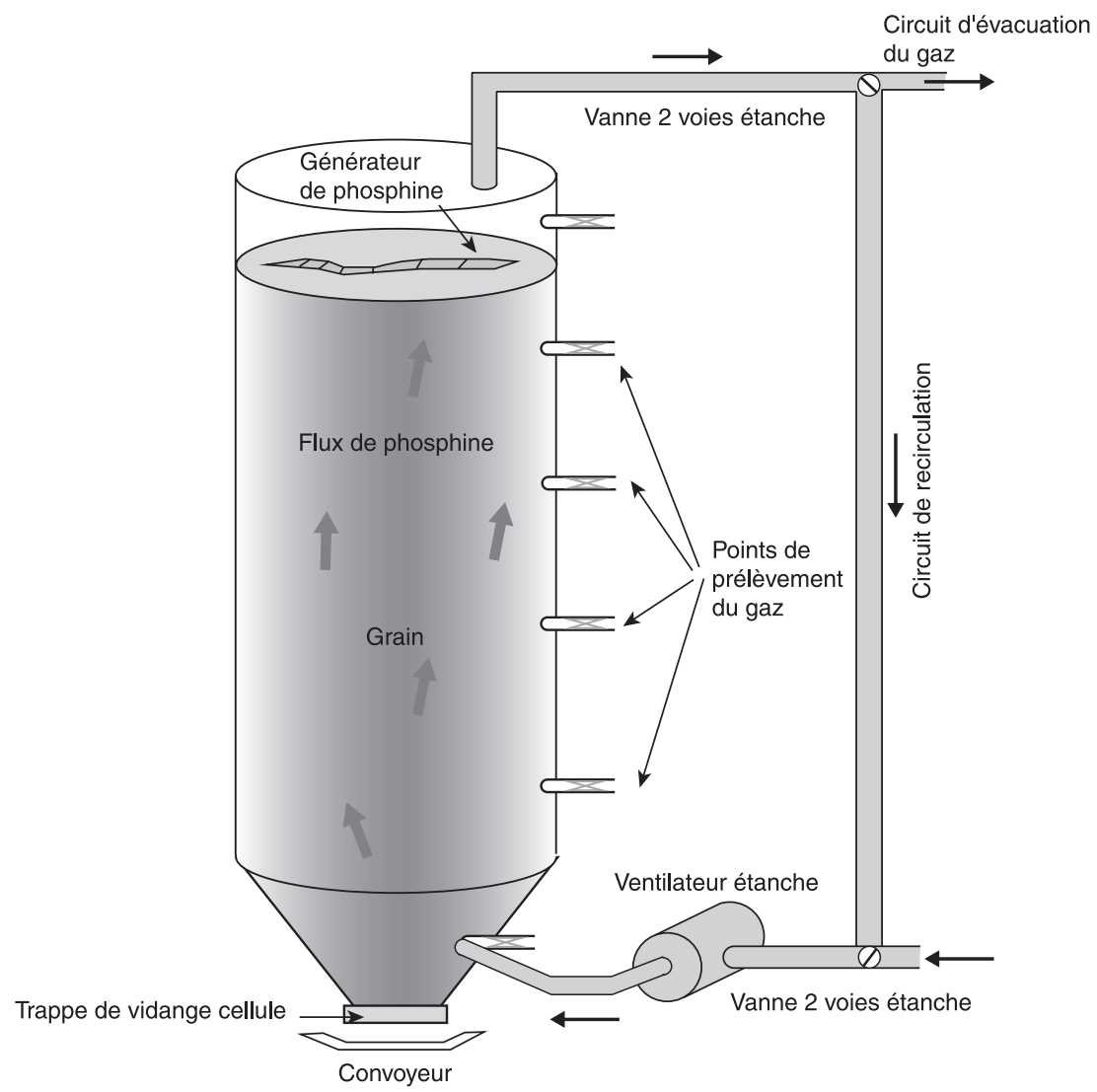

Figure 6.1. Schéma d'une cellule à grain au cours d'un gazage à la phosphine avec un système (J-système) de recirculation du gaz (P. Ducom, communication personnelle).

Ce type de formulation en générateur solide facilite le dosage de la quantité de gaz à mettre en œuvre (par simple comptage des pilules ou des comprimés), mais rend très progressive l'augmentation de la concentration. Cette augmentation peut demander plusieurs heures à un jour selon les conditions de température et d'hygrométrie de l'air dans l'enceinte de gazage (Annis, 2000). Dans cette situation, la « dose effective » de 
gaz est exprimée par une unité spécifique : le produit de la concentration par le temps (appelé CT) qui est déterminée à partir de la mesure des concentrations de gaz durant toute la période de fumigation. La fumigation à la phosphine demande davantage de temps que le gazage au bromure de méthyle ( $72 \mathrm{~h}$ à deux semaines contre $24 \mathrm{~h}$ ). C'est un gaz corrosif pour les métaux, ce qui le rend inutilisable dans un environnement avec des installations électriques ou des appareils électroniques.

\section{Les résidus des traitements des graines et la LMR}

Les traitements des graines après récolte avec des pesticides de contact persistants génèrent des résidus qui perdurent plus ou moins longtemps dans les graines traitées et ne doivent pas dépasser la limite maximale de résidus (LMR). Il existe une LMR tolérée pour chaque substance active susceptible d'être utilisée comme pesticide pour le traitement d'un végétal, de fruits, de graines ou de toute autre partie utilisable à des fins alimentaires. Le registre mondial des LMR est tenu par la Commission mixte FAO-OMS du Codex alimentarius [site Internet : http://www.codexalimentarius.net/mrls/pestdes/jsp_q-f.jsp].

Les LMR du Codex alimentarius sont prioritairement appliquées aux échanges internationaux de denrées alimentaires et entrent naturellement en vigueur dans les accords sanitaires et phytosanitaires (accords SPS) de l'Organisation mondiale du commerce (OMC). Il est souhaitable qu'elles soient également appliquées au niveau du commerce local. Un extrait de la base de données du Codex alimentarius sur les LMR pour les haricots frais et les graines sèches de haricot est présenté à titre d'exemple dans le tableau 6.2.

Pour l'Afrique, ces dispositions sur les normes sanitaires et phytosanitaires des produits alimentaires sont reprises dans la convention phytosanitaire, harmonisées et mises en œuvre pour l'ensemble des pays africains par l'Organisation africaine de protection des plantes (OAPP) dépendant du Conseil phytosanitaire inter-africain (CPI). La sécurité dans l'application des pesticides fait partie des priorités de l'OAPP [site Internet : http://www.au-appo.org/fr/].

Le devenir des résidus en protection des denrées stockées est sensiblement différent de celui observé en protection des cultures. La dégradation des teneurs en résidus d'organo-phosphorés (malathion, chlorpyriphos-méthyl, pyrimiphos-méthyl) ou de pyréthrinoïdes (deltaméthrine, cyperméthrine, perméthrine, etc.) dans les grains est beaucoup plus lente, même en conditions de température et d'humidité du grain de climat tropical (Fleurat-Lessard, 2001). Les durées de demi-vie des résidus (disparition de $50 \%$ de la dose appliquée) dans les graines varient en fonction des niveaux de température et des propriétés intrinsèques de chaque substance active pesticide. Elles peuvent être très courtes, par exemple trois semaines avec un organo-phosphoré appliqué sur des grains conservés à $30^{\circ} \mathrm{C}$, ou très longues, par exemple avec un pyréthrinoïde appliqué sur des grains à $20-25^{\circ} \mathrm{C}$ (Fleurat-Lessard et al., 2002).

\section{Les inconvénients des pesticides et les risques encourus par les utilisateurs}

\section{Les usages détournés des pesticides}

L'augmentation constante du coût des pesticides au cours des dernières années et la généralisation des problèmes de résistance des ravageurs aux produits les plus utilisés 
Tableau 6.2. Exemple de limites maximales de résidus (LMR) des produits phytosanitaires insecticides légalement tolérées dans les haricots frais (consommés en tant que légumes), et dans les graines de haricots secs de consommation différée après récolte. Données de l'index des LMR officielles du Codex alimentarius.

\begin{tabular}{|c|c|c|c|c|}
\hline & & Haricot frais & Haricot sec & $\begin{array}{l}\text { Légumineuses } \\
\text { (toutes } \\
\text { espèces) }\end{array}$ \\
\hline Substance active & Classe pesticide & LMR (mg/kg) & LMR (mg/kg) & LMR (mg/kg) \\
\hline Acéphate & Ins_OP & 5 & & \\
\hline Aldicarbe & Ins_Carb & & 0,1 & \\
\hline Aldrine et dieldrine & Ins_Ochl & & & $* * 0,05$ \\
\hline Cyperméthrine & Ins_Pyr & 0,05 & & \\
\hline Deltaméthrine & Ins_Pyr & & 1 & 0,2 \\
\hline Fenvalérate & Ins_Pyr & 0,1 & & \\
\hline Imidaclopride & Ins_Neo & 2 & & \\
\hline Malathion & Ins_OP & 1 & & \\
\hline Méthamidophos & Ins_OP & 1 & & $* *$ \\
\hline Méthidathion & Ins_OP & & 0,1 & \\
\hline Méthomyl & Ins_Carb & 1 & 0,05 & \\
\hline Parathion-méthyl & Ins_OP & & & $* * 0,05$ \\
\hline Perméthrine & Ins_Pyr & & 0,1 & \\
\hline Phorate & Ins_OP & & 0,05 & $* * 0,05$ \\
\hline Pirimicarbe & Ins_Carb & & & 0,7 \\
\hline Propargite & Ins_Sulf & & & 0,3 \\
\hline Spinosad & Ins_Bio & & & 0,01 \\
\hline
\end{tabular}

** Substance active à usage limité ou interdit ; LMR provisoire avant suppression

OP : organophosphoré ; Carb : carbonate ; Ochl : organochloré ; Pyr : pyréthrinoïde ; neo : néonicotinoïde ; Sulf : sulfure ; Bio : biopesticide.

a fait se détourner les petits producteurs de leur usage courant. Ces effets néfastes sont aggravés par une tendance assez générale à utiliser un produit autorisé à l'emploi sur une culture particulière pour un autre usage non autorisé (culture légumière ou fruitière, stock de céréales, hygiène domestique et vétérinaire, etc.). Ainsi, on rencontre fréquemment des situations où le producteur de légumineuses utilise des pesticides spécifiques du coton pour traiter toutes les autres cultures, tout au long de l'année (comme le niébé ou la tomate), alors que ces pesticides du coton ne sont pas autorisés à l'emploi sur produit végétal de consommation directe. Ces pratiques de " détournement d'usage ", assimilables à un abus de traitement des cultures maraîchères et horticoles, peuvent présenter un danger pour le consommateur final quand il s'agit de légumes ou de graines largement et régulièrement autoconsommés par la famille de l'agriculteur. La connaissance des effets des pesticides sur la santé humaine semble très insuffisante chez les producteurs. 


\section{Les méthodes alternatives aux pesticides applicables au niveau villageois}

Dans les pays en développement, la distribution des pesticides n'est pas toujours organisée jusqu'au niveau des petits producteurs éloignés des principaux centres urbains. De plus, le contrôle de la qualité des produits phytosanitaires (concentration en matière active respectée ; emballage inviolable ; étiquette neuve, lisible et propre ; contenant non détérioré ; etc.) est difficile à appliquer dans les pratiques commerciales actuelles. Sur ce marché des pesticides cohabitent beaucoup de négociants formels et « informels », ces derniers étant le plus souvent incontrôlables (Sougnabe et al., 2010). Face à cette difficulté temporelle d'approvisionnement en intrants phytosanitaires des producteurs de légumineuses, les stratégies de gestion des populations de ravageurs ne peuvent dépendre que de pratiques alternatives, dérivées le plus souvent des méthodes traditionnelles au niveau villageois (Abate et al., 2000).

Dans ces conditions, la gestion durable des principaux problèmes de conservation des graines de légumineuses est plutôt fondée sur la prévention des risques, notamment par l'adaptation des pratiques de conservation qui peut amener à un investissement faible ou nul en pesticides : cultures de variétés moins sensibles aux ravageurs de stockage ; élimination rapide des graines triées et considérées inconsommables ; conservation des graines en récipients étanches, mélangées à des poudres minérales, des extraits de plantes ou des huiles essentielles de fabrication locale; etc.

Des moyens physiques peuvent y être associés en tant que mesures préventives complémentaires, en particulier la pratique de la désinfestation thermique à la récolte (en saison sèche). Le séchage par solarisation qui assure également la désinsectisation est de mieux en mieux maîtrisé au plan technique sans moyens spécifiques autres que ceux disponibles au niveau des exploitations agricoles (Chauhan et Ghaffar, 2002 ; Maina et Lale, 2004). Le stockage dans des «silos » ou des récipients partiellement ou totalement enterrés fait partie des méthodes traditionnelles de l'Afrique du Nord et de certains pays du Sahel. La température des graines s'y maintient à des niveaux plus bas que dans les greniers aériens, ce qui limite le taux de multiplication des insectes. Certains greniers aériens construits avec des parois en briques d'argile ou de terre de forte épaisseur et bien isolés thermiquement au niveau du toit sont plus favorables à la bonne conservation des graines pour la même raison. Les petits producteurs qui conservent une partie de leur récolte de légumes secs pour servir de semence préfèrent souvent utiliser les méthodes de prévention non chimiques plutôt que les pesticides pour préserver la capacité germinative des semences : cendres, argile finement broyée, feuilles de neem, poudre fine de feuilles de tabac ou d'eucalyptus, écorces d'agrumes et même parfois du sable ou de la latérite peuvent être mélangés en forte proportion aux stocks de graines (Lienard et Seck, 1994 ; Murdock et al., 2003).

\section{Principal risque de l'usage courant des pesticides : l'apparition de résistances}

Le principal inconvénient de l'usage régulier de pesticides pour la lutte contre les ravageurs des cultures est l'apparition et la multiplication de races d'insectes résistantes aux substances actives les plus régulièrement utilisées. Les résistances apparaissent le plus souvent lorsqu'une même substance active est utilisée systématiquement sur 
la même espèce de ravageur. Ces populations résistantes peuvent devenir invasives en quelques années. Les cas de résistance les plus inquiétants sont ceux qui se généralisent en quelques années au monde entier comme Tribolium castaneum (Herbst) dans les stocks de graines de céréales qui a acquis une résistance généralisée au lindane et au malathion, deux insecticides utilisés par le passé pour la protection des stocks de grains et graines. Un autre exemple est celui de Callosobruchus maculatus qui a également développé une résistance à la phosphine (Ahmed et al., 2002) et à un insecticide organophosphoré au Nigeria (Odeyemi et al., 2006).

La prévention des risques d'apparition de résistances des insectes aux pesticides fait généralement intervenir différentes stratégies, comme la mise en place de réseaux de surveillance de l'apparition des résistances, la gestion raisonnée de l'usage des pesticides et l'amplification des recherches à caractère fondamental dans les centres de recherche agronomique.

L'aire d'extension des populations résistantes aux pesticides peut être limitée par :

- le changement régulier de famille chimique avec des substances à activité équivalente ;

- la réduction de la persistance des résidus (quand ils ne sont plus actifs sur les insectes visés) ;

- l'utilisation de synergistes de l'activité des substances actives, comme le butoxyde de pipéronyl pour les pyréthrinoïdes, le dillapiol ou les composés soufrés des alliacées (voir chapitre 7);

- la diversification des méthodes de protection ou de lutte contre les ravageurs limitant le recours aux pesticides.

\section{Préconisations dans le cadre d'une protection phytosanitaire durable}

\section{Les exigences phytosanitaires de l'accès des légumineuses au marché global}

Dans l'esprit des conférences internationales des Nations unies sur l'alimentation et l'agriculture recommandant des pratiques agronomiques durables et un nouveau modèle de protection des cultures fondés sur les progrès des connaissances en écologie, les principes d'intervention phytosanitaire ont été radicalement transformés au cours de la fin du siècle dernier (Ferron, 1999 ; Edwards, 2002 ; Deguine et al., 2008).

\section{Les solutions alternatives aux pesticides en protection phytosanitaire raisonnée et durable des graines de légumineuses}

Les dégâts et pertes économiques occasionnés par les ravageurs des cultures vivrières dans les pays africains sont très variables selon les régions climatiques et la destination des productions. Ainsi, les grains et graines alimentaires (céréales et légumineuses, pour l'essentiel) ne seront pas protégés des attaques parasitaires de la même façon s'ils sont destinés à la consommation familiale, à la semence ou à la commercialisation sur le marché local ou par l'intermédiaire des négociants (Bosch et Borus, 2009). Il se dessine dans cette différence une stratégie raisonnée de protection phytosanitaire qui est élaborée et mise en œuvre (empiriquement) en fonction d'un cadre socio-économique donné et 
qui n'est pas seulement fondée sur l'utilisation de pesticides ou de procédés alternatifs de substitution (Deguine et Ferron, 2004).

L'arsenal des moyens, outils et produits de substitution aux pesticides chimiques susceptibles de faire évoluer la protection phytosanitaire vers des stratégies durables et économes en intrants pesticides est très ouvert dans les pays en développement. Les méthodes physiques de substitution aux pesticides qui peuvent entrer dans les systèmes de protection fondés sur la prévention du risque sont nombreuses. L'incorporation de poudres minérales (cendres de bois, terre de diatomées, argile en poudre fine, balle de riz moulue, sable) aux stocks de graines prévient la reproduction et le développement des insectes de ces stocks. La solarisation des graines à la récolte assure une désinsectisation thermique (Chauhan et Ghaffar, 2002 ; Murdock et al., 2003). La conservation en récipients étanches et dans un endroit frais (greniers en terre, bidons métalliques ou plastiques à fermeture étanche, greniers enterrés) limite également les attaques (Vincent et al., 2000 ; Fleurat-Lessard et Vincent, 2005). Ces méthodes associées à l'utilisation des bio-insecticides d'origine végétale (voir chapitre 7) et la lutte biologique (voir chapitre 9) peuvent assurer une bonne protection des stocks en milieu paysan.

\section{Conclusion}

Pour les producteurs de légumineuses, prendre la décision d'utiliser des pesticides en respectant les principes de l'agriculture durable est complexe. La mise en œuvre d'une stratégie de lutte impose l'intégration de multiples facteurs d'ordre écologique, entomologique, matériel et technique. Le choix des approches à mettre en pratique pour la gestion de ces risques, en utilisant des moyens chimiques (pesticides) ou des méthodes et stratégies alternatives, est largement dépendant des habitudes et des ressources locales (extraits de plantes, moyens physiques de lutte, techniques de confinement des stocks, adaptation des locaux et du matériel de stockage). Ce choix est également dépendant de nombreux facteurs culturels et socio-économiques. L'approche durable de la protection phytosanitaire des légumineuses dans les pays en développement associe l'ensemble des stratégies de protection des plantes et des récoltes, tant sur le plan quantitatif que qualitatif. L'une de ses priorités est de réduire la part des dépenses pour l'achat de produits phytosanitaires des exploitations agricoles. L'application pratique de ces principes de protection phytosanitaire durable des cultures et des récoltes est largement indépendante du niveau de technicité ou d'équipement et d'intrants disponibles, et peut théoriquement être réalisée aussi bien dans les pays en développement que dans les pays dits « développés ».

Des études de transposition au terrain des principes de la protection intégrée « associative » sont entreprises partout dans le monde pour réduire les utilisations des pesticides organiques de synthèse, y compris en Afrique (Swella et Mushobozy, 2007). La construction des stratégies de protection phytosanitaire intégrées des cultures et des récoltes de légumineuses - qui consiste à associer de façon optimale un certain nombre de ces moyens techniques pour limiter la dynamique de multiplication des ravageurs ou les dommages qu'ils engendrent - est en expansion en Afrique dans le cadre de la transition nécessaire vers l'agriculture durable. Mais le taux de pénétration des principes de la protection intégrée appliquée aux stocks de graines est faible à inexistant au niveau des populations rurales des petits producteurs locaux. 
Cette réflexion sur l'usage raisonné des pesticides en protection des légumineuses souligne la diversité extrême des moyens de production et de conservation des récoltes que l'on rencontre en Afrique tropicale, et des niveaux de risque d'attaque par les bioagresseurs de ces productions en phase de post-récolte.

La formation des producteurs pour la compréhension des principes et des modes opératoires de la protection intégrée des stocks de graines reste à amplifier en milieu rural, pour que les pratiques de protection raisonnée contre les insectes, largement exposées dans ce chapitre, deviennent acceptables par les agriculteurs en restant compatibles avec leurs ressources matérielles et économiques. Au niveau de la politique d'accompagnement par les pouvoirs publics de la transition vers la protection phytosanitaire intégrée des légumineuses en Afrique, des incitations technico-économiques sont proposées dans de nombreux pays (Sénégal, Mali, Bénin, Nigéria, Kenya, Ouganda, Cameroun, Tchad, etc.) pour la conversion des producteurs à ces démarches (voir ci-après). Ces actions sont de nature à favoriser cette évolution vers la protection phytosanitaire durable des légumineuses cultivées en Afrique. Elles paraissent indissociables des initiatives à prendre par les organisations en charge de l'amélioration de la santé des plantes, de l'environnement rural et de la sécurité des consommateurs, dans des domaines aussi différents que la politique de développement agricole, la réglementation, le contrôle des flux commerciaux des produits phytosanitaires et la formation professionnelle en milieu rural.

\section{Les grandes lignes de la transition en cours vers la protection phytosanitaire durable des légumineuses en Afrique}

\section{Améliorer le contrôle du marché des pesticides (importation et marché intérieur)}

- Mise en place d'un contrôle des flux commerciaux et du respect des bonnes pratiques d'utilisation des pesticides autorisés pour la protection des légumineuses.

- Amélioration de la réglementation sur l'utilisation des pesticides autorisés par denrée.

- Mise en place d'un contrôle des importations de pesticides (autorisés sur culture ou denrée agricole).

\section{Diminuer la dépendance des producteurs vis-à-vis des firmes phytosanitaires ou des fournisseurs de semences}

- Politique concertée de réduction de l'usage des pesticides importés pour les producteurs de légumineuses " commerciales".

- Augmentation des capacités du service public de conseil agricole pour promouvoir la réduction des usages de pesticides et la transition vers la protection intégrée (incluant les bonnes pratiques traditionnelles).

- Sélection (réglementaire) des produits les moins dangereux pour les applicateurs et l'environnement des cultures vivrières (légumineuses et céréales pour l'essentiel).

- Introduction et développement des méthodes de lutte non chimiques et peu dépendantes du niveau de ressources des producteurs de légumineuses.

\section{Augmenter les capacités du secteur public au soutien à l'agriculture durable}

- Politique de soutien et de développement progressif de la protection intégrée des cultures.

- Création ou renforcement des services régionaux pour une bonne coordination de la formation et du conseil sur les stratégies de protection durable des cultures destinées à la mise sur le marché local ou régional. 
- Politique de soutien aux initiatives collectives locales pour la coordination des bonnes pratiques économes en intrants externes (phytosanitaires, engrais, semences).

- Réalisation de guides illustrés de bonnes pratiques en protection des cultures de légumineuses contre les ravageurs (tenant compte de l'environnement et des pratiques locales ou régionales).

- Encouragement et soutien à la diffusion de variétés résistantes ou tolérantes aux ravageurs.

\section{Renforcer la recherche finalisée et le transfert des progrès technologiques marquants}

- Développement d'une politique publique de soutien à la recherche finalisée pour assurer la transition vers des systèmes de production et de stockage durables et économes en pesticides.

- Évaluation de l'importance de l'endettement des producteurs de légumineuses et de céréales vivrières de qualité commerciale en crédits d'intrants phytosanitaires et en semences pour élaborer des plans d'apuration.

- Création de fonds de soutien régionaux pour l'accès aux intrants externes (phytosanitaires, semences, fertilisants) et au matériel d'application des traitements.

- Amplification des recherches finalisées sur les itinéraires de culture économes en intrants phytosanitaires et sur les alternatives à la lutte chimique en utilisant des sources renouvelables de produits locaux de substitution.

- Recherche et sélection des variétés adaptées aux conditions agroclimatiques régionales permettant d'améliorer la durabilité et la qualité des productions et de réduire le besoin en pesticides.

- Développement d'un plan d'action national pour diffuser les informations techniques innovantes et compatibles avec les principes d'une agriculture durable et respectueuse de l'environnement (site Internet).

5. Ouvrir des voies nouvelles pour l'homologation des produits de protection des plantes à activité non létale (différents des pesticides chimiques de synthèse)

- Mise en place de nouvelles procédures raisonnables, simplifiées et économiques pour l'homologation des produits alternatifs aux pesticides.

- Renforcement des services publics d'assistance et de conseil aux producteurs de légumineuses et céréales.

- Création d'une agence nationale d'évaluation des produits locaux de substitution aux pesticides et de réglementation sur les usages autorisés, en relation avec le Conseil phytosanitaire interafricain (CPI) de l'Organisation de l'unité africaine.

- Mise en relation des experts en économie rurale et des ingénieurs chargés du développement des résultats de la recherche et des expériences pilotes des systèmes de protection phytosanitaire durables. 


\title{
Chapitre 7
}

\section{Biocontrôle des Bruchinae par les substances végétales : méthodologies et applications}

\author{
Catherine Regnault-Roger
}

Les problèmes de protection des cultures sont inhérents à l'avènement de l'agriculture. Les livres sacrés comme le Veda en Inde ou la Bible dans le Bassin méditerranéen, ou les traditions orales ancestrales africaines qui se sont transmises de génération en génération, soulignent que depuis des millénaires la survie de l'espèce humaine dépend de sa capacité à protéger les végétaux essentiels à son alimentation, dans les champs ou après la récolte. La préservation des cultures et des récoltes s'inscrit dans un phénomène de compétition entre consommateurs au premier rang desquels s'affrontent l'homme, les insectes et les rongeurs (Ferron, 1989). Aujourd'hui, l'agriculture spéculative et productiviste ne tolère pas ces pertes qui caractérisaient l'agriculture vivrière des siècles passés et qui sont provoquées par les déprédations des insectes, acariens, nématodes, oiseaux et autres rongeurs, ainsi que par les maladies dues aux agents pathogènes. Face à l'expansion démographique et à la mondialisation, il importe que l'agriculture soit de plus en plus performante afin de satisfaire les besoins toujours accrus en produits agricoles alimentaires, mais aussi non alimentaires, à l'échelle planétaire.

Dans ce contexte, le développement des pesticides chimiques, faciles à produire et peu coûteux, a constitué au $\mathrm{Xx}^{\mathrm{e}}$ siècle une révolution technologique. Une utilisation intensive et souvent sans discernement des pesticides chimiques s'est accompagnée de désordres écologiques à de multiples niveaux provoquant la pollution des eaux de surface ou des eaux souterraines, la rupture des chaînes trophiques par bioaccumulation ou bioamplification et des phénomènes de résistance des espèces visées (Regnault-Roger, 2005). Aussi, de nombreuses initiatives se sont déployées depuis plusieurs années pour développer des méthodes alternatives afin de diminuer l'utilisation de ces pesticides chimiques. Parmi ces méthodes alternatives, les stratégies de gestion des ravageurs des cultures et des denrées stockées, fondées sur l'utilisation de substances botaniques et 
de molécules végétales suscitent un intérêt qui va grandissant, et de nombreux travaux s'attachent à découvrir les propriétés insecticides de bon nombre d'espèces végétales.

La recherche de nouveaux composés végétaux s'effectue le plus souvent à partir d'observations sur des pratiques ancestrales de protection des cultures en champ et dans les greniers à grains. De l'enquête ethnobotanique à la valorisation des composés actifs, la prospection pour de nouvelles ressources végétales nécessite aujourd'hui d'intégrer la prise en compte de l'efficacité biologique, mais aussi du respect des écosystèmes, c'està-dire de la minimisation des effets non intentionnels.

Différentes initiatives ont été prises dans ce domaine. À partir d'exemples qui s'inscrivent dans le biocontrôle des insectes ravageurs par des allomones ${ }^{3}$ et extraits végétaux, on examinera les bénéfices et les risques de cette approche de biocontrôle des bioagresseurs dans la perspective de l'agriculture durable.

\section{Approche méthodologique pour la prospection de molécules végétales à potentiel phytosanitaire}

\section{Intérêt d'une enquête ethnobotanique}

Actuellement, une des démarches les plus simples à mettre en œuvre pour identifier des végétaux, pouvant être des sources potentielles d'insecticides phytochimiques, est la réalisation d'une enquête ethnobotanique sur les pratiques traditionnelles d'utilisation des plantes contre les insectes phytophages et les agents phytopathogènes. L'utilisation de ces moyens de lutte est très ancienne, car les agriculteurs ont eu recours depuis très longtemps à des adjonctions de substances inertes (terre, poudre) ou de débris de plantes pour conserver les denrées stockées. Golob et Weley (1980) ont souligné la pérennité de ces méthodes encore pratiquées dans les milieux ruraux africains. On constate ainsi que l'histoire des hommes fourmille d'observations fortuites donnant naissance à des pratiques empiriques véhiculées à travers les siècles et dont la rationalité a été établie par l'avancée des sciences et techniques au cours du XXe siècle (Regnault-Roger, 2008). Ces observations de terrain, pour être exploitables, doivent s'accompagner d'une enquête ethnobotanique qui donnera, outre des informations socio-ethnologiques, des précisions sur l'état du végétal utilisé comme phytoprotecteur, son aspect et son état physique (frais, broyé, séché), son odeur, sa maturité au moment de la récolte, les conditions dans lesquelles il s'est développé et les conditions dans lesquelles s'effectue cette protection : utilisation d'un espace ouvert ou fermé (greniers à grain, silos), température, hygrométrie, photopériode. Il importe de préciser les plantes que l'on veut protéger et le type d'activité observée sur le terrain vis-à-vis des bioagresseurs : antiappétent, répulsif, effet létal ou knock-down vis-à-vis des insectes, immunité naturelle de la plante vis-à-vis d'agents phytopathogènes.

L'étape suivante consiste à vérifier en laboratoire si ces pratiques empiriques ont un fondement réel. Cela suppose de choisir un modèle expérimental et de définir les expériences à réaliser en fonction des objectifs retenus.

\footnotetext{
3 Substances produites par une espèce animale ou végétale agissant sur le comportement ou la physiologie d'une autre espèce.
} 


\section{Modèles biologiques et démarche expérimentale}

Plusieurs critères président au choix du modèle biologique. La démarche la plus logique est celle qui consiste à prendre comme premier modèle l'espèce identifiée lors de l'enquête ethnobotanique. On peut ainsi recréer une situation expérimentale, analogue à celle du terrain, dans laquelle sont contrôlés les paramètres environnementaux, mais aussi ceux relatifs à la biologie des bioagresseurs. Ces conditions expérimentales permettent de vérifier l'efficacité des pratiques traditionnelles tout en disposant des repères objectifs nécessaires pour approfondir la démarche scientifique.

Au cours de l'expérimentation, le végétal à tester est mis en présence du bioagresseur et on observe, pendant une période de temps donné, les effets de la plante sur sa reproduction, son comportement et son développement. Les expérimentations sont effectuées selon des protocoles classiques vérifiant les critères scientifiques de pertinence et fiabilité des résultats obtenus et leur reproductibilité (effectifs, témoins, répétitions, analyses statistiques, etc.). Après avoir testé l'activité insecticide du végétal, il est nécessaire d'identifier les composés actifs grâce à des analyses chimiques. Les extraits végétaux sont fractionnés, puis analysés par chromatographie. Les composés sont isolés, identifiés et sont ensuite testés sur une espèce d'insectes. Il existe donc à ce stade expérimental un va-et-vient permanent entre les laboratoires de chimie et de biologie. En effet, indépendamment de la variabilité résultant des techniques d'extractions utilisées $(\mathrm{pH}$, solvants, température, etc.), le profil phytochimique des végétaux n'est pas constant. Il dépend des conditions climatiques, de la nature du sol sur lequel la plante s'est développée, du degré de maturité de la plante, de l'intensité de son métabolisme et de son chémotype (Regnault-Roger, 2005). À l'issue de ces étapes, on est en mesure de vérifier si des relations structures - activités peuvent se dégager et être exploitées.

Pour élargir l'utilisation des composés ainsi caractérisés, il faut se demander quelle est l'importance du spectre d'activité de ces composés en les testant sur d'autres espèces. On peut aussi réaliser des associations moléculaires pour voir s'il existe des synergies entre composés. On dénombre en effet dans un extrait végétal brut un grand nombre de composés qui peuvent interagir. À ce stade de la recherche, de nouveaux composés végétaux sont identifiés et leurs activités ciblées.

Un des enjeux de l'agriculture durable est de définir comment on veut utiliser ces nouvelles connaissances dans une approche appliquée. Veut-on mettre à la disposition des acteurs ruraux des préparations faciles à réaliser en situation (par exemple des décoctions ou des purins) ? Ou bien souhaite-t-on inclure les nouvelles matières actives dans des formulations qui seront soumises à la procédure d'homologation ? Dans ce cas, il convient dès lors de passer du laboratoire au stade recherche et développement industriel (R\&D) : essais en conditions d'exploitation, dossiers toxicologiques et écotoxicologiques pour les autorisations de mise sur le marché, choix d'une stratégie commerciale, rentabilité du marché visé, etc. Selon la réglementation appliquée à l'utilisation des produits phytosanitaires dans chaque pays, le processus d'homologation des molécules ou extraits végétaux à caractère biopesticide est plus ou moins long. 


\section{Contrôle de la bruche du haricot Acanthoscelides obtectus (Say) par les plantes aromatiques méditerranéennes pour la protection des graines de légumineuses}

Pour illustrer la démarche méthodologique exposée ci-dessus, on prendra en exemple le cas des plantes aromatiques méditerranéennes. Le point de départ a été l'observation des méthodes de protection traditionnelles des récoltes de graines de haricot (Phaseolus vulgaris L.) par les agriculteurs du sud-ouest de la France. L'enquête ethnobotanique a souligné que les petits producteurs avaient coutume, par le passé, de mettre dans les sacs de grains de haricots des plantes odorantes comme la menthe, l'ail ou le laurier afin de limiter les attaques dues aux larves de la bruche $A$. obtectus.

Ces observations ont guidé le choix d'un premier modèle biologique : le haricot (P. vulgaris) et la bruche $A$. obtectus. Par la suite, d'autres espèces d'insectes ont été choisies pour la diversité des ordres auxquels elles appartiennent, et en raison de l'incidence économique de leurs dégâts.

\section{Analyse de l'activité des plantes aromatiques}

Dans un premier temps, l'efficacité de plantes méditerranéennes a été testée. Il apparaît qu'elles exercent un effet protecteur sur les graines de légumineuses soit en provoquant la mort de l'insecte, soit en inhibant sa reproduction. Des plantes odorantes, appartenant à différentes familles - Myrtaceae, Poaceae, Umbelliferae, Lauraceae, Myristicaceae manifestent cette activité. Les Lamiaceae (ex-labiées) sont les plus efficaces ; c'est notamment le cas du thym et du serpolet (Thymus vulgaris L. et Thymus serpyllum L.), du romarin (Rosmarinus officinalis L.) et de l'origan (Origanum vulgare L.) (RegnaultRoger et Hamraoui, 1993).

Les agriculteurs ont sélectionné de façon empirique la menthe (Mentha piperata L.) et le laurier (Laurus nobilis L.) qui agissent sur la reproduction en réduisant la fécondité des femelles d'A. obtectus dans les sacs de grains de haricot. Ainsi la tradition a privilégié une activité qui s'inscrit dans la durée, en limitant le renouvellement des générations du ravageur.

\section{Activité des différentes fractions des plantes aromatiques méditerranéennes et identification des molécules allélochimiques actives}

Les Lamaciae sont réputées pour leur richesse en huiles essentielles. Les huiles essentielles sont obtenues par entraînement à la vapeur d'eau. Elles se distinguent des autres huiles végétales par leur volatilité. Leurs constituants appartiennent, de façon quasi-exclusive, à deux familles chimiques : les terpénoïdes (mono et sesquiterpènes de faible poids moléculaire) et, dans une moindre proportion, les phénylpropanoïdes. Quelquefois des produits de dégradation de composés non volatils y sont également identifiés (Bruneton, 1999). La composition chimique des huiles essentielles varie considérablement en fonction de plusieurs facteurs liés :

- à la génétique de la plante qui induit l'existence de chémotypes (par exemple chez le thym T. vulgaris) ; 
- à sa physiologie, car le métabolisme secondaire de la plante n'est pas identique à tous les stades de son développement;

- aux conditions pédologiques et climatiques (acidité du sol, chaleur, photopériode, hygrométrie) qui influencent le métabolisme secondaire de la plante.

Enfin, le facteur humain avec le choix de protocoles analytiques interfère sur les constituants extraits des huiles essentielles.

La toxicité des huiles essentielles s'exerce de plusieurs manières chez A. obtectus : une toxicité par inhalation sur les insectes adultes (Regnault-Roger et al., 1993), une action ovicide et larvicide (Regnault-Roger et Hamraoui, 1994a) et une activité antinutritionnelle pour les larves se développant à l'intérieur des cotylédons (Regnault-Roger et Hamraoui, 1994b). Les insectes mâles sont plus sensibles que les insectes femelles. La reproduction des insectes est également affectée, certaines huiles essentielles agissant précocement aux premières étapes, d'autres aux stades ultimes. Par ailleurs, les deux effets (létal et inhibition de la reproduction) ne se superposent pas toujours. À titre d'exemple, le thym serpolet $T$. serpyllum et le romarin $R$. vulgare sont très actifs dans les deux cas, tandis que l'huile essentielle de persil (Petroselinum sativum L.), qui est faiblement toxique pour les adultes, inhibe totalement la reproduction d'A. obtectus. La toxicité par inhalation et l'activité antinutritionnelle, très marquées pour la majorité des huiles essentielles, présentent aussi des différences. Ainsi l'huile essentielle de la muscade (Myristica fragans Van Houtten) est peu toxique pour les adultes d'A. obtectus, mais exerce un effet inhibiteur sur la reproduction. En revanche, son effet antinutritionnel vis-à-vis des larves est puissant puisqu'aucune émergence d'adultes n'est notée en sa présence.

Le fractionnement du végétal par hydrodistillation laisse un résidu botanique solide dont il faut tester l'activité sur l'insecte, afin de vérifier si d'autres composés non extraits avec les huiles essentielles agissent sur l'animal : on constate que certains résidus de plantes hydrodistillées extraits du thym, du serpolet, du romarin, de la sarriette (Satureja hortensis L.) ou de l'origan sont toxiques vis-à-vis d'A. obtectus (Regnault-Roger et Hamraoui, 1994-1995). Les propriétés insecticides des plantes aromatiques, couramment utilisées dans la protection des stocks, ne sont pas le fait d'un seul composé ni même d'un seul extrait.

Dans certains cas, l'utilisation des huiles essentielles en phytoprotection peut s'avérer délicate en raison de la multiplicité des profils phytochimiques qu'elles présentent. Ces variations peuvent représenter un inconvénient pour la fiabilité de traitements phytosanitaires en application industrielle. Il est donc nécessaire de caractériser leurs constituants majoritaires afin de réaliser des analyses structures - activités.

L'analyse chromatographique en phase gazeuse identifie les monoterpènes majoritaires des huiles essentielles que nous avons étudiées (Regnault-Roger et al., 1993). Ils développent, à des degrés divers, une toxicité aiguë sur l'adulte, ainsi que des activités ovicides et larvicides précoces ou tardives (Regnault-Roger et Hamraoui, 1995). L'analyse chromatographique en phase liquide des résidus botaniques après hydrodistillation identifie de nombreux composés appartenant aux acides phénols et flavonoïdes, parmi lesquels l'acide rosmarinique et la lutéoline 7-glucoside sont les composés les plus abondants. Les polyphénols affectent plus ou moins rapidement la motricité naturelle de l'insecte. Celle-ci est altérée dès le premier jour pour la quercétine ou de manière plus tardive, le quatrième jour, pour la naringine, le syringaldéhyde ou l'acide 
vanillique. Dans certains cas, notamment pour la lutéoline 7-glucoside, un effet knockdown se produit. Au bout de huit jours, tous les insectes sont dans un état comateux ou morts. La toxicité des polyphénols est corrélée positivement avec le pouvoir attractif des composés (Regnault-Roger et al., 2004).

Un élargissement à d'autres modèles animaux permet d'effectuer des tests comparatifs afin de cerner l'ampleur du spectre d'activité et la spécificité de la molécule d'intérêt. Ainsi, on constate que les composés les plus actifs sur un insecte d'une espèce donnée ne sont pas forcément les plus toxiques pour une autre espèce. Le linalool, qui est un des composés les plus toxiques sur la bruche $A$. obtectus, a peu d'effet chez la mouche Ceratis capitata. L'anéthole qui est peu actif sur A. obtectus est très toxique pour d'autres espèces d'insectes (Hamraoui et Regnault-Roger, 1997). Il apparaît que les insectes appartenant à des espèces différentes manifestent des sensibilités diverses à une même molécule et que cette sensibilité, dans certains cas, est liée à la présence de structures chimiques définies. La bruche $A$. obtectus serait plus sensible aux dérivés phénoliques, le puceron Rhopalosiphum padi aux structures méthoxylées, tandis que la mouche $C$. capitata et le puceron Metopolophium dirrhodum réagissent, sans différence notable, aux deux groupements fonctionnels (Regnault-Roger, 1999). Il ressort de cette observation qu'il faut déterminer pour chaque espèce-cible quelles sont les molécules les plus actives dans une famille de composés réputée insecticide, afin de mettre au point des formulations efficaces en évitant les surdosages.

Cette recherche met en évidence que les plantes aromatiques méditerranéennes et leurs molécules allélochimiques exercent leurs activités à un double niveau chez la bruche A. obtectus. Les monoterpènes, et dans une moindre mesure les polyphénols, sont toxiques au stade adulte par inhalation. Ils provoquent soit la mort des insectes soit une diminution de leur activité reproductrice. Les composés terpéniques ont une action ovicide ou larvicide. Il apparaît que même une brève exposition aux vapeurs terpéniques au début du développement larvaire a des conséquences sur le développement ultérieur des larves qui ont réussi à pénétrer dans le cotylédon. Les plantes aromatiques méditerranéennes et les molécules allélochimiques qu'elles contiennent peuvent contrôler l'accroissement des populations de la bruche du haricot $A$. obtectus, en tuant une partie de la population adulte et en limitant les chances de développement de leur descendance.

\section{Perspectives et prospective pour l'utilisation des molécules allélochimiques et des extraits végétaux dans la lutte phytosanitaire}

Les récents développements scientifiques ont montré que les allomones et les extraits végétaux présentaient plusieurs propriétés intrinsèques qui leur permettent de s'inscrire dans des stratégies alternatives visant à limiter l'emploi des pesticides organiques de synthèse dans l'agriculture. Toutefois, leur utilisation peut actuellement s'envisager de deux manières. La première vise à renforcer la protection du végétal par l'application classique de formulations comprenant des substances actives allélochimiques d'origine végétale. La seconde est centrée sur la défense interne du végétal. Elle vise à développer les mécanismes de défense de ce dernier de deux manières différentes. On peut accroître la biosynthèse des facteurs allélochimiques toxiques vis-à-vis des insectes par 
sélection génétique classique ou par sélection assistée par marquage (SAM) ou par génie génétique. Mais il est également possible de stimuler les défenses naturelles des plantes par des éliciteurs (Regnault-Roger, 2005 ; Pajot et Regnault-Roger, 2008). Les mêmes molécules allélochimiques, par exemple des polyphénols, peuvent être impliquées à la fois dans la médiation chimique interspécifique et dans le renforcement de la résistance naturelle des plantes en opposant aux agresseurs soit une barrière chimique constitutive (phytoanticipines) soit une défense chimique inductible (phytoalexines). Tout l'intérêt du développement de nouvelles spécialités à base d'extraits végétaux ou des molécules allélochimiques qu'ils contiennent est souligné si l'on considère les avantages écologiques et environnementaux des formulations à base de produits végétaux, par rapport à celles des pesticides organiques de synthèse. Elles développent une sélectivité et une spécificité dans leurs activités sur les espèces cibles, ce qui diminue les effets non intentionnels sur les organismes non-cibles. Biosynthétisées, elles sont biodégradables par voie enzymatique avec en général des demi-vies courtes. Leur non-persistance dans l'environnement limite les risques de bioaccumulation et de bioamplification au niveau des chaînes trophiques. Les molécules allélochimiques appartiennent à plusieurs familles chimiques différentes et leurs cibles biochimiques et moléculaires chez les organismes visés sont variées. De ce fait, leur utilisation raisonnée diminue les risques de phénomènes de résistance chez les organismes cibles, et par conséquent, s'inscrit dans un meilleur respect des écosystèmes (Regnault-Roger, 2005). Toutefois, ces avantages ne s'entendent que si l'utilisation de ces formulations évite les erreurs passées constatées dans l'emploi des pesticides chimiques. En effet, un usage répété, intensif et inapproprié d'une même molécule d'origine végétale, bien que biodégradable, ne pourrait que conduire à reproduire les désordres écologiques dus à la pression de sélection et à générer des résistances acquises décrites par Mouchès (2005).

Quand on examine l'utilisation des extraits végétaux en phytoprotection au cours du siècle passé, force est de constater que différents facteurs ont limité cet emploi (Isman, 2005 ; Regnault-Roger et Philogène, 2008). Parmi les obstacles rencontrés, certains sont d'ordre commercial, d'autres d'ordre toxicologique, écotoxicologique ou éthique.

La spécificité et la sélectivité de l'activité des molécules allélochimiques et leur biodégradabilité, qui présentent des avantages écologiques et environnementaux, limitent leur attractivité et leur utilisation pour l'agriculteur : en effet, l'étroitesse du spectre d'activité et la nécessité d'un renouvellement fréquent des traitements génèrent des coûts supplémentaires en termes de main-d'œuvre et de volumes d'intrants phytosanitaires utilisés. La qualité de la formulation commercialisée est fonction non seulement d'une teneur en matière active minimum, mais aussi de sa stabilité qui permet de conserver l'efficacité du produit. Intervient également la protection juridique des technologies innovantes qui garantit à l'industriel un retour sur les investissements. La disponibilité, l'accessibilité et le renouvellement de la matière première sont des facteurs d'importance. Pour être exploitable, une source végétale doit être abondante et se reproduire aisément, ce qui exclut les espèces arboricoles forestières qui poussent lentement ou les espèces rares et menacées d'extinction.

Un autre point à prendre en considération réside dans les effets non intentionnels sur les espèces non-cibles des extraits végétaux. En effet, ce n'est pas parce qu'ils sont naturels que les extraits végétaux sont dénués de toxicité. Parmi les substances actives qui ont été commercialisées au cours des siècles précédents figure la nicotine, extraite du tabac, 
très toxique pour les mammifères et les hommes, et qui a donné son nom au syndrome nicotinique (Regnault-Roger, 2005). Un autre exemple plus récent est l'élimination de la roténone de l'Annexe I des produits autorisés dans l'Union européenne (JOUE, 2008), car suspectée d'avoir une incidence sur la maladie de Parkinson (Betarbet et al., 2000). Il en est de même du neem extrait du margousier (Azadirachta indica A. Juss), un arbuste tropical abondant en Inde, qui contient de nombreux composés dont le plus actif est l'azadirachtine. La Commission européenne est en train d'étudier l'homologation de cette substance. L'azadirachtine inhibe la croissance des insectes en influençant la production des ecdystéroïdes, indispensables pour la mue des larves. Qualifié de «tree for solving global problems " (arbre pour résoudre les problèmes mondiaux) par le National Research Council en 1992, le neem est considéré par certains comme le biopesticide par excellence (Kleeberg, 2004). Les extraits de neem ont d'ailleurs fait l'objet de nombreuses expérimentations en Afrique de l'Ouest, notamment au Nigeria, que ce soient des extraits artisanaux ou une formulation appelée Reppellin ${ }^{\circledR}$. Ils ont été expérimentés sur la bruche Callosobruchus maculatus, la pyrale du niébé Maruca vitrata Fab., ainsi que sur des termites. Le neem est déjà homologué dans de nombreux pays où il est très utilisé, malgré un coût élevé de production, pour la protection des cultures fruitières, légumières, les plantes ornementales, les cultures en serre, les grandes cultures et le bétail (Copping, 2009), ainsi que pour des usages domestiques. Toutefois, des travaux récents indiquent que l'azadirachtine pourrait être chez l'homme un perturbateur endocrinien, mais des résultats contradictoires ont été relevés (Falconer et al., 2006 ; Pfau et al., 2009).

En matière de prospective, la recherche de nouvelles molécules végétales est toujours d'actualité. Les familles de plantes développant des molécules allélochimiques de défense sont ubiquistes, mais un grand nombre de ces familles sont tropicales, car cette flore se développe dans des conditions environnementales très favorables aux bioagresseurs. Ces plantes ont synthétisé, en réponse à ces attaques, des molécules de défense qui font actuellement l'objet de nombreuses recherches. Des recherches sont aussi menées afin d'étudier, non seulement des plantes qui sont traditionnellement connues pour receler des molécules ayant des activités phytopharmaceutiques ou des activités insecticides, mais aussi des plantes qui sont plus rares, car moins nombreuses et d'un accès plus difficile (Arnason et al., 2008). Ainsi, des extraits d'écorce de plantes appartenant aux genres Swietenia ou Cedrela contiennent des limonoïdes qui seraient des régulateurs de croissance pour la pyrale du maïs, Ostrina nubilalis. Le potentiel phytosanitaire de plusieurs limonoïdes identifiés dans d'autres bois exotiques comme les cèdres tropicaux (Cedrella odorata L., C. salvadorensis Standley) est également en cours d'étude.

Les Pipéracées - famille pantropicale - produisent non seulement des composés insecticides comme les pipéramides (Scott et al., 2003), mais aussi des synergistes naturels comme le dillapiol (Philogène, 2008). Des naphtoquinones, extraites d'une Scrophulariacée originaire des Andes chiliennes (Calceolaria andina L.), font l'objet d'études, car elles présentent une spécificité dans l'activité toxique qui épargnerait les insectes auxiliaires (Thacker, 2002).

Des familles de la flore tropicale, comme les Ancistocladaceae d'Afrique de l'Ouest (Ancistrocladus sp.) ou les Canellaceae (Pleodendron sp., Warburgia sp.) en Amérique centrale, sont étudiées comme sources de nouveaux réducteurs de croissance des insectes ou d'antiappétants (Arnason et al., 2008). 
Les cellules oléagineuses idioblastiques de l'avocatier (Persea americana Miller, Lauraceae) synthétisent de la persine, un analogue structural de la monolinoléine, qui inhibe la croissance des larves d'insectes généralistes comme Spodoptera exigua (Hübner) ou spécialistes (Bombyx mori L.) (Rodriguez-Saona et al., 2008).

Les huiles essentielles sont également très prospectées pour leurs qualités insecticides ou répulsives. Il a été constaté qu'au Togo des huiles essentielles extraites de plantes aromatiques sont utilisées pour la protection des stocks. L'activité insecticide des huiles essentielles de la famille des Poacées, Cymbopogon schoenanthus et Cymbopogon nardus, et d'une Lamiaceae, Ocimum basilicum, L. a été explorée sur Callosobruchus maculatus et ses hyménoptères parasitö̈des (Ketoh et al., 2002). Les huiles essentielles, constituées de mélanges de monoterpènes, sont des neurotoxiques qui agissent sur des cibles différentes en fonction de leur nature chimique. L'huile essentielle d'O. basilicum contient deux composants majeurs, le linalool et l'estragol, qui perturbent l'activité neuronale au niveau des insectes. Le linalool provoque une réduction de l'amplitude et de la fréquence des potentiels d'action puis entraîne une diminution de la phase de post-hyperpolarisation qui suit la transmission de l'influx nerveux. L'estragol induit plus spécifiquement une réduction de la phase de post-hyperpolarisation. La sommation de ces deux effets neurotoxiques provoque la paralysie, puis la mort des insectes. D'autres composés comme le terpinène -4-ol et le 1,8-cineole ont une action anticholinestérasique. Le thymol se fixe sur les récepteurs de l'acide gamma aminobutyrique (Gaba) associés aux canaux chlore situés sur la membrane des neurones post-synaptiques perturbant ainsi l'activité régulatrice de ces cellules (Huignard et al., 2008a). Ces monoterpènes qui agissent comme des fumigants naturels sont particulièrement adaptés pour un usage en milieu rural africain. Les huiles essentielles sont moins dangereuses, tout au moins aux doses employées, que les fumigants chimiques qui nécessitent des équipements de protection et un niveau de formation et d'information que les producteurs agricoles africains n'ont pas (voir chapitre 6).

Ces huiles essentielles proviennent des ressources végétales locales et procurent aux paysans une source appréciable de revenus, le procédé d'extraction des huiles essentielles par entraînement à la vapeur d'eau pouvant être réalisé dans les villages (Glitho et al., 2008). Plusieurs programmes d'utilisation des huiles essentielles extraites de Poaceae sur la gestion des populations des bruches du niébé sont actuellement menés en Afrique de l'Ouest. Un programme phare, car fédérateur entre quatre pays du golfe du Bénin, a été financé par le Conseil ouest et centre africain pour la recherche et le développement agricole (Coraf-Wecard). Il s'intitule " Potential use of botanical extracts on vegetables as alternative to chemical in peri-urban zones of Bénin, Côte d'Ivoire, Ghana and Togo » et a pour objectif d'évaluer l'efficacité de produits végétaux à base de neem (Azadirachta indica) et de papayer (Careca papaya) sur une culture régionale commune, le chou, soumise aux dégâts du ravageur Plutella xylostella, et sur une deuxième culture dont le choix est laissé à l'appréciation de chaque équipe nationale. Après la mise en place d'essais préliminaires en champ, une production en conditions réelles a été réalisée en partenariat avec les producteurs dans les quatre pays par le biais d'une formation « champécole-paysans » (FFS : Farmer-Field-School). À la fin du projet, il sera examiné s'il est possible de généraliser l'adoption de cette technologie (Regnault-Roger, 2009).

Utilisées et produites de manière moins artisanale aux États-Unis, en particulier sur la côte californienne, les huiles essentielles qui bénéficient d'une exemption dans la 
procédure d'homologation en Amérique du Nord, connaissent actuellement un succès commercial (Regnault-Roger et Philogène, 2008).

\section{Conclusion}

$\mathrm{Au}$ stade de nos connaissances actuelles, le développement de bio-insecticides extraits des plantes s'inscrit dans le cadre de l'agriculture et du développement durable, en proposant des solutions alternatives ou complémentaires à l'utilisation des pesticides organiques de synthèse pour la protection des cultures.

Le développement de formulations phytosanitaires à base de molécules allélochimiques présente plusieurs atouts. Ces spécialités sont en effet utilisables dans le cadre de l'agriculture biologique, si l'ensemble des principes actifs et des adjuvants est autorisé dans les cahiers des charges de cette démarche agricole, mais aussi dans l'agriculture conventionnelle, seules ou en association avec des pesticides organiques de synthèse. Leur emploi, dans l'un ou l'autre cas, s'accompagne de fait d'une diminution des volumes de pesticides chimiques utilisés. Des efforts sont cependant nécessaires pour promouvoir cette catégorie de produits phytopharmaceutiques. Ils requièrent de prendre en compte l'ensemble des bénéfices et des risques de cette technologie, dans ses aspects concernant aussi bien l'innocuité et l'efficacité des substances actives végétales que la qualité des produits commercialisés et la protection de l'environnement.

Le développement des bio-insecticides d'origine végétale concerne aujourd'hui tout particulièrement les pays tropicaux. En effet, ils possèdent une flore abondante et diversifiée qui représente une véritable richesse. Cette flore est susceptible de fournir de nouvelles sources de composés végétaux à propriétés phytopharmaceutiques. Encore faudrait-il que le développement de nouvelles substances actives d'origine végétale se fasse dans le respect des contraintes écologiques. Il est par ailleurs impératif que le savoir-faire des populations indigènes, qui utilisent ces plantes de manière empirique, soit valorisé et que leurs connaissances soient protégées notamment en matière de propriété intellectuelle. Ce n'est que dans ces conditions que le développement des bio-insecticides d'origine végétale rencontrera les critères du développement durable qui sont définis dans le rapport Brundtland (1987), à savoir : écologiquement sain, économiquement viable et socialement équitable. 


\title{
Chapitre 8
}

\section{Contrôle des Bruchinae par sélection variétale et génie génétique}

\author{
Jacques Huignard, Catherine Regnault-Roger
}

Les graines des légumineuses sauvages ne sont généralement attaquées que par une seule espèce de Bruchinae. Les autres espèces ne parviennent pas à se reproduire ou à se développer dans ces graines. Les légumineuses, en réponse aux pressions de sélection exercées par les différentes espèces de Bruchinae présentes dans l'écosystème, ont mis en place un important ensemble de défenses que seules des espèces spécialistes arrivent à contourner (Janzen, 1967).

Les graines contiennent de nombreux composés toxiques vis-à-vis des larves de Bruchinae ; ce sont des alcaloïdes, des saponines, des tannins, des acides aminés non protéiques ou des protéines antimétaboliques. Les systèmes de détoxification sont souvent complexes comme l'ont montré Rosenthal et al. (1977) en analysant les capacités de développement de Caryedes brasiliensis dans des graines de Dioclea megacarpa riche en L-canavanine, un acide aminé libre très toxique pour les autres espèces de Bruchinae.

Des systèmes de défenses mécaniques limitent la reproduction et le développement des larves. Les légumineuses produisent des graines de petite taille ayant des téguments très durs que les larves ne peuvent pas perforer ou des gousses non déhiscentes recouvertes de nombreux poils ou d'une gomme empêchant la ponte des femelles.

Les légumineuses peuvent mettre en place des systèmes de défense rapides en réponse aux attaques exercées par les insectes phytophages. Ainsi, les feuilles de niébé consommées par Spodoptera frugiperda réagissent aux sécrétions orales produites par les larves en produisant un éliciteur qui induit la synthèse des messages chimiques attirant les ennemis naturels de ce phytophage (Schmeltz et al., 2007). Les plantes peuvent réagir au dépôt d'un œuf en empêchant la pénétration des larves néonates comme cela a été observé au niveau des gousses de pois consommées par les larves de B. pisorum (Doss et al., 2000). 
La sélection variétale pratiquée chez un certain nombre d'espèces de légumineuses a favorisé une augmentation de la taille des graines, une diminution de l'épaisseur des téguments et une réduction de la concentration des composés secondaires dans les graines. Elle a ainsi permis une amélioration de la qualité nutritionnelle des graines de légumineuses et a favorisé la reproduction et le développement des bruches. C'est ce qui explique l'importance des pertes dans les cultures ou durant le stockage des graines de légumineuses cultivées.

Pour limiter ces pertes, les agronomes ont cherché à réintroduire à l'intérieur des graines des protéines antimétaboliques afin de lutter contre les insectes ravageurs. Ces protéines, thermolabiles, sont détruites lors de la cuisson des graines et ne modifient pas leurs qualités nutritionnelles.

Les lignées de légumineuses résistantes vis-à-vis des Bruchinae ont tout d'abord été obtenues par les techniques de sélection variétale. Elles proviennent de croisements entre des individus d'une même espèce ou d'espèces proches provenant de lignées sauvages et de lignées cultivées. Elles peuvent également être obtenues par un travail de screening, analysant les capacités de développement des bruches dans les graines des différentes lignées d'une même espèce de légumineuse, présentes dans une banque de gènes. C'est à partir d'une étude systématique de 6000 lignées de $V$. unguiculata que Singh (1977) a pu trouver une lignée résistante toxique pour les larves de C. maculatus.

Le développement de la biotechnologie a permis d'extraire des gènes codant pour des protéines antimétaboliques dans une espèce et de les introduire par transgenèse dans une autre espèce, afin de lui conférer une résistance vis-à-vis des larves de bruches.

La sélection assistée par marqueurs (SAM) est fondée sur une approche moléculaire et génétique ; c'est un outil puissant pour aider le sélectionneur à connaître les caractéristiques génétiques des plantes et à localiser les gènes de résistance vis-à-vis des pathogènes ou des insectes ravageurs. Il est possible d'établir, grâce aux marqueurs moléculaires, des cartes génétiques qui permettent l'identification des gènes ou des groupements de gènes impliqués dans les phénomènes de résistance.

Nous examinerons dans ce chapitre quelques exemples de sélection variétale ayant permis de limiter les pertes en graines et nous analyserons les cibles de ces facteurs de résistance au niveau des larves de bruches.

\section{La résistance acquise par sélection variétale}

\section{Les lignées néoplasmiques de Pisum sativum}

Ce mécanisme de résistance a été observé chez différentes lignées de $P$. sativum qui présentent le phénotype neoplasmic pod se caractérisant par l'aptitude de ses plantes à former des cals de cellules indifférenciées au niveau des gousses (néoplasme). Ces lignées sont homozygotes pour le gène neoplasmic pod $(\mathrm{Np} / \mathrm{Np})$. Doss et al., (2000) constatent que le dépôt d'un œuf de $B$. pisorum sur la gousse provoque un brunissement des tissus végétaux, puis stimule les divisions cellulaires entraînant la formation d'un cal. Ce cal, constitué de cellules indifférenciées, surélève l'œuf et empêche la pénétration de la larve $\mathrm{L}_{1}$ à l'intérieur de la gousse (figure 8.1). L'apparition du cal est due à une réaction de la plante à l'émission de substances déposées par la femelle de $B$. pisorum sur la gousse lors de la phase de ponte. Quatre substances appelées « bruchines » ont 
été extraites à partir de broyats de $B$. pisorum ou de $C$. maculatus. Ce sont de longues chaînes $\alpha, \omega$ diols estérifiées par l'acide 3-hydroxypropanoïque. Ces bruchines activent un gène MtN19-like qui induit des divisions cellulaires et la formation de nodules au niveau de la gousse (Doss, 2005). Ce gène présente des séquences similaires à celles du gène MtN19 (Medicago truculata Nodulin) connu pour induire la formation de cals au niveau des racines de luzerne. En plus de cette action au niveau des divisions cellulaires, la bruchine $\mathrm{B}$ active le gène CYP93C18 qui permet la synthèse d'une phytoalexine de la famille des isoflavones, la pisatine. Cette substance intervient dans la défense de $P$. sativum contre des attaques fongiques et microbiennes et exerce un effet répulsif visà-vis des larves d'insectes et sans doute de bruches (Cooper et al., 2005).
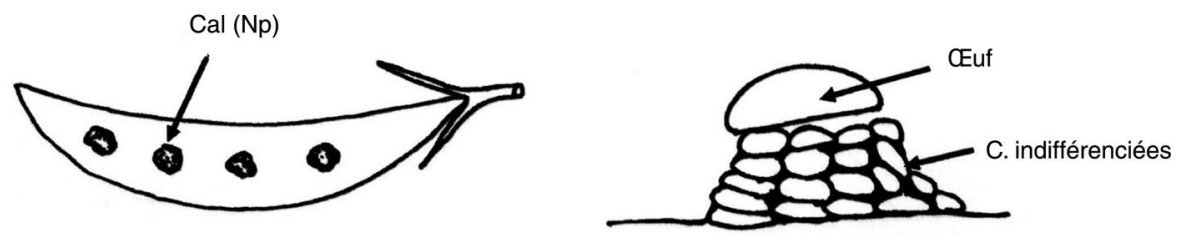

Figure 8.1. Gousse de $P$. sativum de la lignée $\mathrm{Np}$ avec des cals apparus huit jours après une application de bruchine B et vue détaillée d'un cal avec un œuf de B. pisorum au-dessus des cellules indifférenciées (C. indifférenciées) (J. Huignard, d'après Doss et al., 2000).

\section{Les lignées de $V$. unguiculata produisant des graines riches en inhibiteurs de protéases et en viciline}

\section{Les inhibiteurs de protéases}

Des lignées $V$. unguiculata appelées TVu 2027 et IT81D-1045 dont les graines sont résistantes vis-à-vis des larves de $C$. maculatus ont été sélectionnées à l'Institut international d'agronomie tropicale au Nigeria. Les femelles pondent sur les graines de la lignée TVu 2027, mais le taux de survie des larves est inférieur à $10 \%$ (Singh et Singh, 1990). La forte mortalité serait due selon Gatehouse et Boulter (1983) à la présence à l'intérieur des graines de cette lignée d'un taux élevé d'inhibiteur de trypsine (cowpea trypsin inhibitor, CPTI). Cette protéine a été extraite des graines et purifiée. Elle est mélangée à de la farine de graines de niébé d'une lignée sensible et introduite dans des capsules permettant le développement de larves de C. maculatus. Le taux de mortalité dépend de la concentration d'inhibiteur de trypsine ; il est de $100 \%$ lorsque la concentration est de $0,8 \%$.

Des études complémentaires montrent que les larves de C. maculatus sont capables de détourner ces défenses et de se développer dans un milieu riche en inhibiteurs de trypsine comme l'ont constaté Zhu-Salzman et al. (2003). Lorsque des larves se développent dans de la farine de niébé contenant un inhibiteur de protéases de la famille des cystatines extrait du soja (soybean cystacin : $\mathrm{scN}$ ), la croissance des larves $\mathrm{L}_{1}, \mathrm{~L}_{2}, \mathrm{~L}_{3}$ est ralentie, car il y a une diminution des prises alimentaires. En revanche, les larves $\mathrm{L}_{4}$ se nourrissent normalement et se transforment en nymphes, puis en adultes sans mortalité importante. Ces auteurs ont analysé in vitro l'influence des $\mathrm{scN}$ sur l'activité des cystéines protéases 
(C. $m \mathrm{CP})$ produites par l'intestin moyen des larves de C. maculatus. Ces enzymes jouent un rôle majeur dans la digestion des protéines. Elles sont produites par une famille multigénique, comprenant au moins 30 gènes qui ont été séquencés. Lorsque les larves $\mathrm{L}_{1}$ consomment de la farine de niébé contenant du $\mathrm{scN}$, un certain nombre de gènes codant pour des protéases digestives sensibles à cet inhibiteur sont inactivés. Les enzymes ne sont pas produites et les protéines ne sont pas (ou ne sont que partiellement) digérées, ce qui explique le ralentissement de la croissance. D'autres gènes deviennent alors actifs et permettent la synthèse de nouvelles $C . m \mathrm{CP}$ protéases insensibles à $\mathrm{scN}$ qui digèrent les protéines alimentaires (figure 8.2). Ce mécanisme se met progressivement en place et les nouvelles protéases ne deviennent actives qu'au stade $\mathrm{L}_{4}$, ce qui explique la reprise, puis l'accélération de la croissance à ce stade. Il y a donc eu un remodelage qualitatif et quantitatif des C.m CP produites par l'intestin moyen de C. maculatus en présence de $\mathrm{scN}$. Les modifications géniques induites par les inhibiteurs de protéase agissent sur la synthèse et l'association des propeptides à partir desquels se constituent les protéases (Ahn et al., 2007).

L'existence de ce réservoir génétique est un avantage considérable pour cette espèce puisqu'elle lui confère une importante adaptabilité lorsque différents substrats alimentaires sont présents dans les graines. De tels mécanismes de défense vis-à-vis d'autres inhibiteurs existent certainement et expliquent les capacités de développement de C. maculatus et la difficulté d'obtenir des génotypes résistants vis-à-vis de ce Bruchinae, tout au moins en utilisant les inhibiteurs de trypsine comme facteurs de résistance.

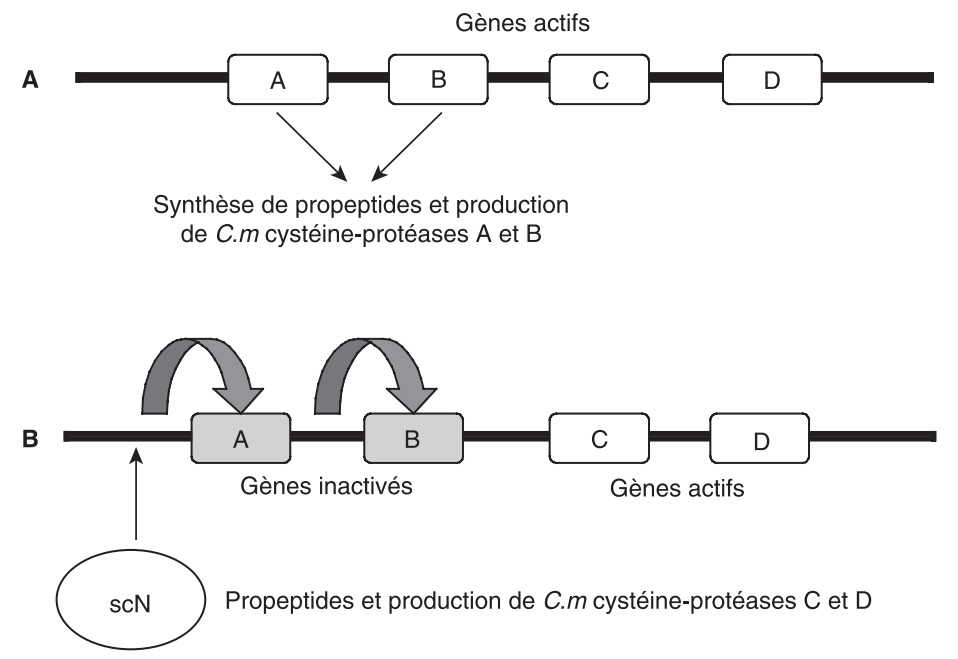

Figure 8.2. Représentation schématique du remodelage chez $C$. maculatus des C.m cystéine-protéases digestives sous l'influence de l'inhibiteur de protéases digestives (soybean cystacin: $\mathrm{scN}$ ) ingéré par les larves (d'après Ahn et al., 2007).

\section{Les vicilines}

Les graines des lignées résistantes vis-à-vis de C. maculatus TVu 2027 ou IT81D1045 contiennent non seulement des inhibiteurs de trypsine, mais également un variant de viciline. La consommation de ce variant est le principal facteur de mortalité lors du 
développement des larves (Macedo et al., 1993). La viciline est une des protéines de réserve contenue dans les graines de $V$. unguiculata. C'est une protéine soluble à structure trimérique du type des globulines dont la masse moléculaire est estimée entre 150 et $190 \mathrm{kDa}$. Elle est caractérisée par son coefficient de sédimentation (7S globuline). Il existe différents variants de viciline qui sont produits par une famille multigénique.

Le variant de viciline trouvé dans les graines des lignées résistantes présente une très forte affinité pour les structures riches en chitine qui tapissent les microvillosités des cellules intestinales de l'intestin moyen des larves (figure 8.3). La présence de viciline modifie la perméabilité des cellules, ce qui entraîne une réduction de la quantité de protéases sécrétées par les cellules intestinales dans la lumière de l'intestin moyen. Les protéines contenues dans les aliments ne sont pas ou sont peu digérées. L'absorption des nutriments est également fortement ralentie (Sales et al., 2000, 2005).

Les variants de viciline contenus dans les cotylédons des lignées de $V$. unguiculata sensibles n'ont qu'une faible affinité vis-à-vis des structures chitineuses de l'intestin moyen de $C$. maculatus. Ces globulines sont reconnues par des récepteurs spécifiques se trouvant sur la membrane des cellules intestinales et traversent la paroi intestinale sans être transformées par un phénomène de transcytose. Elles s'accumulent dans l'hémolymphe, puis sont séquestrées au stade larvaire et au stade adulte dans les cellules du corps gras, des tubes de Malpighi et de l'intestin moyen (Uchôa et al., 2006).
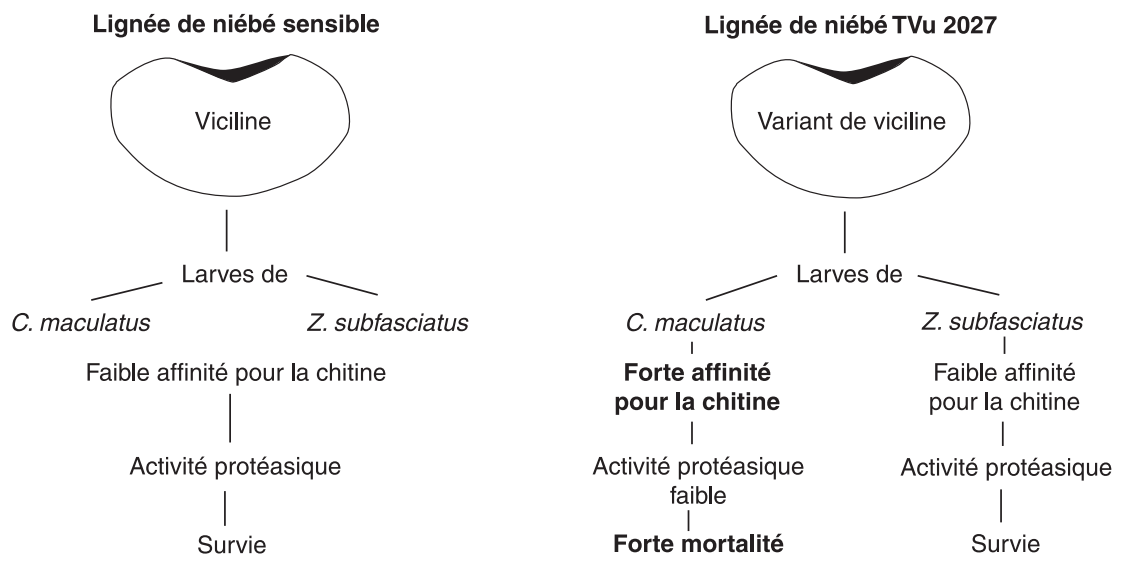

Figure 8.3. Représentation schématique de l'action de la viciline ingérée par les larves de C. maculatus et Z. subfasciatus sur leur développement post-embryonnaire (d'après Sales et al., 2000).

Les vicilines contenues dans d'autres graines de légumineuses comme Vigna angularis, Canavalia ensiformis, Glycine max, Phaseolus vulgaris et $P$. lunatus ont également une grande affinité vis-à-vis de la chitine. Ces protéines issues d'espèces végétales, qui sont phylogénétiquement éloignées de $V$. unguiculata, provoquent une forte mortalité au cours du développement des larves de C. maculatus.

\section{Les lignées de Phaseolus riches en arcelines}

Un certain nombre de variétés sauvages de $P$. vulgaris et de $P$. acutifolius contiennent une famille de protéines appelées arcelines. Ce sont des protéines de la famille des 
phytohémagglutinines qui sont formées de chaînes de glycoprotéines et d'oligosaccharides. Sept variants d'arceline ont été décrits ; l'arceline 1 et l'arceline 5 ont un effet inhibiteur sur le développement de Z. subfasciatus, mais sont peu toxiques vis-à-vis d'A. obtectus.

L'arceline 1, contenue dans les graines de certaines lignées sauvages de P. vulgaris, est très toxique pour Z. subfaciatus. Lorsqu'elle se trouve dans l'intestin moyen, elle interagit avec les glycoprotéines membranaires de l'intestin moyen, ce qui provoque une dégradation de l'épithélium intestinal. Elle pénètre ensuite dans l'hémolymphe. Ce sont les modifications structurales et fonctionnelles des cellules intestinales qui causent la mort des larves de $Z$. subfasciatus. L'arceline 1 ne provoque, en revanche, aucune modification de la structure de l'épithélium intestinal chez $A$. obtectus et ne passe pas dans l'hémolymphe (Paes et al., 2000).

Les graines de la lignée de P. vulgaris G02771 ou de la lignée de P. acutifolius N1576 produisent des graines riches en arceline 5 qui ne permettent pas le développement de Z. subfasciatus (Goossens et al., 2000). Ces auteurs ont réalisé des P. acutifolius transgéniques dans lesquels ils ont introduit le gène Arc 5 extrait de $P$. vulgaris. Ce gène s'exprime dans cette lignée transgénique, mais les graines qu'elle produit ne provoquent qu'une faible mortalité chez Z. subfasciatus. Le phénomène est en fait plus complexe et un autre facteur de mortalité, encore non déterminé, est associé à l'arceline 5 dans les graines de la lignée G02771. Les graines des lignées G02771 et N1576 ne provoquent qu'une faible mortalité chez $A$. obtectus, mais entraînent un allongement de la durée du développement post-embryonnaire.

Certaines lignées de haricot, dont les graines sont riches en arceline, ont été sélectionnées au Ciat (Internal Center for Tropical Agriculture) en Colombie. Ces graines sont non seulement résistantes vis-à-vis des larves de Z. subfasciatus, mais perturbent également le développement et la physiologie des adultes d'A. obtectus. Le développement postembryonnaire d'A. obtectus est plus long que dans les graines sans arceline et la fécondité des femelles est plus faible. La présence prolongée des larves et l'absence d'arceline dans l'hémolymphe sont des facteurs favorables pour la lutte biologique à l'aide de D. basalis (Velten et al. 2008).

\section{Les lignées résistantes obtenues par transgenèse}

L'intestin moyen des larves de Bruchinae produit des $\alpha$-amylases qui digèrent l'amidon contenu dans les graines de légumineuses. Les graines de $P$. vulgaris ne permettent pas le développement de $C$. maculatus et de $C$. chinensis. Elles contiennent des inhibiteurs d' $\alpha$-amylase qui empêchent la digestion de l'amidon et provoquent la mort des larves de ces deux espèces et de Bruchus pisorum (Ishimoto et al., 1996). Ces inhibiteurs sont inactifs sur les $\alpha$-amylases produites par l'intestin moyen de Z. subfasciatus et d'A. obtectus dont la plante-hôte est $P$. vulgaris. Deux inhibiteurs ont été isolés à partir des graines de haricot : $\alpha \mathrm{AI}-1$ est extrait de lignées cultivées, $\alpha \mathrm{AI}-2$ de lignées sauvages ; ce sont des glycoprotéines qui présentent en commun $78 \%$ de leurs séquences en acides aminés.

Les gènes codant pour ces protéines ont été séquencés et introduits par transgenèse dans des légumineuses, afin de créer des lignées dont les graines sont résistantes vis-à-vis des bruches. 


\section{Les lignées de $P$. sativum transgéniques}

Le gène codant pour $\alpha \mathrm{AI}-1$, extrait de $P$. vulgaris, est transféré dans le génome du pois et s'exprime dans cette plante. Les lignées de pois transgéniques ainsi créées assurent une bonne protection contre B. pisorum dans les cultures (Morton et al., 2000). L'inhibiteur $\alpha \mathrm{AI}-1$ présent dans les graines des lignées de pois transgéniques Laura et Greenfeast provoque une forte mortalité au stade $\mathrm{L}_{1}$ dès que les larves commencent à se nourrir. L'expression de ce gène dépend des conditions environnementales : un stress hydrique associé à des températures élevées $\left(32: 27^{\circ} \mathrm{C}\right)$ durant la formation des gousses réduit le nombre de graines et le taux de $\alpha \mathrm{AI}-1$, ce qui entraîne une augmentation des pertes dues à $B$. pisorum. Ainsi, $39 \%$ des œufs de $B$. pisorum se développent et donnent naissance à des adultes. Ce taux de survie n'est que de 1,2\% lorsque les larves se développent dans des graines de pois transgéniques de la même lignée, mais placées en atmosphère plus humide et dans les conditions $27: 22^{\circ} \mathrm{C}$ durant la phase de formation des gousses. Ces dernières conditions accroissent de 36,3 \% le taux de $\alpha$ AI-1 (De Sousa-Majer et al., 2004). Les graines des lignées transgéniques Laura et Dundale dans lesquelles a été introduit le gène codant pour $\alpha \mathrm{AI}-2$ ne provoquent pas de mortalité importante au stade $\mathrm{L}_{1}$, mais le développement post-embryonnaire de B. pisorum est considérablement ralenti (De Sousa-Majer et al., 2007).

Les graines des lignées transgéniques $\alpha \mathrm{AI}-1$ ne provoquent aucune perturbation du métabolisme lorsqu'elles sont consommées par des rats. En revanche, elles peuvent avoir une certaine influence sur le métabolisme des volailles en perturbant la digestion des glucides (De Sousa-Majer et al., 2007). Prescott et al. (2005) constatent que l' $\alpha$-AI introduite par transgénèse dans les pois transgéniques présente une structure différente de celle trouvée dans les haricots et interagit avec d'autres protéines. Il faudrait vérifier que cela n'entraîne pas de réactions allergiques chez les consommateurs.

\section{Les lignées de $V$. unguiculata et de Cicer arietinum transgéniques}

Le gène $\alpha \mathrm{AI}-1$, extrait de P. vulgaris, est introduit par l'intermédiaire d'Agrobacterium tumefasciens dans le génome d'une lignée de $V$. unguiculata cultivée en Inde. Ce gène s'exprime dans cette lignée transgénique et se maintient dans la descendance. La mortalité larvaire est de $70 \%$ chez $C$. maculatus et de $80 \%$ chez $C$. chinensis. Les adultes émergeant de ces graines sont de petite taille et ont une durée de vie très limitée (Solleti et al., 2008). On rappellera que l'introduction d'un gène codant pour la protéine CRY extrait de Bacillus thuringiensis confère une résistance vis-à-vis du foreur de gousses Maruca vitrata (Adesoye et al., 2008).

Des lignées de pois chiche (Cicer arietinum) transgéniques produisant $\alpha \mathrm{AI}-1$ ont également été obtenues (Sarmah et al., 2004). Leurs graines ne permettent pas le développement de C. maculatus et de $C$. chinensis.

Ces travaux récents, réalisés en conditions confinées, ne semblent pas avoir analysé les conséquences de cette transformation génétique sur la qualité nutritionnelle des graines, et des essais en plein champ ne paraissent pas encore avoir été entrepris. La présence des inhibiteurs d' $\alpha$-amylase dans les graines pourrait également influencer selon Luthi et al., (2010) le développement des parasitoïdes larvophages et nuire au contrôle biologique des espèces insensibles à cet inhibiteur comme A. obtectus. 


\section{La sélection assistée par marqueurs (SAM) de lignées résistantes}

Les études génétiques permettent l'établissement d'une cartographie des QTL (Quantitative Trait Loci) afin de localiser les loci qui contribuent aux mécanismes de résistance des légumineuses vis-à-vis des Bruchinae. Certains sont caractéristiques d'une composante de la résistance ou d'un type de résistance ou d'une méthode d'innoculation (Ouellet et al., 2005). Assembler ces différents allèles (pyramidage) permet d'obtenir ainsi des génotypes qui confèrent aux plantes la capacité à mieux réagir contre les insectes. L'étude cartographique des chevauchements des QTL associés aux phénomènes de résistance avec ceux associés à la variance phénotypique de molécules allélochimiques présent dans les graines constitue une étape essentielle de la démarche pour cibler les gènes de résistance.

Somta et al. (2008) ont analysé les phénomènes de résistance de Vigna angularis vis-à-vis de $C$. maculatus et de $C$. chinensis. Ils ont croisé une lignée sensible à ces deux Bruchinae avec $V$. nepalensis, une espèce proche ne permettant pas le développement des bruches. La lignée hybride obtenue ne permet pas non plus le développement des insectes. Une analyse génétique a montré que la résistance de cette lignée vis-à-vis de C. chinensis était liée à 5 QTL et à 2 QTL pour la résistance vis-à-vis de C. maculatus. Les localisations des QTL étant différentes, il faudrait déterminer plus précisément les facteurs qui provoquent la mortalité des deux espèces de Bruchinae.

L'étude de la lignée sauvage de $V$. radiata (TC11966) a permis de localiser un gène conférant une résistance vis-à-vis de $C$. chinensis. Un gène de résistance a été localisé dans la lignée TC11966 ; ce gène occupe la même position que le gène Va, contrôlant la production d'acide vignalique, un alcaloïde cyclo-peptidique qui est très toxique pour les larves de C. chinensis (Somta et Srinives, 2007). On pourrait émettre l'hypothèse que la mortalité observée lors du développement larvaire soit due à la présence de cet acide dans les graines.

L'efficacité de la sélection assistée par marqueurs réside dans la force de l'association entre les marqueurs moléculaires et le caractère recherché (Ramalingam et al., 2003). Le travail d'identification d'un facteur de résistance et la découverte d'association avec des QTL de résistance se positionne comme une étape clé dans une stratégie de recherche de gènes candidats. Un des prolongements qui peut s'opérer à partir de cette démarche est la mise en oeuvre du génie génétique, afin de surexprimer l'expression génétique du végétal pour une intensification de la production des composés allélochimiques d'autodéfense que son propre métabolisme élabore.

\section{Conclusion}

L'utilisation de lignées de légumineuses cultivées résistantes vis-à-vis des bruches, obtenues soit par sélection soit par transgenèse, représente un mode de contrôle efficace de ces ravageurs et limite l'utilisation de traitements chimiques. Les graines de légumineuses sauvages contiennent de nombreux composés secondaires et des molécules protéiques encore mal connus dont certains méritent sans doute d'être exploités. Le développement des méthodes de sélection assistée par marqueurs va permettre de caractériser 
les gènes impliqués dans la biosynthèse de ces composés, puis de les incorporer dans le génome des plantes cultivées afin de les rendre résistantes. Ces méthodes de lutte peuvent cependant poser un certain nombre de problèmes qu'il conviendra d'appréhender avant de les développer à grande échelle. Il faut rechercher si les transformations introduites sont stables et n'altèrent pas la qualité nutritionnelle ou la qualité gustative des graines. Il est important de suivre les capacités de développement des insectes afin de voir s'il n'y a pas au cours du temps sélection d'individus capables de détoxifier les composés secondaires présents dans les graines et de provoquer à nouveau des pertes. Il faut également surveiller l'apparition d'éventuels phénomènes de résurgence où le contrôle du ravageur principal laisse une niche écologique vacante pour un ravageur secondaire. Ces méthodes de lutte évitent l'utilisation de pesticides au niveau des stocks de graines et peuvent s'avérer très intéressantes pour les agriculteurs si les lignées sélectionnées sont facilement disponibles et peu onéreuses. 



\title{
Chapitre 9
}

\section{Méthodes de biocontrôle par lutte biologique impliquant des macro-organismes}

\author{
Jacques Huignard, Isabelle Adolé Glitho, Mbacke Sembene
}

Des hyménoptères parasitoïdes se développent aux dépens des larves, des nymphes ou des œufs des Coléoptères Bruchinae. Ils sont présents dans les cultures et ils peuvent, comme leurs hôtes, se reproduire puis se développer dans les systèmes de stockage après la récolte des graines. Les taux de parasitisme dans les cultures et au début du stockage sont généralement faibles et les parasitoïdes ne peuvent pas contrôler les populations de bruches. La lutte biologique peut se faire à deux niveaux :

- soit en lâchant des parasitoïdes adultes à l'intérieur du système de stockage afin d'augmenter la pression parasitaire. Il faut avoir une bonne connaissance des conditions de reproduction et de développement des parasitoïdes et du taux de contamination des graines au moment du lâcher. Cette méthode de lutte nécessite la mise en place d'élevages de parasitoïdes ;

- soit en favorisant la reproduction et le développement des hyménoptères parasitoïdes qui sont présents dans le système de stockage grâce à l'apport de nutriments qui accroissent la longévité des adultes et augmentent la fécondité des femelles.

Des essais de lutte biologique contre les Bruchinae se développant aux dépens du niébé (Sanon et al., 1998, van Huis et al., 2002) ou du haricot (Schmale et al., 2006) ont été réalisés. Nous présenterons ces travaux et analyserons les différents problèmes que pose le développement de cette méthode de lutte dans les systèmes de stockage.

\section{La lutte biologique dans les systèmes de stockage de niébé à l'aide des hyménoptères parasitoïdes}

En zone sahélienne sèche au Niger, deux Eupelmidae, Eupelmus orientalis et Eupemus vuilleti, et un Pteromalidae, Dinarmus basalis, (planche couleur III photos 10 à 13), se développent aux dépens des larves et des nymphes de Bruchidius atrolineatus et de 
Callosobruchus maculatus dans les cultures de niébé, mais les taux de parasitisme sont toujours inférieurs à $10 \%$. Lors de la récolte, les larves de parasitoïdes sont introduites avec leurs hôtes dans les stocks de graines et les adultes de la nouvelle génération émergent à ce niveau. Les adultes d'E. orientalis sont incapables de se reproduire dans les systèmes de stockage et quittent rapidement cet environnement confiné. Les conditions de maintien de cette espèce dans la nature durant la saison sèche ne sont pas connues. En revanche, $D$. basalis et $E$. vuilleti peuvent se reproduire et se développer dans les systèmes de stockage.

Lorsque l'on suit les variations des effectifs d'adultes de bruches (Bruchidius atrolineatus et Callosobruchus maculatus) dans des stocks de graines récoltées dans les cultures de niébé, on constate que l'accroissement des effectifs de B. atrolineatus est limité en raison de l'apparition d'un fort taux d'adultes en diapause reproductrice à partir du mois de décembre. C. maculatus devient rapidement l'espèce dominante et ses effectifs augmentent progressivement malgré la présence des deux espèces de parasitoïdes (figure 9.1). E. vuilleti est l'espèce la plus abondante; ses effectifs s'accroissent au cours du temps tandis que les populations de D. basalis se maintiennent toujours à un faible niveau. Les deux espèces de parasitoïdes ne peuvent pas contrôler les populations de C. maculatus et les pertes en fin de stockage sont de l'ordre de $600 \mathrm{~g}$ par kilo de graines. Cette absence de contrôle est due au faible taux de parasitisme au début du stockage et à la compétition interspécifique entre les deux espèces de parasitoïdes qui est favorable à E. vuilleti (Monge et al., 1995).

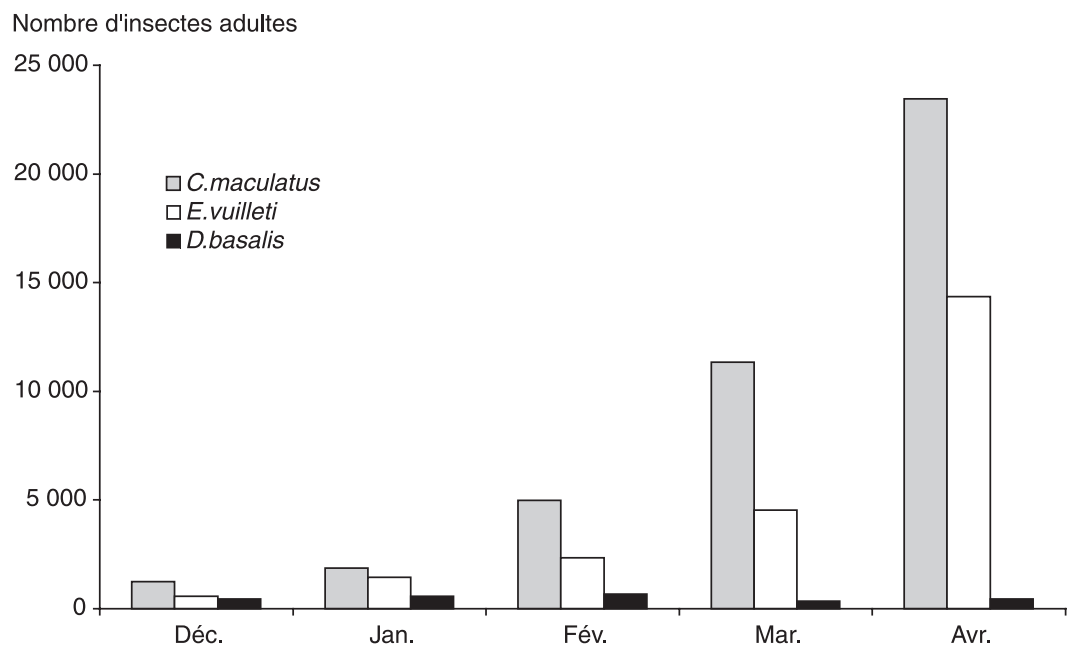

Figure 9.1. Variations temporelles des effectifs de C. maculatus et de ses parasitoïdes E. vuilleti et $D$. basalis dans un grenier expérimental contenant $3 \mathrm{~kg}$ de graines de niébé récoltées dans des cultures dans la région de Niamey au Niger.

\section{Les deux espèces de parasitoïdes larvaires sont-elles de bons auxiliaires de lutte biologique?}

Jerwis et Kid (1966) ont défini les caractéristiques biologiques que doit présenter un bon auxiliaire de lutte biologique. Sanon et al. (1998) ont analysé ces caractéristiques chez D. basalis et E. vuilleti. 


\section{Cas de D. basalis}

C'est un ectoparasitoïde capable de se reproduire aux dépens des larves et nymphes de diverses espèces de Bruchinae qui se développent elles-mêmes aux dépens des graines de légumineuses cultivées (niébé, haricot) dans les cultures, puis dans les stocks.

Le taux intrinsèque d'accroissement de D. basalis calculé d'après la formule de Giga et Smith (1983) est toujours plus élevé que celui de son hôte quelles que soient les conditions thermiques (figure 9.2).

L'accroissement du nombre d'hôtes disponibles entraîne une augmentation rapide du nombre d'hôtes parasités. Lorsque le nombre d'hôtes disponibles est supérieur ou égal à 30 , le nombre de larves parasitées ne varie plus de manière significative, quel que soit le nombre d'hôtes disponibles.

Les femelles de D. basalis ont de très bonnes capacités de détection de la qualité des hôtes. Elles sont attirées dans un premier temps par l'odeur des graines de niébé, ce qui permet la localisation de l'habitat de l'hôte, puis dans un second temps par l'odeur des larves ou des nymphes de $C$. maculatus. Cette reconnaissance résulte d'un processus de mémorisation des conditions environmentales au début de la vie imaginale. Les femelles sont capables de se déplacer à l'intérieur d'un système de stockage et de localiser rapidement les larves de bruches se développant à l'intérieur des graines (Gauthier et al., 1999).

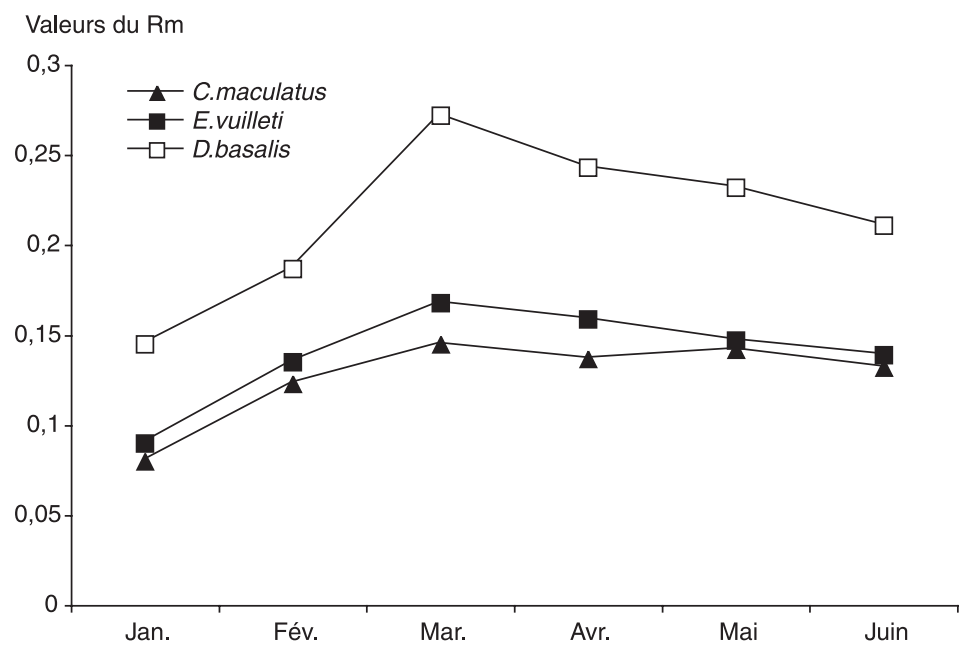

Figure 9.2. Variations du Rm : $\operatorname{Logn} \mathrm{N} x \mathrm{~S} / \mathrm{T}+1 / 2 \mathrm{~L}$.

$\mathrm{N}$ : fécondité, $\mathrm{S}$ : taux de survie larvaire, $\mathrm{T}$ : durée de développement, $\mathrm{L}$ : durée de vie des adultes. Ces paramètres ont été déterminés au cours d'une période de six mois; les températures moyennes ont varié de $25^{\circ} \mathrm{C}$ en janvier et février, à $34{ }^{\circ} \mathrm{C}$ en avril et mai.

Les femelles de D. basalis en situation de compétition intra ou interspécifique évitent le superparasitisme et le multiparasitisme. Un tel comportement est lié à la reconnaissance d'informations chimiques issues de larves-hôtes parasitées par un congénère ou par l'espèce concurrente, E. vuilleti. Il favorise l'émission des œufs sur les hôtes sains et accroît les chances de développement de la descendance.

Si l'on se réfère aux critères définis par Jerwis et Kid, D. basalis est donc un bon auxiliaire de lutte biologique. 


\section{Cas d'Eupelmus vuilleti}

Ce parasitoïde présente des capacités parasitaires différentes de celles de D. basalis. Lorsque l'on compare les deux espèces placées dans les mêmes conditions climatiques $\left(30{ }^{\circ} \mathrm{C}, 12: 12 \mathrm{~h} \mathrm{LD}\right)$, on constate que la durée de développement d'E. vuilleti (15 à 17 jours à $33{ }^{\circ} \mathrm{C}$ ) est plus longue que celle de $D$.basalis (12 à 14 jours). Les femelles d'E. vuilleti pondent moins d'œufs au cours de leur vie imaginale (120 œufs) que celles de $D$. basalis (250 œufs) et le taux de survie des larves est plus réduit en raison d'un fort taux de superparasitisme (Darrouzet et al., 2002). E. vuilleti est en effet très agressif vis-à-vis de ses compétiteurs, quel que soit le type de superparasitisme (self ou superparasitisme). Dans ces conditions, le taux intrinsèque d'accroissement de la population d'E. vuilleti est plus faible que celui de D. basalis quelles que soient les variations thermiques (figure 9.2) ; il est proche de celui de son hôte, $C$. maculatus.

\section{Essais de lutte biologique en conditions expérimentales au Burkina Faso}

Des jarres en terre cuite de $50 \mathrm{~L}$ contenant $3 \mathrm{~kg}$ de graines de niébé récoltées dans les cultures dans la région de Bobo-Dioulasso sont placées dans les conditions naturelles durant sept mois et demi de novembre à juin. Dans cette zone, seul D. basalis est présent dans les cultures de niébé, puis dans les stocks. Les effectifs d'adultes sont suivis, soit en l'absence de toute nouvelle introduction de parasitoïdes (lot témoin), soit après des lâchers d'adultes de D. basalis.

Dans le lot témoin, le nombre de parasitoïdes présents au début du stockage ne permet pas de contrôler les populations de C. maculatus qui s'accroissent rapidement ; les différentes générations qui se succèdent provoquant des pertes de plus en plus importantes (figure 9.3). Les effectifs d'adultes de parasitoïdes ne deviennent importants qu'à la fin du stockage. Ils provoquent une chute du nombre de bruches, mais les dégâts ont déjà eu lieu. Les pertes en poids de graines sont de l'ordre de 650 grammes par kilo au bout de sept mois de stockage.

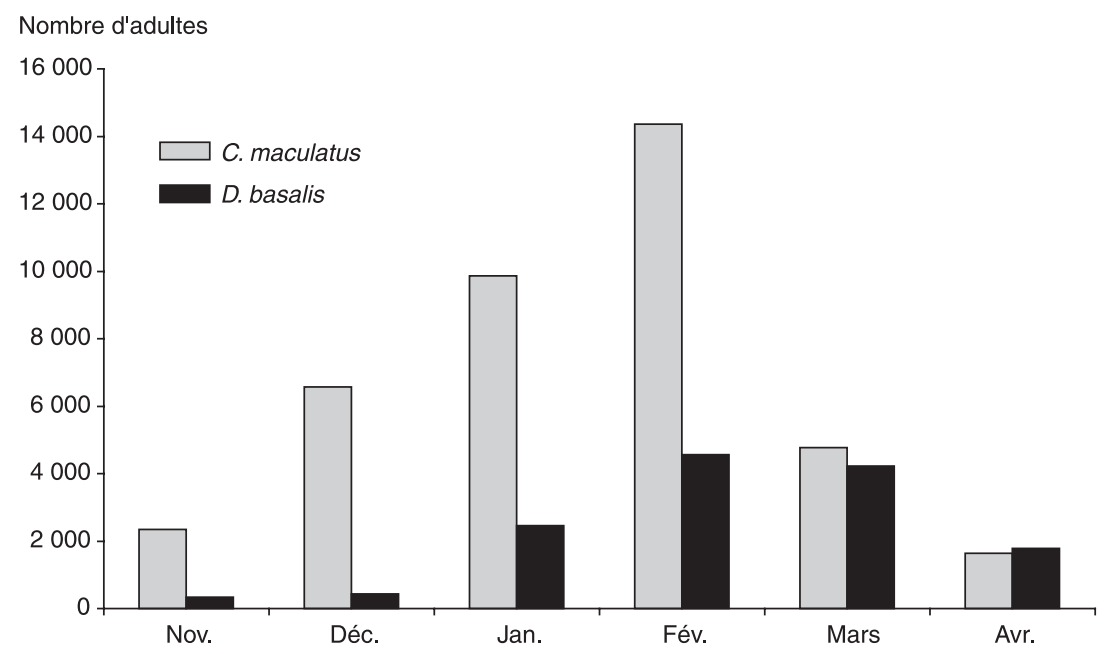

Figure 9.3. Variations des effectifs de $C$. maculatus et de $D$. basalis au cours de sept mois successifs après le stockage de graines de niébé récoltées dans des cultures en octobre. 
Pour le lot traité en lutte biologique, il faut dans un premier temps réaliser des essais en laboratoire qui prennent en compte l'activité reproductrice et les conditions de développement de $D$. basalis. Les résultats obtenus montrent que le lâcher d'un couple d'adultes pour 20 hôtes au début du stockage peut assurer un contrôle efficace des effectifs de $C$. maculatus. Il convient donc d'estimer sur un lot de graines la contamination initiale en suivant les émergences d'adultes de bruches et d'adapter le nombre d'adultes de parasitoïdes qui doivent être introduits dans le stock à cette contamination. La contamination initiale étant estimée à 2000 larves et nymphes de C. maculatus, 100 couples de D. basalis sont introduits au début du stockage. Ils ont limité l'accroissement des effectifs de bruches dès leur introduction et leurs descendants contrôlent bien les populations du ravageur (figure 9.4). Les parasitoïdes introduits ont provoqué une réduction de 94,7\% des effectifs de C. maculatus par rapport au lot témoin non traité. Les pertes en poids de graines sont estimées à $103 \mathrm{~g}$ par kilo.

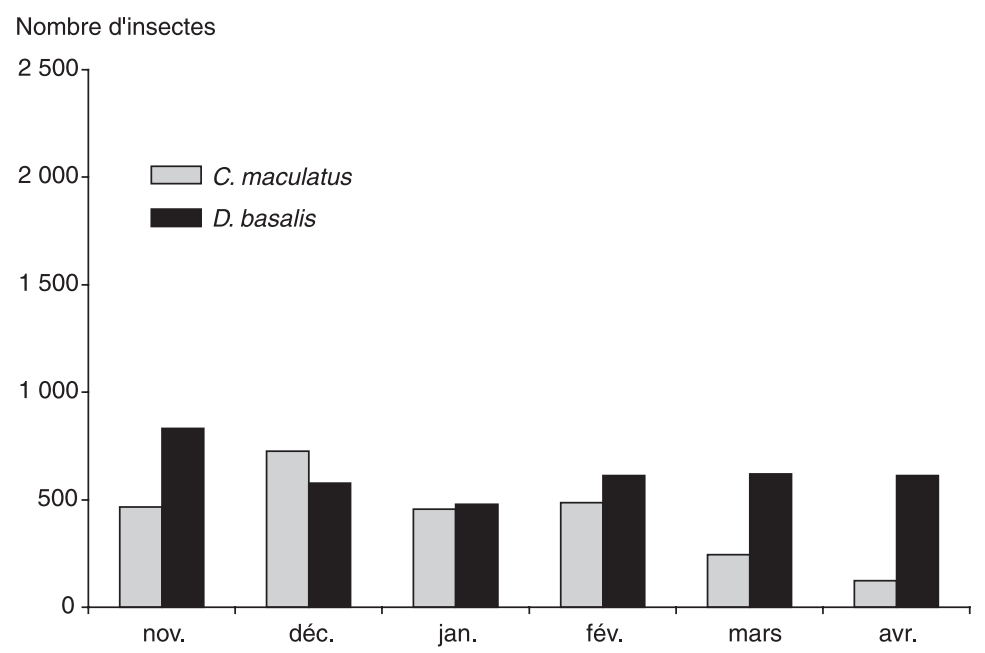

Figure 9.4. Variations des effectifs de bruches et de D. basalis émergeant au cours du temps dans un grenier après le lâcher de 100 couples de parasitoïdes au début du stockage.

Un seul lâcher dans ces conditions peut assurer un contrôle efficace des populations de ravageurs ; des introductions supplémentaires d'adultes de D. basalis au cours du stockage n'ont pas d'effets significatifs sur les effectifs de bruches (Sanon et al., 1998).

\section{Essais de lutte biologique avec $D$. basalis en présence d'E. vuilleti}

La présence d'E. vuilleti dans les systèmes de stockage peut réduire l'efficacité de la lutte biologique contre $C$. maculatus. Un seul lâcher ne permet pas de contrôler la population de ravageurs, car la compétition interspécifique est toujours favorable à E. vuilleti qui limite l'accroissement des populations de $D$. basalis et ne contrôle que très partiellement les populations de C. maculatus. Les pertes en poids de graines sont de 450 g par kilo. Les femelles d'E. vuilleti sont très attirées par les larves de bruches parasitées par $D$. basalis. Elles injectent un venin à l'intérieur du parasitoïde à l'aide de leur 
ovipositeur et le tuent. On peut accroître l'efficacité de la lutte biologique en augmentant le nombre d'adultes de $D$. basalis qui vont être lâchés à l'intérieur du système de stockage (figure 9.5). Les adultes d'E. vuilleti n'éliminent qu'un nombre limité de larves de D. basalis et ce parasitoïde devient rapidement alors l'espèce dominante parvenant à contrôler le ravageur. Les pertes en poids de graines sont de l'ordre de $125 \mathrm{~g}$ par kilo à la fin du stockage.

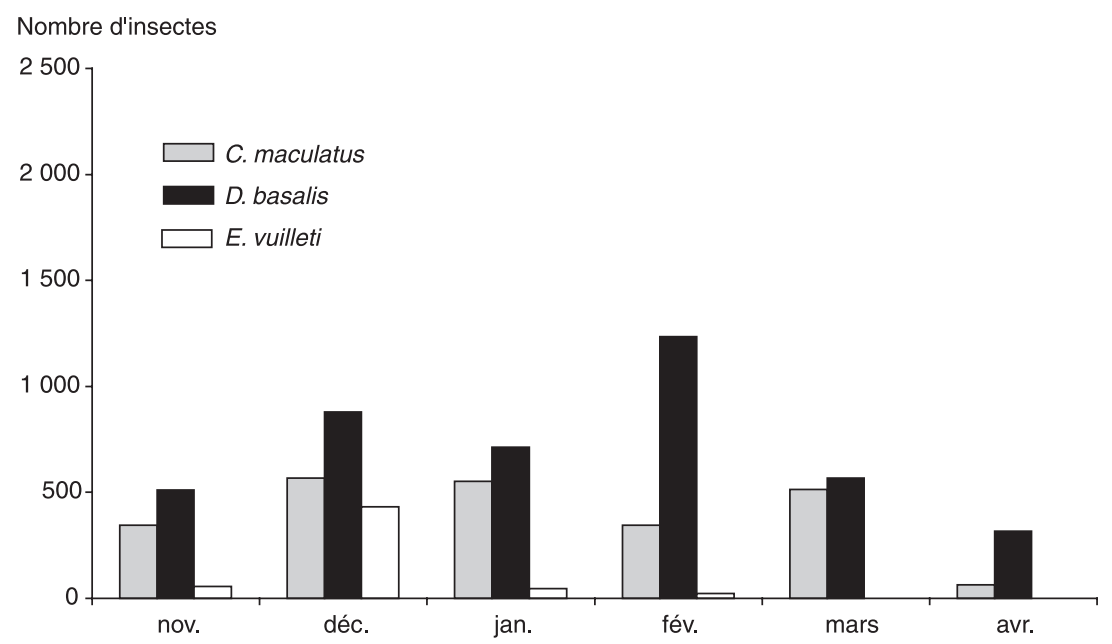

Figure 9.5. Variations des effectifs de C. maculatus, de D. basalis, d'E. vuilleti émergeant au cours du temps dans un grenier après un lâcher de 200 couples de D. basalis au début du stockage.

\section{Lutte biologique avec l'oophage Uscana lariophaga}

Ce parasitoïde est présent dans toutes les cultures de niébé attaquées par les Bruchidius atrolineatus et Callosobruchus maculatus (planche couleur II photo 7). Le taux de parasitisme dû à U. lariophaga est très variable ; 20 à $30 \%$ des œufs de $B$. atrolineatus et 30 à $50 \%$ des œufs de $C$. maculatus dénombrés sur des gousses de niébé sont parasités au Niger (Leroi et al., 1985). Les femelles recherchent les œufs déposés sur les graines et pondent à l'intérieur de ceux-ci. La durée de vie des femelles à $30^{\circ} \mathrm{C}$ est de 2,5 jours et leur fécondité est de 25 œufs en moyenne (van Huis, 1991).

Les femelles recherchent les œufs déposés sur les gousses et vont pondre à l'intérieur de ces derniers. Des stimuli olfactifs issus des graines, puis des œufs de bruches permettent la localisation de l'habitat de l'hôte (la graine), puis de l'œuf. Les femelles de $U$. lariophaga peuvent se déplacer à l'intérieur des stocks de graines et localisent plus rapidement les zones fortement contaminées avec de fortes densités d'œufs que les zones faiblement contaminées. Lorsque les femelles ont découvert des graines portant un nombre important d'œufs sains, elles exploitent ces graines et le taux de parasitisme à ce niveau est élevé. La vitesse de déplacement du trichogramme à l'intérieur du stock est estimée à 1,4 centimètre par heure (Stolk et al., 2005).

$U$. lariophaga est un agent de lutte efficace ; lorsqu'il est introduit seul dans un système de stockage, le parasitoïde peut contrôler les populations de bruches et son efficacité est 
d'autant plus importante que le nombre d'œufs est élevé (van Huis et al., 1998). Lorsque U. lariophaga est introduit dans un système de stockage en présence de D. basalis, son impact est beaucoup plus faible. Le parasitoïde larvaire réduit les populations de bruches et limite le nombre d'œufs disponibles pour U. lariophaga. Cette désynchronisation entre les cycles de développement et de reproduction de l'oophage et de son hôte ne permet pas aux populations d'U. lariophaga de se développer dans le système de stockage (van Huis et al., 2002). Cette situation se rencontre très souvent dans les systèmes de stockage en conditions naturelles où les deux espèces de parasitoïdes sont présentes dans les cultures et émergent dans les stocks après la récolte des graines.

\section{La lutte biologique contre Acanthoscelides obtectus dans les stocks de graines de haricot}

Ce Bruchinae cause des pertes importantes au cours du stockage en Amérique du Sud où cette légumineuse joue un rôle important dans l'alimentation. Schmale et al. (2002) ont examiné les pertes provoquées par A. obtectus dans la région de Restrepo dans la vallée du Cauca en Colombie. Ils constatent que $90 \%$ des systèmes de stockage observés contiennent des graines dans lesquelles se développent des larves d'A. obtectus. Le taux d'infestation moyen est selon les auteurs de 16 bruches pour 1000 graines. Il n'y a, à la récolte, qu'une seule espèce de parasitoïde qui a été trouvée ; il s'agit de l'hyménoptère Eupholidae Horismenus ashmeadii. Cependant, cet hyménoptère ne peut pas se reproduire dans les systèmes de stockage et n'est donc pas un auxiliaire de lutte biologique. D. basalis est présent dans les systèmes de stockage en Amérique du Sud. C'est selon Schmale et al. $(2005,2006)$ un ennemi naturel efficace permettant de contrôler les populations d'A. obtectus. Lorsque le niveau d'infestation des graines est faible, le lâcher dans le grenier de 5 couples de $D$. basalis par kilo de graines permet un contrôle efficace des populations de bruches. Lorsque l'infestation est plus forte, l'efficacité du lâcher est plus limitée et dépend du stade de développement des larves-hôtes. Les populations de $D$. basalis se maintiennent plus facilement dans les systèmes de stockage lorsqu'on les introduit dans des greniers au début du stockage et qu'elles reçoivent un apport alimentaire important sous forme de miel.

Schmale et al. (2003) et Velten et al. (2008) constatent qu'il est possible d'associer lutte biologique et résistance variétale. La présence d'une protéine de stockage, l'arceline, dans les graines de certains génotypes de $P$. vulgaris est toxique pour les larves de Zabrotes subfasciatus (voir chapitre 8). En revanche, elle n'a qu'un effet sublétal chez A. obtectus en ralentissant le développement des larves. La présence prolongée de ces stades larvaires à l'intérieur de la graine favorise, selon ces auteurs, la reproduction et le développement de $D$. basalis et accroît ainsi l'efficacité de la lutte biologique.

La dureté du tégument des graines intervient également dans le succès de la lutte biologique contre $A$. obtectus (Velten et al., 2008). Ce paramètre physique ne semble pas affecter le développement de l'hôte, les larves néonates perforant les téguments durs sans mortalité importante quelle que soit leur dureté. En revanche, il perturbe la reproduction des femelles de $D$. basalis qui ont des difficultés à perforer un tégument dur à l'aide de leur ovipositeur pour atteindre la larve-hôte. Le succès parasitaire est donc plus élevé lorsque les larves d'A. obtectus se développent dans des graines à tégument fin et tendre. 


\section{La lutte biologique contre la bruche de l'arachide}

Il existe plusieurs espèces d'hyménoptères parasitoïdes susceptibles d'être utilisées en lutte biologique. Le trichogramme Uscana caryedoni Viggiani se développe aux dépens des œufs de $C$. serratus déposés sur les gousses d'arachide. Le taux de parasitisme des œufs peut atteindre $30 \%$ après plusieurs mois de stockage (Delobel, 1989b).

Plusieurs espèces de parasitoïdes se développent aux dépens des larves de C. serratus, mais leur biologie est très mal connue et aucune espèce n'est utilisée en lutte biologique :

- Anisopteromalus caryedophagus Rasplus (Pteromalidae). Le taux de parasitisme est difficile à évaluer, mais près de $90 \%$ des cocons dans les pièges sont infestés ;

- Bracon (Ophtalmobracon) sp. Ce braconidae est un ectoparasite s'attaquant fréquemment à $C$. serratus et dont la révision systématique n'est pas encore entreprise ;

- Platyspathius sp. (Braconidae) est un ectoparasite grégaire de larves âgées et plus rarement de nymphes de bruches. Le nombre de parasitoïdes se développant aux dépens d'une seule larve varie de 1 à 4 . Les taux de parasitisme les plus élevés sont obtenus avec des larves des troisième et quatrième stades avant tissage du cocon. La ponte sur nymphe néoformée provoque dans tous les cas la mort de la larve du parasitoïde, probablement en raison de la sclérotinisation progressive du tégument de l'hôte. Dans tous les cas observés, la nymphe déformée du $C$. serratus ne parvient pas à produire un adulte viable.

\section{Comment développer la lutte biologique dans les stocks de niébé au niveau paysan?}

\section{La production de $D$. basalis}

Des élevages ont été réalisés dans des boîtes parallélépipédiques rectangulaires en plexiglas $(17,3 \times 10,7 \times 4 \mathrm{~cm})$ contenant environ 500 graines de niébé saines et 60 couples de Callosobruchus maculatus du morphe non-voilier. Les graines portant 1 à 3 œufs de $C$. maculatus sont conservées jusqu'à l'obtention de larves de bruches âgées de 11 à 16 jours. Ces larves servent d'hôtes pour la reproduction et le développement des adultes de $D$. basalis qui sont introduits dans les boîtes pendant 4 jours. Les adultes de D. basalis émergés sont récupérés dans ces boîtes et sont soit utilisés pour un élevage de masse d'une nouvelle génération d'adultes, soit conditionnés par couples (20 ou 40) dans de petites boîtes plastiques de forme cylindrique $(3 \mathrm{~cm}$ de diamètre et $5 \mathrm{~cm}$ de hauteur) pour être introduits dans les greniers.

\section{Les essais de lutte biologique dans les villages}

Ils ont été réalisés en zone sahélienne sèche dans plusieurs villages soit dans la région de Ouagadougou au Burkina Faso, soit en zone soudanienne, plus humide, dans plusieurs villages situés près de Lomé au Togo (Amévoin et al., 2007). Les greniers traditionnels sont en terre cuite et contiennent $25 \mathrm{~kg}$ de graines de niébé récoltés dans les cultures en octobre. Les graines sont stockées à ce niveau pendant cinq mois. Les greniers contiennent des graines de niébé de la variété Moussa au Burkina Faso et des graines de la variété Glei au Togo. 
Suivant les greniers, il n'y a aucune nouvelle introduction de parasitoïde (témoin), ou il y a introduction d'adultes de $D$. basalis au début du stockage. Les effectifs de bruches sont estimés au début du stockage, puis à intervalles réguliers. Lors de chaque phase d'estimation, $610 \mathrm{~cm}^{3}$ de graines sont prélevées dans le grenier, puis conservées dans des boîtes d'élevage pendant 21 jours afin de suivre les émergences d'adultes de bruches et de parasitoïdes.

Au Togo, compte tenu de l'infestation initiale, l'introduction d'un couple de D. basalis pour 30 hôtes a permis une réduction de plus de $85 \%$ des effectifs de bruches par rapport aux greniers témoins où il n'y avait eu aucune introduction de parasitoïdes. Les pertes en poids de graines sont de l'ordre de $60 \mathrm{~g}$ par kilo alors qu'ils sont de l'ordre de $250 \mathrm{~g}$ par kilo dans les greniers témoins.

Au Burkina Faso, où la contamination initiale était plus élevée, la densité de parasitoïdes était plus faible (1 couple pour 48 hôtes). Dans ces conditions, la réduction des effectifs de bruches est de l'ordre de $70 \%$ par rapport aux greniers témoins. Les pertes en poids de graines sont de l'ordre de $75 \mathrm{~g}$ par kilo (contre $340 \mathrm{~g}$ par kilo dans les greniers témoins). Dans ce cas, l'introduction d'un nombre plus élevé d'adultes de D. basalis aurait sans doute permis une meilleure conservation des graines.

Ces études montrent qu'il est possible d'utiliser la lutte biologique dans les systèmes de stockage en utilisant $D$. basalis et que celle-ci peut permettre la conservation de graines de qualité. Cependant, la mise en œuvre de cette technique nécessite tout d'abord la mise en place d'une structure d'élevage du parasitoïde, permettant d'obtenir un nombre suffisant d'ennemis naturels capables de se reproduire. Il est possible d'utiliser les graines de niébé dans lesquelles se développent les larves de C. maculatus pour réaliser l'élevage de D. basalis. Cela peut cependant poser un problème, car les agriculteurs hésitent à introduire dans leurs stocks des graines de niébé déjà contaminées même si elles hébergent des parasitoïdes. C'est pourquoi Effowe et al. (2010) proposent d'élever ce parasitoïde aux dépens des larves d'un autre Bruchinae ; Acanthoscelides macrophtalmus Schaeffer se développant dans les graines d'une légumineuse pérenne et subspontanée au Togo : Leucaena leucocephala (Lamarck). Cette plante produit des gousses et des graines durant toute l'année. Plusieurs générations de D. basalis se développent sur A. macrophtalmus tout en gardant leurs capacités parasitaires vis-à-vis de C. maculatus. On peut prévoir l'élevage sur cet hôte très abondant, puis son introduction dans les greniers afin d'effectuer un contrôle biologique des Bruchinae du niébé.

Il est d'autre part important comme nous l'avons indiqué précédemment d'estimer l'infestation initiale des graines stockées afin d'ajuster la densité de parasitoïdes à cette infestation. Plusieurs facteurs peuvent perturber la mise en place ou l'efficacité de cette méthode de lutte. La présence d'une espèce concurrente telle que E. vuilleti, très adaptée au multiparasitisme, peut limiter le développement des populations de D. basalis dans les systèmes de stockage. Les élevages et la production de $D$. basalis doivent être conduits de façon rigoureuse et contrôlée en évitant toute prolifération de moisissures ou d'acariens qui peuvent rapidement détruire les élevages. Les parasitoïdes doivent être introduits dans les stocks en absence de tout autre traitement. L'utilisation de biopesticides d'origine végétale est à proscrire, ces substances provoquant une importante mortalité chez les parasitoïdes, beaucoup plus sensibles que leurs hôtes à ces composés (Huignard et al., 2008). 



\section{Conclusion}

\section{Comment assurer la protection des graines de légumineuses dans le cadre d'une agriculture durable ?}

IsABelle Adolé Glitho

Le développement des cultures de légumineuses est une des orientations prioritaires de nombreuses structures internationales et organisations non gouvernementales s'occupant d'autosuffisance alimentaire en Afrique. Les graines de légumineuses représentent, comme nous l'avons vu dans ce livre, une source de protéines importante. Elles entrent dans la composition de nombreux plats traditionnels et contribuent à assurer la sécurité alimentaire de la plupart des populations. Certaines légumineuses, comme l'arachide, le haricot et le soja, sont également des cultures de rente et constituent une source de revenus non négligeable pour les agriculteurs africains. L'objectif des centres de recherche et des organisations internationales qui les soutiennent est d'améliorer les rendements particulièrement dans les zones arides, d'accroître la teneur en protéines des graines et de limiter les attaques d'insectes dans les cultures, puis dans les stocks après la récolte. Parmi les insectes qui posent de nombreux problèmes aux producteurs, les Coléoptères Bruchinae polyvoltins sont certainement les ravageurs les plus nuisibles. Ils se développent et se reproduisent à l'intérieur des stocks; leur contrôle est difficile, car les capacités d'accroissement de ces populations d'insectes sont très importantes, particulièrement en zone tropicale. Même si l'on arrive à sélectionner des variétés très productives, il ne sert à rien de cultiver ces plantes si l'on ne peut pas les conserver. En Afrique de l'Ouest, par exemple, la destruction de plus de $80 \%$ des graines de niébé, après quelques mois de stockage, a conduit les producteurs à diminuer de façon drastique les surfaces consacrées à la culture de cette légumineuse au cours de la campagne agricole suivante. Les agriculteurs ont peur de voir leurs stocks dégradés par les diverses espèces de Bruchinae qui sont présentes dans les graines lors de la récolte. Ils vont donc céder leurs productions à des commerçants qui vont en assurer le stockage dans des silos 
où sont pratiqués des traitements insecticides dans des conditions qui sont parfois peu compatibles avec la santé du consommateur. Ces pratiques leur permettent de vendre les graines de niébé avec de gros profits lors de la période de soudure. L'importance des dégâts entraîne un manque à gagner pour les producteurs et provoque la dépréciation d'une source de protéines peu onéreuse. L'importance des pertes a poussé le Conseil phytosanitaire interafricain à solliciter un regroupement des chercheurs d'Afrique de l'Ouest autour du problème posé par les Bruchinae. Les études du Réseau africain de recherche sur les bruches (Reab), menées en coopération avec des universités européennes, ont permis de mieux connaître la biologie et l'écologie de ce groupe d'insectes et de proposer des méthodes de lutte directement applicables au niveau paysan.

Les études écophysiologiques et phylogénétiques présentées dans ce volume montrent que certaines espèces de Bruchinae possèdent des capacités d'adaptation importantes, car c'est un groupe d'insectes en pleine évolution. Ainsi, les chercheurs de l'université de Lomé au Togo ont pu suivre au cours des dernières années le développement des populations de Callosobruchus rhodesianus dans les cultures de niébé en zone guinéenne. Cette espèce semble s'adapter progressivement aux conditions de stockage et devient progressivement polyvoltine ; elle est en voie de devenir un des ravageurs importants des graines de cette légumineuse au Togo, en Côte d'Ivoire et au Bénin. L'existence d'un polymorphisme imaginal, observé chez plusieurs espèces de Bruchinae, avec un morphe adapté à la colonisation des plantes-hôtes dans les cultures et un morphe adapté aux conditions de stockage, est une des caractéristiques de ce groupe. Ce polymorphisme permet à ces insectes de se reproduire et de se développer dans deux milieux très différents, et de s'adapter aux conditions de stockage dans les greniers.

Les Bruchinae sont capables de se développer dans des graines riches en composés secondaires et de détourner ces défenses végétales en mettant en place, comme nous l'avons vu dans ce volume, des systèmes de détoxification sophistiqués. Les espèces se développant aux dépens des graines de légumineuses sauvages, riches en composés secondaires, sont capables de s'adapter sur des plantes cultivées lorsque celles-ci sont introduites dans leur aire de répartition. Elles peuvent en effet se reproduire, puis se développer aux dépens des graines produites par des plantes qui ont été sélectionnées pour leur faible teneur en composés secondaires. C'est le cas de Careydon serratus dont les différentes populations se développent en Afrique sahélienne sur des Césalpinaceae arbustives. Cet insecte a pu coloniser les stocks d'arachide lorsque cette légumineuse a été introduite en Afrique et est devenu un ravageur important, posant de nombreux problèmes aux producteurs. Il n'est pas exclu, compte tenu du nombre d'espèces de Bruchinae se développant sur les légumineuses sauvages en Afrique, que de tels changements de plantes-hôtes soient en cours et que de nouvelles espèces deviennent des ravageurs des graines dans les cultures ou dans les stocks. Des études systématiques, utilisant les techniques modernes de la biologie moléculaire, doivent être réalisées afin de mieux connaître les espèces inféodées aux légumineuses sauvages et aux légumineuses cultivées, et de suivre leur évolution. La formation de chercheurs africains maîtrisant ces disciplines nous semble indispensable. Les chercheurs de l'université de Lomé ont constaté que l'introduction du soja (Glycine max) en zone soudanienne puis le développement des cultures ont permis le passage de C. maculatus sur cette légumineuse, ce qui risque de poser rapidement des problèmes de conservation dans cette zone. Certaines espèces ont été capables de se développer dans un environnement climatique différent de celui de leur 
zone d'origine. C'est le cas d'Acanthoscelides obtectus originaire d'Amérique équatoriale et qui a suivi l'extension des cultures de haricot en milieu tempéré, en Amérique du Nord, en Europe, puis en Afrique. Les systèmes de stockage de graines représentent un passage obligatoire pour survivre durant la période hivernale, car ce Bruchinae n'est pas capable de s'adapter à ces conditions climatiques en entrant en diapause reproductrice. A. obtectus a retrouvé en Afrique centrale et dans certaines zones d'Afrique de l'Est des conditions proches de celles de sa zone d'origine, ce qui explique l'importance des pertes causées par cette espèce au cours du stockage des graines de haricot.

La lutte contre les Bruchinae étant difficile, tout un ensemble de méthodes de contrôle des populations doit être mis en œuvre. Ces méthodes doivent être adaptées à chaque espèce de ravageurs et à chaque situation de stockage. Les agriculteurs africains arrivent à protéger de petits stocks en utilisant le savoir-faire local ; ils introduisent souvent des cendres ou du sable fin dans les greniers traditionnels. Dans ces conditions, les adultes émergeant des graines se déplacent difficilement dans les stocks et se reproduisent mal, ce qui limite les pertes. Le stockage à l'intérieur de récipients étanches dans une atmosphère pauvre en oxygène peut être également un moyen de conservation efficace des petits stocks de graines. Un projet soutenu par une organisation non gouvernementale (Perdue Improved Cowpea Storage, financée par la fondation Bill et Melinda Gates) est actuellement en cours de développement en Afrique de l'Ouest. Des graines de niébé sont placées dès la récolte dans des sacs à double paroi en polyéthylène résistant de $80 \mu \mathrm{m}$ d'épaisseur, hermétiquement fermés. Chaque sac contenant $50 \mathrm{~kg}$ de graines est conservé pendant plusieurs mois. Les larves se développant dans les graines meurent par la privation d'oxygène et il n'y a que très peu d'attaques de bruches. Le coût de ce mode de conservation et sa faisabilité à long terme restent cependant à évaluer.

L'utilisation au cours du stockage traditionnel de plantes aromatiques qui libèrent dans l'atmosphère du grenier des composés volatils, répulsifs ou toxiques vis-à-vis de Bruchinae, est également très fréquente et a donné lieu à de nombreuses recherches. Un certain nombre de composés, et notamment des huiles essentielles, ont été extraits de ces plantes ; leur activité insecticide a été testée en laboratoire, mais rarement en conditions réelles de stockage. Les terpènes contenus dans les huiles essentielles ou les composés soufrés extraits de la Capparidacée sahélienne Boscia senegalensis sont très toxiques vis-à-vis des Coléoptères Bruchinae et sont susceptibles d'être utilisés en fumigation. Si le mode d'action de quelques substances est connu (Huignard et al., 2008b), il reste cependant beaucoup à faire avant de recommander l'usage de ces biopesticides dans les structures de stockage. Il faut en effet connaître leur mode d'action, leur rémanence et leur éventuelle toxicité vis-à-vis des consommateurs. Ces substances, susceptibles d'être extraites localement en utilisant les ressources de la flore locale, pourraient remplacer les insecticides de synthèse, mais la généralisation de leur emploi doit passer par une procédure d'homologation afin d'éviter toute prise de risque. Ce n'est pas parce qu'elle est d'origine naturelle qu'une substance n'est pas toxique pour le consommateur.

La lutte chimique à l'aide des insecticides de synthèse pose, comme nous l'avons vu, de nombreux problèmes en particulier au niveau des petits paysans et des petits centres de stockage. Ils ne peuvent utiliser les méthodes de traitement les plus efficaces comme la fumigation en raison de leur coût et de leur difficulté d'emploi. L'usage inapproprié d'insecticides souvent non homologués pour la conservation des graines de légumineuses, le non-respect des doses et l'absence de précaution lors des traitements peuvent avoir de 
graves conséquences sanitaires tant pour les producteurs que pour les consommateurs. Il est donc nécessaire de renforcer les services de conseil et d'assistance aux producteurs de légumineuses, afin de limiter les risques de mauvais usage des pesticides et de diminuer la dépendance des agriculteurs ou des coopératives vis-à-vis des firmes phytosanitaires. Les traitements en culture avant la récolte des gousses ne peuvent être recommandés que dans deux cas : la lutte contre les bruches monovoltines et le contrôle des insectes ravageurs s'attaquant aux gousses vertes de haricot destinées à l'exportation.

Les études réalisées sur la physiologie, la génétique et l'écologie des Bruchinae et de leurs parasitoïdes ont permis de proposer d'autres méthodes de lutte susceptibles d'être utilisées tant au niveau des centres de stockage que chez les producteurs villageois, afin d'assurer la transition vers des systèmes de production et de stockage durables et économes en pesticides. La lutte biologique à l'aide de l'hyménoptère $D$. basalis peut permettre un contrôle efficace des Bruchinae tels que C. maculatus ou A. obtectus, comme l'ont montré des recherches réalisées tant en Amérique du Sud qu'en Afrique. Cet hyménoptère parasitoïde, qui possède de remarquables capacités de détection de ses hôtes à l'intérieur des systèmes de stockage, peut limiter l'accroissement des populations de bruches dans les stocks de niébé ou de haricot et permettre une bonne conservation des récoltes, ainsi que l'a montré un programme de recherche réalisé en coopération par des universités africaines et européennes. Des études réalisés au Togo dans plusieurs zones de production du niébé en collaboration avec les villageois ont permis de constater l'efficacité de ce contrôle biologique qui est assez simple à mettre en place. Il faut cependant mieux maîtriser les conditions d'élevage afin de permettre la production importante et régulière de parasitoïdes durant toute la période de stockage. Cette méthode de lutte est non polluante puisqu'il s'agit d'augmenter la pression parasitaire d'un hyménoptère déjà présent dans l'écosystème. Elle n'a qu'un très faible coût, contrairement aux autres méthodes de lutte.

L'analyse des conditions de développement des larves de bruches a permis d'étudier les mécanismes mis en place par les différentes espèces pour détoxifier les composés secondaires présents dans les graines. Les nombreux travaux réalisés au cours de ces dernières années ont particulièrement étudié, comme nous l'avons vu dans le chapitre 8, les protéines antimétaboliques. La connaissance des mécanismes de biosynthèse de ces protéines a permis d'obtenir des lignées résistantes par sélection ou par transgenèse. La diffusion de ces lignées résistantes dans les zones de production complète l'ensemble des méthodes de lutte pour assurer un contrôle des populations de bruches dans le cadre d'un développement durable. Les graines produites par ces lignées résistantes ne semblent pas poser de problèmes majeurs d'un point de vue nutritionnel chez l'homme puisque les protéines antimétaboliques sont détruites lors de la cuisson. Leur utilisation en alimentation animale peut être, en revanche, plus problématique. Les conditions de production de ces lignées résistantes et le rendement en graines dans les différents agrosystèmes restent à déterminer. L'apparition d'éventuels phénomènes de résistance vis-à-vis des inhibiteurs d' $\alpha$-amylase doit être suivie compte tenu des importantes capacités d'adaptation des Bruchinae.

Malgré les résultats très encourageants obtenus ces dernières années, les chercheurs ne considèrent pas que la lutte soit terminée, car les différentes espèces de Bruchinae peuvent contourner «les pièges » développés par l'homme. Aucune méthode de lutte ne viendra à bout définitivement des bruches. Il faut en permanence jouer sur une 
combinaison de méthodes dans le cadre d'une lutte intégrée pour contenir la pression de ces ravageurs. Mais nous savons aujourd'hui limiter les pertes à des seuils de dégâts économiquement acceptables. La vulgarisation des paquets technologiques demande du temps, de la main-d'œuvre et un effort financier provenant des pays eux-mêmes ou des quelques organisations ou fondations internationales. La réussite de cette vulgarisation repose bien évidemment sur la disponibilité des agriculteurs, mais beaucoup plus sur la démonstration de l'efficacité des technologies proposées. Il est indispensable de faire un suivi des technologies mises en place chez les producteurs et de les adapter le cas échéant. Il faut assurer la formation des agriculteurs (hommes et femmes), non seulement sur le plan agronomique, mais également sur la biologie des insectes afin qu'ils puissent choisir la bonne méthode de lutte. Le présent ouvrage devrait être un outil indispensable pour la réalisation de cet objectif. L'exploitation de son contenu va permettre aux chercheurs, impliqués dans l'amélioration des systèmes de stockage des récoltes, de trouver un modèle de recherche scientifique sur l'analyse des relations plantes-insectes. Il fournira aux services de vulgarisation agricole des pays africains des méthodes de gestion des stocks de légumineuses.

Il nous semble indispensable de valoriser les légumineuses et particulièrement les légumineuses vivrières qui jouent un rôle très important dans l'alimentation de nombreuses populations à travers le monde et notamment en Afrique. La valorisation de ces plantes passe par une bonne conservation des récoltes. Nous espérons que ce livre, présentant la biologie des ravageurs et les méthodes de contrôle fondées sur les techniques traditionnelles et sur celles provenant des recherches biotechnologiques les plus récentes, fournira aux universitaires et aux agronomes toutes les informations permettant de mieux maîtriser la lutte contre les ravageurs en système post-récolte pour réaliser une agriculture durable. 



\section{Références bibliographiques}

Abate T., Ampofo J.K.O., 1996. Insect pests of beans in Africa : their ecology and management. Annual Review of Entomology, 41, 45-73.

Abate T., van Huis A., Ampofo J.K.O., 2000. Pest management strategies in traditional agriculture : An african perspective. Annual Review of Entomology, 45, 631-659.

Ahmed S., Khan M.A., Ahmad N., 2002. Determination of susceptibility level of phosphine in various strains of Callosobruchus maculatus. International Journal of Agriculture and Biology, 4, 329-331.

Ahn J.E., Lovingshimer M.R., Salzman R.A., Presnail J.K., Lu A.L., Zhu-Salzman K., 2007. Cowpea bruchid Callosobruchus maculatus conteracts dietary protease inhibitors by moduling propeptides of major digestive insects. Insect Molecular Biology, 16, 295-304.

Ali-Diallo B., Huignard L., 1992. Oviposition of four strains of Careydon serratus in presence of pods or seeds of their wild and cultivated host plants. Journal of African Zoology, 107, 113-120.

Alvarez N., McKey D., Hossaert-McKey M., Born C., Mercier L., Benrey B., 2005. Ancient and recent evolutionary history of the bruchid beetle Acanthoscelides obtectus, a cosmopolitan pest of beans. Molecular Ecology, 14, 1015-1024.

Amévoin K., Glitho I.A., Monge J.-P, Huignard J., 2005. Why Callosobruchus rhodesianus causes limited damages during storage of cowpea seeds in a tropical humid zone in Togo ? Entomologia Experimentalist et Applicata, 116, 175-182.

Amevoin K., Sanon A., Apossaba M., Glitho I.A., 2007. Biological control of bruchids infesting cowpea by the introduction of Dinarmus basalis adults into farmers'stores in West Africa. Journal of Stored Product Research, 43, 240-247.

Annis P.C., 2000. Phosphine dosage regimes required for high mortality : a database approach. In : Proceedings International Conference on Controlled Atmospheres and Fumigation of Stored Products (E.J. Donahaye., S. Navarro, J.G. Leesch, éds.), 45-55.

Aparecida L., Sperandio A., Zugoloto F.S., 2004. Oviposition behavior of Zabrotes subfasciatus females under conditions of host deprivation. Iheringia, 94 (3), 1-7.

Appleby J.H., Credland P.F., 2001. Bionomics and polymorphism in Callosobruchus subinnotatus. Bulletin of Entomological Research, 91, 235-244.

Armentia A., Lombardero M., Blanco C., Fernandez S., Fernandez A., Sanchez-Monge A., 2006. Allergic hypersensitivity to the lentil pest Bruchus lentis. Allergy, 61, 1112-1116.

Arnason J.T., Durst T., Philogène B.J.R., Scoot I.M., 2008. Prospection d'insecticides phytochimiques de plantes tempérées ou tropicales communes ou rares. In : Biopesticides d'origine végétale (C. Regnault-Roger, B.J.R. Philogène, C. Vincent, éds.), Lavoisier, 87-100. 
Becerra J.X., 1997. Insects on plants : macroevolutionary chemical trends in host use. Science, 276, 253-256.

Bernard J.-L., 2008. Protection chimique des plantes cultivées et durabilité. Oléagineux Corps Gras Lipides, 14, 332-344.

Bernays E.A., Chapman R.F., 1994. Host-Plant Selection by Phytophagous Insects, Chapman and Hall, Londres, 312 p.

Betarbet R., Sherer T.B., MacKenzie G., Garcia-Osuna M., Panov A.V., Greenamyre J.T., 2000. Chronic systematic pesticide exposure reproduces features of Parkinson's disease. Nature Neuroscience, 3, 1301-1306.

Birch A.N.E., Fellows L.E., Evans S.V., Doherty K., 1986. Para-aminophenylalanine in Vigna : possible taxonomic and ecological significance as a seed defence against bruchids. Phytochemistry, 25, 2745-2749.

Bisby F.A., Buckingham J., Harborne J.B., 1994. Phytochemical dictionary of the Fabaceae. Vol. 1. Plants and their constituents, Chapman and Hall, Londres, $1051 \mathrm{p}$.

Bleiler J.A., Rosenthal G.A., 1988. Biochemical ecology of canavanine-eating seed predators. Ecology, 69, 427-433.

Bodin A., Jaloux B., Delbecque J.-P., Vannier F., Monge N., Mondy N., 2009. Reproduction in a variable environment : How does Eupelmus vuilleti, a parasitoid wasp, adjust oogenesis to host availability? Journal of Insect Physiology, 55, 643-648.

Boland J., Koomen I., van Lidth de Jeude J., Oudejans J., 2007. Les pesticides : composition, utilisation et risques, Fondation Agromisa, Wageningen, Pays-Bas [www.agromisa.org].

Borowiec L., 1987. The genera of seed-beetles (Coleoptera, Bruchidae). Polskie Pismo Entomologiczne, 57, 3-207.

Bosch C.H., Borus D.J., 2009. Céréales et légumes secs de l'Afrique tropicale. Conclusions et Recommandations basées, Fondation Prota, Wageningen, Pays-Bas, 94 p.

Boxall R.A., 1998. A critical review of the methodology for assessing farm-level grain losses after harvest, rapport G 191 du Tropical Development and Research Institute, 139 p.

Brink M., Belay G., 2006. Ressources végétales de l'Afrique tropicale 1 - Céréales et légumes secs, Fondation Prota, Wageningen, Pays-Bas.

Brundtland G.H., 1987. Our common future, Oxford University Press, Oxford, Royaume-Uni.

Bruneton J., 1999. Pharmacognosie, Lavoisier, Paris, 1243 p.

Casas J., Vannier F., Mandon N., Delbecque J.-P., Giron D., Monge J.-P., 2009. Mitigation of egg limitation in parasitoids : immediate hormonal response and enhanced oogenesis after host use. Ecology, 90, 537-545.

Center T.D., Johnson C.D., 1974. Coevolution of some seed beetles (Coleoptera : Bruchidae) and their hosts. Ecology, 55, 1096-1103.

Chauhan Y.S., Ghaffar M.A., 2002. Solar heating of seeds - a low cost method to control bruchid (Callosobruchus spp.) attack during storage of pigeonpea. Journal of Stored Products Research, 38, 87-91. 
Chevrier C., Bressac, C, 2002. Sperm storage and use after multiple mating in Dinarmus basalis. Journal of Insect Behavior, 15, 385-398.

Clement S.L., 1992. On the function of pea flower feeding by Bruchus pisorum. Entomologia Experimentalis et Applicata, 63, 115-121.

Compton J.A.F., Floyd S., Ofosu A., Agbo B., 1998. The modified count and weight method : an improved procedure for assessing weight loss in stored maize cobs. Journal of Stored Products Research, 34, 277-285.

Cooper L., Doss R.P., Price R.R., Nelson K., Oliver J.E., 2005. Application of bruchin B to pea pods results in the up regulation of CYP93C18, a putative isoflavone synthetase gene, and increase in the level of pisatin, an isoflavone phytoalexin. Journal of Experimental Botany, 56, 1229-1237.

Copping L.G., 2009. The Manual of Biocontrol Agents. $4^{\text {th }}$ edition, British Crop Protection Council, Alton, U.K, 758 p.

Cortesero A.M., Monge J.-P, Huignard J., 1993. Response of the parasitoid Eupelmus vuilleti to the odours of the phytophagous host and its host plant in an olfactometer. Entomologia Experimentalis et Applicata, 69, 109-116.

Cortesero A.M., Monge J.-P, Huignard J., 1995. Influence of two successive learning processes on host and host plant odor responses in Eupelmus vuilleti CRW (Hymenoptera : Eupelmidae). Journal of Insect Behavior, 8, 751-762.

Darrouzet E., Huignard J., Chevrier C., 2002. Effect of differential host exposure on reproduction in the solitary ectoparasitoid Eupelmus vuilleti. Entomologia Experimentalis et Applicata, $103,73-81$.

DEAPEA, 2005. Chapitre 13, Gestion des nuisibles II : Usage plus sûr des pesticides, <http:// www.encapafrica.org/egssaa/PDF_French/Chapitre\%2013_Safer_\%20Use_\%20of_\%20 Pesticides_French_\%20Final.pdf $>$.

Decelle J., 1981. Bruchidae related to grain legumes in the afro-tropical area. In : The Ecology of Bruchids Attacking Legumes (V. Labeyrie, éd.), Junk Publications, 193-198.

Deguine J.-P., Ferron P., 2004. Protection des cultures et développement durable : bilan et perspectives. Colloque Développement durable, Ouagadougou, 33-41.

Deguine J.-P., Ferron P., Russell D., 2008. Protection des cultures : de l'agrochimie à l'agroécologie, Éditions Quae, Versailles, 187 p.

Delobel A., 1989a. Influence des gousses d'arachide (Arachis hypogaea) et de l'alimentation imaginale sur l'ovogénèse, l'accouplement et la ponte chez la bruche Caryedon serratus. Entomologia Experimentalis et Applicata, 52, 281-289.

Delobel A., 1989b. Uscana caryedoni (Hym.: Trichogrammatidae) : possibilités d'utilisation en lutte biologique contre la bruche de l'arachide, Caryedon serratus. Entomophaga, 34, 351-363.

Delobel A., Matokot L., 1991. Control of stored groundnut insect pests in african subsistence farming. In : Proceeding of the $V^{\text {th }}$ International Working Conference on Stored Product Protection (F. Fleurat-Lessard, P. Ducom, éds), 1599-1607, <http://bru.gmprc.ksu.edu/proj/iwcspp/>.

Delobel A., Tran M., 1993. Les Coléoptères des denrées alimentaires entreposées dans les régions chaudes, Orstom/CTA, $424 \mathrm{p}$. 
Delobel A., Delobel B., 2003. Les plantes-hôtes des bruches (Coleoptera, Bruchidae) de la faune de France, une analyse critique. Bulletin Mensuel de la Société Linnéenne de Lyon, 72, 199-221.

Delobel A., Delobel H., Tran M., Sembene M., Han S.H., 1995. Observations sur les relations trophiques entre les bruches du genre Caryedon (Coléoptères, Bruchidae) et leurs planteshôtes sauvages au Sénégal. Bulletin de l'Institut Fondamental d'Afrique Noire, 48, 79-88.

Delobel A., Tran M., Sembene M., 2000. Influence du choix alimentaire sur la fécondité et le développement larvaire des Caryedon des Légumineuses (Coleoptera: Bruchidae) au Sénégal. Annales de la Société Entomologique de France, 36, 61-73.

Delobel B., Delobel A. 2006. Dietary specialization in European species groups of seed beetles (Coleoptera : Bruchidae : Bruchinae). Oecologia, 149, 428-443.

De Luca Y., 1956. Contribution à l'étude morphologique et biologique de Bruchus lentis. Annales École d'Agriculture d'Alger, 1, 4-6.

Denlinger D.L., 2002. Regulation of diapause. Annual Review of Entomology, 47, 93-122.

De Sousa M.D.J., Hardle D.C., Turner N.C., Higgins T.J.V., 2007. Bean $\alpha$-amylase inhibitors in transgenic peas inhibit the development of the pea weevil larvae. Journal of Economic Entomology, 100, 1416-1422.

De Sousa-Majer M.J., Turner N.C., Hardle D.C., Morton R.L., Lamont B., Higgins T.J.V., 2004. Response to water deficit and high temperature of transgenic peas containing a seedspecific $\alpha$-amylase inhibitor and the subsequent effects on pea weevil survival. Journal of Experimental Botany, 55, 497-505.

Doos R.P., 2005. Treatment of pea pods with Bruchid B results in up regulation of a gene similar to MtN19. Plant Physiology and Biochemistry, 43, 225-231.

Doss R.P., Oliver J.E., Proebsting S.W., Potter S.R., Kuy S.R., Clement S.L., 2000. Bruchins : Insect-derived plant regulators that stimulate neoplasm formation. Proceedings National Academy of Science USA, 97, 6218-6223.

Doury G., Bigot Y., Périquet G., 1997. Physiological and biochemical analysis in the female venom gland and salivary secretion in the ectoparasitoid wasp Eupelmus orientalis. Journal of Insect Physiology, 43, 69-81.

Duckett C.N., 1997. The scientific method and the predictive value of classification. Chrysomela, 34, 3-4.

Duckett C.N., Gillespie J.J., Kjer K.M., 2003. Relationships among the subfamilies of Chrysomelidae inferred from small subunit ribosomal DNA and morphology, with special emphasis on the relationship among the flea beetles and the Galerucinae. In : New Contributions in Chrysomelidae Biology (P. Jolivet, M. Schmitt, J. Santiago-Blay, éds), SPB Academic Publications, 3-18.

Edwards C.A., 2002. Sustainable agricultural practices. In : Encyclopaedia of Pest Management (D. Pimentel, éd.). Marcel Dekker Publications, 812-814.

Effowe T.Q., Amevoin K., Nuto Y., Mondedji D., Glitho I.A., 2010. Reproductive capacities and development of a seed beetle Acanthoscelides macrophtalmus, a potential host for mass rearing of Dinarmus basalis. Journal of Insect Science, 10, 137-151. 
Ehrlich P.R., Raven P.H., 1964. Butterflies and plants : a study in coevolution. Evolution, 18, 586-608.

Falconer I.R., Chapman H.F., Moore M.R., Ranmuthugala G., 2006. Endocrine-disrupting compounds : A review of their challenge to sustainable and safe water supply and water use. Environmental Toxicology, 21, 181-191.

Farrell B.D., Dussourd D.E., Mitter C., 1991. Escalation of plant defense : Do latex and resin canals spur plant diversification? American Naturalist, 138, 881-900.

Farrell B.D., Sequeira A.S., 2004. Evolutionary rates in the adaptive radiation of beetles on plants. Evolution, 58, 1984-2001.

Ferron P., 1989. Préface. In : Combattre les ravageurs des cultures (G. Riba et C. Silvy, éds), Inra, Paris, $230 \mathrm{p}$.

Ferron P., 1999. Protection intégrée des cultures : évolution du concept et de son application. Cahiers Agricultures, 8, 386-396.

Fleurat-Lessard F., 2001. Devenir des résidus d'insecticides au cours du stockage et à la transformation : des risques à gérer avec précision. Industries des Céréales, 121, 5-17.

Fleurat-Lessard F., Wilbert T., Vidal M.L., 2002. Models linking insecticidal efficacy decline and residues concentration decrease with time, temperature and Aw in CPM treated wheat. In : Proceedings of the VIII In International Working Conference on Stored Product Protection (P. Credland, D.M. Armitage, C.H. Bell, P.M. Cogan, éds), Cabi Publications, 639-645.

Fleurat-Lessard F., Vincent C., 2005. Méthodes physiques contre les ravageurs des cultures et des denrées stockées. In : Enjeux Phytosanitaires pour l'Agriculture et l'Environnement (C. Regnault-Roger, éd.), Lavoisier, 805-832.

Fricke C., Arnqvist G., 2007. Rapid adaptation to a novel host in a seed-beetle (Callosobruchs maculatus) : the role of sexual selection. Evolution, 61, 440-454.

Garin C.F., Juan C., Petitpierre E., 1999. Mitochondrial DNA phylogeny and the evolution of host-plant use in Palearctic Chrysolina (Coleoptera, Chrysomelidae) leaf-beetles. Journal of Molecular Evolution, 48, 435-44.

Gatehouse A.M.R., Boulter D., 1983. Assessment of the anti-metabolic effects of trypsine inhibitors from cowpea and other legumes on the development of Callosobruchus maculatus. Journal of Science, Food and Agriculture, 34, 345-350.

Gatehouse A.M.R., Minney, B.H., Dobie P., Hilder, V., 1990. Biochemical resistance to bruchid attacks in legume seeds ; investigation and exploitation. In : Bruchids and Legumes : Economics, Ecology and Coevolution (K. Fujii, A.M.R. Gatehouse, C.D. Johnson, R. Mitchel, T. Yoshida, éds), Kluwer Publications, 241-256.

Gauthier N., 1996. Étude d'un ectoparasitoïde solitaire Dinarmus basalis en situation de competition intra et interspécifique : activité reproductrice et réponses comportementales, thèse de doctorat, université de Tours, France, $183 \mathrm{p}$.

Gauthier N., Monge J.-P., Huignard J., 1996. Superparasitism and host discrimination in the solitary ectoparasitoid Dinarmus basalis. Entomologia Experimentalis et Applicata, 79, 91-99. 
Gauthier N., Sanon A., Monge J.-P., Huignard J., 1999. Interspecific relations between two sympatric species of hymenoptera, Dinarmus basalis and Eupelmus vuilleti, ectoparasitoids of the bruchid Callosobruchus maculatus. Journal of Insect Behavior, 12, 339-413.

Germain J.-F., Huignard J., Monge J.-P., 1985. Influence des inflorescences de la plante-hôte Vigna unguiculata sur la diapause reproductrice de Bruchidius atrolineatus. Entomologia Experimentalis et Applicata, 39, 35-42.

Germain J.-F., Monge J.-P., 1987. Development of two bruchid populations (Bruchidius atrolineatus and Callosobruchus maculatus) infesting stored cowpea. Journal of Stored Product Research, 23, 157-162.

Giga D.P., Smith R.H, 1983. Comparative life history of four Callosobruchus spp. infesting cowpea with special reference to Callosobruchus rhodesianus. Journal of Stored Product Research, 19, 189-198.

Giga D.P., Smith R.H., 1985. Oviposition markers of Callosobruchus maculatus and Callosobruchus rhodesianus : asymmetry of interspecific responses. Agricultural Ecosystems and environment, 12, 219-223.

Giga D.P., Smith R.H., 1987. Egg production and development of Callosobruchus rhodesianus and Callosobruchus maculatus on several commodities at two different temperatures. Journal of Stored Product Research, 23, 9-15.

Gill T., Kumari S., Sharma V.., Badran A.A., Kumari M., Sobit R.C. 2006. Genetic variation in polymorphic males of Callosobruchus maculatus. Cytologia, 71, 57-62.

Giron D., Pincebourde S., Casas J., 2004. Lifetime gains of host feeding in a synovigenic wasp. Physiological Entomology, 29, 436-442.

Glitho I.A., 1990. Les Bruchidae ravageurs de V. unguiculata en zone sahélienne. Analyse de la diapause reproductrice en zone sahélienne, thèse, université de Tours, $135 \mathrm{p}$.

Glitho I.A., Kétoh G.K., Nuto Y., Amevoin S.K., Huignard J., 2008. Approches non toxiques et non polluantes pour le contrôle des populations des insectes nuisibles en Afrique du Centre et de l'Ouest. In : Biopesticides d'origine végétale (C. Regnault-Roger, B.J.R. Philogène, C. Vincent, éds), Lavoisier, 207-218.

Golob P., Weley D.J., 1980. The use of plants and minerals as traditional protectants of stored products. Tropical Products Institute Publications, 138, 1-32.

Gòmez-Zurita J., Hunt T., Kopliku F., Vogler A.P., 2007. Recalibrated tree of leaf beetles (Chrysomelidae) indicates independent diversification on angiosperms and their insect herbivores. Plos One, 2, 360.

Goossens A., Quintero C., Dillen W., De Rycke R., Valor. J.F., De Clercq J., van Montagu M., Cardona C., Angenon G., 2000. Analysis of bruchid resistance in the wild common bean accession G02771 : no evidence for insecticidal activity of arcelin. Journal of Experimental Botany, 51, 1229-1236.

Guéguen J., Duc G., 2008. La filière protéagineuse, quels défis ?, Éditions Quæ, 147 p.

Hamilton W.D., 1967. Extraordinary sex ratio. Science, 477-488.

Hamraoui A., Regnault-Roger C., 1994. Oviposition and larval growth of Acanthoscelides obtectus Say in regard to host and non-host plants from Leguminosae family. Journal of Applied Entomology, 119, 195-199. 
Hamraoui A., Regnault-Roger C., 1997. Comparaison des activités insecticides des monoterpènes sur deux espèces d'insectes ravageurs des cultures Ceratitis capitata et Rhopalosiphum padi. Acta Botanica Gallica, 144, 413-417.

Hardie D.C., Clement S.L., 2001. Development of bioassays to evaluate wild pea germplasm for resistance to pea weevil (Coleoptera : Bruchidae). Crop Protection, 20, 517-522.

Hariri G., 1981. Distribution and importance of bruchid attacks on different species of pulses consumed in the Near East. In : The Ecology of Bruchids attacking legumes (V. Labeyrie, éd.), Junk Publications, 215-221.

Hodges R.J., Bernard M., Knipschild H., Rembold F., 2010. African postharvest losses information system - a network for the estimation of cereal weight losses. In : Proceedings of the $X^{\text {th }}$ International Working Conference of Stored Product Protection (O.M. Carvalho, éd.), Julius Kühn-Institut Publications, 958-964.

Hoffmann A., Labeyrie V., 1962. Les Bruchidae. In : Entomologie appliquée à l'agriculture (A.S. Balachowsky, éd.), Masson, 434-484.

Horler D.F., 1970. Methyl n-tetradeca-trans-2,4,5-trienoate, an allenic ester produced by the male dried bean beetle, Acanthoscelides obtectus (Say). Journal of Chemical Society, 859-862.

Hotzy C., Arnqvist G., 2009. Sperm competition favors harmful males in seed beetles. Current Biology, 19, 404-407.

Huignard J., 1974. Influence de la copulation sur la fonction reproductrice femelle chez Acanthoscelides obtectus. Annales de Sciences Naturelles, 16, 361-434.

Huignard J., Dugravot S., Ketoh G.K., Thibout E., Glitho A.I., 2008a. L'utilisation des composés secondaires des végétaux pour la protection des graines d'une légumineuse. Conséquences sur les ravageurs et les parasitoïdes. In : Biopesticides d'origine végétale (C. Regnault-Roger, B.J.R. Philogène, C. Vincent, éds), Lavoisier, 187-202.

Huignard J., Lapied B., Dugravot S., Magnin-Robert M., Ketoh G.K., 2008b. Mode d'actions neurotoxiques des dérivés soufrés et de certaines huiles essentielles et risques liés à leur utilisation. In : Biopesticides d'origine végétale (C. Regnault-Roger, B.J.R. Philogène, C. Vincent, éds), Lavoisier, 219-230.

Huignard J., Baehr J.C., Desroches P., Mandon N., 1996. Adaptation of a Callosobruchus maculatus strain to Vicia faba, as its new host plant. Entomologia Experimentalis et Applicata, 80, 156-159.

Huignard J., Dupont P., Tran B., 1990. Coevolutionary relations between bruchids and their host plants. The influence on the physiology of the insects. In : Bruchids and Legumes : Economics, Ecology and Coevolution (K. Fuji, A.M.R. Gatehouse, C.D. Johnson, R. Mitchel, T. Yoshida, éds), Kluwer Publications, 171-179.

Ishimoto M., Sato T., Chrispeels M.J., Kitamura K., 1996. Bruchid resistance of transgenic azuki bean expressing seed $\alpha$-amylase inhibitor of common bean. Entomologia Experimentalis et Applicata, 79, 309-315.

Isman M.B., 2005. Botanical insecticides, deterrents and repellents in modern agriculture and an increasingly regulated world. Annual Review of Entomology, 50, 45-66.

Jackai L.E.N., Daoust R.A., 1986. Insect pests of cowpea. Annual Review of Entomology, 31, 95-119. 
Jaenike J., 1990. Host specialization in phytophagous insects. Annual Review of Ecology and Systematics, 21, 243-273.

Jaloux B., Errard C., Mondy N., Monge J.-P., 2005. Source of chemical signal which enhance multiparasitism preferences by a cleptoparasitoid. Journal of Chemical Ecology, 31, 13251327.

Jaloux B., Monge J.-P., 2006. Kairomone stimulates increased probes and host stings in a cleptoparasitoid. Physiological Entomology, 31, 197-200.

Jaloux B., Deshayes M., Monge J.-P., 2007. Learning affects the preference for parasitized hosts of the facultative kleptoparasitoid E. vuilleti. Behavioral Ecology and Sociobiology, 67, 357- 364 .

Janzen D.H., 1967. Seed-eaters versus seed size, number, toxicity and dispersal. Evolution, $23,1-27$.

Janzen D.H., 1981. The defense of legumes against herbivores. In : Advances in Legume Systematics (R.M Polhill, P.H. Raven, éds), The Royal Botanic Gardens Publications, 951-977.

Janzen D.H., Juster, H.B., Bell, E.A., 1977. Toxicity of secondary compounds to the seedeating larvae of the bruchid beetle Callosobruchus maculatus. Phytochemistry, 16, 223-227.

Jermy T., Szentesi A., 2003. Evolutionary aspects of host plant speciation : A study of bruchids. Oikos, 101, 196-204.

Jerwis M., Kidd N., 1966. Insect natural enemies : practical approaches to their study and evaluation, Chapman and Hall Publications, 327 p.

Johnson C.D., 1981a. Seed beetle host specificity and the systematics of the Leguminosae. In : Advances in Legume Systematics (R.M Polhill, P.H. Raven, éds), The Royal Botanic Gardens Publications, Kew, 995-1027.

Johnson C.D., 1981b. Interactions between bruchid (Coleoptera) feeding guilds and behavioral patterns of pods of the Leguminosae. Environmental Entomology, 10, 249-253.

Johnson C.D., 1981c. Host preferences of Stator in nonhost seeds. Environmental Entomology, $10,857-863$.

Johnson C.D., 1987. Relationships between Mimosestes (Coleoptera) and Acacia (Leguminosae): Is there coevolution between these genera ? In : Proceedings of the VI ${ }^{\text {th }}$ international symposium on insect-plant relationships (V. Labeyrie, G. Fabres, D. Lachaise, éds), W. Junk Publications, 347-352.

Johnson C.D., 1988. The possible beginning of adaptation to a new host by bruchid beetles in Venezuela. Biotropica, 20, 80-81.

Johnson C.D., 1990. Coevolution of Bruchidae and their hosts : evidence, conjecture, and conclusions. In : Bruchids and Legumes : Economics, Ecology and Coevolution (K. Fuji, A.M.R. Gatehouse, C.D. Johnson, R. Mitchel, T. Yoshida, éds), Kluwer Publications, 181-188.

Johnson C.D., Siemens D.H., 1991. Expanded oviposition range by a seed beetle in proximity to a normal host. Environmental Entomology, 20, 1577-1582.

Johnson C.D., Siemens, D.H., 1996. Oviposition behavior, guilds, distribution and new host records for the genus Mimosestes Bridwell (Coleoptera : Bruchidae) from Colombia, Ecuador, Venezuela and Mexico. The Coleopterists Bulletin, 50, 155-160. 
JOUE, 2008a. Journal officiel de l'Union européenne. Décision de la commission du 10 avril 2008 concernant la non-inscription de la roténone, de l'extrait d'Equisetum et de l'hydrochlorure de quinine à l'annexe I de la directive 91/414/CEE du Conseil et le retrait des autorisations de produits phytopharmaceutiques contenant ces substances [notifiée sous le numéro C(2008) 1293]. L1008/30, 18.4.2008.

Kato T., Bonet A., Yoshitake H., Romero-Napoles J., Jinbo, U., Shimada M., 2010. Evolution of host utilization patterns in the seed-beetle genus Mimosestes Bridwell (Coleoptera : Chrysomelidae : Bruchinae). Molecular Phylogenetics and Evolution, 55, 816-832.

Kaur D., Pajni H.R., Tewari K., 1999. Morphological and reproductive dimorphism in Zabrotes subfasciatus. International Working Conference on Stored Product Protection, 2, 14-19.

Kergoat G.J., 2004. Le genre Bruchidius (Coleoptera, Bruchidae) : un modèle pour l'étude des relations évolutives entre les insectes et les plantes, thèse de doctorat, spécialité Diversité du vivant, Paris-VI, 194 p.

Kergoat G.J., Álvarez N., Hossaert-McKey M., Faure N., Silvain J.-F. 2005a. Parallels in the evolution of the two largest New and Old World seed-beetle genera (Coleoptera, Bruchidae). Molecular Ecology, 14, 4003-4021.

Kergoat G.J., Delobel A., Fédière G., Le Rü B., Silvain J.-F., 2005b. Both host-plant phylogeny and chemistry have shaped the African seed-beetle radiation. Molecular Phylogenetics and Evolution, 35, 602-611.

Kergoat G.J., Delobel A., Le Rü B., Silvain J.-F., 2008. Seed-beetles in the age of the molecule : recent advances on systematics and host-plant association patterns. Researches on Chrysomelidae, 1, 52-79.

Kergoat G.J., Delobel A., Silvain J.-F., 2004. Phylogeny and host-specificity of European seed beetles (Coleoptera, Bruchidae), new insights from molecular and ecological data. Molecular Phylogenetics and Evolution, 32, 855-865.

Kergoat G.J., Silvain J.-F., Buranapanichpan S., Tuda M., 2007a. When insects help to resolve plant phylogeny : evidence for a paraphyletic genus Acacia from the systematics and hostplant range of their seed-predators. Zoologica Scripta, 36, 143-152.

Kergoat G.J., Silvain J.-F., Delobel A., Tuda M., Anton K.-W., 2007b. Defining the limits of taxonomic conservatism in host-plant use for phytophagous insects : molecular systematics and evolution of host-plant associations in the seed-beetle genus Bruchus Linnaeus (Coleoptera : Chrysomelidae : Bruchinae). Molecular Phylogenetics and Evolution, 43, 251-269.

Ketoh G.K., Glitho A.I., Huignard J., 2002. Susceptibility of the bruchid Callosobruchus maculatus and its parasitoid Dinarmus basalis to three essential oils. Journal of Economic Entomology, 95, 174-182.

Kingsolver J.M., 1995. On the family Bruchidae. Chrysomela, 30, 3.

Kleeberg H., 2004. Neem based products : registration requirements, regulatory processes and global implications. In : Neem Today and in the New Millennium (O. Koul, S. Wahab, éds), Springer Netherlands, 109-123.

Koona P., Tatchago V., Malaa D., 2007. Impregnated bags for safer storage of legume grains in West and Central Africa. Journal of Stored Products Research, 43, 248-251. 
Kurota H., Shimada M., 2007. Over-wintering stage polymorphism of a bruchid beetle : geographical variation in optimal diapause strategy. Ecological Entomology, 32, 722-731.

Lawrence J.F., 1982. Coleoptera. In : Synopsis and Classification of Living Organism, vol. 2 (S.P. Parker, éd.), MacGraw-Hill Publications, 482-553.

Lecointre G., Le Guyader H., 2001. Classification phylogénétique du vivant, Éditions Belin, Paris, $543 \mathrm{p}$.

Lenga A., Thibeaudeau C., Huignard J., 1991. Influence of thermoperiod and photoperiod on reproductive diapause in Bruchidius atrolineatus. Physiological Entomology, 16, 295-303.

Leroi B., Alzouma I., Germain J.-F., Huignard J., 1985. Oviposition and development of Bruchidius atrolineatus and Callosobruchus maculatus in Vigna inguiculata cultures in Niger. Insect Science Application, 6, 691-699.

Lienard V., Seck D., 1994. Revue des méthodes de lutte contre Callosobruchus maculatus, ravageur des graines de niébé en Afrique tropicale. Insect Science and its Application, 15, 301-311.

Lingafelter, A., Pakaluk, J., 1997. Comments on the Bruchinae and Chrysomelidae. Chrysomela, 33, 3-4.

Luthi C.E, Alvarez-Alfageme F., Romeis J., 2010. The potential of transgenic legumes in integrated bruchid management : assessing the impact on bruchid parasitoids. In : Proccedings of $X^{\text {th }}$ International Working Conference on Stored Product Protection, 979-984.

Macedo M.L.R., Andrade L.B.S., Moraes R.A., Xavier-Filho J., 1993. Vicilin variants and the resistance of cowpea seeds Vigna inguiculata to the cowpea weevil Callosobruchus maculatus. Comparative Biochemestry Physiology, 105, 89-94.

Macedo M.L.R., Freire M.G.M., da Silva M.B.R., Coelho L.C.B.B, 2006. Insecticidal action of Bauhinia monandra leaf lectin (BmoLL) against Anagasta kuehniella (Lepidoptera : Pyralidae), Zabrotes subfasciatus and Callosobruchus maculatus (Coleoptera : Bruchidae). Comparative Biochemistry and Physiology, 146, 486-498.

Maina Y.T., Lale N.E.S., 2004. Integrated management of Callosobruchus maculatus infesting cowpea seeds in storage using varietal resistance, application of neem seed oil and solar heat. International Journal of Agriculture and Biology, 1560, 440-446.

Marvaldi A.E., Sequeira A.S., O’Brien C.W., Farrell B.D., 2002. Molecular and morphological phylogenetics of weevils (Coleoptera, Curculionoidea) : Do niche shifts accompany diversification ? Systematic Biology, 51, 761-785.

Mbata G.N., 1994. Effects of infestation of cultivars of Bambara groundnuts by Callosobruchus subinnotatus on biochemical deterioration and germination of the seeds. Journal of Plant Diseases and Protection, 100, 155-164.

Medjdoub F., 2007. Étude bioécologique de Bruchus rufimanus et diapause reproductrice dans la région de Tizi Ouzou, thèse de doctorat, université de Tizi Ouzou, Algérie, 130 p.

Messina F.J, 1990. Alternative life-histories in Callosobruchus maculatus : Environmental and genetic bases. In : Bruchids and Legumes : Economics, Ecology and Coevolution (K. Fuji, A.M.R. Gathehouse, C.D. Johnson, R. Mitchell, T. Yoshida, éds), Kluwer Publications, 303-315. 
Mondy N., Corio-Costet M.-F., Bodin A., Mandon N., Vannier F., Monge J.-P., 2006. Importance of sterols aquired through host feeding in synovigenic parasitoid oogenesis. Journal of Insect Physiology, 52, 897-904.

Monge J.-P., Dupont P., Idi A., Huignard J., 1995. The consequences of interspecific competition between Dinarmus basalis and Eupelmus vuilleti on the development of their host populations. Acta Oecologica, 16, 19-30.

Monge J.-P., Lenga A., Huignard J., 1989. Induction of reproductive diapause in Bruchidius atrolineatus during the dry season in a sahelian zone. Entomologia Experimentalis et Applicata, 53, 95-104.

Moon J., Salzman R.A., Ahn J.-E., Koiwa H., Zhu-Salzman K., 2004. Transcriptional regulation in cowpea bruchid guts during adaptation to a plant defence protease inhibitor. Insect Molecular Biology, 13, 283-291.

Morse G.E., Farrell B.D., 2005. Ecological and evolutionary diversification of the seed beetle genus Stator (Coleoptera : Chrysomelidae : Bruchinae). Evolution, 59, 1315-1333.

Morton R.L., Schroeder H.E., Bateman K.S., Chrispeels M.J.C, Armstrong E.A., Higgins T., 2000. Bean $\alpha$-amylase inhibitor 1 in transgenic peas (Pisum sativum) provides complete protection from pea weevil (Bruchus pisorum) under field conditions. Proceedings of the National Academy of Science USA, 3820-3825.

Mouchès C., 2005. Les mutations responsables des résistances aux insecticides. In : Enjeux phytosanitaires pour l'agriculture et l'environnement (C. Regnault-Roger, éd.), Lavoisier, Paris, 207-224.

Muchero W., Diop N.N., Bhat P., Fenton R., Wanamaker S., Pottoroff M., Hearne S., Cisse N., Fatokun C., Ehlers J.D., Robert P.A., Close T.J., 2009. A consensus genetic map of cowpea and syntheny based on EST-derived SNPs. Proceedings of the National Academy of Science USA, $106,18159-18164$.

Mulungu L.S., Luwondo E.N., Reuben S.O., Mulungu R.N., 2007. Effectiveness of local botanicals as protectants against Zabrotes subfasciatus. Journal of Entomology, 4 (3), 210-217.

Munier-Jolain N., Carrouée B., 2003. Quelle place pour le pois dans une agriculture respectueuse de l'environnement? Argumentaire agro-environemental. Cahiers Agricultures, 12, 111-120.

Murdock L.L., Seck D., Ntoukam G., Kitch L., Shade R.E., 2003. Preservation of cowpea grain in Sub-Saharian Africa. Field Crops Research, 82, 169-178.

Murdock L.L, Shade R.E., Kitch L., Nkoutam G., Loewenberg J., Huesing J.E. Moar W., Chambliss O.L., Endondo C., Wolfson J.L., 1997. In : Post harvest storage of cowpea in Sub-Saharian Africa (B.B. Singh, D.R Mohan Raj, K.E. Dashiell, L.E.N. Jackai, éds), 302-312.

Muthomi J.W., Otieno P.E., Chemining' Wa G.N., Nderitu J.H., Wagacha J.M., 2008. Effect of chemical spray on insect pests and yield quality of food grain legumes. Journal of Entomology, $5,156-163$.

Nahdy M.S., Silim S.N., Ellis R.H., 1999. Effect of field infestation of Cajanus cajan pods on production of active and sedentary morphs of Callosobruchus chinensis. Journal of Stored Product Research, 35, 339-354.

Nakai T., Yajima A., Akasaka K., Kaihoku T., Ohtaki M., Nukuda T., Ohuri H., Yabuta G., 2005. Synthesis of the four stereoisomers of 2,6 dimethyloctane-1,8-dioic acid a component of 
the copulation relesase pheromone of Callosobruchus maculatus. Bioscience, Biotechnology, Biochemistry, 69, 2401-2408.

N'Diaye S., Labeyrie V., 1990. Étude de l'adaptation de Bruchus affinis à Lathyrus sylvestris : analyse de la mortalité avant l'installation des larves dans la graine. Entomologia Experimentalis et Applicata, 55, 195-204.

Nelson M., Dempster W.F., Allen J.P, Silverstone S., Alling A., van Thillo M., 2008. Cowpeas and pinto beans : Performance and yields of candidate space crops in the laboratory biosphere closed ecological system. Advances in Space Research, 41, 748-753.

Nojima S., Shimonura K., Honda H., Yamamoto I., 2007. Contact sex pheromone components of Callosobruchus maculatus. Journal of Chemical Ecology, 33, 923-933.

Odeyemi O.O., Gbaye O.A., Akeju O., 2006. Resistance of Callosobruchus maculatus (Fab.) to pirimiphos methyl in three zones in Nigeria. In : Proceedings of I $X^{\text {th }}$ International Working Conference on Stored Product Protection (I. Lorini et al., éds), 324-329.

Oliveira A.S., Pereira R.A., Lima L.M., Morais A.H.A., Melo F.R., Franco O.L., Bloch C., Grossi-de-Sá M.F., Sales M.P., 2002. Activity toward bruchid pest of a Kunitz-type inhibitor from seeds of the Algaroba tree (Prosopis juliflora D.C.). Pesticide Biochemistry and Physiology, 72, 122-132.

Ouedraogo A.P., Monge J.-P., Huignard J., 1991. Importance of temperature and seed water content on the induction of imaginal polymorphism in Callosobruchus maculatus. Entomologia Experimentalis et Applicata, 59, 59-66.

Ouellet T., Harris L., Gleddie S., Belzile F., 2005. Génomique structurale et fonctionnelle appliquée à la lutte phytosanitaire : le cas de la fusariose de l'épi chez les céréales. In : Enjeux phytosanitaires pour l'agriculture et l'environnement (C. Regnault-Roger, éd.), Lavoisier, 733-747.

Paes N.S., Gerhardt I.R., Coutinho M.V., Yokoyama M., Santana E., Harris N., Chrispeels M.J., Grossi-de-Sá M.F., 2000. The effect of arcelin 1 on the structure of the midgut of the larvae and immunolocalization of the arcelin protein. Journal of Insect Physiology, 46, 309-402.

Pajni H.R., Sood S., 1975. Effect of pea pollen feeding on maturation and copulation of Bruchus pisorum. Indian Journal of .Experimental Biology, 13, 202-203.

Pajot É., Regnault-Roger C., 2008. Stimulation des défenses naturelles des plantes et résistance induite : une nouvelle stratégie phytosanitaire ? In : Biopesticides d'origine végétale (C. Regnault-Roger, B.J.R. Philogène, C. Vincent, éds), Lavoisier, 231-250.

Parr M.J., Tran B.M.D., Simmonds M.S.J., Credland P.F., 1998. Duration of behaviour patterns during oviposition by the bruchid beetle Callosobruchus maculatus. Physiological Entomology, 23, 150-157.

Paul U.V., Hilbeck A., Edwards P.J., 2010. Pre-harvest infestation of beans (Phaseolus vulgaris L.) by Acanthoscelides obtectus Say (Coleoptera : Bruchidae) in relation to bean pod maturity and pod aperture. International Journal of Pest Management, 56 (1), 41-50.

Pfau W., Bieler C., Neurath G., 2009. Safety of azadirachtin. Toxicology Letters, 189-214. 
Phillipps T.W., Phillips J.K., Webster F.X., Tang R., Burkholder W.E., 1996. Identification of sex pheromone from Callosobruchus maculatus and related studies with C. analis. Journal of Chemical Ecology, 22, 2233-2249.

Philogène B.J.R., 2008. Action synergique des composés d'origine végétale. In : Biopesticides d'origine végétale (C. Regnault-Roger, B.J.R. Philogène, C. Vincent, éds.), Lavoisier, 277-286.

Pimbert M., 1987. Analyse, en olfactomètre tubulaire, de l'influence de différents stimulus olfactifs dans la recherche du partenaire sexuel par Zabrotes subfasciatus. Entomologia Experimentalis et Applicata, 45, 23-27.

Prescott V.E., Campbell P.M., Moore A., Mattes J., Rothenberg M.E., Foster P.S., Higgins T.J.V., Hogan S.P., 2005. Transgenic expression of bean $\alpha$-amylase inhibitor in peas results in altered structure and immunogenicity. Journal of Agriculture and Food Chemistry, 53, $9023-$ 9030 .

Rajendran S., 2001. Alternatives to methyl bromide as fumigant for stored food commodities. Pesticide Outlook, 12, 249-253.

Ramalingam J., Vera Cruz C.M., Kukreja K., Chittoor J.M., Wu J.-L., Lee S.W., Baraoidan M., George M.L., Cohen M.B., Hulbert S.H., Leach J.E., Leung H., 2003. Candidate defense genes from rice, barley, and maize and their association with qualitative and quantitative resistance in rice. Molecular Plant Microbiological Interactions, 16, 14-24.

Ratnadass A., Fleurat-Lessard F., 1991. Improvements in the practical methods of assessment of losses caused by insects in grain stored at the village level in tropical Africa. In : Proceedings of $V^{\text {th }}$ International Working Conference on Stored Product Protection (F. Fleurat-Lessard, P. Ducom, éds), 1681-1692.

Regnault-Roger C., 1999. Diversification des stratégies de protection des plantes : intérêt des monoterpènes. Acta Botanica Gallica, 146, 35-43.

Regnault-Roger C., 2005. Enjeux phytosanitaires pour l'agriculture et l'environnement, Lavoisier, $1012 \mathrm{p}$.

Regnault-Roger C., 2008. Recherche de nouveaux biopesticides d'origine végétale à caractère insecticides : démarche méthodologique et application aux plantes aromatiques méditerranéennes. In : Biopesticides d'origine végétale (C. Regnault-Roger, B.J.R. Philogène, C. Vincent, éds), Lavoisier, 25-50.

Regnault-Roger C., 2009. Moyens alternatifs et agriculture durable en Afrique de l'Ouest. Phytoma, 624, 41-44.

Regnault-Roger C., Hamraoui A., 1993. Efficiency of plants from South of France used as traditional protectant of Phaseolus vulgaris L. against its bruchid Acanthoscelides obtectus Say. Journal of Stored Product Research, 29, 259-264.

Regnault-Roger C., Hamraoui A., 1994a. Reproductive inhibition of Acanthoscelides obtectus Say (Coleoptera), bruchid of kidney bean (Phaseolus vulgaris L.) by some aromatic essential oils. Crop Protection, 13, 624-628.

Regnault-Roger C., Hamraoui A., 1994b. Antifeedant effect of Mediterranean plant essential oils upon Acanthoscelides obtectus Say (Coleoptera), bruchid of kidney beans, Phaseolus 
vulgaris L. In : Stored Product Protection (E. Highley, E.J. Wright, H.J. Banks, B.R. Champ, éds), Cabi Publications, 837-840.

Regnault-Roger C., Hamraoui A., 1994-95. Comparison of the insecticidal effects of water extracted and intact aromatic plants on Acanthocelides obtectus, a bruchid beetle pest of kidney beans. Chemoecology, 5/6, 1-5.

Regnault-Roger C., Hamraoui A., 1995. Fumigant toxic activity and reproductive inhibition induced by monoterpenes upon Acanthoscelides obtectus, bruchid of kidney bean (Phaseolus vulgaris L.). Journal of Stored Product Research, 31, 291-299.

Regnault-Roger C., Hamraoui A., Holeman M., Théron É., Pinel R., 1993. Insecticidal effect of essential oils from Mediterranean plants upon Acanthoscelides obtectus, a pest of kidney bean. Journal of Chemical Ecology, 19, 1231-1242.

Regnault-Roger C., Ribodeau M., Hamraoui A., Bareau I., Blanchard P., Gil M.I., Tomas Barberan F., 2004. Disturbance of Acanthoscelides obtectus behaviour by polyphenolic compounds identified in insecticidal Labiatae botanicals. Journal of Stored Product Research, 40, 395-408.

Regnault-Roger C., Philogène B.J.R., 2008. Past and current prospects for the use of botanicals and plant allelochemicals in integrated pest management. Pharmaceutical Biology, 46, 1-12.

Reid C.A.M., 1995. A cladistic analysis of subfamilial relationships in the Chrysomelidae sensu lato (Chrysomeloidea). In : Biology, Phylogeny and Classification of Coleoptera : Papers celebrating the $80^{\text {th }}$ birthday of R.A. Crowson (J. Pakaluk, S.A. Slipinski, éds), Muzeum i Instytut Zoologii Publications, 559-631.

Reid C.A.M., 1996. More on the family Bruchidae. Chrysomela, 31, 3.

Reuben S.O.W.M., Masunga M., Makundi R., Misangu R.N., Kilonzo B., Mwatawala M., Lyimo H.F., Ishengoma C.G., Msuya D.G., Mulugu L.S., 2006. Control of cowpea weevil (Callosobruchus maculatus F.) in stored cowpea (Vigna unguiculatus L.) grains using botanicals. Asian Journal of Plant Science, 5, 91-97.

Robert P., 1985. A comparative study of some aspects of the reproduction of three Caryedon serratus strains in presence of its potential host plants. Oecologia, 65, 425-430.

Rodriguez-Saona C.R., Millar J.G., Trumble J.T., 2008. Les cellules oléagineuses idioblastiques : une nouvelle source de produits botaniques actifs dans le contrôle des insectes. In : Biopesticides d'origine végétale (C. Regnault-Roger, B.J.R. Philogène, C. Vincent, éds), Lavoisier, 321-340.

Rönn J., Katvala M., Arnqvist G., 2007. Coevolution between harmful male genitalia and female resistance in seed beetles. Proceedings of the National Academy of Sciences of the USA, 104, 10921-10925.

Rosenthal G.A., 1990. Biochemical adaptations by the bruchid beetle, Caryedes brasiliensis. In : Bruchids and Legumes : Economics, Ecology and Coevolution (K. Fuji, A.M.R. Gatehouse, C.D. Johnson, R. Mitchel, T. Yoshida, éds), Kluwer Publications, 161-169.

Rosenthal G.A., Dahlman D.L., Janzen D.H., 1977. Degradation and detoxification of canavanine by a specialized seed predator. Science, 196, 658-660.

Roubaud É., 1916. Les insectes et la dégénérescence des arachides au Sénégal. Annuaire et Mémoires du Comité d'Études Historiques et Scientifiques de l'A.O.F., Gorée, Imprimerie du Gouvernement Général, 1, 363-438. 
Sagot R., Bouffil F., 1935. Études sur la bruche de l'arachide (Pachymoerus acaciae). Bulletin d'A.O.F., 18, 79-91.

Sales M.P., Gerhardt I.R., Grossi-de-Sá M.F., Xavier-Filho J., 2000. Do legume storage proteins play a role in defensing seeds against bruchids ? Plant Physiology, 124, 515-522.

Sales M.P., Andrade L.B.S., Ary M.B., Miranda M.R.A., Teixeira F.M., Oliveira, A.S., Fernandes K.V.S, Xavier-Filho J., 2005. Performance of bean bruchids Callosobruchus maculates and Zabrotes subfasciatus (Coleoptera : Bruchidae) reared on resistant (IT81D-1045) and susceptible (Epace 10) Vigna unguiculata seeds : relationships with trypsin inhibitor and vicilin excretion. Comparative Biochemistry and Physiology, 142, 422-426.

Sano-Fujii I., 1981. Effect of bean water content on the production of the active form of southern cowpea weevil Callosobruchus maculatus. Journal of Stored Product Research, 20, 153-161.

Sano-Fujii I., 1986. The genetic basis of the production of the active form of Callosobruchus maculatus. Journal of Stored Product Research, 22, 115-123.

Sanon A., Ouedraogo A.P., Tricault Y., Credland P., Huignard J., 1998. Biological control of bruchids in cowpea stores by release of Dinarmus basalis (Hymenoptera : Pteromalidae) adults. Environmental Entomology, 27, 717-725.

Sarmah B., Moore A., Tate W., Molvig L., Morton R.L, Rees D.P., Chiaiese P., Maarten J.C., Tabe L.M., Higgins T.J.V., 2004. Transgenic chickpea seeds expressing high levels of a bean $\alpha$-amylase inhibitor. Molecular Breeding, 14, 73-82.

Schmale I., Wäckers C., Cardona C., Dorn S., 2002. Field Infestation of Phaseolus vulgaris by Acanthoscelides obtectus (Coleoptera : Bruchidae), Parasitoid Abundance, and Consequences for Storage Pest Control. Environmental Entomology, 31(5), 859-863.

Schmale I., Wäckers F.L., Cardona C., Dorn S., 2003. Combining parasitoid and plant resistance for the control of Acanthoscelides obtectus in stored beans. Journal of Stored Product Research, 39, 401-411.

Schmale I., Wäckers F.L., Cardona C., Dorn S., 2005. How host larval age and nutrition and density of the parasitoid Dinarmus basalis influence control of Acanthoscelides obtectus. Bulletin of Entomological Research, 95, 145-150.

Schmale I., Wäckers F.L., Cardona C., Dorn S., 2006. Biological control of the bean weevil Acanthoscelides obtectus by the native parasitoid Dinarmus basalis on small-scale farms in Colombia. Journal of Stored Product Research, 42, 31-41.

Schmelz E.A., Leclere S., Carroll M.J., Alborn H.T., Teal P.E.A., 2007. Cowpea chloroplastic ATP synthase is the source of multiple plant defense elicitors during insect herbivory. Plant Physiology, 144, 793-805.

Schmitt M., 1998. Again, bruchid classification. Chrysomela, 36, 3-4.

Scott I.M., Jensen H., Scott J.G., Isman M.B., Aranson J.T., Philogène B.J.R., 2003. Botanical insecticides for controlling agricultural pest : piperamides and the Colorado potato beetle Leptinotara decemlineata (Coleoptera : Chrysomelidae). Archives of Insect Biochemistry, 54, 212-225.

Sembene M., 2006. The origin of groundnut infestation by the seed beetle Careydon serratus : results from cytochrome and ITS1 gene sequences. Journal of Stored Product Research, 42, 97-111. 
Sembene M., Brizard J.-P., Delobel A., 1998. Allozyme variation among populations of groundnut seed-beetle Caryedon serratus in Senegal. Insect Science and its Application, 18, 77-86.

Sembene M., Delobel A., 1996. Identification morphométrique de populations soudanosahéliennes de bruche de l'arachide, Caryedon serratus. Journal of African Zoology, 110, 357-366.

Sembene M., Delobel A., 1998. Genetic differentiation of groundnut seed-beetle populations in Senegal. Entomologia Experimentalis et Applicata, 87, 171-180.

Sembene M., Kébé K., Rasplus J.-Y., Delobel, A., 2010. When phylogenetic information revels the peculiarity of Caryedon serratus (Coleoptera, Chrysomelidae, Bruchinae) feeding on Cassia sieberiana DC (Caesalpinioideae). African Journal of Biotechnology, 9 (10), 1470-1480.

Sembene M., Rasplus J.-Y., Silvain J.-F., Delobel A., 2008. Genetic differentiation in sympatric populations of the groundnut seed beetle, Caryedon serratus new insights from molecular and ecological data. International Journal of Tropical Insect Sciences, 28 (3), 1688-177.

Sharah H.A., Ali E.A., 2008. Impact of insecticide spray regimes on insect abundance in cowpea (Vigna unguiculata) in Northeastern Nigeria. International Journal of Agriculture and Biology, 10, 255-260.

Shimonura K., Nojima S., Yajima S., Ohsawa K., 2008. Homofarnesals : female sex attractant pheromone components of Callosobruchus chinensis. Journal of Chemical Ecology, 34, 467-477.

Shinoda K., Yoshida T., 1990. Life history of the azuki bean weevil Callosobruchus chinensis in the field. In: Bruchids and Legumes : Economics, Ecology and Coevolution (K. Fuji, A.M.R. Gathehouse, C.D. Johnson, R. Mitchell, T. Yoshida, éds), Kluwer Publications, 149-159.

Siemens D.H., Johnson C.D., Woodman R.L., 1991. Determinants of host range in bruchid beetles. Ecology, 72, 1560-1566.

Silvain J.-F., Delobel A., 1998. Phylogeny of West African Caryedon (Coleoptera : Bruchidae) : congruence between molecular and morphological Data. Molecular Phylogenetics and Evolution, 9, 533-541.

Singh S.R., 1977. Cowpea cultivars resistant to insect pests in the world germplasm collection. Tropical Grain Legume Bulletin, 9, 3-7.

Singh B.B., Singh S.R., 1990. Breeding for bruchid resistance in cowpea. In : Bruchids and Legumes : Economics, Ecology and Coevolution (K. Fuji, A.M.R. Gatehouse, C.D. Johnson, R. Mitchel, T. Yoshida, éds), Kluwer Publications, 219-228.

Smith A.M., 1990 Pea weevil (Bruchus pisorum) and crop loss-implications for management. In : Bruchids and Legumes : Economics, Ecology and Coevolution (K. Fuji, A.M.R. Gathehouse, C.D. Johnson, R. Mitchell, T. Yoshida, éds), Kluwer Publications, 105-114.

Solleti S.K., Bakshi S., Purkayastha J., Sanjib K.P., Sahoo L., 2008. Transgenic cowpea (Vigna unguiculata) seeds expressing a bean $\alpha$-amylase inhibitor 1 confer resistance to storage pests, bruchid beetles. Plant Cell Reports, 27, 1841-1850.

Somta R., Kaga A., Tomooka N., Isemura T., Vaughan D.A., Srinives P., 2008. Characterization of resistance to three Bruchid species in cultivated rice bean. Theoritical and Applied Genetics, $117,621-628$. 
Somta R., Srinives P., 2007. Genome research in mungbean (Vigna radiate) and blackgram (Vigna mungo). Science Asia, 33, 69-74.

Sougnabe S.P., Yandia A., Acheleke J., Brevault T., Vaissayre M., Ngartoubam L.T., 2010. Pratiques phytosanitaires paysannes dans les savanes d'Afrique centrale. In : Actes du colloque "Savanes africaines en développement : innover pour durer» (J. Jamin, L. Seiny-Boukar, P. Boumard, éds), 20-23 avril 2009, Garoua, Cameroun, Prasac, N'Djamera, Tchad, Cirad, Montpellier, cédérom.

Southgate B.J., 1979. Biology of the Bruchidae. Annual Review of Entomology, 24, 449-473.

Spinola M., 1843. Dei Prioniti e dei Coleotteri ad essi piu zffini osservazioni. Memorie della Reale Accademia delle Scienze de Torino, 1, 387-418.

Stanton W.R., 1970. Les légumineuses à grain en Afrique, FAO, 199 p.

Stolk C., Ghimire M.N., Souquié S., van der Welf W., van Huis A., 2005. Host finding by Uscana lariophaga in stored cowpea, the effect of distance, time interval, host patch size and spatial. Bulletin of Entomological Research, 95, 231-241.

Swella G.B., Mushobozy D.M.K., 2007. Evaluation of the efficacy of protectants against cowpea bruchids [Callosobruchus maculatus (F.)] on cowpea seeds [Vigna unguiculata (L.) Walp.]. Plant Protection Science, 43, 68-72.

Swigonova Z., Kjer K.M., 2004. Phylogeny and host-plant association in the leaf-beetle genus Trirhabda LeConte (Coleoptera : Chrysomelidae). Molecular Phylogenetics and Evolution, 32, 358-374.

Teixeira I.R.V., Zucoloto F.S., 2003. Seed suitability and oviposition behaviour of wild and selected populations of Zabrotes subfasciatus (Boheman) (Coleoptera : Bruchidae) on different hosts. Journal of Stored Products Research, 39, 131-140.

Termonia A., Hsiao T.H., Pasteels J.M., Milinkovitch M., 2001. Feeding specialization and host-derived chemical defense in chrysomeline leaf beetles did not lead to an evolutionary dead end. Proceedings of the National Academy of Sciences of the USA, 98, 3909-3914.

Thacker, J.M.R., 2002. An Introduction to Arthropod Pest Control, Cambridge University Press, Cambridge, Royaume-Uni.

Tran, B., Huignard J., 1992. Interactions between photoperiod and food affect the terminaison of reproductive diapause in Bruchus rufimanus. Journal of Insect Physiology, 38, 633-642.

Tuda M., Ronn J., Buranapanichpan S., Wasano N., Arnqvist G., 2006. Evolutionary diversification of the bean beetle genus Callosobruchus (Coleoptera : Bruchidae) : traits associated with stored-product pest status. Molecular Ecology, 15, 3541-3551.

Uchôa A.F., Da Matta R.A., Retamal C., Albuquerque-Cunha J.M., Souza S.M., Samuels R.I., Silva C.P., Xavier-Filho J., 2006. Presence of storage seed protein in internal organs of larval Callosobruchus maculatus. Journal of Insect Physiology, 52, 169-171.

Utida S., 1972. Density dependent polymorphism in the adult of Callosobruchus maculatus. Journal of Stored Product Research, 8, 111-126.

Van Huis A., 1991. Biological methods of bruchid control in the tropic : a review. Insect Science Application, 12, 87-102. 
Van Huis A., van Alebeek F.A.N., van Es M., Sagnia S.B., 2002. Impact of the egg parasitoid Uscana lariophaga and the larval-pupal parasitoid Dinarmus basalis on Callosobruchus maculatus populations and cowpea losses. Entomologia Experimentalis et Applicata, 104, 289-297.

Van Schoonhoven A., Cardona C., Valor J., 1983. Resistance to the bean weevil and the Mexican bean weevil (Coleoptera : Bruchidae) in non-cultivated common bean accessions. Journal of Economic Entomology, 76, 1255-1259.

Velten G., Rott A.S., Cardona C., Dorn S., 2007. Effects of a plant resistance protein on parasitism of the common bean bruchid Acanthoscelides obtectus (Coleoptera : Bruchidae) by its natural enemy Dinarmus basalis (Hymenoptera : Pteromalidae). Biological Control, 43, 78-84.

Velten G., Rott A.S., Conde Petit B.J., Cardona C., Dorn., 2008. Improved bruchid management through favourable host plant traits and natural enemies. Biological Control, 47, 133-140.

Verma K.K., Saxena R., 1996. The status of Bruchidae as a family. Chrysomela, 32, 3.

Vincent C., Panneton B., Fleurat-Lessard F., 2000. La lutte physique en phytoprotection, Inra, $345 \mathrm{p}$.

Vincent C, Weintraub P., Hallman G.J., Fleurat-Lessard F., 2009. Insect management with physical methods in pre- and post-harvest situations. In Integrated Pest Management (E.B. Radcliffe, W.D. Hutchison, R.E. Cancelado, éds), 309-323.

Wahlberg N., 2001. The phylogenetics and biochemistry of host-plant specialization in melitaeine butterflies (Lepidoptera : Nymphalidae). Evolution, 55, 522-537.

Yamamoto I., 1990. Chemical ecology of bruchids. In : Bruchids and Legumes : Economics, Ecology and Coevolution (K. Fuji, A.M.R. Gathehouse, C.D. Johnson, R. Mitchell, T. Yoshida, éds), Kluwer Publications, 53-62.

Zannou E., Glitho A.I., Huignard J., Monge J.-P., 2003. Life history of flight morph females of Callosobruchus maculatus : evidence of a reproductive diapause. Journal of Insect Physiology, 49, 575-582.

Zhu-Salzman K., Koiwa H., Salzman R.A., Shade R.E, Ahn J.E., 2003. Cowpea bruchid Callosobruchus maculatus uses three-components strategy to overcome plant defensine cystein inhibitor. Insect Molecular Biology, 12, 135-145. 


\section{Liste des auteurs}

\section{Isabelle Adolé Glitho}

Professeur des universités

Laboratoire d'entomologie appliquée

Faculté des Sciences, université de Lomé

BP 1515, Lomé (Togo)

Courriel : iglitho@yahoo.fr

\section{Francis Fleurat-Lessard}

Chargé de recherche à l'Institut national

de recherche agronomique

UR 1264 Mycologie et sécurité des aliments

(Inra Bordeaux-Aquitaine)

71 avenue Édouard Bourleaux,

33883 Villenave d'Ornon (France)

Courriel : francis.fleurat-lessard@bordeaux. inra.fr

\section{Jacques Huignard}

Professeur des universités honoraire

Faculté des Sciences, université de Tours

Avenue Monge, 37200 Tours (France)

Courriel : jacques.huignard@club-internet.fr

\section{Gaël J. Kergoat}

Chargé de recherche à l'Institut national

de recherche agronomique

UMR CBGP (Inra, IRD, Cirad, Montpellier

SupAgro)

Campus de Baillarguet, CS 30016,

34988 Montferrier-sur-Lez (France)

Courriel : kergoat@supagro.inra.fr

\section{Jean-Paul Monge}

Professeur des universités

Institut de recherche sur la biologie

de l'insecte (UMR CNRS 6035)

Faculté des Sciences, université de Tours

Avenue Monge, 37200 Tours (France)

Courriel : jean-paul.monge@univ-tours.fr

\section{Nazaire Nkouka}

Chercheur associé au Cirad et consultant international de la FAO

Ancien secrétaire scientifique du Conseil phytosanitaire interafricain/Union africaine Avenue Agropolis, 34000 Montpellier (France)

Courriel : nkoukanazaire@yahoo.fr

\section{Catherine Regnault-Roger}

Professeur des universités

UMR CNRS Uppa 5254 IPRM-EEM

Université de Pau et des Pays de l'Adour

BP 1155, 64013 Pau cedex (France)

Courriel : catherine.regnault-roger@univ-pau.fr

\section{Mbacke Sembene}

Maître de conférences

Laboratoire de génétique des populations,

Département de biologie animale,

Faculté des Sciences et Techniques

Université de Dakar, BP 5005, Dakar (Sénégal)

Courriel : mbacke.sembene@ird.fr 
Édition : Corinne Thonnat Mise en page : Desk

Maquette, infographie : Éditions Quæ Imprimerie :

Dépôt légal : novembre 2011 

